\author{
UNIVERSIDADE DE SÃO PAULO \\ ESCOLA DE ENGENHARIA DE SÃO CARLOS
}

JESÚS DANIEL VILLALBA MORALES

\title{
Detecção de Dano em Estruturas Via Inteligência Computacional e Análise Dinâmica
}

São Carlos, São Paulo 



\title{
JESÚS DANIEL VILLALBA MORALES
}

\section{Detecção de Dano em Estruturas Via I nteligência Computacional e Análise Dinâmica}

\begin{abstract}
Tese apresentada ao Departamento de Engenharia de Estruturas da EESC-USP como parte dos requisitos necessários à obtenção do título de Doutor em Engenharia Civil -
\end{abstract}

Área de concentração: Estruturas.

Orientador: Prof. Dr. José Elias Laier.

Programa de Pós-graduação em Estruturas

VERSÃO CORRIGIDA

A versão original encontra-se disponível no programa

São Carlos, 2012. 
AUTORIZO A REPRODUÇÃO E DIVULGAÇÃO TOTAL OU PARCIAL DESTE TRABALHO, POR QUALQUER MEIO CONVENCIONAL OU ELETRÔNICO, PARA FINS DE ESTUDO E PESQUISA, DESDE QUE CITADA A FONTE.

Villalba Morales, Jesús Daniel

V Deteç̧ão de Dano em Estruturas Via Inteligencia

695d Computacional e Analise Dinâmica. / Jesús Daniel

Vilialba Morales; orientador José Elias Daier. Săo

Carlos, 2012.

Tese (Doutorado) - Programa de e Área de Concentração em -- Escola de Engenharia de São Carlos da Universidade de São Paulo, 2012.

1. Detecção de dano. 2. Monitoreamento de Saúde Estrutural. 3. Inteligencia Computacional. 4. Dinâmica das Estruturas. 5. Método dos Elementos Finitos. I. Titulo. 


\section{FOLHA DE JULGAMENTO}

Candidato: Engenheiro JESUS DANIEL VILLALBA MORALES.

Título da tese: "Detecção de dano em estruturas via inteligência computacional e análise dinâmica".

Data da defesa: 29/11/2012

\section{Comissão Julgadora:}

Prof. Titular José Elias Laier (Orientador)

(Escola de Engenharia de São Carlos/EESC)

Prof. Dr. Edson Denner Leonel

(Escola de Engenharia de São Carlos/EESC)

Prof. Dr. André Teófilo Beck

(Escola de Engenharia de São Carlos/EESC)

Prof. Titular Edison Gonçalves

(Escola Politécnica/USP)

Prof. Dr. Walter Libardi

(Universidade Federal de São Carlos/UFSCar)
Resultado:
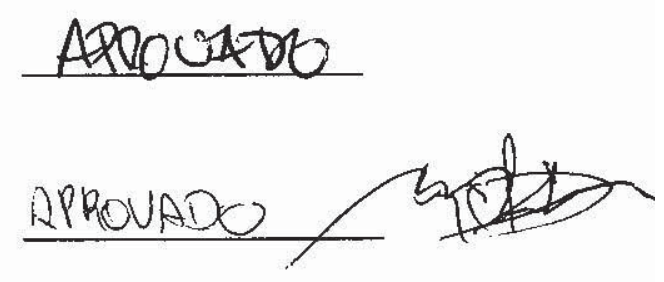

APROVADO
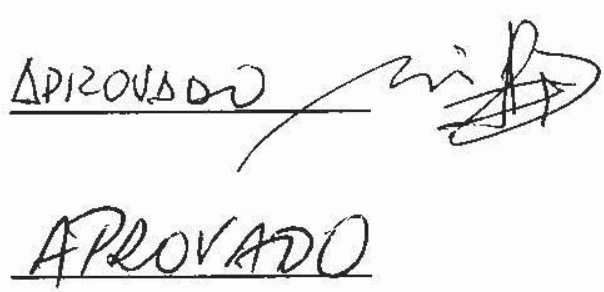

Coordenador do Programa de Pós-Graduação em Engenharia Civil (Engenharia de Estruturas):

Profa. Associada Ana Lucia Homce de Cresce El Debs

Presidente da Comissão de Pós-Graduação:

Prof. Titular Denis Vinicius Coury 

La presente tesis doctoral es el resultado de muchos años de esfuerzo y se la dedico a las nuevas generaciones de mi familia. En especial a mis sobrinos Javier, Luis Daniel, Margarita, Alejandra y Francisco y a mis ahijados Yara, Dariana, Natália y José Julián. Deseo to mejor para ustedes de todo corazón, que se esfuercen siempre por alcanzar sus sueños y que crezcan con un espiritu fuerte y un corazón cálido.

$\mathcal{A}$ mis padres Isaías y Ermidia. $\mathcal{A}$ mis hermanos Sergio Andrés y María Luisa. A mis padres de crianza Francisco y Agustina. A mis hermanos de crianza Jary, Nohemit, Lisbeth y Mariluz. Este gran logro también es de ustedes. 

"If you can't fly then run, if you can't run then walk, if you can't walk then crawl, but whatever you do you have to keep moving forward."

—Martin Luther King Jr.

"You must be the change you want to see in the world."

- Mohandas Karamchand Gandhi.

"The greatest glory in living lies not in never falling, 6ut in rising every time we fall."

- Nelson Mandela. 



\section{AGRADECIMENTOS}

Ao Prof. Dr. José E. Laier por ter-me dado a oportunidade de trabalhar sob sua orientação durante todos estes anos.

Á Profa. Dra. Esperanza Maldonado (In memoriam) pela sua amizade e por ter orientado meus primeiros passos no mundo da dinâmica das estruturas e da engenharia de terremotos.

À minha namorada Lorena Chilito pelo seu amor e grande apoio, sobretudo nas etapas difíceis. À família Chilito Amaya pelo carinho dado.

À minha família e amigos na Colômbia pelo apoio desde a distância.

A todos as pessoas que me acompanharam durante todos estes anos no Brasil, em especial aos meus amigos Beto, Denis, Denise, Dorival, Ellen, Erika, Fabio, Ivan, Jesús, José Luis, Marcela, Pilar e Wagner.

A todos meus amigos, colegas, professores e funcionários do Departamento de Estruturas da Escola de Engenharia de São Carlos da Universidade de São Paulo.

Ao serviço de Biblioteca da USP, sem cuja ajuda a fundamentação adquirida para a realização deste trabalho não teria sido possível.

À Profa. Angela Giampedro, docente do centro cultural da USP São Carlos, pelas inúmeras revisões do inglês dos meus trabalhos publicados. Aprendi muito de cada revisão realizada.

À CNPq pela bolsa de estudos. 



\section{RESUMO}

\section{VILLALBA MORALES, J. D. (2012). Detecção de Dano em Estruturas Via}

Inteligência Computacional e Análise Dinâmica. Tese (Doutorado) Escola de Engenharia de São Carlos, Universidade de São Paulo, São Carlos.

Nesta tese doutoral estudam-se formas de resolver o problema de detecção de dano em estruturas a partir da aplicação de técnicas de inteligência computacional e da resposta dinâmica da estrutura. Duas opções para a formulação do problema são consideradas. Primeiro, um problema de otimização é estabelecido a partir da minimização da diferença entre os parâmetros dinâmicos experimentais da estrutura na condição com dano e aqueles calculados utilizando um modelo de elementos finitos que representa tal condição. Diferentes técnicas metaheurísticas (algoritmos genéticos, particle swarm optimization, evolução diferencial), algumas em versões com adaptação de parâmetros, são empregadas. Estuda-se, ainda, a formulação do problema de otimização como um com múltiplos objetivos. Uma nova forma de avaliar o desempenho de uma metodologia de detecção de dano é proposta, que está baseada na capacidade da metodologia para obter um nível determinado de exatidão no cálculo da extensão do dano e na presença de falso-negativos e falso-positivos nos resultados. Segundo, aplicam-se redes neurais para determinar o mapeamento entre os parâmetros dinâmicos experimentais da condição atual da estrutura e a extensão ou posição do dano nesta. Estruturas do tipo viga e treliça foram submetidas a diferentes cenários de dano com 0 intuito de determinar o desempenho das metodologias propostas. Resultados mostram a habilidade de técnicas de inteligência computacional para detecção de cenários de dano com uns poucos elementos danificados; porém não é possível garantir que as metodologias terão sucesso para o $100 \%$ dos casos. Recomenda-se a utilização de técnicas de busca local para melhorar a solução encontrada pelos algoritmos globais. Finalmente, observou-se que se requer da determinação da quantidade mínima de informação a ser utilizada, uma função objetivo adequada e uma alta qualidade nas medições para garantir uma detecção de dano confiável.

Palavras-chave: detecção de dano, inteligência computacional, parâmetros dinâmicos 



\section{ABSTRACT}

VILLALBA MORALES, J. D. (2009). Structural Damage Detection by means of Computational Intelligence Techniques and Dynamic Analysis. 2009. Doctoral Thesis - School of Engineering of Sao Carlos, University of Sao Paulo.

This research aims at studying how to solve the damage detection problem by using computational intelligence techniques and the dynamic response of the structure. Two different ways for formulating the solution to the problem are implemented. In first place, an optimization problem is formulated as the minimization of the difference between the experimental dynamic parameters for the current structure and those from a finite element model that represent the damaged condition. Several metaheuristics (genetic algorithms, particle swarm optimization and differential evolution) are used to solve the optimization problem, where most of them present adaptive configurations. The implication of a multi-objective approach is also studied. A new scheme to determine the algorithm's performance is proposed, which computes three error indicators concerning differences between the real and computed damage extents and the presence of false-positives and false-negatives. In second place, artificial neural networks are used to determine the mapping between the experimental dynamic parameters and either the damage extension (quantification) or the damage position (localization). Different damage scenarios were simulated in beam and truss structures to verify the performance of the proposed methodologies. Results show the ability of computational intelligence techniques to detect damage scenarios with a few damaged elements; however, it is not possible to guarantee a $100 \%$ of success. It is suggested to use local search techniques to improve the solution found by the different proposed algorithms. Three main conclusions are the followings: i) it is necessary to determine the minimum quantity of modal data that permits guarantying a reliable damage detection, ii) objective functions plays a very important role to the success of the algorithms and iii) noise prejudice the damage identification process.

Keywords:damage detection, computational intelligence, dynamic parameters 



\title{
LISTA DE SIMBOLOS E ABREVIATURAS
}

\author{
AF \\ Fator de amplificação no DEA. \\ ANN \\ Rede neural artificial. \\ BFGS \\ Algoritmo quase-Newton Broyden-Fletcher-Goldfarb-Shanno \\ BP \\ Back Propagation. \\ $\mathrm{c} 1, \mathrm{c} 2$ \\ Parâmetro cognitivo e social no PSO, respectivamente. \\ CIT \\ Técnica de Inteligência Computacional \\ $\mathrm{CR}$ \\ Taxa de cruzamento no DEA. \\ DEA Algoritmo de evolução diferencial. \\ DOF Grau de liberdade. \\ ex \\ Valor obtido experimentalmente. \\ $f$ \\ Flexibilidade modal \\ RFV Vetor de Força Residual \\ GA Algoritmo Genético. \\ HS \\ Harmony Search. \\ $\mathrm{k}$ \\ Matriz de rigidez de um elemento \\ $\mathrm{K}$ \\ Matriz de rigidez da estrutura. \\ LM Algoritmo Levenberg-Marquardt \\ FEM Modelo de elementos finitos. \\ m \\ Matriz de massa de um elemento \\ M \\ Matriz de massa da estrutura \\ $\mathrm{mh}$ \\ metaheurística \\ MLP Perceptron multi-camada.
}


MSE

N

NDEI

NElem

NES, NEM

ngll

$\mathrm{nm}$

NSGA

PSO

RFV

SCG

SEREP

SPEA

IS

$\mathrm{t}$

TC, TM

wf

W

$\Phi$

$\omega$

$\beta$

Energia de deformação modal.

Tamanho da população para as metaheurísticas.

Número de elementos danificados identificados no GA multicromossomo.

Número de elementos na estrutura.

Número de cenários de dano simples e múltiplos utilizados para o treinamento da ANN, respectivamente. \# de graus de liberdade lidos.

\# de modos medidos.

Non-Dominated Sorting Genetic Algorithm

Particle Swarm Optimization.

Residual Force Vector

Algoritmo Scaled Conjugate Gradient

System Equivalent Reduction Expansion Process

Strength Pareto Evolutionary Algorithm

Sistemas imunes.

Iteração/ geração atual.

Taxas de cruzamento e mutação no AG.

Fator de inércia PSO.

Fator de peso na função objetivo.

Forma modal.

Frequência Natural.

Fator de redução da rigidez. 


\section{LISTA DE FIGURAS}

FIGURA 1. 1 METODOLOGIA DE DETECÇÃO DE DANO BASEADA EM VIBRAÇÃO.

FIGURA 2. 1 REDE NEURAL PERCEPTRÓN MULTI-CAMADA. 13

FIGURA 2. 2 TIPOS DE FUNÇÕES DE ATIVAÇÃO: A) HARD LIMITER, B)

LINEAR E C) SIGMOIDE. 14

FIGURA 2. 3 ALGORITMO PARTICLE SWARM OPTIMIZATION ................. 19

FIGURA 2. 4 ALGORITMO DE EVOLUÇÃO DIFERENCIAL. ..................... 21

FIGURA 2. 5 ALGORITMOS GENÉTICOS. .................................. 24

FIGURA 4. 1 METODOLOGIA DE DETECÇÃO DE DANO $\ldots \ldots \ldots \ldots \ldots \ldots \ldots \ldots . \ldots 48$

FIGURA 4. 3 EXEMPLO DE UM CROMOSSOMO UTILIZADO NA SEGUNDA

PARTE DA EXECUÇÃO DO RCGA. 53

FIGURA 4. 4 EXEMPLO DE CLASSIFICAÇÃO DE UM CENÁRIO DE DANO CALCULADO PELO RCGA SEGUNDO O TIPO DE ERRO ENCONTRADO. ...56

FIGURA 4. 5. VIGA ANALISADA. 57

FIGURA 4. 7 EXEMPLO 2 DE IDENTIFICAÇÃO INCORRETA DO CENÁRIO DE

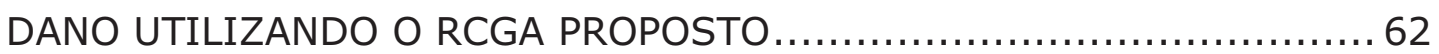

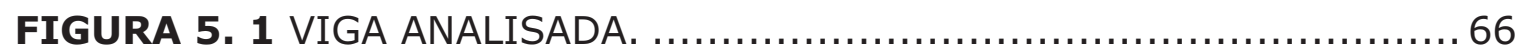

FIGURA 6. 1 TRELIÇA COM 61 ELEMENTOS .................................. 82

FIGURA 6. 2 RESULTADOS DA APLICAÇÃO DO DEA NA DETECÇÃO DO

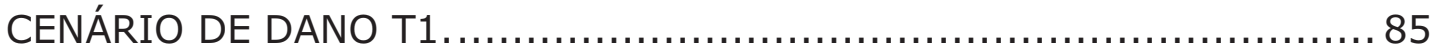

FIGURA 6. 3 RESULTADOS DA APLICAÇÃO DO DEA NA DETECÇÃO DO CENÁRIO DE DANO T2. 86 
FIGURA 6. 4 RESULTADOS DA APLICAÇÃO DO DEA NA DETECÇÃO DO CENÁRIO DE DANO T3.

FIGURA 6. 5 RESULTADOS DA APLICAÇÃO DO DEA NA DETECÇÃO DO CENÁRIO DE DANO T4.

FIGURA 6. 6 RESULTADOS DA APLICAÇÃO DO DEA NA DETECÇÃO DO CENÁRIO DE DANO T5. 88

FIGURA 6. 7 RESULTADOS DA APLICAÇÃO DO DEA NA DETECÇÃO DO CENÁRIO DE DANO T6. 89

FIGURA 7. 1 TRELIÇAS ANALISADAS. 95

FIGURA 7. 2 CROMOSSOMO TÍPICO PARA REPRESENTAR UM INDIVÍDUO. 97 FIGURA 7. 3 EVOLUÇÃO DO CROMOSSOMO BINÁRIO PARA O MELHOR INDIVÍDUO. CENÁRIO S9: UM ELEMENTO DANIFICADO. 104

FIGURA 7. 4 EVOLUÇÃO DO CROMOSSOMO BINÁRIO PARA O MELHOR INDIVÍDUO. CENÁRIO S9: UM ELEMENTO DANIFICADO.CENÁRIO M5: TRÊS ELEMENTOS DANIFICADOS. 104

FIGURA 8. 1 VIGAS UTILIZADAS PARA AVALIAR O DESEMPENHO DA ANN PROPOSTA. 108

FIGURA 8. 2 EXEMPLO DA TOPOLOGIA DA ANN PROPOSTA PARA UMA ESTRUTURA COM 4 ELEMENTOS FINITOS.

FIGURA 8. 3 PASSOS PRÉVIOS AO TREINAMENTO DA ANN PROPOSTA....111

FIGURA 8. 4 RELAÇÃO ENTRE O NÚMERO DE CENÁRIOS DE DANOS MÚLTIPLOS E O NÚMERO DE ELEMENTOS DA VIGA.

FIGURA 8. 5 APLICAÇÃO DA ANN PROPOSTA NA DETECÇÃO DE UM CENÁRIO DE DANO SIMPLES.

FIGURA 8. 6 APLICAÇÃO DA ANN PROPOSTA NA DETECÇÃO DE UM CENÁRIO DE DANOS MÚLTIPLOS UNIFORME. 
FIGURA 8. 7 APLICAÇÃO DA ANN PROPOSTA NA DETECÇÃO DE UM CENÁRIO DE DANOS MÚLTIPLOS DISPERSO.

FIGURA 9. 1 METODOLOGIA DE DETECÇÃO DE DANO DE DUAS ETAPAS. 122 FIGURA 9. 2 DEFINIÇÃO DE ZONAS PARA UMA ESTRUTURA DO TIPO VIGA:

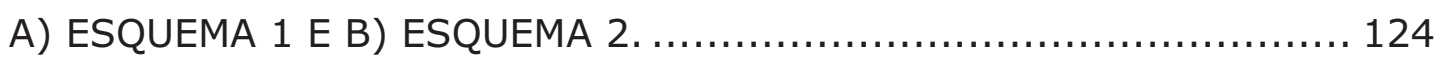

FIGURA 10. 1 ALGORITMO DO NSGA-II FONTE: DEB (2001) ............... 138

FIGURA 10. 2 ALGORITMO DO SPEA-II. FONTE: ZITZLER ET AL (2001). . 139

FIGURA 10. 3 VIGA COM MÚLTIPLO SUPORTES............................... 139

FIGURA 10. 4 EXEMPLOS DE CONJUNTOS DE PARETO OBTIDOS. .......... 143

FIGURA 10. 5 EXEMPLO NO AVANÇO DO CONJUNTO DE PARETO............ 144

FIGURA 10. 6 VARIAÇÃO DO CONJUNTO DE PARETO EM FUNÇÃO DO NÍVEL DE RUÍDO NAS MEDIÇÕES................................................... 144

FIGURA 10. 7 PERDIDA DA DIVERSIDADE DA POPULAÇÃO .................. 146 



\section{LISTA DE TABELAS}

TABELA 2. 1 EXEMPLOS DE APLICAÇÕES DE TÉCNICAS DE INTELIGÊNCIA COMPUTACIONAL EM ENGENHARIA DE ESTRUTURAS. ... 25

TABELA 4. 1 OPERADORES E PARÂMETROS GENÉTICOS PARA O RCGA..... 52

TABELA 4. 2 NÍVEIS DE ERRO DO NOVO MÉTODO DE AVALIAÇÃO DE UMA METODOLOGIA DE DETECÇÃO DE DANO ................................... 55

TABELA 4. 3 DISTRIBUIÇÃO DE RESULTADOS PARA O RCGA SEGUNDO O

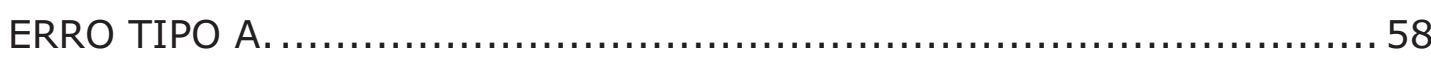

TABELA 4. 4 DISTRIBUIÇÃO DE RESULTADOS PARA O RCGA SEGUNDO O

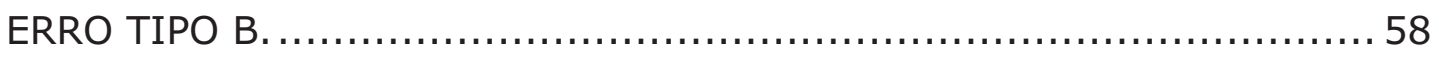

TABELA 4. 5 DISTRIBUIÇÃO DE RESULTADOS PARA O RCGA SEGUNDO O ERRO TIPO C. 59

TABELA 4. 6 DISTRIBUIÇÃO DOS RESULTADOS DO RCGA SEGUNDO A QUANTIDADE DE FALSOS POSITIVOS ENCONTRADOS. 59

TABELA 4. 7 NÍVEL DE SUCESSO DA METODOLOGIA PROPOSTA SEGUNDO A QUANTIDADE ELEMENTOS DANIFICADOS. 60

TABELA 4. 8 ALGUNS EXEMPLOS DE APLICAÇÃO COM SUCESSO DO RCGA PROPOSTO EM DETECÇÃO DE DANO SIMPLES E MÚLTIPLO. 61

TABELA 5. 1 CASOS DE INFORMAÇÃO MODAL INCOMPLETAS ANALISADOS.

TABELA 5. 2 CENÁRIOS DE DANO SIMPLES.................................... 67

TABELA 5. 3 CENÁRIOS DE DANOS MÚLTIPLOS............................... 67

TABELA 5. 4 APLICAÇÃO DO PSO PROPOSTO NA IDENTIFICAÇÃO DO DE DANO SIMPLES S1. 
TABELA 5. 5 APLICAÇÃO DO PSO PROPOSTO NA IDENTIFICAÇÃO DO DE DANO SIMPLES S2

TABELA 5. 6 APLICAÇÃO DO PSO PROPOSTO NA IDENTIFICAÇÃO DO DE DANO SIMPLES.

TABELA 5. 7 APLICAÇÃO DO PSO PROPOSTO NA IDENTIFICAÇÃO DO DE DANO SIMPLES S4

TABELA 5. 8 APLICAÇÃO DO PSO PROPOSTO NA IDENTIFICAÇÃO DO DE DANO MÚLTIPLO M1.

TABELA 5. 9 APLICAÇÃO DO PSO PROPOSTO NA IDENTIFICAÇÃO DO DE DANO MÚLTIPLO M2.

TABELA 5. 10 APLICAÇÃO DO PSO PROPOSTO NA IDENTIFICAÇÃO DO CENÁRIO DE DANO MÚLTIPLO M3.

TABELA 5. 11 APLICAÇÃO DO PSO PROPOSTO NA IDENTIFICAÇÃO DO DE DANO MÚLTIPLO M4. 73

TABELA 5. 12 RESULTADOS PARA 50 CENÁRIOS DE DANO OBTIDOS UTILIZANDO O PSO PROPOSTO. 74

TABELA 5. 13 EXEMPLO DE UMA IDENTIFICAÇÃO DE DANO ERRÔNEA UTILIZANDO O PSO PROPOSTO. 75

TABELA 5. 14 EXEMPLO DE UMA IDENTIFICAÇÃO CORRETA UTILIZANDO O PSO E SOB A CONSIDERANDO DE MEDIÇÕES LIVRES DE RUÍDO......... 75

TABELA 5. 15 APLICAÇÃO DO PSO PROPOSTO NA DETECÇÃO DE CENÁRIOS DE DANO SIMPLES. MEDIÇÕES EM 25\% DOS DOFS VERTICAIS. 76

TABELA 5. 16 APLICAÇÃO DO PSO PROPOSTO NA DETECÇÃO DE CENÁRIOS DE DANO SIMPLES. MEDIÇÕES EM 25\% DOS DOFS VERTICAIS. 77

TABELA 6. 1 CENÁRIOS DE DANO SIMULADOS. 82

TABELA 6. 2 LISTA DE FUNÇÕES OBJETIVO. 85 
TABELA 6. 3 DESEMPENHO DO DEA NA IDENTIFICAÇÃO DOS ELEMENTOS REALMENTE DANIFICADOS. 89

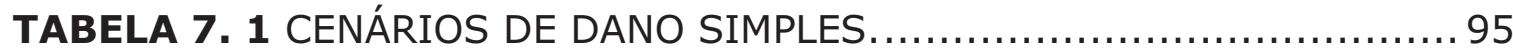

TABELA 7. 2 CENÁRIOS DE DANOS MÚLTIPLOS ............................ 96

TABELA 7. 3 FAIXA DE VALORES PARA OS PARÂMETROS GENÉTICOS. ..... 98

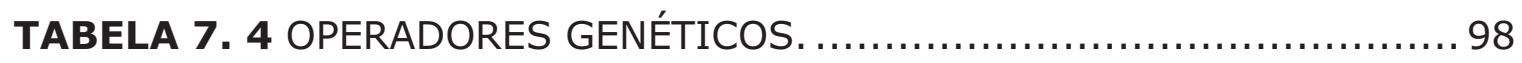

TABELA 7. 5 RESULTADOS DA APLICAÇÃO DO GA MULTI-CROMOSSOMO

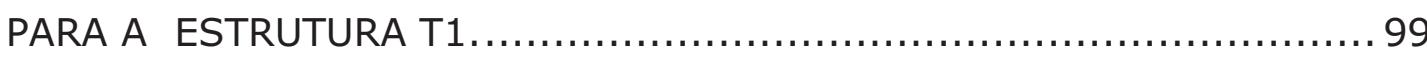

TABELA 7. 6 RESULTADOS DA APLICAÇÃO DO GA MULTI-CROMOSSOMO

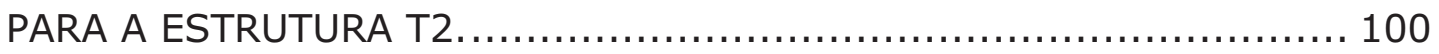

TABELA 7. 7 RESULTADOS DA APLICAÇÃO DO GA MULTI-CROMOSSOMO PARA A ESTRUTURA T3.......................................... 100

TABELA 7. 8 RESULTADOS DA APLICAÇÃO DO GA MULTI-CROMOSSOMO PARA A ESTRUTURA T4. 101

TABELA 7. 9 RESULTADOS DA APLICAÇÃO DO GA MULTI-CROMOSSOMO PARA A ESTRUTURA T5 102

TABELA 7. 10 RESULTADOS DA APLICAÇÃO DO GA MULTI-CROMOSSOMO PARA A ESTRUTURA T6. 102

TABELA 7. 11 DESEMPENHO DO ALGORITMO MULTI-CROMOSSOMO QUANDO APLICADO AOS DIFERENTES CENÁRIOS DE DANO. 103

TABELA 8. 1 CARACTERIZAÇÃO GEOMÉTRICA DAS VIGAS ANALISADAS. 108

TABELA 8. 2 QUANTIDADE DE CENÁRIOS DE DANOS UTILIZADOS PARA O TREINAMENTO DA REDE. 114

TABELA 8. 3 PERCENTAGENS DE CENÁRIOS SIMULADOS PARA OS QUAIS A ANN PROPOSTA APRESENTOU UM DETERMINADO GRAU DO ERRO TIPO A. 
TABELA 8. 4 PERCENTAGENS DE CENÁRIOS SIMULADOS PARA OS QUAIS A ANN PROPOSTA APRESENTOU UM DETERMINADO GRAU DO ERRO TIPO B. 116

TABELA 8. 5 PERCENTAGENS DE CENÁRIOS SIMULADOS PARA OS QUAIS A ANN PROPOSTA APRESENTOU UM DETERMINADO GRAU DO ERRO TIPO C.

TABELA 8. 6 DESEMPENHO DA ANN PROPOSTA EM FUNÇÃO DO NÚMERO DE MODOS UTILIZADOS.

TABELA 9. 1 ESPECIFICAÇÃO DA INFORMAÇÃO SOBRE AS VIGAS ANALISADAS.

TABELA 9. 2 RESULTADO DA RESPOSTA DA REDE NEURAL: CENÁRIO DE DANO 1

TABELA 9. 3 RESULTADO DA RESPOSTA DA REDE NEURAL: CENÁRIO DE DANO 2

TABELA 9. 4 RESULTADO DA RESPOSTA DA REDE NEURAL INCLUINDO O POS-PROCESSAMENTO PROPOSTO: CENÁRIO DE DANO 3 128

TABELA 9. 5 RESULTADO DA RESPOSTA DA REDE NEURAL INCLUINDO O POS-PROCESSAMENTO PROPOSTO: CENÁRIO DE DANO 4. 128

TABELA 9. 6 RESULTADOS EM FUNÇÃO DO NÚMERO DE ZONAS CONSIDERADAS COMO DANIFICADAS. 129

TABELA 9. 7 VIGA COM 15 ELEMENTOS. 130

TABELA 9. 8 VIGA COM 24 ELEMENTOS. 130

TABELA 9. 9 VIGA COM 30 ELEMENTOS. 130

TABELA 9. 10 EFEITO DO RUÍDO. 131

TABELA 9. 11 INFLUÊNCIA DA EXTENSÃO DO DANO NO SUCESSO DA METODOLOGIA PROPOSTA. 
TABELA 10. 1 RESULTADOS PARA OS ALGORITMOS PROPOSTOS. 141

TABELA 10. 2 DISTRIBUIÇÃO DE FALSOS POSITIVOS. 142

TABELA 10. 3 EXEMPLOS DA DISTRIBUIÇÃO DE FALSOS POSITIVOS SEGUNDO A EXTENSÃO DO DANO.

TABELA 10. 4 CONJUNTO DE PARETO CONTENDO INDIVÍDUOS COM DIVERSIDADE NO ESPAÇO DE SOLUÇÕES. 



\section{SUMÁRIO}

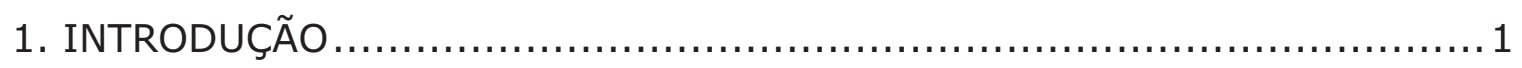

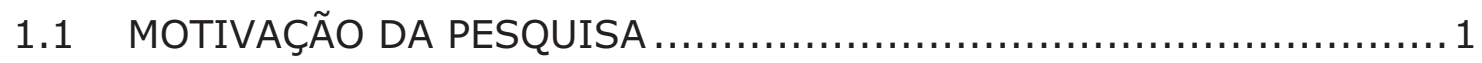

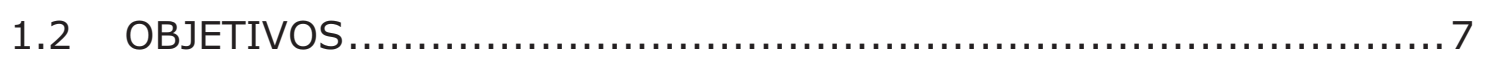

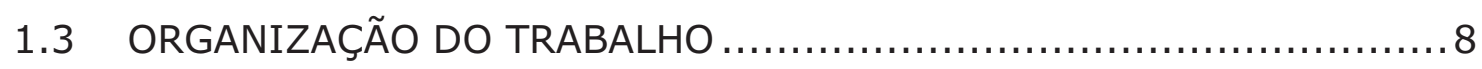

2. INTELIGÊNCIA COMPUTACIONAL ......................................... 11

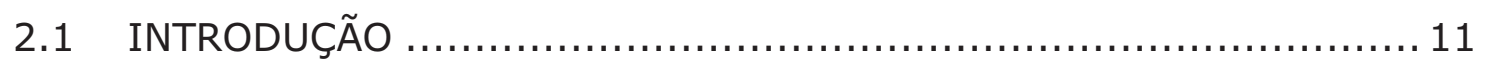

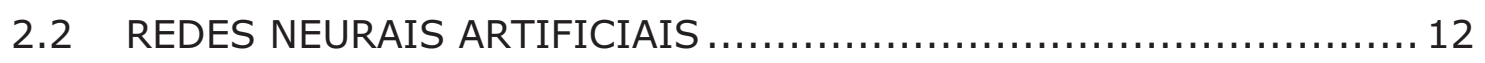

2.3 METAHEURÍSTICAS BASEADAS EM POPULAÇÕES ....................... 15

2.4 APLICAÇÃO DE INTELIGÊNCIA COMPUTACIONAL EM ENGENHARIA DE

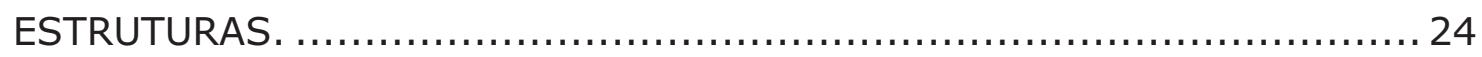

3. REVISÃO DE METODOLOGIAS DE DETECÇÃO DE DANO ........................ 29

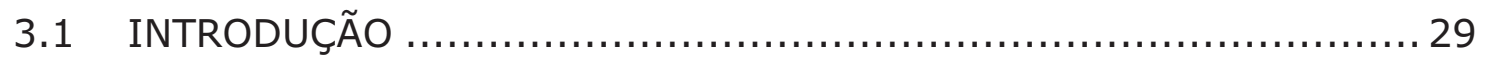

3.2 TÓPICOS EM DETECÇÃO DE DANO UTILIZANDO A RESPOSTA

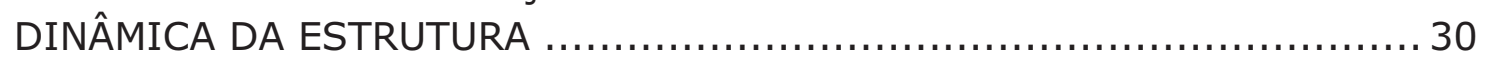

3.3 METODOLOGIAS DE DETECÇÃO DE DANO QUE EMPREGAM

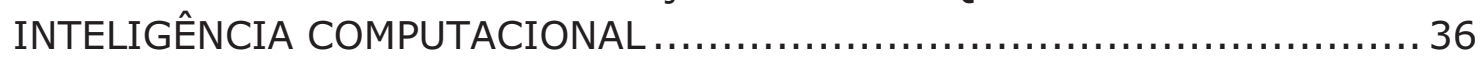

3.4 METODOLOGIAS DE DETECÇÃO DE DANO QUE FAZEM REDUÇÃO DO

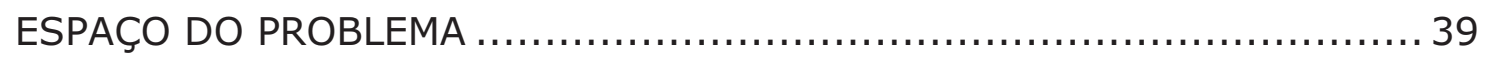

3.5 METODOLOGIAS DE DETECÇÃO DE DANO BASEADAS EM MUDANÇAS

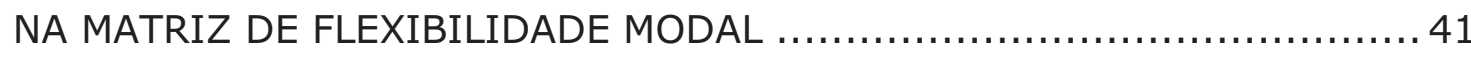

3.6 METODOLOGIAS DE DETECÇÃO DE DANO BASEADAS EM DIFERENTES TIPOS DE RESPOSTA ESTRUTURAL ............................. 43

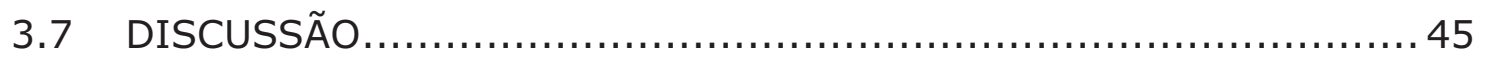

4. EXEMPLO I: ESQUEMA DE AVALIAÇÃO DE METODOLOGIAS DE DETECÇÃO

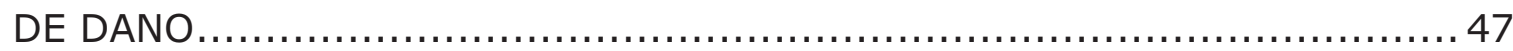

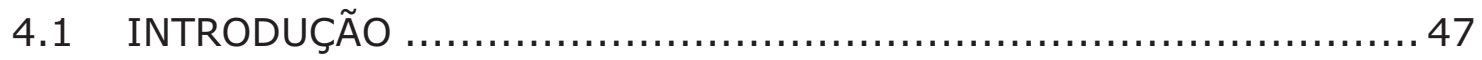

4.2 METODOLOGIA DE DETECÇÃO DE DANO BASEADO EM HEURÍSTICAS 48

4.3 CARACTERTÍSCAS DO ALGORITMO GENÉTICO DE CÓDIGO REAL ... 51

4.4 NOVO SISTEMA DE AVALIAÇÃO DO DESEMPENHO DE METODOLOGIAS DE DETECÇÃO DE DANO DE NIVEL III ...................... 54

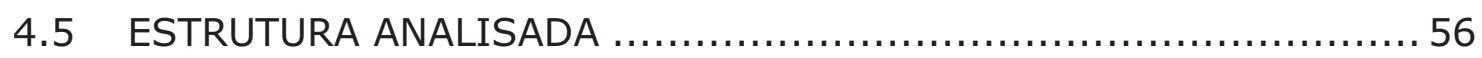

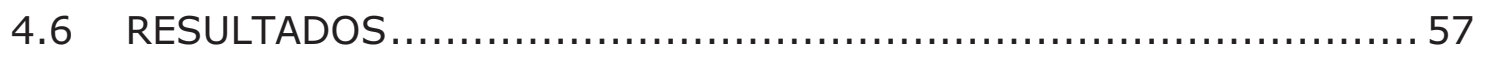

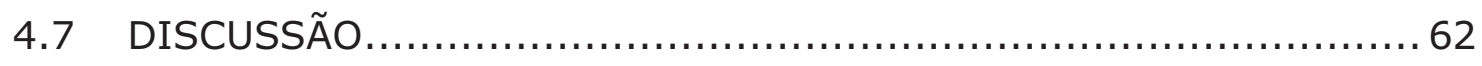


5. EXEMPLO II: PARTICLE SWARM OPTIMIZATION ......................... 65

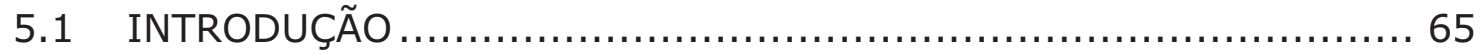

5.2 DESCRIÇÃO DO PROBLEMA E DA ESTRUTURA ANALISADA ...........66 66

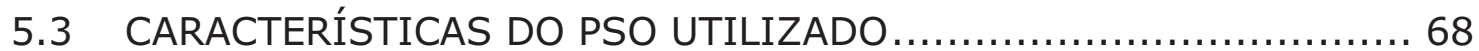

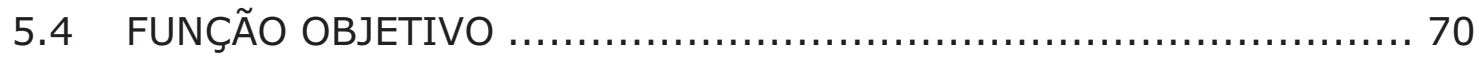

5.5 DETERMINAÇÃO DA QUANTIDADE ÓTIMA DE MEDIÇÕES ............. 70

5.6 VERIFICAÇÃO DA QUANTIDADE ÓTIMA ESCOLHIDA ................ 74

5.7 INFLUÊNCIA DO NÚMERO DE MODOS UTILIZADOS NA

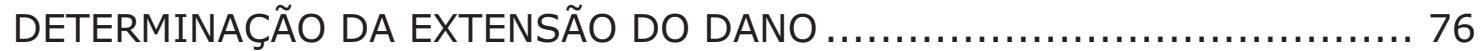

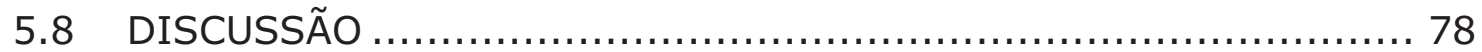

6. EXEMPLO III: ALGORITMO DE EVOLUÇÃO DIFERENCIAL.................. 81

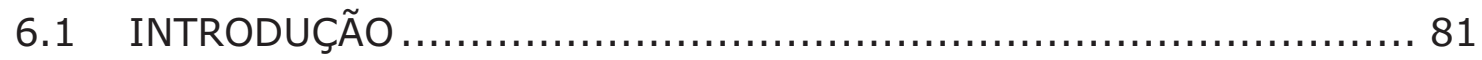

6.2 ESTRUTURA ANALISADA E CENÁRIOS DE DANO $\ldots \ldots \ldots \ldots \ldots \ldots \ldots . \ldots 2$

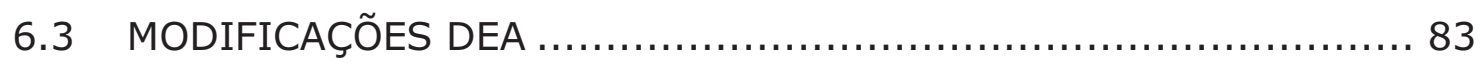

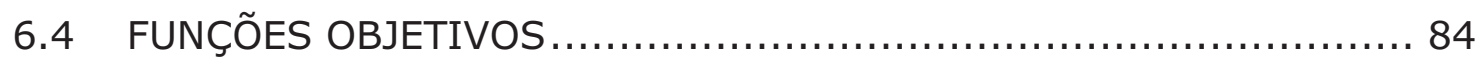

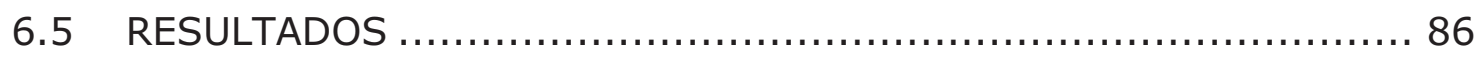

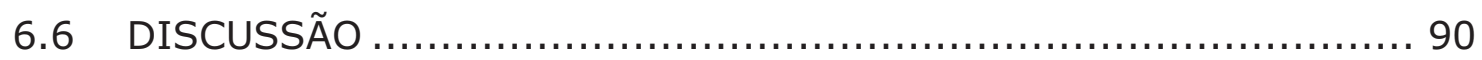

7. EXEMPLO IV: ALGORITMO GENÉTICO MULTI-CROMOSSOMO ................ 93

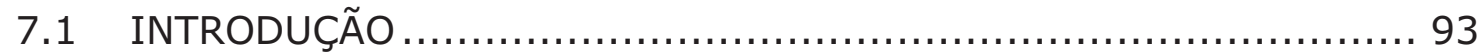

7.2 ESTRUTURA ANALISADA E CENÁRIOS DE DANO $\ldots \ldots \ldots \ldots \ldots \ldots \ldots \ldots . \ldots$

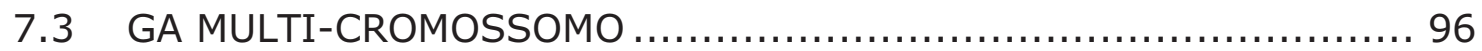

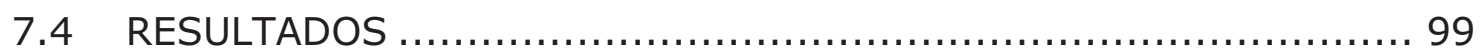

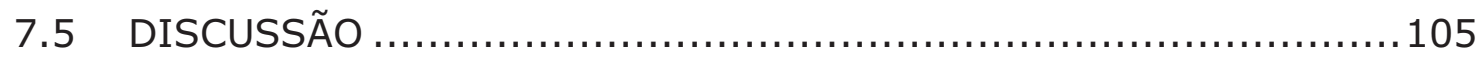

8. EXEMPLO V: REDES NEURAIS ARTIFICIAIS- QUANTIFICAÇÃO .............. 107

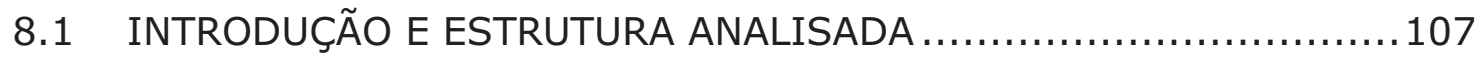

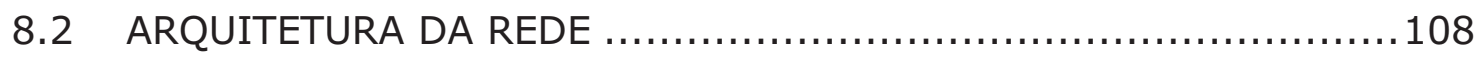

8.3 DEFINIÇÃO DE ETAPAS ANTERIORES AO TREINAMENTO DA REDE. 110

8.4 APLICAÇÃO DA REDE E REFINAMENTO DOS RESULTADOS ...........112

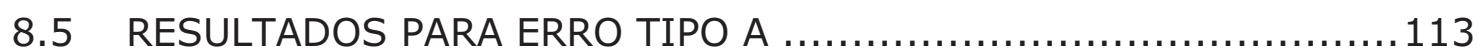

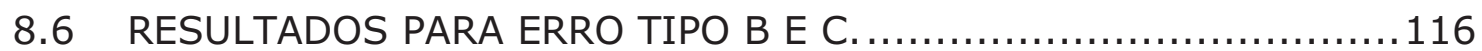

8.7 RESULTADOS PARA CENÁRIOS DE DANO INDIVIDUAIS ..............117

8.8 RELAÇÃO ENTRE A QUANTIDADE DE MODOS MEDIDOS E O DESEMPENHO DA METODOLOGIA PROPOSTA. .............................118

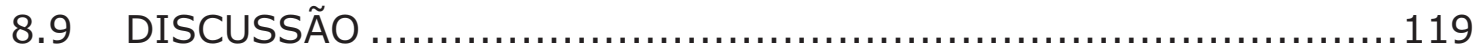


9. EXEMPLO VI: REDES NEURAIS ARTIFICIAIS- LOCALIZAÇÃO 121

9.1 COMO UTILIZAR REDES NEURAIS EM LOCALIZAÇÃO DE DANO .... 121

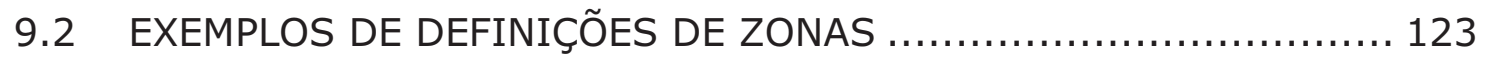

9.3 CARACTERÍSTICAS DA REDE NEURAL UTILIZADA................... 125

9.4 ESQUEMA DE POS-PROCESSAMENTO DOS RESULTADOS ............ 126

9.5 INFLUÊNCIA DO TIPO DE ALGORITMO DE TREINAMENTO ESCOLHIDO NO DESEMPENHO DA METODOLOGIA PROPOSTA ........................ 129

9.6 INFLUÊNCIA DO RUIDO NO DESEMPENHO DA METODOLOGIA

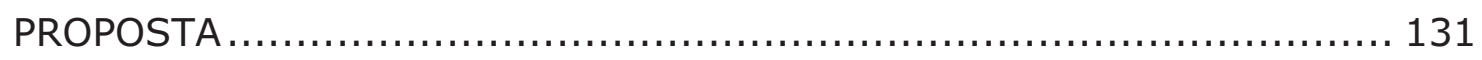

9.7 INFLUÊNCIA DA EXTENSÃO DO DANO NO DESEMPENHO DA

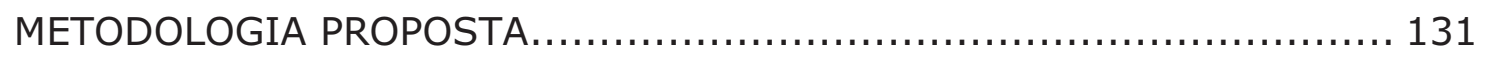

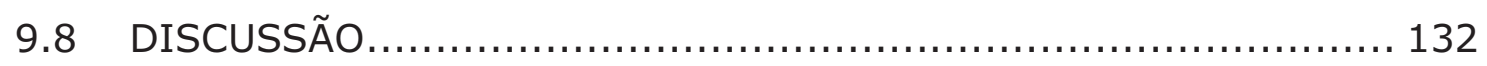

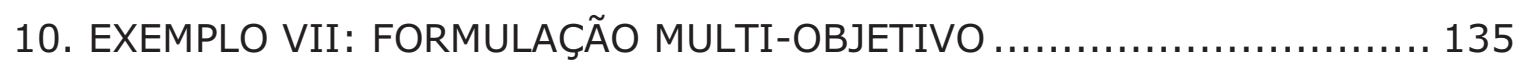

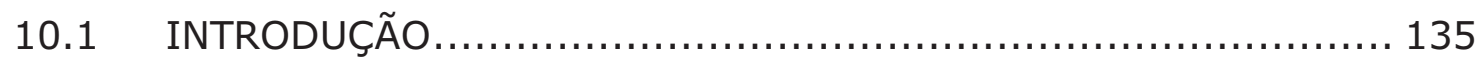

10.2 "NON-DOMINATED SORTING GENETIC ALGORITHM II (NSGA-II)" 137

10.3 "STRENGTH PARETO EVOLUTIONAY ALGORITH II, (SPEA-II)" ... 138

10.4 ESTRUTURA ANALISADA E DEFINIÇÃO DAS CARACTERÍSTICAS DO

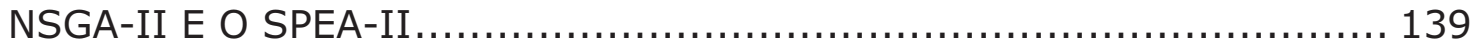

10.5 DETERMINAÇÃO DA VIABILIDADE DA FORMULAÇÃO MULTI-

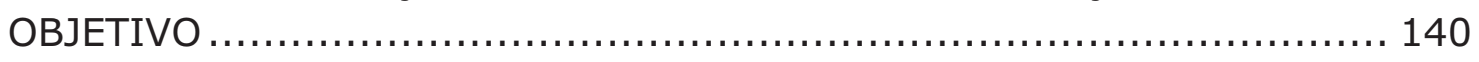

10.6 CARACTERÍSTICAS DO CONJUNTO DE PARETO OBTIDO ........... 142

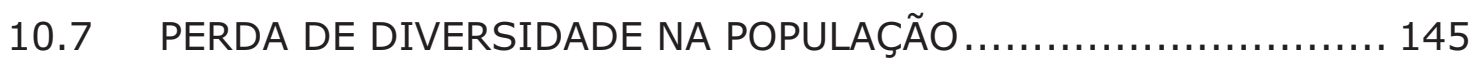

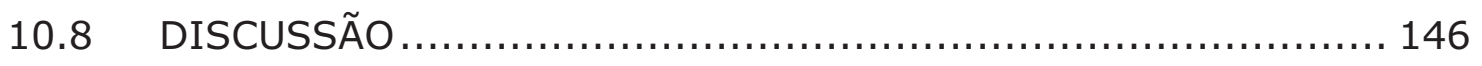

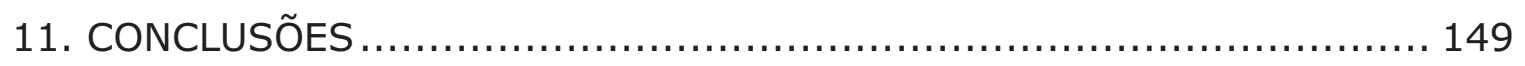

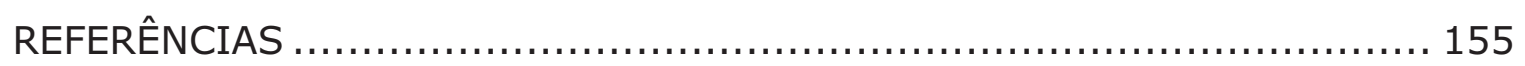





\section{INTRODUÇÃO}

\subsection{MOTIVAÇÃO DA PESQUISA}

Dano pode ser considerado como qualquer perturbação introduzida em um sistema que prejudica seu comportamento atual ou futuro (Doebling et al., 1998). Em uma estrutura o dano corresponde a uma degradação das suas propriedades (rigidez, massa, amortecimento). Neste trabalho o dano é considerado isotrópico e será modelado como uma redução da rigidez do elemento danificado. Apesar de o dano ser um fenômeno tipicamente não linear, o modelo de dano isótropo pode ser adotado devido ao fato de que o comportamento da estrutura é linear antes e depois do dano para perturbações relativamente pequenas (Koh e Dyke, 2007). Uma abordagem mais detalhada sobre o fenômeno do dano pode ser encontrada em textos clássicos como Lemaitre (1996).

A avaliação da integridade estrutural tem sido motivo de interesse por parte da comunidade cientifica há algumas décadas, devido às possíveis implicações econômicas e sociais que se originam pela presença do dano em uma 
estrutura. Por causa disto, uma grande quantidade de linhas de pesquisa tem sido seguida para poder avaliar o estado dos diferentes tipos de estruturas (mecânicas, civis, aeronáuticas) a partir da determinação experimental da sua resposta atual. Uma dessas linhas utiliza a resposta dinâmica da estrutura em dois estados - um deles considerado o estado inicial- para o desenvolvimento de metodologias não destrutivas de detecção de dano. O conceito utilizado é simples: a presença do dano sugere que a resposta dinâmica da estrutura para o estado atual é diferente daquela do estado inicial e que esta diferença poderia ser utilizada como um indicador da degradação mecânica da estrutura. Nesse sentido, o trabalho apresentado por Cawley e Adams em 1979 é talvez o primeiro reportado na literatura que utiliza o conceito anterior - especificamente, mudanças nas frequências naturais - para a localização do dano.

Uma metodologia de detecção de dano pode ser classificada como proposto por Rytter (1993), em função da informação que forneça sobre o dano. Tal sistema de classificação é um dos mais utilizados na literatura e indica que a presença do dano em uma estrutura pode ser caracterizada segundo um dos seguintes níveis de identificação: nível I quando a metodologia consegue determinar unicamente se a estrutura apresenta ou não dano, nível II se a localização do dano é fornecida, nível III quando é possível quantificar a extensão do dano e o nível IV que se encontra relacionado à determinação da vida útil da estrutura. Além da classificação anterior, uma metodologia de detecção de dano baseada em vibração poderia pertencer a um de dois grupos conforme se utiliza sinais ou modelos de elementos finitos para sua formulação (Zou et al., 2000). Quando somente sinais são empregados, a metodologia consegue atingir, na melhor das hipóteses, o nível II de identificação, enquanto com outro grupo é possível atingir o nível III. O autor considera que uma forma adequada para a realização da localização e a quantificação do dano é a partir da combinação de uma metodologia baseada em sinais que permita determinar se a estrutura apresenta ou não dano e de uma metodologia que envolva a atualização de um modelo de elementos finitos (FEM), conforme ilustra o fluxograma apresentado na Figura 1.1. 


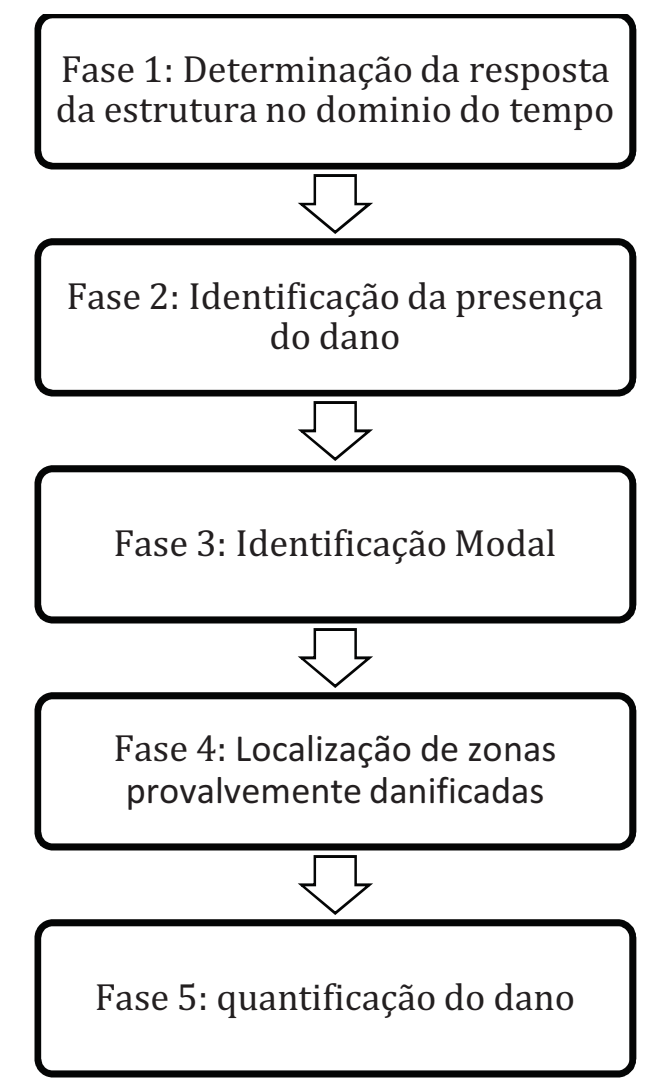

Figura 1. 1 Metodologia de deteç̧ão de dano baseada em vibração.

A primeira fase da metodologia descrita na Figura 1.1 corresponde à avaliação experimental da estrutura no domínio no tempo. Nesse sentido, podem ser realizados ensaios de vibração forçada ou de vibrações ambientais. Este último tem ganhado ampla importância no campo da análise modal, pois apresenta a vantagem de não requerer de medições das forças que excitam a estrutura.

Na Fase 2, o sinal obtido no ensaio dinâmico é, então, utilizado no domínio do tempo ou da frequência para determinar se há dano na estrutura. Uma metodologia de detecção de dano no domínio do tempo foi proposta por Zhang (2007), que permite identificar a presença do dano em forma estatística a partir de medições de vibrações ambientais sobre uma ponte. Um processo de normalização de informação é necessário para a determinação de pares de sinais que tenham sido medidos sob condições operacionais e ambientais semelhantes para as condições com e sem dano. No domínio da Frequência pode-se encontrar, por exemplo, o trabalho de Sun e Chang (2004). Eles aplicaram a Transformada Wavelet num sinal de aceleração e utilizaram as variações nos 
maiores coeficientes de energia entre duas condições da estrutura para identificar a presença do dano. A identificação é realizada mediante uma técnica de controle de processos estatísticos aplicada sobre os indicadores de dano. Metodologias de detecção de dano cujo desenvolvimento implica a análise da resposta da estrutura em um dos domínios anteriores têm sido amplamente estudadas pela comunidade científica.

Se a aplicação da Fase 2 da metodologia resulta na identificação positiva da presença do dano na estrutura, então, se realizaram as fases seguintes.

A Fase 3 consiste em determinar as características modais da estrutura, que serão utilizadas para a localização e quantificação do dano. Diversas técnicas podem ser utilizadas para a identificação modal tais como multiple reference Ibrahim time domain, least-squares complex exponential, polyreference complex exponential, Covariance driven Stochastic Subspace Identification method, Pick Picking e Frequency Domain Decomposition method (Cunha et al., 2007).

Na Fase 4 aplica-se uma metodologia de localização de possíveis zonas danificadas com o intuito de eliminar aquelas zonas nas quais se tenha certeza que não há a presença do dano. Cabe salientar que não é objetivo desta etapa definir com exatidão a posição do dano, mas sim determiná-la de forma aproximada.

A Fase 5 precisa inicialmente da definição de um modelo numérico que represente a condição inicial da estrutura e que será atualizado de forma a obter um modelo representativo da condição com dano. Nas fases anteriores pode-se ou não requerer de tal modelo se medições da resposta da estrutura na situação inicial estão disponíveis. A determinação da localização exata e extensões dos elementos realmente danificados é realizada considerando unicamente aqueles elementos que pertencem às zonas identificadas na Fase 4. Depois da realização da fase de quantificação espera-se encontrar um cenário de dano similar ao real, onde os elementos que foram erroneamente identificados como danificados apresentem um valor de dano próximo a zero. Um grande número de metodologias de detecção de dano reportadas na literatura atingem o nível III de identificação mediante a realização simultânea das Fases 4 e 5. Porém, há metodologias que realizam os processos de localização e quantificação sequencialmente, sendo que algumas delas serão descritas brevemente no capítulo 3. Esta forma de se resolver o problema de detecção de dano ganha importância à medida que o tamanho da estrutura cresce devido a que o 
tamanho do espaço de possíveis soluções - número de combinações possíveis de elementos danificados e extensões de dano- incrementa de maneira não linear em função da quantidade de elementos na estrutura.

Por outro lado, o problema de detecção do dano em uma estrutura é considerado de difícil solução pelo fato de envolver informações incompletas e imprecisas. Nesse sentido, a utilização de técnicas de inteligência computacional (CITs) para resolvê-lo mostra-se plausível. Begambre (2007) citou algumas vantagens da aplicação de técnicas heurísticas na solução do problema em questão em relação à aplicação de técnicas clássicas de otimização. Entre elas destacam-se a habilidade para a determinação de uma solução global, menor dependência da solução inicial, menor sensibilidade ao ruído e que não seja necessário o cálculo de derivadas para orientar a busca. Outra vantagem dessas técnicas é a possibilidade de paralelização dos seus algoritmos, que as torna atrativas para utilização em problemas que envolvem alto custo computacional. As duas principais desvantagens das técnicas heurísticas são a necessidade da definição a priori dos parâmetros, que podem influenciar consideravelmente seu desempenho, e que não garantem a determinação da resposta ótima ao problema estudado. Cabe salientar que são poucos os trabalhos que fazem comparações entre os dois diferentes estilos de computação- clássico vs heurístico- quando aplicados ao problema de detecção de dano. Neste trabalho serão utilizadas CITs para o desenvolvimento de metodologias que permitam avaliar a integridade estrutural, sendo que as duas principais CIT utilizadas pela comunidade científica correspondem às redes neurais artificiais (ANNs) e aos algoritmos genéticos (GAs).

A utilização de ANNs num ambiente supervisionado - apresentação de exemplos formados por pares de dados de entrada e saída- consiste no treinamento da rede com vetores de entrada formados a partir dos parâmetros dinâmicos da estrutura quando apresenta diferentes cenários de dano- vetor de saída. As saídas da rede correspondem a fatores de redução da rigidez dos elementos na estrutura quando esta é utilizada para quantificação do dano. Villalba e Laier (2012a) realizaram uma revisão bibliográfica sobre a aplicação de ANNs na avaliação da integridade estrutural. Eles concluíram que a arquitetura mais utilizada é a perceptron multicamada, que o tempo de treinamento pode inviabilizar a utilização de um algoritmo de treinamento específico, que o número 
de casos de treinamento necessário para uma correta generalização aumenta consideravelmente à medida que a estrutura cresce, entre outras conclusões.

No caso do problema de detecção de dano ser formulado como um problema de otimização, a utilização de metaheurísticas tem ganhado muita importância. Em relação à definição de quais são às variáveis de otimização do problema, a representação habitual do dano como uma redução da rigidez do elemento faz com que haja uma variável por cada elemento na estrutura. A respeito da função objetivo, observa-se que a maioria dessas metodologias formula o problema como de um único objetivo; porém, a escolha de uma função objetivo adequada é também tema de discussão. Diferentes metaheurísticas têm sido utilizadas para resolver o problema, sendo que GAs são os mais utilizados, como comentado anteriormente. Villalba e Laier (2012b) estudaram a aplicação de GAs em detecção de dano estrutural e observaram que uma configuração ótima dos algoritmos ainda não foi definida, que a presença do ruído diminui a precisão dos resultados obtidos, que a implementação de algoritmos híbridos seria uma boa solução para melhorar o resultado final, entre outras questões.

Um fator comum a ambas as técnicas apresentadas nos dois parágrafos anteriores é que falta uma maior quantidade de testes sobre estruturas cujo FEM tenha uma alta quantidade de elementos, sendo que as metodologias discutidas são testadas apenas em estruturas que possuem poucos elementos estruturaisgeralmente entre 5 e 100 elementos para o caso de estruturas com elementos de barra. Cabe ressaltar que a quantidade de trabalhos reportados na literatura que utiliza ANNs supera consideravelmente àqueles que utilizam GAs. Em um menor número encontram-se aplicações de outras TICs como o Particle Swarm Optimization (PSO) e o Algoritmo de Evolução Diferencial (DEA). Além disso, são poucos os trabalhos que comparam os resultados a partir de diferentes CITs para determinar qual seria a mais indicada.

Neste trabalho procura-se desenvolver metodologias de detecção de dano que utilizem CITs como ferramenta computacional para a solução do problema e cuja formulação envolva as mudanças nos parâmetros dinâmicos da estrutura que acontecem com o dano. As metodologias mencionadas devem atingir os níveis de identificação II e/ou III. O desempenho das metodologias propostas será avaliado a partir da geração de cenários de dano aleatórios desde os quais são determinados os parâmetros dinâmicos para a condição com dano; isto se deve ao caráter numérico da presente tese doutoral. Porém, algumas questões 
que caracterizam as medições obtidas em ensaios dinâmicos são levadas em conta na simulação, entre elas a presença de ruído nas medições. Além disso, considera-se em todos os exemplos analisados que o número de elementos danificados é pequeno e que a extensão do dano não é severa. Na seguinte seção serão consignados os objetivos a serem atingidos com a presente pesquisa.

\subsection{OBJETIVOS}

\subsubsection{Objetivo Principal}

Desenvolver metodologias que permitam determinar a integridade de estruturas a partir do uso de técnicas de inteligência computacional e das mudanças que ocorrem na resposta dinâmica como consequência do dano.

\subsubsection{Objetivos Específicos}

Os objetivos específicos da presente tese são os seguintes:

- Estudar o estado atual do problema de detecção de dano quando resolvido a partir das mudanças nas propriedades dinâmicas da estrutura.

- Utilizar redes neurais artificiais do tipo perceptron multicamada para localizar e quantificar dano em vigas a partir de mudanças na flexibilidade modal.

- Propor metaheurísticas adaptativas para resolver o problema de otimização associado ao problema de detecção de dano. 
- Definir novas características para as metaheurísticas que permitam acelerar sua convergência baseados nas particularidades do problema estudado.

- Sugerir um esquema de avaliação do desempenho de metodologias de deteç̧ão de dano a partir da análise dos resultados da sua aplicação na detecção de uma quantidade representativa de cenários de dano.

- Analisar o efeito de medições incompletas, a presença de ruído e dos parâmetros dinâmicos utilizados na função objetivo sobre o desempenho de uma metodologia que permita avaliar a integridade estrutural.

- Analisar as características de uma formulação multi-objetivo para o problema de deteç̧ão de dano.

\subsection{ORGANIZAÇÃO DO TRABALHO}

A seguir apresenta-se o conteúdo que será tratado nos diferentes capítulos que constituem esta tese.

No capítulo 2 é realizada uma breve introdução aos fundamentos das CITs e apresenta-se uma breve descrição das técnicas que serão utilizadas na solução do problema de deteç̧ão de dano. Mostram-se, ainda, alguns exemplos da aplicação de CITs no campo da engenharia de estruturas.

No capítulo 3 apresenta-se uma revisão completa de metodologias de detecção de dano que utilizam parâmetros dinâmicos e realiza-se uma breve discussão sobre o tema.

No capítulo 4 introduze-se um novo operador de mutação para um GA de código real que permite acelerar a convergência do algoritmo para o cenário de dano correto e é mostrado em detalhe o esquema de avaliação de metodologias de detecção de dano proposto.

No capítulo 5 é mostrada a aplicação da metaheurística Particle Swarm Optimization, em uma versão adaptativa, na detecção de dano de uma estrutura do tipo viga. Neste exemplo, estuda-se o efeito que o fato da informação modal utilizada ser incompleta traz sobre o desempenho da metodologia proposta. 
No capítulo 6 é proposto um algoritmo de evolução diferencial adaptativo para detectar o dano em estruturas de tipo treliça. Neste exemplo se compara o desempenho do algoritmo em função dos parâmetros dinâmicos escolhidos para formar a função objetivo.

No capítulo 7 comprova-se a eficiência da utilização de um GA que utiliza múltiplos cromossomos para localização e quantificação do dano. Tal representação permite a variação dinâmica dos elementos considerados como danificados para cada um dos indivíduos na população.

No capítulo 8 mostra-se a aplicação de uma metodologia de detecção de dano que utiliza redes neurais e cujo vetor de entrada esta composto por valores de residuais da diagonal da matriz de flexibilidade para quantificar dano em vigas com múltiplos suportes.

No capítulo 9 propõe-se uma rede neural que permite localizar zonas provavelmente danificadas em estruturas do tipo viga sob a condição de medições incompletas e ruidosas.

No capítulo 10 estuda-se o problema de detecção de dano quando formulado como um de otimização multi-objetivo.

No capítulo 11 são apresentadas as conclusões obtidas da realização do presente trabalho e se propõem alguns tópicos que permitam a elaboração de trabalhos futuros. 


\section{INTELIGÊNCIA COMPUTACIONAL}

\subsection{INTRODUÇÃO}

A inteligência computacional agrupa um conjunto de paradigmas baseados principalmente em comportamentos observados na natureza que permitem encontrar soluções a problemas complexos para os quais técnicas matemáticas tradicionais falham. Caracterizam-se por serem uma combinação de aprendizagem, adaptação e evolução (Sumathi e Paneerselvam, 2010). Por conseguinte, um paradigma é descrito como um caso particular de atributos de inteligência computacional que mostram um comportamento específico (Eberhart e Shi, 2007).

A inteligência computacional é um ramo da inteligência artificial sendo formada principalmente por redes neurais artificiais, computação evolutiva, inteligência de enxame, sistemas fuzzy e sistemas imunes artificiais (Engelbrecht, 2007). Estas técnicas também são caracterizadas por tratar 
problemas que envolvem dados incompletos e/ou incertos, tomando o nome de Soft Computing Techniques. Ainda, algumas das técnicas de inteligência computacional (CITs) podem ser chamadas de Meta-heurísticas como será mostrado na seção 2.3. Os principais tipos de problema nos quais se tem a aplicação de CITs são os seguintes: problemas de otimização, problemas de controle, problemas de classificação, problemas de regressão e problemas completos NP (Sumathi e Paneerselvam, 2010).

O estudo de cada uma dos paradigmas anteriores é amplo; não obstante, uma pequena introdução sobre as técnicas que serão utilizadas nesta pesquisa é apresentada. As técnicas aplicadas aqui são algoritmos genéticos, particle swarm optimization, algoritmo de evolução diferencial e redes neurais artificiais. $\mathrm{Na}$ literatura há outras técnicas que poderiam ser aplicadas na solução do problema de detecção de dano tais como Simulated Annealing (Kirkpatrick et al., 1983), Foreging Bacterial Optimization Algorithm (Passino, 2002), Bee Colony Algorithm (Karaboga e Bastur, 2007), Firefly Algorithm (Yang, X. S., 2009), Harmony Search (Lee e Geem, 2005), sistemas fuzzy, sistemas imunes (De Castro e Timmis, 2002), entre outros.

Cabe ressaltar que até agora não se tem definida uma CIT que seja melhor para todos os tipos de problemas, isto justifica a utilização de diferentes técnicas na resolução de um determinado problema e a definição de algoritmos híbridos (Engelbrecht, 2007).

Na última seção deste capítulo será apresentada uma breve revisão de metodologias que utilizam CITs para resolver problemas de engenharia de estruturas com o intuito de mostrar ao leitor como elas têm sido importantes neste campo.

\subsection{REDES NEURAIS ARTIFICIAIS}

Redes neurais artificiais (ANNs) simulam o comportamento do cérebro humano na resolução de problemas da vida real, sendo sua primeira aparição na literatura referida ao trabalho de McCulloh e Pitts em 1943, que apresentaram algumas indicações sobre a operação dos neurônios (Ham e Kostanic, 2001). 
Entre as principais características das ANNs se encontram sua capacidade em aprender e generalizar a partir de exemplos, sua habilidade para tratar com dados incompletos, imprecisos e/ou ruidosos, capacidade de auto-adaptação a mudanças no problema analisado, entre outras.

Um dos tipos de ANNs mais utilizados é o Perceptrón Multi-Camada (MLP), que permite mapear as relações que existem entre um conjunto de entradas e suas respectivas saídas tal que a apresentação de novas entradas possa resultar em valores de saída confiáveis. A arquitetura deste tipo de rede constitui-se de neurônios que se distribuem em três tipos de camadas - entrada, ocultas e saída-, como mostrado na Figura 2.1. Aqueles na camada de entrada recebem a informação medida e neles não é realizada operação alguma. Os neurônios na camada de saída estão em número igual aos valores de saída. Em relação ao número de camadas ocultas, estas podem ser uma, duas ou mais, sendo que comumente são utilizadas até duas camadas ocultas. Panchal et al. (2011) afirmam que não há razões teóricas para utilizar mais de duas camadas ocultas.

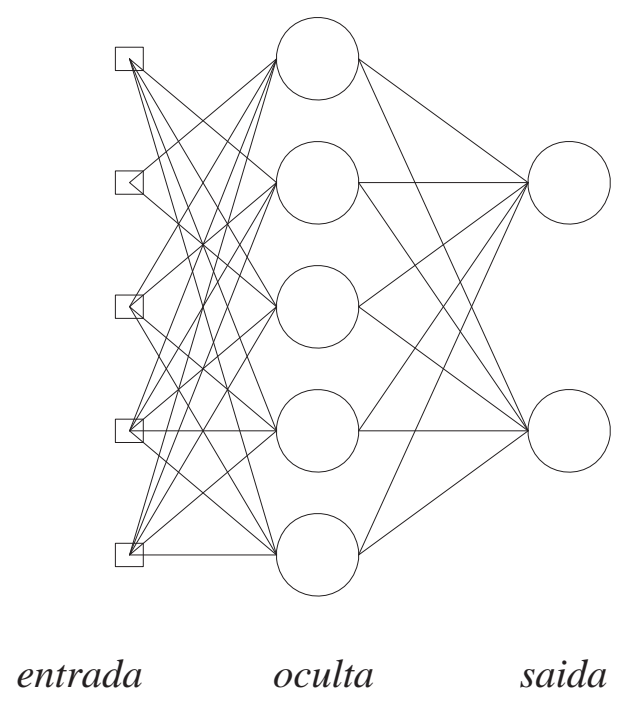

Figura 2. 1 Rede Neural perceptrón Multi-camada.

Os neurônios nas diferentes camadas encontram-se interconectados e para cada conexão existe um valor de peso que imita a sinapse entre neurônios no cérebro, que pode assumir um valor positivo (excitante) ou negativo (inibente). Outro parâmetro da rede MLP é o limiar de ativação que se utiliza para aumentar ou diminuir o valor de ativação de um neurônio. Pesos e limiares contem as 
relações entre os valores de entrada e de saída que permitem à rede funcionar e correspondem a incógnitas cujos valores deverão ser encontrados. Sua determinação será realizada a partir do treinamento da rede como explicado nos seguintes parágrafos.

Redes MLP foram amplamente aplicadas depois da publicação do algoritmo inicial de treinamento denominado back-propagation no ano 1986 (Nunes Da Silva et al., 2010). Tal algoritmo é aplicado em dois passos: forward e backward, sendo que no inicio definem-se valores aleatórios para os pesos das conexões e limiares.

No primeiro passo, cada caso de treinamento é apresentado à rede e é propagado até obter um valor nos neurônios da saída. Em cada neurônio das camadas ocultas e de saída é realizado um processo de soma onde se pondera o valor que vem de cada neurônio na camada anterior pelo seu respectivo peso. 0 valor obtido se introduz em uma função de ativação que permite determinar o valor de saída do correspondente neurônio. A função de ativação tem como objetivo limitar os valores que saem dos neurônios a certa faixa, usualmente entre 0 e 1 ou - 1 e 1, com algumas delas mostradas na Figura 2.2. Os valores encontrados depois da aplicação das funções de ativação nos neurônios da camada de saída são comparados com as verdadeiras saídas e se determina o erro relativo ao caso de treinamento apresentado.

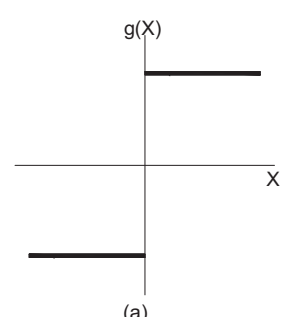

(a)

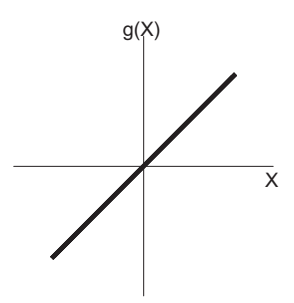

(b)

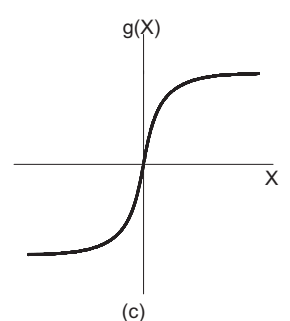

(c)

Figura 2. 2 Tipos de funções de ativação: a) Hard Limiter, b) Linear e c) sigmoide.

No segundo passo, utiliza-se o erro calculado para atualizar os pesos das diferentes camadas em um processo realizado em sentido contrario ao primeiro passo, e que envolve o cálculo de algumas derivadas do erro em relação aos pesos. Este processo é realizado para todos os casos de treinamento, sendo que depois disso considera-se que uma época tem acontecido. O treinamento pode 
ser interrompido depois de se atingir um erro mínimo desejado ou um número máximo de épocas.

Diferentes tipos de treinamento podem ser utilizados para realizar a aprendizagem de uma rede. A escolha de qual método utilizar deve levar em consideração a relação entre a capacidade de generalização desejada e o tempo de processamento. Têm-se algoritmos muito eficientes para a obtenção de uma generalização adequada tal como o Levenberg- Mardquart. No entanto, seu tempo de processamento pode ser muito alto, o que é uma desvantagem na medida em que o número de pesos na rede aumenta. Metaheurísticas têm sido utilizadas amplamente como algoritmo de treinamento na última década e um exemplo disso é o trabalho proposto por Ilonen et al (2003).

Não há uma regra única para se estabelecer o número de neurônios na camada oculta, este valor é dependente do problema analisado e pode ser determinado a partir do método da validação cruzada. Sua definição é de grande importância já que um valor pequeno não permitirá que a rede aprenda adequadamente (underfitting) e um valor grande faz com que a rede sobreaprenda os casos de treinamento e perca a capacidade de generalização (overfitting). A definição do número de casos de treinamento é também dependente do problema.

Para concluir, há uma grande variedade de tipos de redes neurais artificiais que poderiam ser utilizadas para solucionar diferentes problemas tais como ANN de base radial, ANN Wavelet (Zhang e Benveniste, 1992), ANN Probabilística (Specht, 1990), ANN-Fuzzy (Jang, 1993), Learning Vector Quantization (Kohonen, 1990), entre outras. Nesta pesquisa redes do tipo MLP foram utilizadas para resolver o problema de detecção de dano.

\subsection{METAHEURÍSTICAS BASEADAS EM POPULAÇÕES}

Metaheurísticas são uma classe de técnicas computacionais que permitem encontrar soluções ótimas ou quase-ótimas para problemas de otimização em um tempo razoável e que são caracterizadas pela facilidade de serem propostas e implementadas computacionalmente (Talbi, 2009). Elas têm sido amplamente 
utilizadas na resolução de problemas complexos onde não se tem algoritmos específicos para resolvê-los, como no caso do problema de detecção de dano. Uma característica apreciável das metaheurísticas é a sua facilidade de paralelização, o que as converte em ferramentas importantes para a solução de problemas complexos. Dado que metaheurísticas não garantem que encontrarão a solução requerida para o problema, é necessário que diversas execuções do algoritmo sejam realizadas para poder se definir qual a solução final do problema entre as respostas encontradas.

Cabe salientar que a utilização de técnicas clássicas de otimização pode não ser recomendada em alguns casos como apresentam algumas limitações (Deb, 2001):

- A solução inicial escolhida influi na convergência para a solução ótima.

- Na presença de múltiplos ótimos locais a maioria das técnicas tende a ficar presas neles.

- O fato de uma técnica resolver de forma adequada um problema determinado não garante que apresente a mesma efetividade para resolver algum outro problema.

- Espaços de busca discretos são difíceis de tratar.

- Não são eficientemente usados em computadores paralelos.

Metaheurísticas podem ser classificadas segundo vários critérios tais como se são ou não inspiradas na natureza, utilização ou não de memória, se o algoritmo é determinístico ou estocástico, número de soluções que são modificadas simultaneamente para chegar na resposta do problema ou se seguem um processo greedy - a solução é construída variável por variável- ou iterativo (Talbi, 2009).

Entre as características que determinam o sucesso de uma metaheurística na solução de um problema está a forma como elas combinam a exploração e a intensificação do espaço de busca. A exploração refere-se à visita das diferentes regiões no espaço enquanto que a intensificação trata da procura da melhor solução nas regiões mais aptas. Nesse sentido, precisa-se um bom balanço entre estas duas características já que, por exemplo, se unicamente intensificação é realizada então o algoritmo pode convergir para um ótimo local.

A utilização de uma metaheurística específica requer a definição dos seus parâmetros- como, por exemplo: taxas de mutação e cruzamento nos GAs-, 
sendo que os valores escolhidos influenciam altamente o processo de busca. Atualmente, os valores desses parâmetros são definidos a partir de execuções prévias do algoritmo por parte do analista. No entanto, a melhor configuração de parâmetros pode variar de um problema para outro, o que torna desejável que o algoritmo tenha a capacidade de controlar seus próprios parâmetros. Três tipos de controle têm sido trabalhados na literatura no caso de algoritmos evolutivos (Eiben et al., 1999):

- Controle determinístico de parâmetros. Uma regra determinística é utilizada para a determinação dos valores dos parâmetros sem se requerer de informação alguma relacionada ao processo de busca.

- Controle adaptativo de parâmetros. As mudanças são realizadas levando em conta a informação sobre a busca que é obtida durante o processo evolutivo.

- Controle auto-adaptativo de parâmetros. Os parâmetros são variáveis que devem ser determinadas ao longo do processo evolutivo.

Devido ao fato das metaheurísticas não garantirem que a resposta ótima ao problema será encontrada, elas podem ser hibridizadas com alguma técnica de busca local com o intuito de melhorar o desempenho da metaheurística. Uma forma de fazer isto é realizar uma busca local ao redor da solução encontrada pela metaheurística. Assim por exemplo, o método Nelder-Mead Simplex (Nelder e Mead, 1965) poderia ser uma técnica útil para esse fim.

A função objetivo escolhida para o problema estudado deve ser adequada para facilitar o desempenho da metaheurística, sendo que o problema poderia estar ou não restrito a algumas condições, apresentar um ou múltiplos ótimos locais e ser mono ou multi-objetivo.

Os problemas de otimização encontrados no mundo real podem ter restrições sobre o espaço de solução; portanto durante o processo iterativo podem se produzir soluções que não são factíveis. Assim, por exemplo, uma restrição no dimensionamento de uma estrutura poderia consistir de valores limites para as dimensões das seções dos elementos. Para tratar de se levar em conta as restrições do problema têm-se diferentes tipos de técnicas tais como funções de penalidades, representações especiais e operadores que fazem com que haja somente soluções factíveis, algoritmos de reparação de soluções e técnicas híbridas (Coello, 2002). 
Funções objetivo multi-modais requerem que características adicionais sejam implementadas nas metaheurísticas para que estas possam reter diversos ótimos durante o processo iterativo e assim incrementar as chances de se encontrar o ótimo global. Entre os conceitos utilizados para se tratar com o tipo de problema anterior se encontram o crowding, que busca inserir novos indivíduos na população mediante a substituição de indivíduos similares, e o sharing, no qual a aptidão de um indivíduo determinado é diminuído em função da quantidade de indivíduos com os que compartilha uma região determinada do espaço (Sareni e Krähenbühl, 1998).

Metaheurísticas foram aplicadas inicialmente para resolver problemas com um único objetivo e depois estendidas para sua aplicação em problemas multiobjetivo. Muitos problemas requerem que vários objetivos sejam atingidos simultaneamente, sendo eles algumas vezes conflitantes. Um exemplo clássico deste tipo é a otimização de uma estrutura onde se requer que se tenha um peso mínimo e uma deflexão mínima. Nesse caso os objetivos são considerados opostos devido ao fato de que não é possível melhorar um deles sem prejudicar o outro. Sendo assim, mais de uma solução ao problema é viável, que é a principal diferença com otimização de um único objetivo. Esse conjunto de possíveis soluções é comumente chamado de conjunto ótimo de Pareto e são determinadas seguindo critérios de dominância. Para um problema multi-objetivo se deseja, então, encontrar soluções aproximadas ao Pareto ótimo e que essas soluções sejam tão diversas quanto possível (Deb, 2001).

Por outro lado, um tema que tem ganhado bastante acolhida na literatura é o que trata da paralelização das metaheurísticas. Este tema é de bastante importância para a diminuição do tempo de execução quando se têm grandes espaços de busca e/ou funções objetivo cuja avaliação envolva um alto custo computacional- como no caso do problema de detecção de dano onde é necessário calcular os parâmetros dinâmicos para a configuração estrutural representada por cada individuo. Além disso, pode-se utilizar a paralelização para encontrar melhores soluções a um problema. Uma das formas de paralelização mais simples consistiria na distribuição da avaliação da aptidão dos indivíduos da população nos diferentes processadores disponíveis. Metaheurísticas específicas têm sido desenvolvidas nas quais as diferentes operações realizadas são paralelizadas, como mostrado no livro de Alba (2005). 
Diversos textos têm sido escritos sobre metaheuristicas como, por exemplo, González (2007) e Talbi (2009) e servem de ajuda ao leitor que deseje aprofundar seus conhecimentos sobre este paradigma computacional. Nas seguintes subseções apresenta-se uma breve introdução a algumas metaheurísticas baseadas em população.

\subsubsection{Particle Swarm Optimization.}

O Particle Swarm Optimization (PSO) é um algoritmo estocástico que utiliza populações de soluções candidatas para encontrar uma solução ótima a um problema de otimização. Foi proposto por Kennedy e Eberhart em 1995 e está baseado em um modelo simplificado de interação entre indivíduos, no qual se considera que há a colaboração de todos os indivíduos de uma população para a determinação da solução de um problema que atinge à comunidade. Este tipo de algoritmo é parte das técnicas baseadas em inteligência de enxame.

Na Figura 2.3 é mostrado o algoritmo necessário para a implementação da versão básica do PSO.

\section{Inicio}

1. Iniciar a posição de $\mathrm{N}$ Partículas: $P_{0}^{i}$.

2. Iniciar as velocidades das partículas: $V_{0}^{i}$.

3. Determinar a aptidão de cada partícula. Se a aptidão de uma partícula dada for melhor que o pbest até o momento, esse valor deve ser atualizado.

4. Definir como o gbest a posição já visitada no espaço de busca que produz a melhor aptidão.

5. Calcular a nova velocidade de cada partícula e redefinir suas posições.

6. Verificar critérios de parada. No caso em que os critérios não sejam cumpridos, aplicar os passos 4-7 sobre as novas partículas.

7. Mostrar a solução

Fim

Figura 2. 3 Algoritmo Particle Swarm Optimization 
A analogia utilizada pelo PSO consiste, então, em definir um conjunto de possíveis soluções do problema, chamadas de partículas. Cada partícula está caracterizada por uma posição e uma velocidade com a qual percorre o espaço de soluções. Um processo iterativo é iniciado, para o qual se tem que avaliar a aptidão de cada uma das partículas da população a partir da função objetivo. Essas partículas têm a capacidade especial de se "lembrar" da melhor posição onde já estiveram; informação que é transmitida para as outras partículas com o objetivo de se conhecer onde está localizada a melhor delas - a posição dessa partícula corresponde ao ponto com o mínimo global atual e essa topologia de vizinhança é chamada de global. Os movimentos das partículas, atualização da posição e da velocidade, são então dirigidos por essas informações. Parâmetros de aceleração são utilizados para levar em conta o peso das informações adquiridas em iterações anteriores, isto permite avaliar se a partícula confia mais no conhecimento que ela adquiriu ou no conhecimento ganho pelas outras partículas. Na medida em que as iterações avançam, as partículas convergem para o local do espaço onde se encontra a solução ótima para o problema estudado. Como critério de convergência podem ser utilizados a mudança no valor da aptidão da melhor partícula entre duas iterações consecutivas ou um número predefinido de iterações.

Os valores das velocidades e das posições das partículas podem ser calculados como (Shi e Eberhart, 1998):

$v_{i}^{t+1}=w f \times v_{i}^{t}+c_{1} \times r_{1 i}^{t} \times\left(\right.$ pbest $\left._{i}-x_{i}^{t}\right)+c_{2} \times r_{2 i}^{t} \times\left(\right.$ gbest $\left.-x_{i}^{t}\right)$

$x_{i}^{t+1}=x_{i}^{t}+v_{i}^{t+1}$

onde $i$ é a i-esima partícula no enxame, $t$ é a atual iteração; $c_{1}$ e $c_{2}$ são os parâmetros de aceleração (cognitivo e social, respectivamente), $r_{1 i}$ e $r_{2 i}$ são números aleatórios entre 0 e 1 e wf é o peso de inércia. 


\subsubsection{Algoritmo de Evolução Diferencial}

O algoritmo de evolução diferencial, DEA, foi proposto por Storn e Price em 1995 para resolver problemas envolvendo domínios contínuos. Os passos para a aplicação do DEA a um problema de otimização estão resumidos na Figura 2.4 .

\section{Inicio}

1. Gerar os vetores iniciais.

2. Calcular o custo de cada vetor.

3. Fazer para cada vetor.

3.1 Definir o vetor alvo.

3.2 Calcular o vetor mutação.

3.3 Calcular o vetor tentativa.

3.4 Comparar os valores de custo dos vetores alvo e tentativa e escolher o melhor.

4. Verificar critérios de convergência. Se eles não são atingidos então repetir passos 2-4, senão ir a passo 5 .

5. Mostrar o vetor solução.

Fim

Figura 2. 4 Algoritmo de evolução diferencial.

O algoritmo começa com a geração aleatória ou heurística de N vetores população- que correspondem as prováveis soluções do problema analisado e na qual $N$ é o tamanho da população. Após o passo anterior, calcula-se o custo de cada vetor utilizando o valor da função objetivo que define o processo de otimização. Subsequentemente, uma nova população é gerada a partir dos vetores iniciais mediante a comparação de cada vetor na população, chamado de vetor alvo, contra um novo vetor chamado de vetor tentativa. Essa comparação, chamada de competição, é realizada em função do custo de ambos os vetores - o custo é referido à qualidade da solução e é calculado utilizando a função objetivo. No caso de um problema de maximização, o vetor com o maior custo é escolhido para ser incluído na população da iteração seguinte. Um total de N competições é necessário para formar a nova população. Então, um critério de convergência é 
verificado como no caso do PSO. Um processo iterativo, entre os passos 2 e 4, é realizado até atingir o critério de parada. Sendo assim, os vetores alvo na segunda iteração (ou na iteração atual) são obtidos a partir da nova população que foi gerada na primeira iteração (ou na iteração anterior). Finalmente, o algoritmo selecionará o vetor na população final que tiver o custo mais alto como a solução encontrada para o problema analisado na presente execução.

O processo para gerar o vetor tentativa é como segue (Storn e Price, 1997):

Primeiro, um vetor mutação, $v_{i}^{t}$, é gerado a partir da variação do melhor vetor na população

$v_{i}^{t}=x_{\text {best }}^{t}+A F \cdot V_{\text {amp }}$,

onde $i$ é a posição do vetor alvo na população, $x_{\text {best }}^{t}$ é o melhor vetor na população para a iteração atual $t$ e $A F$ é o fator de amplificação, que é um parâmetro do DEA que permite controlar a amplitude da variação introduzida por Vamp. O termo Vamp é um vetor quantidade que pode ser calculado como (Storn e Price, 1997)

$V_{\text {amp }}=\sum_{k=1}^{4}\left((-1)^{k+1} x_{k}^{t}\right)$,

onde $x_{k}^{t}$ são vetores na iteração atual- ou população da iteração $t$-, os quais são aleatoriamente escolhidos a partir da população atual. Esses vetores não podem ser repetidos e devem ser diferentes daquele do melhor vetor.

A seguir, o $i$-ésimo vetor tentativa pode ser calculado utilizando 0 cruzamento binário: 
$u_{i}^{t}=\left[\begin{array}{lll}u_{i, 1} & \cdots & u_{i, N}\end{array}\right]^{t}$,

onde cada termo no vetor tentativa é definido como

$u_{i, j}^{t}=\left\{\begin{array}{cc}v_{i, j}^{t} & \text { if }\left(R_{j}<C R\right) \\ \operatorname{tg}_{i, j}^{t} & \text { if }\left(R_{j} \geq C R\right)\end{array}\right.$,

onde $t g$ é o vetor alvo, $R j$ é um número aleatório gerado para cada posição j do i-ésimo vetor, que pode assumir um valor entre 0 e 1 , e CR é a taxa de cruzamento, que é um parâmetro do DEA que controla a contribuição de ambos vetores, mutação e alvo, para formar o vetor tentativa. Um valor de CR igual a 1 significa que o vetor tentativa será igual ao vetor de mutação.

\subsubsection{Algoritmos Genéticos}

O algoritmo genético (GA) é um algoritmo evolutivo utilizado na solução de problemas de busca. Foi originalmente proposto por John Holland durante os anos 60s (Coley, 1999) e segue uma analogia com as leis da seleção natural e a sobrevivência do mais apto. Para sua aplicação deve-se, primeiro, definir uma população de indivíduos em forma codificada, os quais correspondem a possíveis soluções do problema. Estes indivíduos são avaliados para se observar a sua adaptação ao ambiente no qual se encontram, sendo os melhores indivíduos escolhidos para reprodução. Os indivíduos obtidos após a fase de reprodução, que compartilham algumas características dos pais, podem ou não ser submetidos a um processo de mutação. Esse processo permite a introdução de novas características na população e a recuperação de material genético perdido no processo iterativo. Um critério elitista pode ser aplicado com o intuito de preservar a melhor solução encontrada pelo algoritmo até uma geração específica, dado que esta solução pode ser perdida de uma geração para outra. A nova população tem agora as características dos melhores indivíduos da geração anterior. O procedimento anterior é repetido até encontrar uma convergência da 
população ao indivíduo mais apto ou quando é atingido um número predeterminado de gerações. A solução ao problema corresponderá então àquela com a aptidão mais alta na população no caso de um problema de maximização.

Na Figura 2.5 é mostrado o pseudocódigo para a implementação de um algoritmo genético clássico. GAs podem ser trabalhados com diferentes representações como a binária e a real, sendo que para ambas as representações existem operadores específicos.

\section{Inicio}

1. Gerar população inicial.

2. Determinar aptidão dos indivíduos.

3. Selecionar melhores indivíduos da população.

4. Fazer o cruzamento dos indivíduos selecionados.

5. Realizar a mutação dos indivíduos gerados no processo de cruzamento.

6. Aplicar elitismo e definir a nova geração.

7. Verificar critérios de parada. No caso que os critérios não sejam cumpridos, aplicar sobre a nova geração os passos 2-7.

8. Mostrar a solução.

Figura 2. 5 Algoritmos Genéticos.

\subsection{APLICAÇÃO DE INTELIGÊNCIA COMPUTACIONAL EM ENGENHARIA DE ESTRUTURAS.}

Na Tabela 2.1 mostram-se alguns trabalhos que tratam da aplicação de CITs no campo da engenharia de estruturas. Entre as principais linhas de aplicação destacam-se a deteç̧ão de dano em estruturas, otimização da configuração estrutural, a identificação de sistemas, a localização ótima de sensores, controle ótimo de vibrações, entre outras. 
Tabela 2. 1 Exemplos de aplicações de técnicas de inteligência computacional em engenharia de estruturas.

\begin{tabular}{|c|c|c|}
\hline Aplicação & $\begin{array}{c}\text { Sistema } \\
\text { Inteligente }\end{array}$ & Autores \\
\hline \multirow{9}{*}{$\begin{array}{l}\text { Otimização } \\
\text { Estruturas }\end{array}$} & ANN & Tashakori (2002) \\
\hline & GA & Cheng(2007) \\
\hline & PSO & Li et al. (2007) \\
\hline & $\mathrm{HS}$ & Saka (2007) \\
\hline & DEA & Hull et al. (2006) \\
\hline & IS & Omkar et al. (2008) \\
\hline & FBOA & Teodoro et al. (2010) \\
\hline & $\mathrm{BCA}$ & Sonme (2011) \\
\hline & FA & Gandomi et al. (2011) \\
\hline \multirow{4}{*}{$\begin{array}{l}\text { Identificação } \\
\text { Estrutural }\end{array}$} & ANN & Subhudi e Jena (2009) \\
\hline & GA & Perry et al. (2006) \\
\hline & DEA & Tang et al. (2008) \\
\hline & BCA & Kang et al. (2009) \\
\hline \multirow{4}{*}{$\begin{array}{l}\text { Localização Ótima de } \\
\text { Sensores/Atuadores }\end{array}$} & SA \& GA & Worden e Burrows (2001) \\
\hline & PSO & Mohan Rao e Anandakumar (2007) \\
\hline & GA & Liu et al. (2003) \\
\hline & $\mathrm{HS}$ & Bekdaş and Nigdeli (2011) \\
\hline \multirow{6}{*}{$\begin{array}{l}\text { Engenharia } \\
\text { Terremotos } \\
\text { Dinâmica } \\
\text { estruturas }\end{array}$} & RNA & Salajegheh e Heidari (2005) \\
\hline & Fuzzy & Karimi e Hüllermeier (2007) \\
\hline & GA & Nagai et al. (2005) \\
\hline & PSO & Xiao et al. (2011) \\
\hline & IS & Lee et al. (2006) \\
\hline & $\mathrm{HS}$ & Haydar et al. (2011) \\
\hline
\end{tabular}

A determinação do tamanho ótimo de uma estrutura envolve, em geral, a determinação das propriedades da estrutura que levam a um custo mínimo, mas garantido que ela se comporte adequadamente. Pavlovcic et al (2004) propuseram minimizar uma função objetivo que envolve os diferentes custos de uma estrutura de aço. Esses custos tem origem no peso de todos os elementos na estrutura, na realização de conexões soldadas ou com parafusos, pintura dos elementos, transporte e alinhamento dos elementos, entre outros. Como ferramenta de otimização foi utilizado um GA. No trabalho anterior se utiliza uma única função objetivo; porém, atualmente tem-se abordado formulações multiobjetivo como no caso do trabalho de Su et al (2011) no qual se otimiza simultaneamente o peso de uma treliça e seu deslocamento máximo em nos de controle.

O processo de identificação estrutural consiste em determinar quais são as características reais de uma estrutura determinada a partir das medições da sua 
resposta, portanto é semelhante ao problema de detecção de dano. Xue et al (2009) identificaram os parâmetros de um sistema (massa, amortecimento, rigidez) desde medições de aceleração e um PSO. Unicamente soluções factíveis foram permitidas a ser parte do processo de busca e para isso se propôs uma restrição no algoritmo que evita que aquelas partículas representando sistemas instáveis continuem no processo. A metodologia foi aplicada com sucesso na identificação de um sistema histerético de dois graus de liberdade e um edifício cujo MEF tinha 10 graus de liberdade.

Com a localização ótima de sensores para caracterização de uma estrutura busca-se obter a informação mais representativa sobre a mesma a partir de uma quantidade limitada de sensores, sendo que algumas metodologias incluem também a determinação do número mínimo de sensores que pode ser utilizado. No trabalho de Guo et al. (2004) utiliza-se um GA binário para localizar sensores em uma treliça. Cada posição do cromossomo indica se há um sensor ou não em um grau de liberdade (DOF) da estrutura, com a restrição que a soma de sensores tem que ser igual ao número de sensores disponíveis. Melhoras nos operadores de cruzamento e mutação foram propostas tal que os indivíduos na nova população corresponderam unicamente a soluções factíveis.

Uma das formas de se resolver o problema de vibrações de uma estrutura é a partir do posicionamento de sistemas ativos, passivos ou híbridos que permitam o controle da estrutura. Para isso, é desejável conhecer quais os locais ótimos para a instalação desses dispositivos que permitam o maior efeito de atenuação da resposta da estrutura. Movaffagi e Friberg (2006) determinaram a posição ótima de amortecedores visco-elasticos em estruturas altas utilizando GAs. A função objetivo foi baseada na minimização das acelerações medidas em certos pontos da estrutura. Como restrição se tem o número máximo de amortecedores a serem localizados e esta foi tratada a partir de uma função de penalidade.

$\mathrm{Na}$ engenharia de terremotos podem se encontrar problemas diversos nos quais se têm aplicações de CITs. Aguirre e Contreras (2002) utilizaram GAs para separar os efeitos de localidade e de fonte desde 4 registros de sismos provenientes de 4 locais de medição diferentes. Del Pezzo et al (2003) utilizaram uma rede neural MLP para diferenciar registros de eventos sísmicos resultantes de explosões que realizam os pescadores da Bahia de Pozzouli (Italia) de aqueles produto da atividade tecto-volcânica da região. Maldonado et al. (2007) 
aplicaram conjuntos nebulosos para desenvolver uma metodologia baseada na opinião de especialistas que permita a avaliação da vulnerabilidade por terremoto nas edificações de alvenaria de centros urbanos. Panakkat e Adeli (2009) propuseram uma ANN recorrente para a predição do tempo de ocorrência e localização do epicentro de eventos sísmicos de tamanho moderado a grande utilizando como vetor de entrada um total de 8 índices que avaliam a atividade sísmica.

CITs têm sido amplamente aplicadas na solução ao problema de detecção de dano estrutural. No seguinte capítulo serão apresentadas algumas metodologias que permitem avaliar a integridade de uma estrutura a partir do uso de CITs e das mudanças na resposta dinâmica da estrutura devidas ao dano. 


\section{REVISÃO DE METODOLOGIAS DE DETECÇÃO DE DANO}

\subsection{INTRODUÇÃO}

Uma quantidade importante de metodologias de detecção de dano estrutural têm sido propostas na literatura baseadas nas mudanças na resposta estática ou dinâmica da estrutura que acontecem com o dano. Porém, existem algumas questões ainda em aberto que precisam ser resolvidas para que tais metodologias possam ser aplicadas confiavelmente na prática. Neste capítulo apresenta-se inicialmente uma descrição de diferentes fatores que incidem no desempenho de metodologias de detecção de dano baseadas em vibração. Seguidamente, as metodologias apresentadas são agrupadas segundo vários critérios: 1) aplicação de CITs, 2) emprego da flexibilidade modal como parâmetro de entrada - este parâmetro será utilizado neste trabalho para localizar e/ou quantificar dano utilizando ANNs-, 3) formulação de um processo de múltiplas etapas para atingir um nível III de identificação - este tipo de 
formulação poderia ser o mais adequado para detectar dano em estruturas cujo FEM seja conformado por uma alta quantidade de elementos-, e 4) utilização de parâmetros da estrutura diferentes a parâmetros modais ou funções de resposta em frequência. Finalmente, uma discussão é realizada baseada na revisão realizada.

\subsection{TÓPICOS EM DETECÇÃo DE DANO UTILIZANDO A RESPOSTA DINÂMICA DA ESTRUTURA}

O problema de detecção de dano é caracterizado pela sua inerente complexidade que tem raízes nos muitos aspectos experimentais e computacionais envolvidos. Algumas questões que o pesquisador deve responder quando se encontra desenvolvendo uma metodologia de detecção de dano são, por exemplo: a) Como o dano vai ser representado?, b) Será utilizado um modelo numérico para a definição da condição sem dano?, c) Esse modelo é adequado?, d) A resposta estrutural utilizada como indicador da presença do dano é suficientemente sensitiva a este último?, e) Qual é a qualidade esperada das medições realizadas?, e f) Quanta informação deve ser medida para garantir uma detecção de dano confiável?. Estas questões se discutem brevemente nas seguintes seções buscando situar o leitor no estado atual do problema de detecção de dano via parâmetros dinâmicos da estrutura.

\subsubsection{Modelagem do dano}

A modelagem do dano permite definir quais são as mudanças que se originam nos parâmetros estruturais - massa, amortecimento e rigidez - devidas à sua presença. Quando a detecção do dano envolve um FEM da estrutura devem-se realizar algumas considerações. Para uma estrutura não amortecida é geralmente estimado que o dano não produz variação alguma na matriz de massa e que, portanto, as mudanças nas propriedades estruturais são observadas unicamente na matriz de rigidez. Nesse sentido o dano pode ser 
representado como uma redução na matriz de rigidez do elemento danificado, assim

$k_{i}^{d}=\left(1-\beta_{i}\right) k_{i}^{u}$

onde $k_{i}$ é a matriz de rigidez global para o i-ésimo elemento. Os índices sobrescritos $d$ e $u$ referem-se às condições com e sem dano, respectivamente. $\beta$ é o fator de redução de rigidez que pode assumir um valor no intervalo entre 0 e 1. Um valor de 0 indica que o elemento não apresenta dano e um valor de 1 representa a perda total do elemento.

Como a localização dos verdadeiros elementos danificados não é conhecida a priori, o pesquisador é obrigado a calcular o fator de redução de rigidez para cada elemento, danificado ou não, na estrutura. Sendo assim, as variáveis procuradas correspondem ao conjunto de fatores $\beta$ de tamanho igual ao número de elementos na estrutura. A matriz de rigidez da estrutura para a condição danificada, $K_{d}$, pode ser calculada como

$$
K^{d}=\sum_{i=1}^{N E l e m} k_{i}^{d}
$$

onde NElem é o número de elementos na estrutura.

Em elementos de pórtico, um fato implícito na representação anterior é que o dano está completamente contido em um ou vários elementos. Isto significa que em um elemento danificado não é possível ter uma parte do comprimento com dano e a parte restante sem dano. Por conseguinte, pode-se obter uma melhor descrição da integridade da estrutura na medida em que esta é discretizada em mais elementos finitos - isto se deve ao fato do dano poder apresentar dimensões diferentes daquelas dos elementos. No entanto, sob um ponto de vista computacional, a complexidade do problema se incrementa em forma diretamente proporcional ao número de variáveis envolvido. Além disso, dano leve é difícil de ser encontrado devido a que produz pequenas mudanças 
nos parâmetros dinâmicos, as quais poderiam não ser suficientes para que o verdadeiro cenário de dano possa ser encontrado.

Por outro lado, diferentes propostas para modelar o dano podem ser encontradas na literatura.

Di and Law (2007) levaram em conta os tipos de dano a partir do cálculo dos auto-valores da matriz de rigidez. Estes auto-valores são relacionados às formas deformadas do elemento e provê informação sobre a capacidade de carga do elemento.

Chen e Bicanic (2006) utilizaram a matriz de rigidez obtida numericamente por meio da integração de Gauss e definiram o dano como correspondente a cada ponto de Gauss.

$\mathrm{Li}$ et al. (2006) propuseram indicadores de dano individual para as rigidezes axial e transversal de um pórtico 3D. Os autores comentam que a informação proveniente dos indicadores ajudaria a melhorar a habilidade de uma metodologia de localização de dano baseada em energia.

Modelos de dano mais complexos envolvem o estudo, por exemplo, de fissuras; porém este tipo de modelo não será estudado aqui.

\subsubsection{Parâmetros Dinâmicos}

Os parâmetros dinâmicos escolhidos para determinar a integridade da estrutura precisam ser suficientemente sensíveis ao dano de tal forma a permitir sua detecção. Além disso, tem-se que verificar que a presença de ruído nas medições não esconda os efeitos do dano sobre o(s) parâmetro(s) escolhido(s). A definição de qual parâmetro utilizar é ainda uma pergunta aberta, sendo que existem diversos trabalhos que oferecem algumas indicações sobre vantagens e/ou desvantagens da escolha de um parâmetro em específico.

Zhao e De Wolf (1999) calcularam coeficientes de sensibilidade de frequências naturais, formas modais e flexibilidades modais em relação a mudanças na matriz de rigidez. Eles mostraram que para um sistema massamola, sem amortecimento, a característica dinâmica mais sensível ao dano era a flexibilidade modal.

Yam et al. (2002) realizaram uma análise de sensibilidade de parâmetros dinâmicos sobre uma placa e concluíram que a curvatura de formas modais e 
funções de resposta em frequência poderiam oferecer uma maior capacidade para detectar o dano do que frequências naturais e formas modais.

Ndambi et al. (2002) desenvolveram uma pesquisa experimental sob uma viga de concreto armado para comparar diferentes parâmetros dinâmicos- modal assurance criterion, coordinate modal assurance criterion, flexibilidade modal e energia de deformação. Resultados mostraram que o método da energia de deformação modal localiza mais confiavelmente o dano e que a extensão poderia ser calculada por mudanças nas frequências naturais.

Alvandi e Cremona (2006) estudaram o efeito do parâmetro dinâmico escolhido quanto à localização e a quantificação de dano em uma estrutura do tipo viga. Eles observaram que a energia de deformação era mais eficiente para localizar o dano do que mudanças na curvatura de formas modais, mudanças na flexibilidade ou mudanças na curvatura de flexibilidade. Porém, os últimos três parâmetros permitiam calcular a extensão do dano, o que não era possível com o método da energia de deformação.

Uma análise mais completa sobre o tópico da escolha de um parâmetro dinâmico adequado para detecção de dano foi apresentada por Doebling (1998). Nesse artigo foi realizada uma revisão de metodologias de detecção de dano baseadas em vibração a qual foi organizada em função do parâmetro utilizado. Outras revisões da literatura mais recentes foram reportadas por Carden e Fanning (2004) e Fan e Qiao (2011).

\subsubsection{Incertezas no modelo de elementos finitos}

Diversas metodologias de detecção de dano requerem um FEM atualizado para localizar e quantificar o dano. Porém, em alguns casos não é possível garantir essa característica e o pesquisador tem que utilizar o modelo original. Este modelo pode apresentar muitos erros originados a partir de aspectos tais como condições de contorno, propriedades estruturais, conexões entre elementos, fontes de rigidez ignoradas, malha de elementos finitos e tipos de elementos não apropriados (Hu et al., 2001). Sendo assim, esta questão pode ser levada em conta no desenvolvimento da metodologia por incluí-la na formulação ou pela medição do seu efeito no seu desempenho.

Chen (2008) propôs uma metodologia para localizar e quantificar dano em grandes estruturas a partir da obtenção da relação entre o dano e mudanças em 
dados modais incompletos através do método da perturbação. O sistema de equações obtido é resolvido utilizando um método de regularização. Resultados mostraram que a metodologia proposta era pouco influenciada pelas incertezas na modelagem da massa.

Backary et al. (2007) consideraram que os parâmetros estruturais eram variáveis aleatórias independentes distribuídas normalmente de forma a levar em conta as incertezas na modelagem. Depois disso, os parâmetros dinâmicos estatísticos eram introduzidos em uma rede neural para localizar e quantificar o dano.

Perera et al. (2010) formularam o problema de detecção de dano como um multi-objetivo, cujas funções objetivo foram baseadas em residuais de frequências naturais e formas modais, que são parâmetros menos sensíveis a erros no FEM da condição sem dano.

\subsubsection{Medições incompletas}

Medições incompletas de parâmetros modais são relacionadas a duas condições experimentais. A primeira condição está relacionada ao fato de que só uns poucos modos na estrutura podem ser geralmente excitados e a segunda ao fato de que medições podem ser obtidas apenas em alguns poucos graus de liberdade. Isso implica que só um subconjunto da informação modal total pode ser utilizada no processo de detecção de dano e, portanto, dá origem ao seguinte questionamento:é essa informação suficiente para localizar e quantificar o dano de uma forma confiável?. Além disso, algumas metodologias de detecção de dano requerem formas modais completas, razão pela qual deve ser utilizada uma técnica numérica que permita igualar as dimensões dos modelos experimental e analítico. Este tipo de técnica tem que ser evitada, pois introduz erros numéricos no modelo. Por outro lado, a origem da informação, isto é a posição dos locais onde as medições foram realizadas sobre a estrutura, pode influenciar nos resultados. Esta breve discussão mostra a importância de se determinar o efeito de medições incompletas sobre o desempenho da metodologia de detecção de dano proposta.

Reza e Medhi-Pour (2007) propuseram uma metodologia de detecção de dano baseada em vibração utilizando teoria de controle e rotação de subespaços. Seus resultados mostraram que o incremento no número de sensores 
utilizados tinha um efeito positivo sobre o número de detecções exitosas da metodologia proposta.

Law et al. (1998) localizaram dano a partir de um indicador derivado de conceitos de energia. Uma técnica de expansão modal foi utilizada para calcular a informação ausente. Foi observado que a diminuição no número de coordenadas modais medidas implicava em um conjunto maior de elementos erroneamente identificados como danificados.

Abdo e Hori (2002) propuseram uma metodologia de detecção de dano baseada nas mudanças da rotação de formas modais. Eles observaram que algumas formas modais não eram sensíveis ao dano e que essas formas modais não deveriam ser utilizadas, já que poderiam prejudicar a identificação.

Raich e Liszkai (2007) mostraram que diferentes níveis de desempenho podem ser obtidos por diferentes configurações de sensores. Isto mostra que uma localização ótima de sensores é desejável; sendo que diversas técnicas podem ser encontradas na literatura para se resolver esse problema, entre elas as propostas por Guo et al. (2004) e Mohan Rao e Anandakumar (2007).

\subsubsection{Ruído}

Ruído em medições diminui a habilidade de uma metodologia de detecção de dano em identificá-lo, pois oculta as mudanças na resposta da estrutura e leva a metodologia a detectar um cenário de dano incorreto. Assim, quanto maior a precisão nas medições, mais confiável será sua aplicação em detecção de dano.

Algumas das metodologias mencionadas anteriormente realizam uma validação das suas propostas em forma numérica, razão pela qual o ruído tem que ser introduzido em forma de perturbações dos parâmetros dinâmicos analíticos correspondentes à estrutura atual. Uma forma comum para simular ruído é dada por:

$\alpha_{r n}^{d}=\alpha_{n}^{d} \times\left(1+R_{1} \times \gamma\right)$ 
onde $\alpha_{r n}^{d}$ e $\alpha_{n}^{d}$ correspondem ao parâmetro dinâmico utilizado com e sem ruído, respectivamente, $R_{1}$ é um número aleatório entre -1 e 1 que é obtido a partir de uma distribuição uniforme e $\gamma$ é o nível de perturbação.

A seguir serão mostradas algumas conclusões reportadas na literatura sobre a influência do ruído no desempenho de uma metodologia de detecção de dano.

Palacz e Krawczuk (2002) estudaram o desempenho de diversas metodologias de deteç̧ão de dano baseadas em vibração para localizar e determinar a profundidade de uma fissura em uma viga. Os pesquisadores concluíram que na medida em que a qualidade das medições diminuía a precisão dos resultados também diminuía.

Borges et al. (2007) formularam o problema de detecção de dano como um de otimização. Eles mostraram que o espaço de busca é modificado pela presença de ruído nas medições, o que implica na possibilidade do cenário de dano exato não corresponder à solução ótima.

Li et al. (2011) propuseram uma rede neural artificial e um vetor de entrada formado por residuais de funções de resposta em frequência comprimidas utilizando análise de componentes principais. Eles concluíram que o número de componentes principais necessário para assegurar uma detecção de dano confiável incrementava com o aumento do nível de ruído.

\subsection{Metodologias de detecção de dano QUe empregam INTELIGÊNCIA COMPUTACIONAL}

A utilização de CITs para detecção de dano em estruturas tornou-se muito importante nas ultimas décadas simbolizado em uma grande quantidade de trabalhos desenvolvidos e em desenvolvimento que as utilizam

Chang et al. (2000) utilizaram uma rede neural MLP para detectar dano cujos casos de treinamento foram gerados mediante a utilização do método orthogonal arrays. Esse método busca gerar a menor quantidade de experimentos ou combinações a partir de um número determinado de variáveis e 
dos valores que elas podem assumir. O vetor de entrada para a rede estava formado por frequências naturais e mudanças na primeira curvatura modal. A metodologia foi validada numericamente sobre uma viga em balanço cujo MEF tinha 8 elementos.

Sahoo e Maity (2007) propuseram detectar dano em estruturas a partir de um algoritmo neuro-genético cujo vetor de entrada era formado por frequências naturais e deformações medidas em pontos específicos da estrutura. O GA tem a função de otimizar a quantidade de pesos de duas camadas ocultas e as taxas de momentum e de aprendizagem do algoritmo back-propagation. Desta forma, a eleição da configuração da rede e das características do algoritmo de treinamento pode ser definida de forma automática, evitando que o analista tenha que realizar um processo de tentativa e erro. Uma viga ( $F E M=20$ elementos) e um pórtico ( $F E M=42$ elementos) serviram para demonstrar 0 desempenho da metodologia proposta.

Wen et al. (2007) utilizaram uma rede neuro-fuzzy para localizar dano em uma forma não supervisionada. Para isso, definiu-se um parâmetro denominado damage localization feature que dependia unicamente da posição do elemento danificado na estrutura. A ideia básica nesta formulação consiste na comparação do DLF medido com aqueles obtidos a partir de cenários de dano gerados analiticamente. O cenário que apresente a maior correlação do DLF com o medido corresponderá ao estado atual da estrutura. Uma estrutura de 5 andares foi empregada para mostrar o desempenho da metodologia proposta.

Kouchmeshky et al. (2008) propuseram um algoritmo que realiza um processo iterativo de busca dos locais danificados e da extensão de dano em duas fases. A primeira fase tem como objetivo definir um conjunto de soluções candidatas ao problema de detecção de dano. Dois cromossomos reais foram utilizados para representar um indivíduo. O primeiro é utilizado para representar a posição do dano e o segundo para calcular a extensão do dano. O método deterministic crowding é utilizado para garantir a diversidade da população nas diferentes fases. A função objetivo para o problema de minimização é formulada em termos de funções de resposta em frequência. Testes foram realizados sobre uma treliça com 75 elementos sendo observado que a metodologia proposta é precisa para identificar o dano, produzindo poucos elementos falsamente identificados como danificados e apresentando uma convergência rápida. 
Casciati (2008) utilizou o algoritmo de evolução diferencial em sua versão original para detectar dano em uma viga em balanço ( $F E M=16$ elementos), que foi analisada em sub-dominios para melhorar o desempenho da metodologia. Dado que a representação utilizada para o dano implicava em uma variável de otimização por cada elemento na estrutura, a divisão em subdomínios permitiu diminuir o número de variáveis do problema. Nesta metodologia a função objetivo foi definida como uma contribuição linear de termos envolvendo frequências naturais e formas modais.

Begambre e Laier (2009) propuseram a utilização de um PSO autoconfigurado para resolver o problema de otimização associado ao problema de detecção de dano. A adaptação dos parâmetros foi realizada utilizando o método Nelder-Mead Simplex, enquanto que a função objetivo utilizada estava baseada em funções de resposta em frequência. A metodologia foi testada em uma treliça com 10 elementos e uma viga com 12 elementos. No melhor conhecimento do autor, este trabalho poderia ser considerado como o primeiro em detecção de dano que utiliza uma metaheurística com controle de parâmetros.

Sandesh e Shankai (2010) combinaram um GA e um PSO para melhorar as capacidades de busca dos algoritmos individuais. A ideia básica era aproveitar as capacidades de exploração dos GAs e de memória do PSO. Diversas funções de teste reportadas na literatura serviram para mostrar a boa convergência do algoritmo proposto. Seguidamente o algoritmo foi aplicado para detectar fissuras em uma placa utilizando uma função objetivo baseada em acelerações. Resultados mostraram que o algoritmo proposto conseguia uma melhor identificação do estado de dano quando comparado com aquele encontrado pelos algoritmos originais.

Pan et al. (2010) propuseram uma metodologia de detecção de dano que dividia o processo em duas etapas. Primeiro, uma rede neural MLP é utilizada para detectar os locais possivelmente danificados para depois determinar a extensão do dano nesses elementos com ajuda de um GA. Os parâmetros de entrada da rede correspondiam às primeiras frequências naturais, e a função objetivo foi formada a partir de frequências naturais e um critério de correlação. Um edifício com quatro andares foi utilizado para demonstrar o desempenho da metodologia.

Caicedo e Yun (2010) propõem um algoritmo genético de estado permanente combinado com uma técnica que permite gerar diversas soluções 
com a maior diversidade possível. Os autores recomendam que o analista deva incluir uma maior quantidade de informação ou fazer uma inspeção detalhada da estrutura para escolher a resposta final. A principal desvantagem desta metodologia é que o número de soluções diferentes esperadas tem que ser definido a priori.

Fadel Miguel et al. (2012) utilizaram o algoritmo Harmony Search para detectar dano em estruturas do tipo viga. Uma das razões dadas pelos autores para a escolha deste algoritmo é que ele não requer de uma definição detalhada dos seus parâmetros. A metodologia foi validada experimentalmente utilizando três vigas de alumínio em balanço com comprimento de 0,75 m que foram danificadas em múltiplos locais na forma de cortes da seção transversal. A função objetivo utilizada estava baseada em frequências naturais e formas modais. A análise modal foi realizada a partir da medição de vibrações ambientais.

A revisão anterior visa unicamente mostrar as diferentes técnicas de inteligência computacional, incluindo técnicas híbridas, que têm sido aplicadas em detecção de dano. Análises mais amplas da utilização de ANNs e GAs na detecção de dano podem ser encontradas em Villalba e Laier (2012a) e em Villalba e Laier (2012b), respectivamente. Em relação aos resultados apresentados nos trabalhos anteriores, o autor gostaria de salientar o problema da verificação do desempenho das metodologias estudadas em estruturas de grande porte.

\subsection{METODOLOGIAS DE DETECÇÃo DE DANO QUE FAZEM REDUÇÃO DO ESPAÇO DO PROBLEMA}

A solução ao problema de detecção de dano utilizando conceitos de vibração é altamente afetada pelo tamanho da estrutura. Quanto maior a estrutura menor a possibilidade de a metodologia proposta ter um bom desempenho. Por este motivo, algumas metodologias empregam técnicas que permitem identificar elementos (ou zonas) provavelmente danificados. 
$\mathrm{Ni}$ et al. (2002) localizaram dano utilizando uma ANN com vetores de entrada formados por parâmetros dinâmicos que só dependem da localização do dano - a relação entre as mudanças em frequências naturais (Kaminski, 1995) e as mudanças em formas modais (Lam, Ko et al., 1998). Assim, a rede podia ser treinada considerando cenários de dano com diferentes elementos danificados com uma única extensão do dano. A quantificação do dano foi realizada com uma ANN cujo vetor de entrada foi formado por parâmetros dinâmicos dependentes da extensão do dano. Uma estrutura de tipo pórtico, cuja malha do MEF tinha 18 elementos, foi utilizada.

Au et al. (2003) dividiram o processo de detecção de dano em duas etapas. Prováveis elementos danificados eram localizados inicialmente com ajuda de uma metodologia de localização de dano baseada em conceitos de energia (Law, Shi et al., 1998). Essa metodologia precisa de formas modais completas, razão pela qual teve que ser utilizado o método SEREP. A presença do ruído e de medições incompletas diminui a precisão da metodologia de localização. A quantificação do dano foi realizada utilizando um micro-GA, equipado com estratégia de nicho. Duas vigas com 16 e 48 elementos finitos serviram para mostrar o desempenho da metodologia proposta.

Diao et al. (2006) localizaram dano em uma treliça espacial utilizando uma ANN probabilística cujo parâmetro de entrada consistia das mudanças dos valores de energias obtidos aplicando a transformada wavelet packet sobre um sinal de aceleração. A extensão do dano é calculada utilizando uma rede MLP e os valores de energia wavelet. Observou-se uma boa identificação, inclusive quando há a presença de ruído nas medições. Cabe salientar que um único elemento foi considerado como danificado em todos os exemplos estudados.

Yun et al. (2008) implementaram uma metodologia de duas etapas para a localização e quantificação do dano. Primeiramente, foi aplicado um procedimento de seleção de subconjuntos de parâmetros que permite reduzir o número de variáveis do problema. Esse procedimento utiliza o vetor de força residual e tem a capacidade de localizar múltiplos danos. Os dados modais foram obtidos a partir de vibrações ambientais, e a técnica SEREP foi aplicada para a expansão das formas modais. A quantificação foi realizada com um GA de estado permanente. A metodologia proposta foi aplicada em uma torre elétrica do tipo treliça com 47 elementos sob um cenário de dano com múltiplos elementos que apresentam uma perda de rigidez de $50 \%$. 
Perera e Ruiz (2008) justificam a utilização de uma metodologia de detecção de dano em grandes estruturas que seja realizada em várias etapas devido à quantidade limitada de pontos da estrutura que podem ser instrumentados e ao alto número de variáveis de otimização. Por isso, propõem que um FEM menos detalhado seja utilizado junto com funções de dano (Teughels, Maeck et al., 2002) para determinar prováveis zonas danificadas. Em uma segunda etapa, um FEM refinado nas zonas identificadas é usado para quantificar o dano a partir de uma formulação multi-objetivo que é resolvida utilizando o Strengh Pareto Genetic Algorithm. A metodologia foi aplicada em uma viga cujo MEF tinha 100 elementos considerando cenários de dano simples.

Guo e Li (2009) dividiram a solução ao problema de detecção de dano em duas etapas: localização e quantificação. Na primeira etapa, um conjunto de elementos provavelmente identificados como danificado foi determinado por meio da aplicação da teoria da evidência sobre informações provenientes de critérios de correlação de formas modais e frequências naturais. A metodologia é aplicada para detectar danos múltiplos em uma viga em balanço dividida em 20 elementos finitos. Para dois cenários de danos múltiplos, os resultados da metodologia de localização foram comparados com as metodologias originais, mostrando uma redução no número de elementos considerados como provavelmente danificados.

\subsection{METODOLOGIAS DE DETECÇÃO DE DANO BASEADAS EM MUDANÇAS NA MATRIZ DE FLEXIBILIDADE MODAL}

Como mencionado anteriormente, a utilização de um determinado parâmetro dinâmico para a detecção do dano vem com um nível de incerteza inerente; assim, a escolha do parâmetro é de vital importância para a geração de uma metodologia que permita localizar e quantificar o dano de forma precisa. Neste trabalho será utilizada a relação de mudanças na matriz de flexibilidade medida como será mostrado nos capítulos 6, 8, 9 e 10. Este parâmetro apresenta como vantagem a possibilidade de ser construído facilmente a partir das frequências naturais e formas modais e apresenta uma maior sensibilidade 
ao dano que os parâmetros individuais (Perera, Ruiz et al., 2007). Por tal razão, a seguir são apresentadas algumas metodologias que tem utilizado a flexibilidade como um método para localizar e/ou quantificar dano.

O trabalho apresentado por Pandey e Biswas (1994) foi um dos pioneiros na utilização do conceito de mudança na flexibilidade para a definição do estado de uma estrutura. Eles calculavam uma nova matriz correspondente à variação da matriz de flexibilidade entre as condições com e sem dano. Dessa matriz eram, então, determinados os valores máximos para cada coluna e aqueles graus de liberdade com máximos valores permitiam localizar o dano. A metodologia foi testada numérica e experimentalmente sobre vigas. Foi observado que a matriz de flexibilidade poderia ser mais ou menos sensível ao dano dependendo da posição do dano na estrutura.

Lu et al. (2002) utilizaram a curvatura da flexibilidade como indicador da localização do dano em vigas segundo a expressão de diferenças finitas. Para a identificação do dano, o método observa os picos ao longo da deformada, já que para estruturas contínuas este deve ser suave. A principal vantagem desta metodologia é que não são necessários os parâmetros da estrutura não danificada. Uma viga de concreto foi utilizada para mostrar o desempenho da metodologia, observando-se que a curvatura da flexibilidade apresenta problemas para a identificação de dano que se encontre concentrado em uma mesma região da estrutura.

Patjawit e Kanok-Nukulchai (2005) propuseram um índice de dano global baseado na norma espectral da matriz de flexibilidade, que permite determinar se a estrutura apresenta dano quando há uma mudança brusca deste índice. A matriz de flexibilidade é medida em pontos específicos da estrutura, os quais são escolhidos levando em conta que muitos graus de liberdade podem ser insensíveis aos modos de deformação mais altos. A validação experimental foi realizada a partir de ensaios de impacto sobre uma viga de aço e uma de concreto. Resultados mostraram que o índice proposto é mais significante para detecção de dano quando comparados a frequências naturais e formas modais.

Jaishi e Ren (2006) formularam o problema de detecção de dano como um de otimização cuja função objetivo era baseada na matriz de flexibilidade modal medida a partir de vibrações ambientais. O método empregado para resolver o problema é o Trust Region Newton que requer o cálculo do gradiente da função objetivo. Para a normalização dos modos em relação à massa foi utilizado uma 
aproximação baseada no FEM. Uma viga de concreto foi submetida a um incremento sucessivo de carga que produzia uma zona de dano próxima ao centro da viga. Observou-se que a distribuição de dano calculada era compatível com aquelas reportadas por outras metodologias.

Necati- Catbas et al. (2006) realizaram um estudo sobre a aplicabilidade das mudanças na flexibilidade para determinar dano em uma estrutura real. Inicialmente, os autores apresentam a maneira como a matriz de flexibilidade pode ser obtida a partir das medições das funções de resposta em frequência da estrutura. Informação de perfis de deslocamento baseados na matriz de flexibilidade foi utilizada para localizar dano em duas pontes reais. Uma discussão é realizada sobre alguns aspectos que prejudicam a detecção do dano tal como a influência das condições ambientais sobre os dados medidos.

Yang (2009) utilizou a matriz de flexibilidade modal obtida a partir das vibrações ambientais para determinar a presença do dano em uma estrutura. A matriz de flexibilidade assim obtida possui a desvantagem de apresentar formas modais que não podem ser normalizadas à massa, razão pela qual se propôs uma metodologia que permite determinar os coeficientes de normalização de forma simultânea. Diferentes tipos de estruturas foram utilizados para validar a metodologia proposta observando-se que, inclusive na presença de ruído, o dano podia ser identificado com precisão e que os coeficientes de normalização calculados variavam ligeiramente em relação àqueles assumidos.

\subsection{METOdologias DE DETECÇÃo DE DANO BASEAdAs EM DIFERENTES TIPOS DE RESPOSTA ESTRUTURAL}

Diferentes tipos de respostas estruturais têm sido utilizados na literatura para determinar a presença do dano. Algumas delas serão apresentadas nos parágrafos seguintes.

Chou e Ghaboussi (2001) empregaram um GA clássico e medições de deslocamentos em alguns pontos de uma ponte em situação de operação normal para detectar dano. Esta resposta da estrutura foi escolhida devido ao fato de que apresenta uma maior sensibilidade local ao dano que frequências naturais. A 
metodologia proposta além de determinar as propriedades da estrutura permite conhecer os deslocamentos não medidos. O conjunto completo de deslocamentos é utilizado para calcular a força residual no sistema de equações de equilíbrio, que serve como função objetivo. Deste modo evita-se a realização de uma análise estrutural por cada individuo na população com o intuito de se avaliar sua aptidão. Um inconveniente da presente formulação é que o carregamento sobre a estrutura pode não se corresponder com o previsto.

Han et al. (2005) localizaram dano em estrutura do tipo viga a partir de um índice de dano baseado na diferença entre os coeficientes de energia da transformada wavelet packet da resposta no tempo da estrutura para as condições com e sem dano. O nível de decomposição do sinal foi determinado por prova e erro e o umbral que define a presença do dano foi fixado a partir de uma análise estatística. Com esta metodologia não é possível quantificar o dano, porém o valor do índice incrementa na medida em que o dano é maior. Uma limitante das metodologias de detecção de dano baseadas na transformada wavelet é que o tipo de função wavelet utilizado deve ser adequado.

Wang et al. (2006) propuseram dois indicadores de dano baseados na determinação da função de coerência generalizada. O primeiro tem a vantagem de filtrar os efeitos do ruído; porém requer de medições da estrutura na situação sem dano. O segundo identifica dano desde medições da resposta atual da estrutura, más é menos sensível a valores baixos de dano. Um pórtico de aço 3D é utilizado para verificar experimentalmente a metodologia proposta. Observouse que a localização do dano pode ser realizada através do posicionamento e movimento dos transdutores ao longo da estrutura.

Curradelli et al. (2008) encontraram que o coeficiente de amortecimento apresenta maior sensibilidade ao dano que a frequência natural em estruturas de concreto. Nesse trabalho tanto a frequência quanto o amortecimento são determinados desde a aplicação da transformada wavelet sobre um sinal de aceleração tomado a partir de vibrações ambientais. A metodologia proposta consegue determinar unicamente se há ou não a presença de dano na estrutura.

Qian e Mita (2008) utilizaram historias de acelerações e uma ANN perceptron multicamada para determinar a presença de dano em uma estrutura. A ideia base da metodologia consiste em utilizar como vetor de entrada à rede os valores de aceleração do terreno e aqueles medidos em um ou vários pontos da estrutura até o tempo $t$ para determinar a resposta da estrutura em um ou 
vários pontos num tempo posterior a $t$. Assim, uma medida do erro acumulado entre a solução dada pela ANN e o valor da aceleração real medida em diversos passos de tempo permite determinar se há ou não dano na estrutura. A inclusão da aceleração do terreno permite que a rede possa ser utilizada para uma fonte de excitação diferente a aquela utilizada na etapa de aprendizagem.

Como observado nos parágrafos anteriores há uma grande diversidade de características da estrutura que podem ser empregadas na formulação de uma metodologia de detecção de dano que apresentem diversos graus de complexidade.

\subsection{DISCUSSÃO}

No presente capítulo apresentou-se uma breve introdução ao problema de detecção de dano e a sua solução a partir das mudanças que acontecem nos parâmetros dinâmicos devidas ao dano e da utilização de ferramentas de inteligência computacional. Nessa introdução cabe salientar o seguinte:

- Há uma ampla variedade de CITs que têm sido utilizadas na solução ao problema de detecção de dano. Porém, ainda não foi definida qual poderia ser a mais adequada. Cabe salientar que são limitados os exemplos benchmarck que permitem a comparação de diferentes técnicas.

- Novos modelos de dano devem ser propostos em futuras pesquisas com o intuito de se descrever melhor o que está acontecendo na estrutura analisada.

- A sensibilidade dos parâmetros dinâmicos ao dano varia de um parâmetro para outro.

- Deve-se avaliar a influência das condições experimentais no desempenho das metodologias de detecção de dano sendo desenvolvidas. 
- A flexibilidade modal tem sido um parâmetro bastante aceito pela comunidade científica como indicador da presença do dano em uma estrutura.

- Tem-se a necessidade de se propor metodologias que consigam detectar dano em estruturas com um grande número de elementos de forma confiável. 


\section{EXEMPLO I: ESQUEMA DE AVALIAÇÃO DE METODOLOGIAS DE DETECÇÃO DE DANO}

\subsection{INTRODUÇÃO}

O presente exemplo apresenta uma descrição detalhada de uma metodologia de detecção de dano baseada em vibração que envolve um processo de otimização e sua solução mediante a utilização de meta-heurísticas. Além disso, foi introduzido um novo sistema para avaliar a confiabilidade de uma metodologia de detecção de dano em termos de diferentes erros que podem surgir durante o processo de identificação do dano. Um algoritmo genético de código real (RCGA) foi utilizado como técnica de otimização e cujo desempenho foi melhorado com um novo operador de mutação, chamado de M-zero, que permite acelerar a convergência do algoritmo para um cenário de dano com poucos elementos danificados. A avaliação do desempenho da metodologia será 
realizada a partir da simulação de cenários de dano em uma estrutura do tipo viga com múltiplos suportes.

\subsection{MEtodologia DE DETECÇÃo DE DANo BASEAdo EM HEURÍSTICAS}

Neste exemplo, as etapas de localização e quantificação do dano serão realizadas simultaneamente utilizando conceitos provenientes do comportamento dinâmico da estrutura. Metodologias de detecção de dano baseadas em vibração estão fundamentadas no fato que as propriedades dinâmicas de uma estrutura estão conectadas às suas propriedades estruturais. Assim, qualquer mudança nas matrizes do sistema (rigidez, massa ou amortecimento) produz uma mudança nas propriedades dinâmicas (frequências naturais, formas modais e amortecimentos modais). Uma das formas de usar este fato em detecção de dano é a partir da formulação de um problema de otimização no qual se minimiza a diferença entre os parâmetros dinâmicos obtidos por meio de um modelo numérico que representa a estrutura com dano e aqueles obtidos em um ensaio dinâmico real da estrutura. A respeito desta formulação, precisa-se definir quais são as variáveis de otimização, qual técnica de otimização será utilizada e qual função objetivo definirá o problema. Um algoritmo que descreve os passos a seguir para resolver o problema de detecção de dano é apresentado na Figura 4.1.

\footnotetext{
Inicio

1. Definir o MEF para a estrutura sem dano.

2. Definir a função objetivo.

3. Obter os parâmetros dinâmicos para a estrutura danificada:

4. Configurar e aplicar a metaheurística.

5. Mostrar os resultados. Fim
}

Figura 4. 1 Metodologia de detecção de dano. 
O primeiro passo na metodologia proposta consiste em definir um FEM para a estrutura que permita representar com um alto grau de confidência a condição sem dano (modelo 1). O modelo para a condição danificada será obtido atualizando a matriz de rigidez do modelo 1 . Neste trabalho, as variáveis de otimização correspondem a fatores de redução de rigidez na estrutura, sendo o total de variáveis igual ao número de elementos na estrutura- tamanho da estrutura-, tal como foi mostrado no capítulo 3.

No segundo passo, uma função objetivo que permita estabelecer o problema de otimização deve ser definida. A resposta da estrutura escolhida para formar a função objetivo deve apresentar um alto grau de sensibilidade ao dano na estrutura e ser o mais insensível possível à presença de ruído nas medições. Neste exemplo escolheram-se as formas modais e as frequências naturais da estrutura para definir a função objetivo, como indicam as equações 4.1 e 4.2, respectivamente:

$G=\sum_{j=1}^{n m} \frac{200}{1+F_{j}}$,

com

$F_{j}=\left|\frac{\omega_{j}^{m h}-\omega_{j}^{e x}}{\omega_{j}^{e x}}\right|+W \times \underset{i=1 . . . n g l l}{\operatorname{Max}}\left|\frac{\phi_{j}^{m h}-\phi_{j}^{e x}}{\phi_{j}^{e x}}\right|$

onde $n g l l$ é o número de graus de liberdade com informação disponível e $\mathrm{nm}$ indica o número de modos medidos. As variáveis ex e $m h$ indicam informações obtidas a partir dos resultados experimentais e das soluções encontradas pelo otimizador, respectivamente. $\Phi i j$ é o valor da j-ésima forma modal para o iésimo DOF, $\omega$ é referida a um valor de uma frequência natural e $W=2.0$ é o fator de peso. A configuração da função objetivo acima faz com que o problema da 
minimização das diferenças entre os valores experimentais e os calculados seja transformado em um problema de maximização.

No terceiro passo, os parâmetros dinâmicos danificados têm que ser experimentalmente determinados. Devido ao fato da presente pesquisa doutoral ser de caráter numérico, esses parâmetros foram obtidos em forma analítica após a introdução do cenário de dano simulado na matriz de rigidez da estrutura sem dano, segundo Equação 3.2, e a correspondente solução do problema de valores próprios dado na seguinte equação

$$
\left([K]-\omega^{2}[M]\right)\{\Phi\}
$$

onde M é matriz de massa da estrutura. Os parâmetros dinâmicos foram perturbados numericamente por meio da Equação 4.3 sob a consideração que o nível de ruído nas medições é igual 1\% para frequências naturais e 3\% para formas modais (Chen e Nagarajaiah, 2007). Além disso, foi suposto que apenas umas poucas formas modais encontram-se disponíveis em uma quantidade específica dos graus de liberdade verticais da estrutura.

No quarto passo deve-se definir qual a metaheurística a ser utilizada e os parâmetros e operadores que a configuram. Neste exemplo foi utilizado uma versão do RCGA cujas características serão apresentadas na seção 4.3. O melhor individuo na população será escolhido como a solução ao problema para uma execução determinada. Cabe salientar que a escolha do algoritmo que soluciona o problema de otimização é um dos aspectos chaves para uma correta identificação do dano.

O cenário de dano encontrado é mostrado no quinto passo e contém aqueles elementos que apresentaram uma extensão de dano maior que um limiar determinado. Elementos com dano menor do que esse limiar foram considerados como não danificados. Um total de 10 execuções do RCGA foram realizadas e aquela solução com o valor mais alto da função objetivo foi escolhida como o cenário de dano procurado. Neste ponto cabe lembrar que metaheurísticas não garantem a determinação da resposta correta. Sendo assim, uma forma de validar a incerteza da metodologia proposta é contar o número 
total de execuções nas quais o algoritmo encontra um cenário de dano próximo do real.

A filosofia seguida para a formulação da metodologia de detecção de dano proposta tem sido objeto de estudo de muitos pesquisadores nas últimas décadas, sendo a proposta apresentada por Mares e Surace em 1996 uma das primeiras pesquisas publicadas na área. Nesse trabalho foi utilizado um AG clássico e uma função objetivo baseada no vetor de força residual.

\subsection{CARACTERTÍSCAS DO ALGORITMO GENÉTICO DE CÓDIGO REAL}

Neste exemplo a metaheurística que será utilizada no passo 4 da metodologia proposta na Figura 4.1 consiste de um RGCA, que é caracterizado por tratar com variáveis de tipo real. A utilização deste tipo de GA evita o processo de decodificação de variáveis necessário quando se trata de explorar um espaço de busca contínuo com ajuda de um GA de código binário. A faixa de valores que as variáveis de otimização podem assumir no caso do problema de detecção de dano é de 0 a 1, como foi comentado na seção 3.2.1

A Figura 4.2 mostra um exemplo de um cromossomo que representa um cenário de dano para uma estrutura com 6 elementos. Da esquerda para a direita do cromossomo, os valores em cada gene correspondem à extensão do dano para elementos 1 a 6, respectivamente. Portanto, o cromossomo representa um cenário de dano com dano de 0,17 em elemento 2; 0,01 em elemento 3; 0,03 em elemento 4 e 0,20 em elemento 5. Elementos 1 e 6 não apresentam dano.

\begin{tabular}{c|c|c|c|c|c|c|} 
Dano & 0 & 0,17 & 0,01 & 0,03 & 0,20 & 0 \\
\hline Elemento & I & II & III & IV & V & V I
\end{tabular}

Figura 4. 2 Cromossomo representando um cenário de dano. 
Tabela 4.1 mostra as características do RCGA implementado. Os operadores genéticos foram definidos desde a literatura especializada (Herrera et al., 1998), (Coley, 1999) e os valores dos parâmetros genéticos foram definidos a partir de diversas análises realizadas previamente pelo autor. O operador de mutação M-Zero é proposto nesta pesquisa com o intuito de acelerar a convergência do algoritmo para o cenário de dano correto e consiste em introduzir um valor de zero no gene que será mutado.

Tabela 4. 1 Operadores e parâmetros genéticos para o RCGA.

\begin{tabular}{lc}
\hline Seleção & Torneio, $\mathrm{n}=2$ \\
Cruzamento & BLX-a \\
Mutação & M-Zero \& Creep \\
Especial & Elitismo \\
Taxa de Cruzamento & 0,9 \\
Taxa de Mutação & 0,1 \\
\hline
\end{tabular}

Os operadores de mutação na Tabela 4.1 não são utilizados simultaneamente. A mutação de um gene requer, então, um esquema que permita definir qual o operador será aplicado. Para isso, gera-se um número aleatório adicional, no intervalo de 0 a 1 , que se compara contra um limiar prédefinido, sendo aqui utilizado um valor igual a 0,5. Aplica-se o operador M-Zero se o número gerado for menor que o limiar, caso contrario se utiliza o operador creep. O valor do umbral será diminuído proporcionalmente ao incremento no número de gerações devido ao fato de que se espera que o algoritmo convirja para um cenário de dano que inclui os verdadeiros elementos danificados na medida em que o processo evolutivo avança.

Em relação à população inicial, esta será iniciada heuristicamente com o intuito de se orientar a busca para cenários de dano não severos com apenas poucos elementos danificados. Um número aleatório entre 0 e 1 é gerado para cada variável em cada indivíduo. Se esse número for menor que 0,5 as variáveis assumem um valor aleatório entre 0 e 0,5; de outra forma, elas recebem um valor igual a 0 .

Cada execução do RCGA será dividida em duas partes. Na primeira parte, - RCGA é executado considerando como variáveis de otimização todos os elementos na estrutura até ter atingido um dos critérios de convergência apresentados na seção 2.3.3. Depois disso, o RCGA será reinicializado utilizando 
uma quantidade reduzida de variáveis com o intuito de refinar os resultados encontrados na primeira de cada execução (Laier e Villalba, 2009). Nesta etapa, utilizam-se como variáveis de otimização somente aqueles coeficientes de redução de rigidez dos elementos que apresentaram dano maior ou igual a 0,02 no cenário de dano encontrado na primeira parte da execução (so/1). A população inicial é gerada heuristicamente tal que $10 \%$ dos indivíduos sejam iguais a sol1 e o restante, $90 \%$, são gerados a partir de uma perturbação aleatória de sol1. O operador creep é o único que realizará mutação dos indivíduos já que nesta etapa o número de variáveis é esperado ser similar à quantidade de elementos danificados.

O processo finaliza depois da comparação da nova solução contra aquela obtida na primeira parte da execução, sendo escolhida aquela com a aptidão mais alta. Espera-se que o fato de se utilizar um número inferior de variáveis na segunda parte da execução permita um melhor desempenho da metodologia proposta. A definição de tais tipos de heurística faz com que o algoritmo seja adaptado para o problema tratado.

Dano

Elem ento

\begin{tabular}{|c|c|c|}
\hline 0,17 & 0,03 & 0,20 \\
\hline II & IV & V
\end{tabular}

II IV $\quad$ V

Figura 4. 3 Exemplo de um cromossomo utilizado na segunda parte da execução do RCGA.

Para ilustrar como o cromossomo da segunda parte da execução é constituído, considere que o indivíduo apresentado na Figura 4.2 foi a solução encontrada pelo RCGA na primeira parte da execução. Depois da aplicação do critério de seleção de variáveis de otimização observamos que na segunda parte da execução elas correspondem aos fatores de redução da rigidez dos elementos 2, 4 e 5 (Figura 4.3). Para o exemplo mostrado observa-se, então, uma redução de $50 \%$ no total de variáveis consideradas. 


\subsection{NOVO SIStema DE AVALIAÇÃo DO DESEMPENHO DE METOdOLOGIAS DE DETECÇÃO DE DANO DE NIVEL III}

Uma questão muito importante quando do desenvolvimento de uma nova metodologia de deteç̧ão de dano corresponde a como determinar seu desempenho. Geralmente, a valoração das metodologias de detecção de dano baseadas em vibração e na utilização de metaheurísticas é realizada a partir da simulação de um número pequeno de cenários de dano e da comparação direta entre o resultado da metodologia e o cenário real. Neste trabalho é proposto que tal desempenho seja determinado a partir da geração de uma quantidade considerável de cenários de dano de forma a obter uma melhor representatividade dos diferentes cenários de dano - combinações de um número determinado de elementos danificados e de extensões de danopossíveis na estrutura. Para cada cenário de dano, os resultados encontrados são agrupados em função dos 3 tipos de erros que uma metodologia pode cometer durante o processo de identificação do dano. Esses erros são os seguintes:

- Erro Tipo A: Devido à diferença entre o valor da extensão do dano calculada pela metodologia e o valor do dano de um elemento realmente danificado.

- Erro Tipo B: apresenta-se quando a metodologia determina erroneamente que um elemento não danificado apresenta uma determinada extensão de dano.

- Erro Tipo C: A metodologia não consegue determinar que um elemento encontra-se danificado.

Os erros anteriormente mencionados são avaliados para cada elemento na estrutura como uma função da real presença do dano no elemento. Se o elemento é danificado, então os erros tipo A e C são avaliados, de outra forma determina-se o erro tipo B. Um elemento não danificado que apresenta o erro tipo B é chamado de falso positivo e um elemento danificado que não tenha sido identificado é considerado como um falso negativo (Fugate, Sohn et al., 2001). Após a metodologia proposta tiver encontrado o cenário de dano para a 
estrutura, se determina a ocorrência dos erros mencionados em função da diferença entre a extensão do dano real e a calculada, $\Delta \beta$, para cada elemento na estrutura. Uma indicação de falso positivo ocorre se uma extensão de dano maior que 0,03 é determinada para um elemento que não apresenta dano. Um falso negativo consiste de um elemento danificado para o qual foi calculada uma extensão de dano menor que 0,05. Além disso, cada tipo de erro apresenta um nível de erro específico como uma função da magnitude da diferença, como mostrado na Tabela 4.2. Estes níveis foram definidos pelos autores para mostrar mais detalhadamente que a metodologia proposta pode avaliar dano não severo e não foi derivado para uma estrutura específica ou material. O cenário de dano é classificado em função do pior nível de erro encontrado para cada tipo entre todos os elementos na estrutura. Além disso, a quantidade de falsos positivos deverá ser reportada para que a descrição do desempenho da metodologia seja completa.

Tabela 4. 2 Níveis de erro do novo método de avaliação de uma metodologia de detecção de dano.

\begin{tabular}{|c|c|c|c|c|c|}
\hline \multirow[b]{2}{*}{ Tipo de Erro } & \multicolumn{5}{|c|}{ Nível } \\
\hline & 0 & 1 & 2 & 3 & 4 \\
\hline$A$ & --- & $\Delta \beta<0,02$ & $0,02 \leq \Delta \beta<0,05$ & $0,05 \leq \Delta \beta<0,1$ & $\Delta \beta \geq 0,1$ \\
\hline B & $\begin{array}{c}\text { Sem falsos } \\
\text { positivos }\end{array}$ & $\beta<0,05$ & $0,05 \leq \beta<0,1$ & $0,1 \leq \beta<0,2$ & $\beta \geq 0,2$ \\
\hline C & $\begin{array}{c}\text { Sem falsos } \\
\text { negativos }\end{array}$ & $0,1 \leq \beta<0,2$ & $\beta \geq 0,2$ & -- & -- \\
\hline
\end{tabular}

A Figura 4.4 ilustra como a classificação comentada deveria ser realizada quando uma metodologia de detecção de dano é aplicada a uma estrutura com 8 elementos. Neste exemplo, o cenário de dano corresponde a dano nos elementos 3, 4 e 7. As letras $U$ e $D$ indicam elementos sem e com dano, respectivamente, e EX_Y indica um erro do tipo X e nível Y. O cenário de dano encontrado pela metodologia indica a presença do dano nos elementos 3 a 6 . Os verdadeiros elementos 2 e 3 apresentaram diferenças no cálculo do dano inferior a 0,02 e 0,1 , respectivamente. Devido ao fato de o elemento 7 não ter sido identificado como danificado se obtiveram os erros E1_4 e E3_2. O algoritmo forneceu extensões de dano inferiores a 0,2 e 0,05 para os elementos 4 e 5, respectivamente; portanto, esses elementos foram classificados como E2_3 e E2_1. Uma vez que os elementos 1, 2 e 8 não apresentaram erro algum, a 
classificação para o cenário de dano calculado em relação aos três tipos de erro foi EA_4, EB_3 e EC_2.

1) Definir quais são os elementos danificados na estrutura

$\begin{array}{lcccccccc}\text { Elemento } & 1 & 2 & 3 & 4 & 5 & 6 & 7 & 8 \\ \text { Extensão do dano real } & 0 & 0 & 0.250 & 0.170 & 0 & 0 & 0.352 & 0 \\ \text { Classificação } & \mathrm{U} & \mathrm{U} & \mathrm{D} & \mathrm{D} & \mathrm{U} & \mathrm{U} & \mathrm{D} & \mathrm{U}\end{array}$

2) Executar o RCGA

$\begin{array}{lllllllll}\text { Extensão do dano calculada } & 0 & 0 & 0.241 & 0.234 & 0.118 & 0.039 & 0 & 0\end{array}$

3) Valoração do tipo de erro para os elementos com dano

$\begin{array}{lllllllll}\text { Erro Tipo A } & -- & -- & \text { EA_1 } & \text { EA_3 } & - & - & \text { EA_4 } & - \\ \text { Erro Tipo C } & -- & -- & \text { EC_0 } & \text { EC_0 } & -- & - & \text { EC_2 } & -\end{array}$

4) Valoração do tipo de erro para os elementos sem dano

Erro Tipo B EB_0 $\quad$ EB_0 - - $\quad--E_{-} \quad$ EB_3 $\quad$ EB_1 - - $\quad$ EB_0

5) Classificar os resultados para o cenário de dano segundo os tipos de erro encontrados

Erro Tipo A EA_4

Erro Tipo B EB_3

Erro Tipo C EC_2

Figura 4. 4 Exemplo de classificação de um cenário de dano calculado pelo RCGA segundo o tipo de erro encontrado.

Finalmente, a forma proposta de se avaliar o desempenho da metodologia a partir de um cenário de dano específico é aplicada a um conjunto desses cenários, permitindo assim determinar a confiabilidade que tem a metodologia para detectar um cenário de dano desconhecido.

\subsection{ESTRUTURA ANALISADA}

Uma viga com 72 elementos (Figura 4.5) é utilizada para avaliar o desempenho do RCGA proposto e ilustrar o novo procedimento de avaliação de metodologias de detecção de dano que consigam tanto localizar como quantificar o dano. Cada elemento na viga tem as seguintes propriedades: área, $A=1 \times 10^{-3}$ 
$\mathrm{m}^{2}$; momento de inércia, $\mathrm{I}=5 \times 10^{-4} \mathrm{~m}^{4}$; densidade, $\rho=78 \times 10^{2} \mathrm{~kg} / \mathrm{m}^{3}$; e modulo de elasticidade $\mathrm{E}=200 \times 10^{9} \mathrm{~N} / \mathrm{m}^{2}$. Em relação à questão experimental, considerou-se que só as primeiras oito formas modais foram medidas nos graus de liberdade verticais junto às suas respectivas frequências naturais. $O$ tamanho da população utilizado pelo RCGA foi definido como 300 indivíduos.

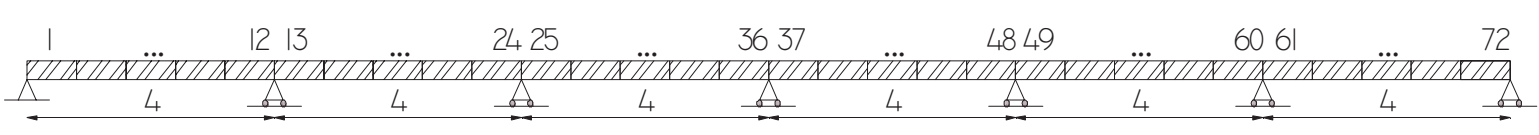

Figura 4. 5. Viga analisada.

Um total de 100 cenários de dano serão simulados, considerando uma faixa de dano entre 0,1 e 0,5 e uma quantidade máxima de 5 elementos danificados. Quantidade e posições dos elementos danificados e as extensões de dano são geradas aleatoriamente.

\subsection{RESULTADOS}

A seguir, os resultados para os 100 cenários de dano simulados para a estrutura analisada são apresentados. Tabela 4.3 mostra a distribuição dos resultados para o Erro Tipo A. O Algoritmo encontrou a extensão do dano com uma diferença inferior a 0,02 em 53\% dos cenários simulados. A diferença entre o dano calculado e o real é menor a 0,1 em $86 \%$ dos casos. Alguns dos casos que apresentaram o Erro Tipo A nível 4 corresponderam a cenários para os quais houve presença de falsos negativos ou cenários com 4 ou 5 elementos danificados com uma diferença significativa nas extensões do dano. Estes resultados mostram que o algoritmo pode determinar os verdadeiros elementos danificados e suas extensões confiavelmente. 
Tabela 4. 3 Distribuição de resultados para o RCGA segundo o Erro Tipo A.

\begin{tabular}{ccccc}
\hline Erro & EA_1 & EA_2 & EA_3 & EA_4 \\
\hline Nível & $\Delta \beta<0,02$ & $0,02 \leq \Delta \beta<0,05$ & $0,05 \leq \Delta \beta<0,1$ & $\Delta \beta \geq 0,1$ \\
\hline \# casos & 53 & 18 & 15 & 14 \\
\hline
\end{tabular}

A Tabela 4.4 reporta o máximo erro no calculo da extensão do dano para um elemento não danificado. Em 40\% dos cenários de dano analisados não são apresentados falsos positivos enquanto que para $74 \%$ de tais cenários a indicação errônea de dano foi menor que 0,01; resultado este que é esperado quando se deseja ter uma metodologia de detecção de dano confiável. Além disso, só $9 \%$ dos exemplos apresentaram falsos positivos com um alto valor de dano, sendo que estes casos correspondiam a aqueles nos quais um erro do tipo A nível 4 e um erro do tipo $C$ estavam presentes simultaneamente ou não.

Tabela 4. 4 Distribuição de resultados para o RCGA segundo o Erro Tipo B.

\begin{tabular}{cccccc}
\hline Erro & EB_0 & EB_1 & EB_2 & EB_3 & EB_4 \\
\hline \multirow{2}{*}{ Nível } & $\begin{array}{c}\text { Sem } \\
\text { falsos } \\
\text { positivos }\end{array}$ & $\beta<0,05$ & $0,05 \leq \beta<0,1$ & $0,1 \leq \beta<0,2$ & $\beta \geq 0,2$ \\
\hline \# casos & 40 & 19 & 15 & 17 & 9 \\
\hline
\end{tabular}

Tabela 4.5 mostra a habilidade da metodologia proposta para identificar corretamente todos os elementos danificados que fazem parte do cenário de dano real. Este tipo de erro é o mais grave porque sua presença compromete a segurança da estrutura e, portanto, é desejável que seja zero. Em 87\% dos exemplos, não há indicações de falsos negativos. Nos exemplos restantes há falsos negativos para os quais só em um $4 \%$ deles o elemento danificado apresentava uma extensão do dano superior a 0,2. A maioria dos exemplos onde se apresentaram tais indicações tinham 4 ou 5 elementos danificados, o que implica que na medida em que o número de elementos danificados incrementa a probabilidade da metodologia proposta identificar todos os elementos danificados diminui.

Tabela 4.6 reporta o número de exemplos para os quais foi determinada uma quantidade específica de falsos positivos. Menos de 4 indicações de falsos positivos estão presentes em $74 \%$ dos cenários analisados, e só $13 \%$ deles teve mais de 5 falsos positivos no cenário de dano calculado. Uma análise detalhada 
mostrou que em geral o número de falsos positivos aumentava com o número de elementos danificados.

Tabela 4. 5 Distribuição de resultados para o RCGA segundo o Erro tipo C.

\begin{tabular}{cccc}
\hline Erro & EC_0 & EC_1 & EC_2 \\
\hline Nível & $\begin{array}{c}\text { Sem falsos } \\
\text { negativos }\end{array}$ & $0,1 \leq \beta<0,2$ & $\beta \geq 0,2$ \\
\hline \# casos & 87 & 9 & 4 \\
\hline
\end{tabular}

Tabela 4. 6 Distribuição dos resultados do RCGA segundo a quantidade de falsos positivos encontrados.

\begin{tabular}{cccccccc}
\hline $\begin{array}{c}\text { Falsos } \\
\text { Positivos }\end{array}$ & $\mathbf{0}$ & $\mathbf{1}$ & $\mathbf{2}$ & $\mathbf{3}$ & $\mathbf{4}$ & $\mathbf{5}$ & $>\mathbf{5}$ \\
\hline \# de Casos & 40 & 12 & 11 & 11 & 9 & 4 & 13 \\
\hline
\end{tabular}

A determinação do número de falsos positivos é importante para uma correta interpretação do desempenho da metodologia de deteç̧ão de dano. Uma metodologia cujos resultados correspondam a cenários de dano com uma alta quantidade de elementos danificados - próxima do total de elementos da estrutura - poderia fazer com que os erros tipo $A$ e $C$ sejam baixos e, portanto ter uma ideia errada do desempenho da metodologia. É importante notar que a distribuição do número de falsos positivos segundo os diferentes graus de erro poderia ser requerida quando a quantidade de tais elementos seja considerável. Do mesmo modo, seria desejável conhecer qual é a distribuição dos diferentes graus de erro para os elementos na estrutura quando a metodologia não apresente um comportamento com uma tendência para os níveis mais baixos do erro A e B. O requisito anterior busca que o esquema de avaliação forneça uma melhor descrição dos resultados da aplicação da metodologia proposta.

O nível de sucesso da metodologia proposta é determinado por contar o número de execuções, de um total de 10, em que a metodologia encontrou os verdadeiros elementos danificados. Para tanto, calcula-se o valor médio e o desvio padrão dos resultados desde o conjunto de cenários de dano com a mesma quantidade de elementos danificados. Tabela 4.7 apresenta os parâmetros anteriores como uma função do número real de elementos danificados. Como mostrado anteriormente, o desempenho da metodologia proposta diminui na medida em que o número de elementos é incrementado 
indicando que o espaço de busca torna-se mais complexo. Uma detecção de dano mais robusta deveria tomar em conta a possibilidade de muitos elementos danificados estejam dispersos ao longo da estrutura.

Tabela 4. 7 Nível de sucesso da metodologia proposta segundo a quantidade elementos

\begin{tabular}{ccccccc}
\multicolumn{8}{c}{ danificados. } \\
\hline $\begin{array}{c}\text { Número de elementos } \\
\text { danificados }\end{array}$ & $\mathbf{1}$ & $\mathbf{2}$ & $\mathbf{3}$ & $\mathbf{4}$ & $\mathbf{5}$ \\
\hline \multirow{2}{*}{$\begin{array}{c}\text { Execuções } \\
\text { exitosas }\end{array}$} & $\begin{array}{c}\text { Desvio padrão } \\
\text { (std) }\end{array}$ & 1,1 & 2,0 & 2,8 & 2,5 & 3,1 \\
\hline
\end{tabular}

Outro aspecto importante que deve ser salientado é que a máxima aptidão que uma solução qualquer poderia atingir não corresponde a valor máximo dado na Equação 4.1, que para as condições do exemplo analisado é igual a 1600 (200x8; onde 8 é o número de modos utilizado). Isto se deve ao fato que não há um conjunto de parâmetros estruturais que permitam obter exatamente os parâmetros dinâmicos com ruído. Entre todos os cenários de dano analisados, a solução que resultou na maior aptidão apresentou um valor de 1506,2. Este valor poderia ser usado como uma referência para estimar a qualidade da solução encontrada. Em relação aos exemplos que resultaram no menor grau de erro no cálculo da extensão do dano, sem falsos positivos nem negativos, estes apresentaram uma aptidão média de 1501,6 ( $s t d=1,6)$. A média do valor da aptidão para os casos nos quais o RCGA produziu um falso negativo foi igual a 1424,3 (std=62,0). Apenas em um exemplo apresentando uma solução errada para o caso onde dois elementos na proximidade do suporte extremo à direita da viga mostrou uma alta aptidão. Este resultado indica a dificuldade que a metodologia teria para detectar alguns cenários de dano.

Por outro lado, na Tabela 4.8 são apresentados alguns resultados para casos pontuais no qual a metodologia apresentou um desempenho excelente tal que o erro no cálculo da extensão do dano foi menor a 0,02 e não teve presença de falsos positivos ou negativos. 
Tabela 4. 8 Alguns exemplos de aplicação com sucesso do RCGA proposto em deteç̧ão de dano simples e múltiplo.

\begin{tabular}{|c|c|c|c|c|}
\hline \multirow[b]{2}{*}{$\begin{array}{c}\text { Tipo de } \\
\text { Dano }\end{array}$} & \multirow[b]{2}{*}{ Cenário } & \multirow[b]{2}{*}{ Elementos } & \multicolumn{2}{|c|}{ Extensão do dano $\beta$} \\
\hline & & & Real & $\begin{array}{c}\text { RCGA M- } \\
\text { Zero }\end{array}$ \\
\hline \multirow{2}{*}{ Simples } & V1 & 14 & 0,422 & 0,423 \\
\hline & V2 & 48 & 0,482 & 0,479 \\
\hline \multirow{15}{*}{ Multiplo } & & 52 & 0,424 & 0,408 \\
\hline & V3 & 53 & 0 & 0,034 \\
\hline & & 64 & 0,384 & 0,368 \\
\hline & & 11 & 0,490 & 0,490 \\
\hline & & 13 & 0,164 & 0,164 \\
\hline & V4 & 47 & 0,319 & 0,313 \\
\hline & & 58 & 0,155 & 0,163 \\
\hline & \multirow{8}{*}{ V5 } & 1 & 0 & 0,124 \\
\hline & & 2 & 0 & 0,075 \\
\hline & & 3 & 0,160 & 0,09 \\
\hline & & 11 & 0,127 & 0,124 \\
\hline & & 19 & 0,387 & 0,385 \\
\hline & & 59 & 0,312 & 0,307 \\
\hline & & 70 & 0,437 & 0,432 \\
\hline & & 71 & 0 & 0,084 \\
\hline
\end{tabular}

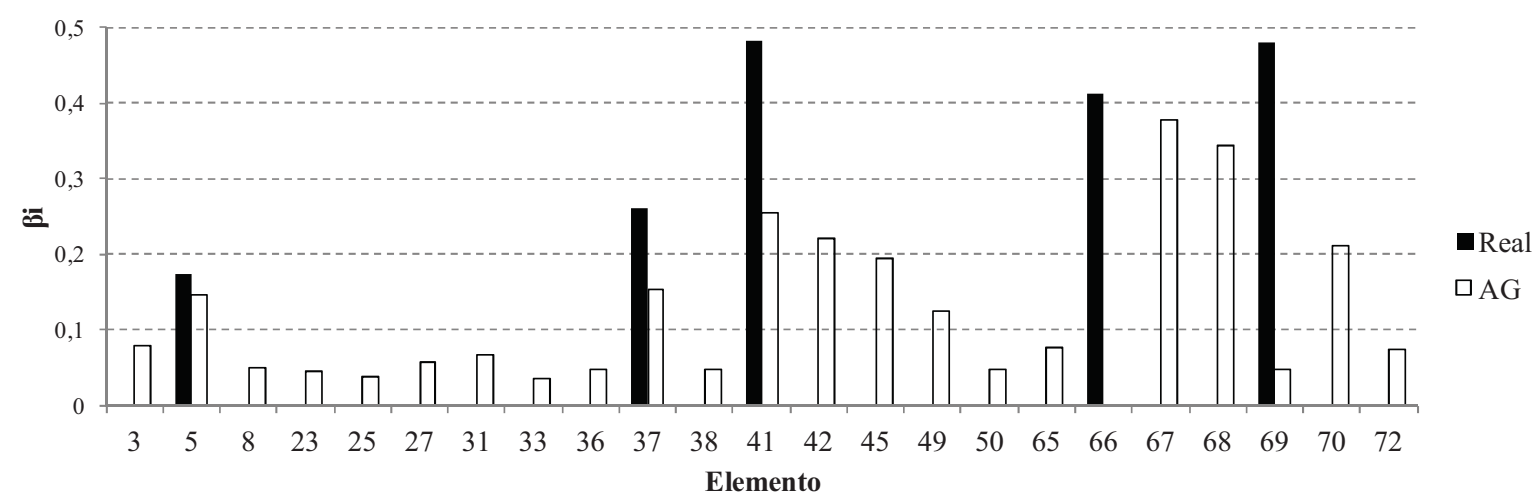

Figura 4. 6 Exemplo 1 de identificação incorreta do cenário de dano utilizando o RCGA proposto.

Exemplo de aplicações do RCGA proposto que não tiveram êxito - o cenário de dano encontrado apresentou falsos negativos- são reportados a seguir. Os resultados para um cenário de dano com 5 elementos danificados são apresentados na Figura 4.6, em que é possível observar que os elementos danificados 66 e 69 não foram identificados e em seu lugar foram detectados os elementos 67 e 68 com uma extensão de dano próxima da real. Um resultado similar é apresentado na Figura 4.7 na qual o elemento 20 não é detectado, mas sim o elemento adjacente (elemento 21). As observações anteriores indicariam 
que a metodologia poderia errar por identificar elementos adjacentes aos verdadeiramente danificados.

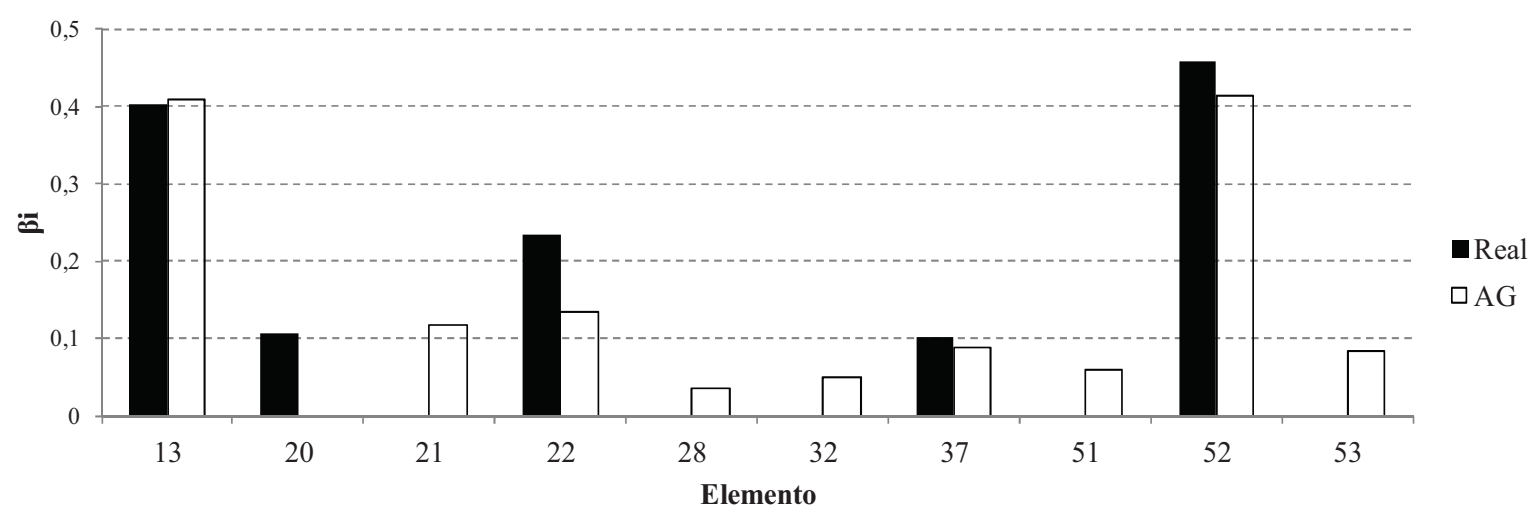

Figura 4. 7 Exemplo 2 de identificação incorreta do cenário de dano utilizando o RCGA proposto.

Cabe salientar que os resultados apresentados foram obtidos a partir da função objetivo proposta e a configuração escolhida para os parâmetros e operadores do RCGA. Portanto, qualquer mudança destes parâmetros poderia levar a um desempenho do RCGA diferente.

\subsection{DISCUSSÃO}

A partir dos resultados obtidos no presente exemplo podem se estabelecer algumas observações:

- Uma descrição mais detalhada do desempenho futuro que teria uma metodologia para localizar e quantificar dano pode ser encontrada a partir do método de avaliação proposto, onde se considera que os resultados do processo de identificação podem incluir 3 diferentes tipos de erro.

- Neste trabalho os cenários de dano utilizados foram gerados aleatoriamente; porém, outras formas de geração de tais cenários 
podem ser exploradas tal que sejam escolhidos os cenários de dano mais adequados para avaliar a metodologia.

- Não é possível garantir que o RCGA proposto terá um bom desempenho para qualquer combinação de elementos danificados e extensões de dano. Na medida em que o número de elementos danificados incrementa se torna mais difícil o processo de identificação de todos os elementos danificados.

- Considera-se importante que novos operadores genéticos sejam propostos de forma a melhorar o desempenho do RCGA. Neste trabalho, a introdução do operador M-zero levou ao algoritmo a convergir mais rapidamente para cenários de dano que apresentam poucos elementos danificados.

- O valor encontrado para a aptidão do melhor individuo poderia servir como indicador da qualidade da solução, mesmo na condição de medições com ruído. Para medições incompletas sem ruído, o algoritmo ainda tem a possibilidade de atingir a aptidão máxima possível.

- O GA na segunda parte da execução pode ser trocado por um algoritmo especializado em busca local que permita um melhor refinamento da solução. 


\section{EXEMPLO II: PARTICLE SWARM}

\subsection{INTRODUÇÃO}

Neste capítulo apresenta-se a aplicação de um algoritmo PSO adaptativo para detectar dano em estruturas do tipo viga com múltiplos apoios e analisa-se a influência das medições incompletas na detecção de dano visando obter a quantidade ótima de informação que deverá ser utilizada (Villalba e Laier, 2012). Tal quantidade será calculada a partir da geração de diferentes combinações de número de formas modais medidas e quantidade de pontos sobre a estrutura onde foram realizados medições. A metodologia utilizada para resolver o problema de detecção de dano é aquela apresentada na Figura 4.1, sendo que a metaheurística utilizada é o PSO com as modificações introduzidas na seção 5.3. Uma nova função objetivo baseada em frequências naturais e formas modais é introduzida. Uma viga cujo modelo de elementos finitos apresenta 34 elementos 
foi utilizada como exemplo. Um número predefinido de cenários de dano será simulado para verificar que a quantidade ótima de medições seja adequada.

\subsection{DESCRIÇÃO DO PROBLEMA E DA ESTRUTURA ANALISADA}

A estrutura analisada é mostrada na Figura 5.1 e consiste de uma viga com múltiplos apoios, que apresenta um comprimento de 4 metros entre apoios e cujo FEM foi discretizado em 34 elementos. Um elemento finito do tipo Bernoulli foi empregado na modelagem numérica, que tem dois nós com dois graus de liberdade cada: um rotacional e outro vertical. A viga é constituída de um único material que tem densidade de $\rho=78 \times 10^{2} \mathrm{~kg} / \mathrm{m}^{3}$ e módulo de elasticidade $\mathrm{E}=200 \times 10^{9} \mathrm{~N} / \mathrm{m}^{2}$. Cada elemento na viga apresenta uma seção transversal com área $A=1 \times 10^{-3} \mathrm{~m}^{2}$ e momento de inércia, $\mathrm{I}=5 \times 10^{-4} \mathrm{~m}^{4}$. Os graus de perturbação dos parâmetros modais considerados neste exemplo são iguais àqueles utilizados no Exemplo I. O detalhe de qual é a informação da resposta dinâmica da estrutura utilizada no processo de identificação do dano será apresentado a seguir.

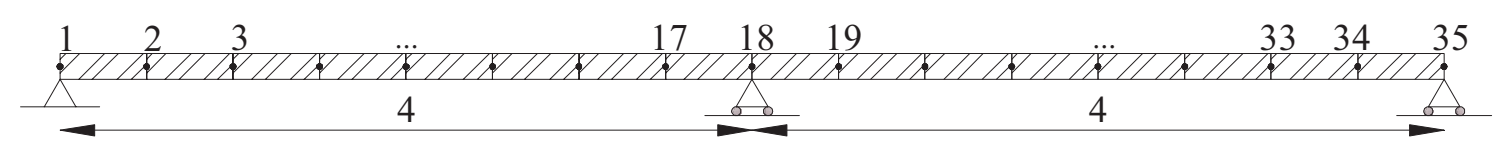

Figura 5. 1 Viga analisada.

A Tabela 5.1 apresenta os diferentes casos de informação modal incompleta que serão analisados para medir o efeito que tal condição experimental exerce no desempenho da metodologia de detecção de dano proposta. Esses casos consistem da quantidade de sensores disponíveis, na forma de porcentagens do total de graus de liberdade verticais no FEM, e da posição dos sensores sobre a viga. Considera-se que os sensores foram distribuídos uniformemente na viga já que a análise do efeito do posicionamento dos sensores no desempenho da metodologia proposta não foi um objetivo deste 
estudo. Além disso, informações sobre os graus de liberdade rotacionais não são utilizadas devido à dificuldade de serem medidas em ensaios dinâmicos reais. No melhor dos casos, considera-se que é possível ter medições em todos os graus de liberdade verticais. Medições incompletas são referidas também à possibilidade de se medir apenas poucos dos primeiros modos da estrutura, sendo definido que a faixa de modos varie entre 2 e 12 para a estrutura analisada.

Tabela 5. 1 Casos de informação modal incompletas analisados.

\begin{tabular}{|c|c|c|}
\hline Caso & $\begin{array}{l}\% \text { DOFs } \\
\text { verticais } \\
\text { medidos }\end{array}$ & $\begin{array}{l}\text { Localização sensores } \\
\text { (a numeração começa no apoio fixo da viga) }\end{array}$ \\
\hline I1 & 100 & Todos os DOFs verticais \\
\hline I2 & 75 & $\begin{array}{c}3,4,5,6,8,9,10, \begin{array}{l}11,13,14,15,16,20,21,22,23,25,26, \\
27,28,30,31,32,33\end{array} \\
\end{array}$ \\
\hline I3 & 50 & $3,5,7,9,10,12,14,16,20,22,24,26,27,29,31,33$ \\
\hline I4 & 25 & $4,8,11,15,21,25,28,32$ \\
\hline
\end{tabular}

Para determinar a quantidade ótima de informação modal necessária, a metodologia proposta será aplicada à detecção dos cenários de dano simples e múltiplos apresentados nas Tabelas 5.2 e 5.3, respectivamente. Os cenários de dano simples foram escolhidos de tal forma que a metodologia pudesse detectar elementos danificados em todas as zonas da viga- próximo aos apoios e no centro de cada trecho de viga. Cenários de danos múltiplos foram escolhidos para levar em conta dano uniforme e disperso ao longo da viga.

Tabela 5. 2 Cenários de dano Simples.

\begin{tabular}{ccccccccc}
\hline \multicolumn{2}{c}{ Cenário S1 } & \multicolumn{2}{c}{ Cenário S2 } & \multicolumn{2}{c}{ Cenário S3 } & \multicolumn{2}{c}{ Cenário S4 } \\
\hline Elem. & $\boldsymbol{\beta}$ & Elem. & $\boldsymbol{\beta}$ & Elem. & $\boldsymbol{\beta}$ & Elem. & $\boldsymbol{\beta}$ \\
\hline 2 & 0,250 & 6 & 0,350 & 15 & 0,170 & 15 & 0,420 \\
\hline
\end{tabular}

Tabela 5. 3 Cenários de danos múltiplos.

\begin{tabular}{ccccccccc}
\hline \multicolumn{2}{c}{ Cenário } & M1 & \multicolumn{2}{c}{ Cenário $\mathbf{M 2}$} & \multicolumn{2}{c}{ Cenário M3 } & \multicolumn{2}{c}{ Cenário M4 } \\
\hline Elem. & $\boldsymbol{\beta}$ & Elem. & $\boldsymbol{\beta}$ & Elem. & $\boldsymbol{\beta}$ & Elem. & $\boldsymbol{\beta}$ \\
\hline 4 & 0,200 & 12 & 0,150 & 3 & 0,200 & 4 & 0,270 \\
20 & 0,200 & 13 & 0,150 & 14 & 0,250 & 8 & 0,230 \\
& & 14 & 0,150 & 20 & 0,400 & 27 & 0,180 \\
& & & & & & 28 & 0,180 \\
\hline
\end{tabular}


O algoritmo proposto será aplicado em um total de 10 execuções para cada cenário de dano analisado e será determinado o número de execuções com êxito nas quais os verdadeiros elementos danificados são encontrados. A quantidade ótima de informação modal foi definida como aquela que permite encontrar os verdadeiros elementos danificados em pelo menos três execuções. Cabe salientar que os resultados apresentados correspondem ao valor médio daqueles provenientes de cinco grupos diferentes de execuções para cada cenário de dano. Como mostrado nas Tabelas 5.2 e 5.3, apenas uns poucos cenários de dano foram testados para determinar a quantidade ótima de informação modal dado que o esforço computacional envolvido é muito alto. Porém, um total de 50 cenários de dano, gerados de forma aleatória, foi simulado com o intuito de provar que a quantidade escolhida como ótima permitia um desempenho adequado da metodologia de detecção de dano proposta.

\subsection{CARACTERÍSTICAS DO PSO UTILIZADO}

Diferentes técnicas têm sido utilizadas para configurar os parâmetros do PSO tal como sistemas fuzzy (Shi e Eberhart, 2001), variação linear em função da quantidade de iterações realizadas (Ratnaweera et al., 2004), auto-adaptação (Parsopoulos e Vrahatis, 2007), adaptação determinística baseada no pbest e gbest (Senthil e Rao, 2008) e o Nelder-Mead Simplex (Begambre e Laier, 2009). Neste trabalho é proposta uma técnica simples e eficiente para adaptar os parâmetros do PSO que considera que cada partícula no enxame tem seus próprios parâmetros de aceleração. Assim, é proposto que o parâmetro cognitivo para a $i$-ésima partícula na iteração atual, $c_{1 i}^{t}$, seja calculado utilizando o valor que foi obtido na iteração anterior, $c_{1 i}^{t-1}$, como segue:

$c_{1 i}^{t}=c_{1 i}^{t-1}+r_{3} \times\left(c_{1 b e s t}^{t-1}-c_{1 i}^{t-1}\right)$, 
na qual $t$ indica a iteração atual, $c_{1 \text { best }}^{t-1}$ é o valor de $c_{1}$ para a melhor partícula no enxame na iteração anterior, $r_{3}$ é um valor aleatório entre 0 e 1 . Os valores iniciais para $c_{1 i}$ são definidos como números aleatórios gerados com uma distribuição uniforme na faixa $[1,8-2,2]$ baseado no valor utilizado no trabalho de Shi e Eberhart (1998). Por outro lado, Clerc and Eberhart (2002) definiram que a soma dos coeficientes de aceleração tinha um valor máximo igual a 4 e que em caso de usar valores maiores era importante a utilização de um fator de constrição que limitara o valor da velocidade. Assim, para evitar a utilização de tal fator o valor do parâmetro social, $c_{2}$, se determina a partir da Equação 5.2

$c_{2 i}^{t}=4-c_{1 i}^{t}$,

Para calcular o fator de peso, leva-se em conta que é desejável incrementar a habilidade de busca global no começo do processo iterativo enquanto no fim a busca deve ter caráter mais local. Por essa razão, o fator de peso pode ser obtido como proposto por Shi e Eberhart (1999) na Equação 5.3

$$
w^{t}=\left(w_{2}-w_{1}\right) \times\left(\frac{t_{\max }-t}{t_{\max }}\right)+w_{1},
$$

onde $t_{\max }$ é o número máximo de iterações permitidas. Os valores para $w_{2}$ e $w_{1}$ são 0,9 e 0,4, respectivamente.

A respeito do tamanho da população, este foi considerado a ser igual a 200 partículas no caso da viga analisada. Um total de 200 iterações foi permitido, sendo que a posição e a velocidade inicial de cada uma das partículas foram geradas heuristicamente seguindo o mesmo procedimento dado para os genes do GA apresentado no Exemplo I. 


\subsection{FUNÇÃO OBJETIVO}

Diferentes configurações de funções objetivo contendo os mesmos parâmetros podem levar a resultados diferentes para uma mesma metodologia de detecção de dano. Por causa disto, neste exemplo é proposta uma função objetivo baseada em frequências naturais e formas modais que é dada por

$$
G=\sum_{j=1}^{n m} \frac{200}{1+F_{j}},
$$

com

$$
F_{j}=\left|\frac{\omega_{j}^{p s o}-\omega_{j}^{e x}}{\omega_{j}^{e x}}\right|+W \times \sqrt{\frac{\sum_{i=1}^{n g l l}\left(\phi_{i j}^{p s o}-\phi_{i j}^{e x}\right)^{2}}{\sum_{i=1}^{n g l l}\left(\phi_{i j}^{e x}\right)^{2}}} .
$$

Assim, como para a Equação 4.1, esta função não requer modos completos, evitando-se que técnicas de redução de modelos ou de expansão de formas modais tenham que ser utilizadas.

\subsection{DETERMINAÇÃo DA QUANTIDADE ÓTIMA DE MEDIÇÕES}

As Tabelas 5.4 a 5.7 apresentam os resultados da metodologia proposta na forma de execuções com êxito quando aplicada à detecção de cenários de dano simples. Os resultados mostram que o desempenho desejado - pelo menos três execuções com êxito - pode ser atingido quando as primeiras 4 formas modais são medidas no $25 \%$ dos DOFs verticais ou quando as duas primeiras 
formas modais são medidas no total dos DOFs verticais. Porém, se for possível medir as primeiras 6 formas modais pode-se obter um desempenho superior a $60 \%$ no número de execuções com êxito e, praticamente, superior a $90 \%$ se as 10 primeiras formas modais fossem utilizadas. A utilização de 12 formas modais produziu uma redução no desempenho da metodologia para todos os casos em comparação com aquele obtido com um número menor de medições. Isto mostra que existe uma máxima quantidade de medições que pode ser utilizada antes do nível de desempenho da metodologia proposta ser prejudicado pelo excesso de informação. Por outro lado, Tabelas 5.6 e 5.7 ilustram a habilidade da metodologia para detectar dano no elemento 15 quando a extensão do dano é variada. Observa-se que quando a extensão do dano é maior, a certeza da metodologia proposta aumenta sem importar a quantidade de informação modal utilizada.

Tabela 5. 4 Aplicação do PSO proposto na identificação do de dano simples S1.

\begin{tabular}{ccccccc}
\hline $\begin{array}{c}\text { \% de } \\
\text { DOFs } \\
\text { verticais }\end{array}$ & $\mathbf{2}$ & $\mathbf{4}$ & $\mathbf{6}$ & $\mathbf{8}$ & $\mathbf{1 0}$ & $\mathbf{1 2}$ \\
\hline 25 & 2 & 5 & 6 & 6 & 9 & 8 \\
\hline 50 & 1 & 5 & 7 & 7 & 9 & 7 \\
\hline 75 & 0 & 4 & 7 & 9 & 8 & 7 \\
\hline 100 & 4 & 7 & 8 & 9 & 10 & 8 \\
\hline
\end{tabular}

Tabela 5. 5 Aplicação do PSO proposto na identificação do de dano simples S2.

\begin{tabular}{ccccccc}
\hline $\begin{array}{c}\text { \% de } \\
\begin{array}{c}\text { DOFs } \\
\text { verticais }\end{array}\end{array}$ & $\mathbf{2}$ & $\mathbf{4}$ & $\mathbf{6}$ & $\mathbf{8}$ & $\mathbf{1 0}$ & $\mathbf{1 2}$ \\
\hline 25 & 2 & 7 & 7 & 8 & 10 & 6 \\
\hline 50 & 3 & 6 & 9 & 8 & 9 & 7 \\
\hline 75 & 3 & 7 & 7 & 9 & 9 & 7 \\
\hline 100 & 6 & 7 & 9 & 9 & 8 & 7 \\
\hline
\end{tabular}

Tabela 5. 6 Aplicação do PSO proposto na identificação do de dano simples.

\begin{tabular}{ccccccc}
\hline $\begin{array}{c}\text { \% de } \\
\begin{array}{c}\text { DOFs } \\
\text { verticais }\end{array}\end{array}$ & $\mathbf{2}$ & $\mathbf{4}$ & $\mathbf{6}$ & $\mathbf{8}$ & $\mathbf{1 0}$ & $\mathbf{1 2}$ \\
\hline 25 & 0 & 3 & 6 & 5 & 9 & 6 \\
\hline 50 & 2 & 4 & 7 & 8 & 8 & 6 \\
\hline 75 & 2 & 2 & 5 & 8 & 8 & 6 \\
\hline 100 & 4 & 6 & 8 & 8 & 9 & 7 \\
\hline
\end{tabular}


Tabela 5. 7 Aplicação do PSO proposto na identificação do de dano simples S4.

\begin{tabular}{ccccccc}
\hline $\begin{array}{c}\text { \% de } \\
\begin{array}{c}\text { DOFs } \\
\text { verticais }\end{array}\end{array}$ & $\mathbf{2}$ & $\mathbf{4}$ & $\mathbf{6}$ & $\mathbf{8}$ & $\mathbf{1 0}$ & $\mathbf{1 2}$ \\
\hline 25 & 3 & 7 & 8 & 9 & 9 & 8 \\
\hline 50 & 2 & 6 & 7 & 9 & 10 & 8 \\
\hline 75 & 3 & 6 & 8 & 9 & 10 & 7 \\
\hline 100 & 7 & 8 & 9 & 9 & 10 & 7 \\
\hline
\end{tabular}

Os resultados da aplicação da metodologia proposta para detectar cenários de danos múltiplos são reportados nas Tabelas 5.8 a 5.11. Para cenários de dano M1 e M3, a metodologia encontra o desempenho desejado utilizando as 6 primeiras formas modais sob o $25 \%$ dos DOFs verticais. Se 8 ou mais formas modais são utilizadas, o desempenho se mantém constante em $80 \%$ para cenário M1 e 40\% para cenário M3. Para uma detecção confiável de cenário M3 são necessárias as primeiras 8 formas modais em qualquer das configurações mostradas na Tabela 5.1. Medições em todos os DOFs verticais ajudam a localizar cenários de dano uniformes mais aproximadamente, como mostrado para cenário de dano M2; porém, obter medições em todos os DOFs verticais pode ser inviável por razões técnicas e econômicas. Além disso, é observado que o algoritmo não converge para a solução correta se uma quantidade menor a 8 formas modais é utilizada. O cenário M4 pode ser detectado se há informação em $50 \%$ dos DOFs verticais e 8 formas modais ou se é possível medir as primeiras 10 formas modais em 25\% dos DOFs verticais. Utilizar mais de 10 formas modais não melhora consideravelmente o desempenho da metodologia para qualquer dos cenários de danos múltiplos analisados. Para todos os casos anteriores, a quantidade ótima de informação superou aquela encontrada para os cenários de dano com um único elemento danificado.

Tabela 5. 8 Aplicação do PSO proposto na identificação do de dano múltiplo M1.

\begin{tabular}{ccccccc}
\hline $\begin{array}{c}\text { \% de } \\
\text { DOFs } \\
\text { verticais }\end{array}$ & $\mathbf{2}$ & $\mathbf{4}$ & $\mathbf{6}$ & $\mathbf{8}$ & $\mathbf{1 0}$ & $\mathbf{1 2}$ \\
\hline 25 & 1 & 1 & 3 & 6 & 8 & 8 \\
\hline 50 & 1 & 1 & 4 & 7 & 8 & 8 \\
\hline 75 & 1 & 1 & 5 & 6 & 9 & 9 \\
\hline 100 & 2 & 3 & 8 & 9 & 9 & 9 \\
\hline
\end{tabular}


Tabela 5. 9 Aplicação do PSO proposto na identificação do de dano múltiplo M2.

\begin{tabular}{ccccccc}
\hline $\begin{array}{c}\% \\
\begin{array}{c}\text { DOFs de } \\
\text { verticais }\end{array}\end{array}$ & $\mathbf{2}$ & $\mathbf{4}$ & $\mathbf{6}$ & $\mathbf{8}$ & $\mathbf{1 0}$ & $\mathbf{1 2}$ \\
\hline 25 & 0 & 0 & 0 & 3 & 3 & 4 \\
\hline 50 & 0 & 0 & 0 & 3 & 4 & 4 \\
\hline 75 & 0 & 0 & 0 & 3 & 2 & 3 \\
\hline 100 & 0 & 1 & 3 & 4 & 4 & 5 \\
\hline
\end{tabular}

Tabela 5. 10 Aplicação do PSO proposto na identificação do cenário de dano múltiplo M3.

\begin{tabular}{ccccccc}
\hline $\begin{array}{c}\text { \% de } \\
\text { DOFs } \\
\text { verticais }\end{array}$ & $\mathbf{2}$ & $\mathbf{4}$ & $\mathbf{6}$ & $\mathbf{8}$ & $\mathbf{1 0}$ & $\mathbf{1 2}$ \\
\hline 25 & 0 & 2 & 3 & 4 & 5 & 3 \\
\hline 50 & 0 & 1 & 3 & 5 & 4 & 5 \\
\hline 75 & 0 & 1 & 1 & 4 & 5 & 5 \\
\hline 100 & 0 & 2 & 5 & 7 & 7 & 6 \\
\hline
\end{tabular}

Tabela 5. 11 Aplicação do PSO proposto na identificação do de dano múltiplo M4.

\begin{tabular}{ccccccc}
\hline $\begin{array}{c}\text { \% de } \\
\text { DOFs } \\
\text { verticais }\end{array}$ & $\mathbf{2}$ & $\mathbf{4}$ & $\mathbf{6}$ & $\mathbf{8}$ & $\mathbf{1 0}$ & $\mathbf{1 2}$ \\
\hline 25 & 0 & 0 & 0 & 1 & 3 & 3 \\
\hline 50 & 0 & 0 & 1 & 3 & 3 & 3 \\
\hline 75 & 0 & 0 & 1 & 1 & 3 & 4 \\
\hline 100 & 1 & 1 & 2 & 4 & 3 & 6 \\
\hline
\end{tabular}

A breve discussão dos parágrafos anteriores permite concluir que o desempenho da metodologia proposta para a identificação de cenários de dano simples e múltiplo é geralmente melhorado na medida em que a quantidade de sensores na estrutura aumenta e que quanto maior o número de formas modais medidas maior é o número de execuções com êxito. Porém, há uma quantidade de informação a partir da qual o desempenho da metodologia proposta pode começar a diminuir. Cabe salientar que há configurações de medições com as quais o algoritmo não consegue convergir em oportunidade alguma para o cenário de dano correto. Finalmente, foi observado que cenários de dano simples são identificados mais facilmente que cenários que apresentem vários elementos danificados. 


\subsection{VERIFICAÇÃO DA QUANTIDADE ÓTIMA ESCOLHIDA}

Como mencionado anteriormente, um total de 50 cenários foram testados para provar que a quantidade de informação modal utilizada seja suficiente para uma correta deteç̧ão do dano. Em função dos resultados apresentados na seção 5.5, a quantidade ótima de informação, considerando principalmente o menor número de sensores utilizados, corresponde a medições das primeiras 10 formas modais em um $25 \%$ dos DOFs verticais. Tal quantidade será utilizada no processo de identificação do dano.

A Tabela 5.12 resume os resultados para os novos cenários em função do número de elementos danificados. Pode ser observado que a quantidade mínima de execuções com êxito foi garantida e que há um número baixo de elementos identificados erroneamente - que são definidos como aqueles elementos não danificados para os quais a metodologia encontrou uma extensão de dano maior a 0,05 . Além disso, a diferença máxima entre a extensão de dano real e a calculada foi baixa. Cabe salientar que um melhor desempenho da metodologia foi obtido quando um único elemento encontrava-se danificado, tal e como mostrado anteriormente. Estes resultados permitem concluir que a quantidade de dados modais utilizado é adequada para detectar dano na viga.

Tabela 5. 12 Resultados para 50 cenários de dano obtidos utilizando o PSO proposto.

\begin{tabular}{|c|c|c|}
\hline \multirow[t]{2}{*}{ Característica } & \multicolumn{2}{|c|}{$\begin{array}{c}\text { Tipo de cenário de } \\
\text { dano }\end{array}$} \\
\hline & Simples & Múltiplo \\
\hline Número mínimo de execuções exitosas & 7 & 3 \\
\hline $\begin{array}{l}\text { Número máximo de elementos identificados } \\
\text { erroneamente como danificados }\end{array}$ & 3 & 4 \\
\hline $\begin{array}{l}\text { Diferença máxima no cálculo da extensão do } \\
\text { dano }\end{array}$ & 0,055 & 0,065 \\
\hline
\end{tabular}

Como mostrado na Tabela 5.12, a metodologia não converge à resposta correta em todas as execuções, assim, é necessário garantir que a melhor solução corresponda a uma das execuções que tiveram êxito. Este fato não foi verificado para um dos cenários de dano analisados que apresentava dois elementos danificados adjacentes localizados perto dos apoios. As cinco melhores soluções para este cenário, entre o total de 10 execuções, são reportadas na 
Tabela 5.13. Somente aqueles elementos que tiveram um fator de redução maior que 0,05 foram apresentados. Pode ser observado que todos os elementos danificados, diferentes do elemento 2 , são identificados e que a diferença entre o valor da função objetivo para estas soluções é baixo (menor que 6). Além disso, nas execuções 1 e 3 um cenário de dano aproximado foi encontrado no qual o elemento 3 é identificado como danificado em lugar do elemento 2. A Tabela 5.14 mostra os resultados para o mesmo cenário quando as medições estão livres de ruído. Neste caso, a metodologia teve êxito em três corridas e atingiu o valor máximo para a função objetivo $\left(\mathrm{FO}_{\max }=2000\right)$. Assim, pode-se concluir que a presença de ruído nas medições torna o espaço de busca mais complexo e que soluções com um diferente conjunto de elementos danificados podem apresentar um valor alto para a função objetivo, o que prejudica a convergência do PSO proposto para o cenário de dano real.

Tabela 5. 13 Exemplo de uma identificação de dano errônea utilizando o PSO proposto.

\begin{tabular}{ccccccc}
\hline Elemento & \multicolumn{7}{c}{ Extensão do dano $(\boldsymbol{\beta})$} \\
\cline { 2 - 7 } Danificado & Real & $\mathbf{1}$ & $\mathbf{2}$ & $\mathbf{3}$ & $\mathbf{4}$ & $\mathbf{5}$ \\
\hline 1 & 0,200 & 0,544 & 0,193 & 0,521 & 0,543 & 0,179 \\
2 & 0,220 & --- & 0,238 & --- & --- & 0,238 \\
3 & --- & 0,081 & --- & 0,098 & --- & --- \\
7 & --- & --- & --- & 0,082 & 0,138 & --- \\
10 & --- & --- & 0,059 & --- & --- & -- \\
24 & --- & 0,064 & --- & 0,062 & 0,097 & -- \\
25 & 0,190 & 0,182 & 0,227 & 0,206 & 0,191 & 0,197 \\
30 & 0,260 & 0,270 & 0,287 & 0,275 & 0,263 & 0,259 \\
\hline FO & & 1965,7 & 1963,3 & 1962,08 & 1962,0 & 1960,6 \\
\hline
\end{tabular}

Tabela 5. 14 Exemplo de uma identificação correta utilizando o PSO e sob a considerando de medições livres de ruído.

\begin{tabular}{ccccccc}
\hline $\begin{array}{c}\text { Elemento } \\
\text { Danificado }\end{array}$ & Real & $\mathbf{1}$ & $\mathbf{2}$ & $\mathbf{3}$ & $\mathbf{4}$ & $\mathbf{5}$ \\
\cline { 2 - 7 } & 0,200 & 0,200 & 0,200 & 0,200 & 0,157 & 0,362 \\
2 & 0,220 & 0,220 & 0,220 & 0,220 & 0,224 & 0,167 \\
21 & --- & --- & --- & --- & 0,094 & 0,083 \\
25 & 0,190 & 0,190 & 0,190 & 0,190 & --- & --- \\
28 & --- & --- & --- & --- & 0,054 & --- \\
29 & --- & --- & --- & --- & --- & 0,076 \\
30 & 0,260 & 0,260 & 0,260 & 0,260 & 0,269 & 0,242 \\
\hline Cost & & 2000 & 2000 & 2000 & 1973,9 & 1972,4 \\
\hline
\end{tabular}




\subsection{INFLUÊNCIA DO NÚMERO DE MODOS UTILIZADOS NA DETERMINAÇÃO DA EXTENSÃO DO DANO}

Tabelas 5.15 e 5.16 apresentam uma descrição completa dos cenários de dano encontrados pela metodologia proposta quando aplicada para detectar os cenários apresentados nas Tabelas 5.2 e 5.3 em função do número de formas modais que se consideram disponíveis. Em relação ao número de sensores, considera-se que eles estão uniformemente distribuídos em 25\% dos DOFs verticais na estrutura. Os resultados apresentados correspondem à melhor solução encontrada pelo PSO proposto no primeiro conjunto de execuções, relembrando que 5 conjuntos de 10 execuções foram realizadas. O valor em parêntesis corresponde ao erro no cálculo da extensão do dano para os elementos verdadeiramente danificados. Apenas aqueles elementos no cenário de dano encontrado pelo PSO que apresentaram um $\beta$ maior que 0,05 são reportados, portanto considerando os elementos com $\beta$ menores a esse valor como não danificados.

Tabela 5. 15 Aplicação do PSO proposto na detecção de cenários de dano simples. Medições em $25 \%$ dos DOFs verticais.

\begin{tabular}{|c|c|c|c|c|c|}
\hline \multirow{2}{*}{$\begin{array}{c}\text { ID } \\
\text { Cenário }\end{array}$} & \multirow{2}{*}{ Elemento } & \multicolumn{4}{|c|}{ Extensão do dano $\beta$} \\
\hline & & Real & 8 modos & 10 modos & 12 modos \\
\hline \multirow{4}{*}{$\mathrm{S} 1$} & 1 & -- & 0,600 & 0,077 & $-\cdots$ \\
\hline & 2 & 0,250 & $--(100)$ & $0,239(4)$ & $0,258(3)$ \\
\hline & 12 & -- & 0,125 & -- & -- \\
\hline & 23 & -- & 0,091 & -- & -- \\
\hline $\mathrm{S} 2$ & 6 & 0,350 & $0,353(1)$ & $0,352(1)$ & $0,345(1)$ \\
\hline \multirow{6}{*}{ S3 } & 1 & -- & 0,114 & -- & -- \\
\hline & 3 & -- & -- & 0,051 & -- \\
\hline & 15 & 0,170 & $0,155(9)$ & $0,172(1)$ & $0,163(4)$ \\
\hline & 18 & -- & -- & 0,071 & -- \\
\hline & 21 & -- & -- & 0,057 & -- \\
\hline & 24 & --- & 0,066 & $--\cdot$ & $-\cdots$ \\
\hline \multirow{4}{*}{ S4 } & 12 & -- & -- & 0,070 & -- \\
\hline & 15 & 0,420 & -- & $0,424(1)$ & $0,399(5)$ \\
\hline & 18 & -- & --- & - - - & 0,050 \\
\hline & 29 & --- & --- & 0,095 & $\ldots$ \\
\hline
\end{tabular}

Observa-se que se 8 formas modais são utilizadas é possível que os verdadeiros elementos danificados possam não ser encontrados tal como 
aconteceu para cenários S1, M2 ou M4. Além disso, observam-se erros na extensão do dano maiores que $60 \%$ resultando em um pobre desempenho da metodologia. Já para 10 ou 12 modos utilizados, nota-se que existe um desempenho da metodologia bastante similar, com erros no cálculo da extensão do dano em geral menores a $10 \%$ e com a identificação de todos os elementos danificados. Este resultado mostra que pode não se obter uma melhoria considerável do desempenho da metodologia quando a quantidade de formas modais é alta. Por outro lado, uma tendência do algoritmo em subestimar ou sobre-estimar a magnitude do dano em função do número de modos não é observada, os valores encontrados parecem depender da dinâmica da execução. Os resultados mostram que apenas poucos elementos são identificados erroneamente com baixos valores de dano.

Tabela 5. 16 Aplicação do PSO proposto na detecção de cenários de dano simples. Medições em $25 \%$ dos DOFs verticais.

\begin{tabular}{|c|c|c|c|c|c|}
\hline \multirow{2}{*}{$\begin{array}{c}\text { ID } \\
\text { Cenário }\end{array}$} & \multirow{2}{*}{ Elemento } & \multicolumn{4}{|c|}{ Extensão do dano $\beta$} \\
\hline & & Real & 8 modos & 10 modos & 12 modos \\
\hline \multirow{6}{*}{ M1 } & 4 & 0,200 & $0,091(55)$ & $0,172(14)$ & $0,225(13)$ \\
\hline & 5 & -- & 0,099 & -- & -- \\
\hline & 8 & -- & 0,112 & -- & $\ldots$ \\
\hline & 17 & -- & 0,065 & $\ldots$ & $\ldots$ \\
\hline & 20 & 0,200 & $0,195(3)$ & $0,194(3)$ & $0,211(5)$ \\
\hline & 28 & --- & --- & --- & 0,050 \\
\hline \multirow{5}{*}{ M2 } & 7 & -- & 0,060 & -- & -- \\
\hline & 12 & 0,150 & $0,056(63)$ & $0,174(16)$ & $0,136(9)$ \\
\hline & 13 & 0,150 & $0,242(61)$ & $0,143(5)$ & $0,144(4)$ \\
\hline & 14 & 0,150 & $0(100)$ & $0,155(3)$ & $0,146(3)$ \\
\hline & 15 & -- & 0,086 & --- & --- \\
\hline \multirow{6}{*}{ M3 } & 3 & 0,200 & $0,185(8)$ & $0,165(18)$ & $0,217(8)$ \\
\hline & 4 & -- & - - & 0,069 & - - \\
\hline & 14 & 0,250 & $0,154(40)$ & $0,243(3)$ & $0,250(0)$ \\
\hline & 20 & 0,400 & $0,199(50)$ & $0,405(1)$ & $0,376(6)$ \\
\hline & 22 & -- & 0,358 & $\ldots$ & -- \\
\hline & 23 & --- & 0,102 & --- & 0,044 \\
\hline \multirow{7}{*}{ M4 } & 4 & 0,270 & $0,203(25)$ & $0,274(1)$ & $0,292(8)$ \\
\hline & 8 & 0,230 & $0,193(16)$ & $0,230(0)$ & $0,213(7)$ \\
\hline & 12 & -- & 0,086 & -- & - . \\
\hline & 18 & - - - & 0,127 & -- & - \\
\hline & 27 & 0,180 & $--(100)$ & $0,184(2)$ & $0,184(2)$ \\
\hline & 28 & 0,180 & $0,227(21)$ & $0,183(2)$ & $0,161(11)$ \\
\hline & 31 & --- & 0,060 & -- & -- \\
\hline
\end{tabular}




\subsection{DISCUSSÃO}

Algumas observações são estabelecidas sob o desempenho da metodologia proposta quando se quer detectar dano utilizando medições incompletas e ruidosas:

- Há uma quantidade ótima de informação modal que permite detectar a maioria dos possíveis cenários de dano. Se uma quantidade menor é utilizada, a metodologia pode não realizar uma correta detecção do cenário de dano. Se uma quantidade maior é utilizada, pode se ter uma perda de recursos e tempo em levar uma prova dinâmica mais completa na procura de informação que não é necessária. Além disso, como mostrado nos resultados pode se chegar a uma diminuição no desempenho se comparado com aquele obtido com uma quantidade de informação menor.

- O custo computacional envolvido com a determinação da quantidade ótima de informação modal é alto devido ao grande número de combinações de quantidades de informação (número de formas modais e localização das medições sobre a estrutura) que devem ser testadas. $\mathrm{Na}$ medida em que o tamanho da estrutura cresce o custo computacional crescerá de uma forma não linear.

- Diferentes combinações de elementos danificados e extensões de dano serão detectadas com diferentes níveis de certeza para uma mesma quantidade de informação modal disponível. Em geral, cenários de dano simples são detectados de forma mais confiável que cenários de danos múltiplos. Entre todos os exemplos analisados, encontrou-se um único caso onde a metodologia não conseguiu determinar quais os verdadeiros elementos danificados.

- A presença de ruído nas medições prejudica o desempenho da metodologia proposta como observado nos resultados. Em condições livres de ruído a metodologia tem a possibilidade de encontrar o cenário de dano exato. Assim, é muito importante obter medições da forma mais limpa possível. 
- Os resultados apresentados neste exemplo são validos para a combinação do algoritmo PSO proposto mais a função objetivo utilizada. Portanto, se alguma dessas opções é modificada os resultados poderiam ser diferentes.

- A adaptação dos parâmetros proposta permitiu que a definição dos valores dos parâmetros do PSO fosse menos rígida, evitando que o usuário precisasse fazer tentativa e erro para sua definição. 


\section{EXEMPLO III: ALGORITMO DE EVOLUÇÃO DIFERENCIAL}

\subsection{INTRODUÇÃO}

A seguir é apresentada a aplicação de um algoritmo de evolução diferencial (DEA) adaptativo na detecção de diversos cenários de dano, simples e múltiplos, para uma estrutura do tipo treliça. As características do algoritmo proposto são apresentadas na seção 6.3, sendo que os operadores utilizados foram já descritos no capítulo 2. A metodologia de detecção de dano aqui utilizada segue a mesma sequencia de passos apresentada na Figura 4.1, sendo que neste caso a metaheurística utilizada será o DEA. Um total de 4 funções objetivo são propostas na seção 6.4 baseadas em diferentes parâmetros dinâmicos com o intuito de determinar a influência da função escolhida no desempenho da metodologia proposta. 


\subsection{ESTRUTURA ANALISADA E CENÁRIOS DE DANO}

A treliça analisada (Figura 6.1) tem como característica, para cada um dos seus elementos, módulo de elasticidade $E=200 \times 10^{9} \mathrm{~N} / \mathrm{m}^{2}$, densidade $\mathrm{p}=78 \times$ $10^{2} \mathrm{~kg} / \mathrm{m}^{3}$ e área da seção transversal $A=1 \times 10^{-3} \mathrm{~m}^{2}$. Considera-se também que as 8 primeiras frequências naturais e formas modais da estrutura atual foram medidas experimentalmente e que estes parâmetros contém os níveis de ruído considerados no Exemplo I .

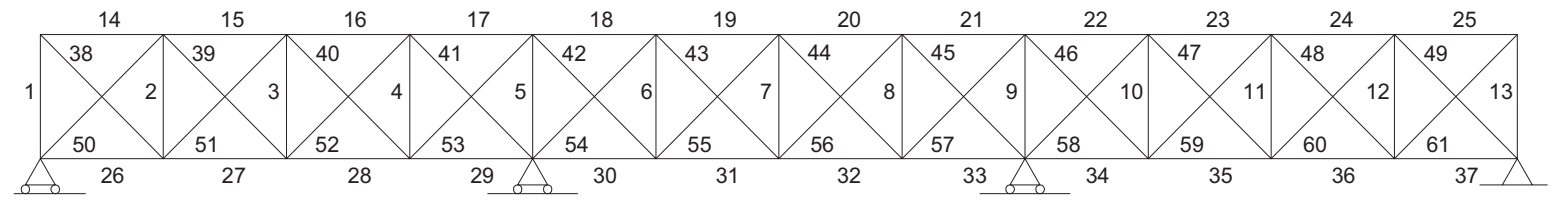

Figura 6. 1 Treliça com 61 elementos.

Os cenários de dano estudados são mostrados na Tabela 6.1, na qual é apresentado o identificador do elemento danificado, Elem, e a sua extensão do dano $\left(\beta_{i}\right)$. Os três primeiros cenários de dano (T1, T2 e T3) consideraram dano em um elemento vertical, horizontal e diagonal, respectivamente. Cenários de dano T4, T5 e T6 indicam 3, 5 e 6 elementos danificados, respectivamente. 0 desempenho da metodologia proposta será avaliado a partir da comparação do cenário de dano real com aquele obtido pelo DEA.

Tabela 6. 1 Cenários de dano simulados.

\begin{tabular}{|c|c|c|c|c|c|c|c|c|c|c|c|}
\hline \multicolumn{2}{|c|}{ T1 } & \multicolumn{2}{|c|}{$T 2$} & \multicolumn{2}{|c|}{ T3 } & \multicolumn{2}{|c|}{ T4 } & \multicolumn{2}{|c|}{ T5 } & \multicolumn{2}{|c|}{$\overline{T 6}$} \\
\hline Elem & $\boldsymbol{\beta}_{\mathrm{i}}$ & Elem & $\overline{\beta_{i}}$ & Elem & $\overline{\beta_{i}}$ & Elem & $\overline{\beta_{i}}$ & Elem & $\boldsymbol{\beta}_{\mathrm{i}}$ & Elem & $\overline{\beta_{i}}$ \\
\hline 3 & 0,15 & 24 & 0,20 & 52 & 0,40 & 3 & 0,15 & 4 & 0,25 & 3 & 0,17 \\
\hline & & & & & & 28 & 0,15 & 15 & 0,20 & 10 & 0,21 \\
\hline & & & & & & 52 & 0,15 & 18 & 0,23 & 14 & 0,14 \\
\hline & & & & & & & & 24 & 0,22 & 17 & 0,18 \\
\hline & & & & & & & & 34 & 0,26 & 37 & 0,20 \\
\hline & & & & & & & & & & 52 & 0,20 \\
\hline
\end{tabular}




\subsection{MODIFICAÇÕES DEA}

Valores para os parâmetros de taxa de cruzamento, CR, e de Fator de amplificação, AF, devem ser designados antes da execução do DEA. A seleção destes parâmetros é realizada normalmente a partir de tentativa e erro, o que envolve a utilização de várias combinações desses parâmetros até se obter um desempenho do EDA desejado. Para evitar este processo, valores diferentes são atribuídos para cada vetor na população e adaptados através da execução do DEA. Os valores iniciais são gerados aleatoriamente entre [0.7-0.9] para o AF e [0.4-0.6] para o CR utilizando uma distribuição uniforme. Estes intervalos de valores foram selecionados visando obter valores próximos daqueles recomendados de 0.8 e 0.5 para AF (Tvridk, 2006) e CR (Ali e Torn, 2004), respectivamente. Os valores de $\mathrm{CR}$ e $\mathrm{AF}$ para a iteração $t+1$ podem ser calculados como

$$
\begin{aligned}
& C R_{i}^{t+1}=C R_{i}^{t}+R_{i, 1} \cdot\left(C R_{\text {best }}^{t}-C R_{i}^{t}\right), \\
& A F_{i}^{t+1}=A F_{i}^{t}+R_{i, 2} \cdot\left(A F_{\text {best }}^{t}-C R_{i}^{t}\right),
\end{aligned}
$$

onde $C R_{b e s t}^{t}$ e $A F_{b e s t}^{t}$ são a taxa de cruzamento e o fator de amplificação para o melhor vetor solução na população, respectivamente. $R_{i, 1}$ e $R_{i, 2}$ são números aleatórios entre 0 e 1 gerados para o vetor solução $i$. Algumas técnicas para 0 controle dos parâmetros do DEA foram reportadas na literatura que estão baseadas em conceitos como auto-adaptação (Gong et al., 2008), adaptação dinâmica (Bi e Xiao, 2011), adaptação em função dos resultados obtidos no processo de busca (Qin et al., 2009), entre outros.

Por outro lado, a definição do tamanho da população proposta por Storn e Price (Storn e Price, 1997) está entre 5NV e 10 NV - NV é o número de variáveis do problema. Porém, neste trabalho não foi seguida essa recomendação e o tamanho da população foi definido como 200 depois de alguns testes. Como 
critérios de parada do algoritmo foram utilizados a quantidade máxima de 200 iterações ou quando o algoritmo atingir 50 iterações sem mudanças significantes no valor da aptidão para o melhor vetor solução atual. Para este exemplo, decidiu-se executar o algoritmo 30 vezes de tal forma a garantir que a metodologia proposta encontrasse o cenário de dano real de uma forma confiável. O algoritmo será executado para cada uma das funções objetivos mostradas na seguinte seção e seguidamente os resultados encontrados são comparados.

\subsection{FUNÇÕES OBJETIVOS}

Neste estudo, o problema de detecção de dano foi tratado como um problema de otimização utilizando as funções objetivos mostradas na Tabela 6.2. Onde MSEj é a energia de deformação modal para o modo $j$, $f_{i j}$ é o valor da posição $(i, j)$ da matriz de flexibilidade. Cabe salientar que para o problema de detecção de dano a maior parte do tempo de execução da metaheurística é gasto na avaliação da função objetivo para a população de soluções.

Os termos MSEj, RFVdj e MF podem ser calculados como:

$M S E_{J}=\{\Phi\}_{J}^{T}[K]\{\Phi\}_{J}$

$R F V_{d j}=\left(\left[K^{\text {dea }}\right]-\omega_{j}^{2, e x}[M]\right)\{\Phi\}_{j}^{e x}$,

onde $K^{\text {dea }}$ é a matriz de rigidez da estrutura calculada com os parâmetros definidos pelo DEA

Todas as funções são formuladas a partir da diferença entre os parâmetros dinâmicos calculados através de um vetor solução específico - possível cenário de dano - e aqueles obtidos experimentalmente. Portanto, cada cenário de dano possível no espaço de busca tem uma probabilidade específica de ser o correto. 
Tabela 6. 2 Lista de funções objetivo.

\section{Parâmetro Dinâmico} Função

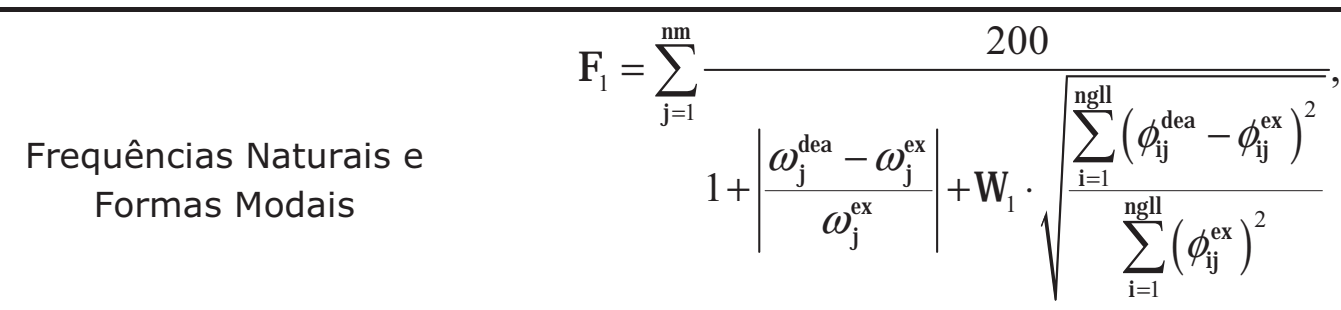

Frequências Naturais e

Energia de Deformação Modal

$$
F_{2}=\sum_{j=1}^{n m} \frac{200}{1+\left|\frac{\omega_{j}^{\text {dea }}-\omega_{j}^{e x}}{\omega_{j}^{e x}}\right|+W_{2} \cdot\left|\frac{M S E_{j}^{\text {dea }}-M S E_{j}^{e x}}{M S E_{j}^{\text {und }}}\right|},
$$

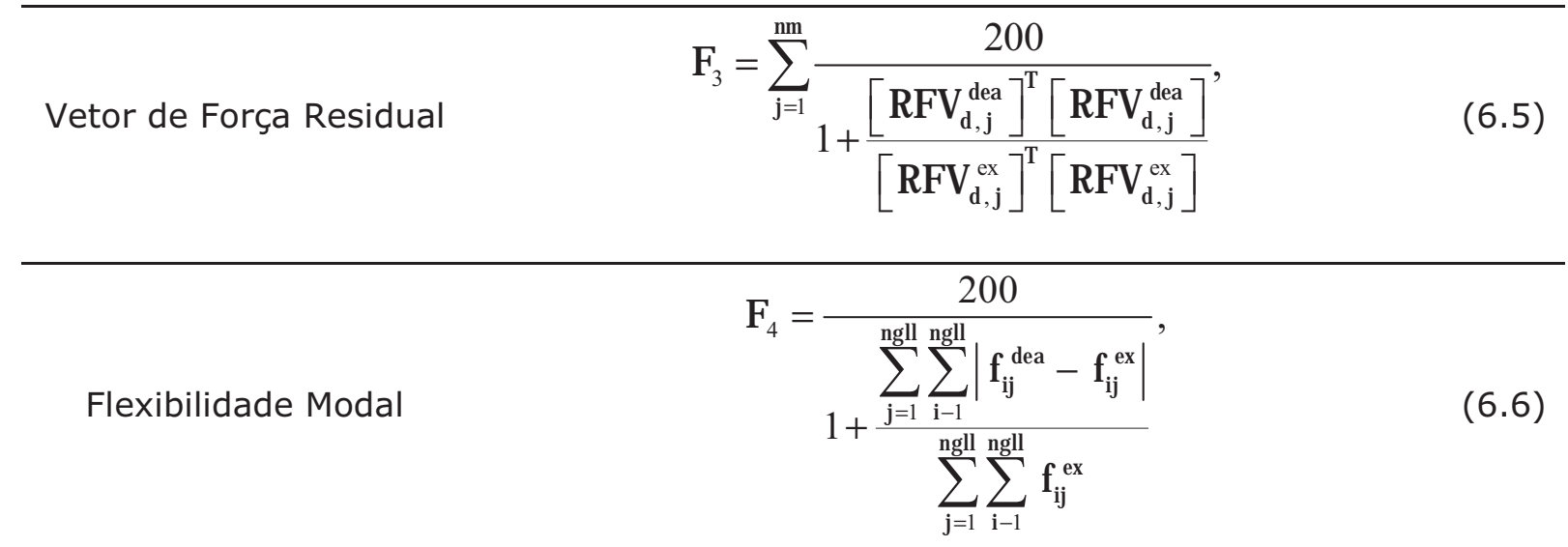
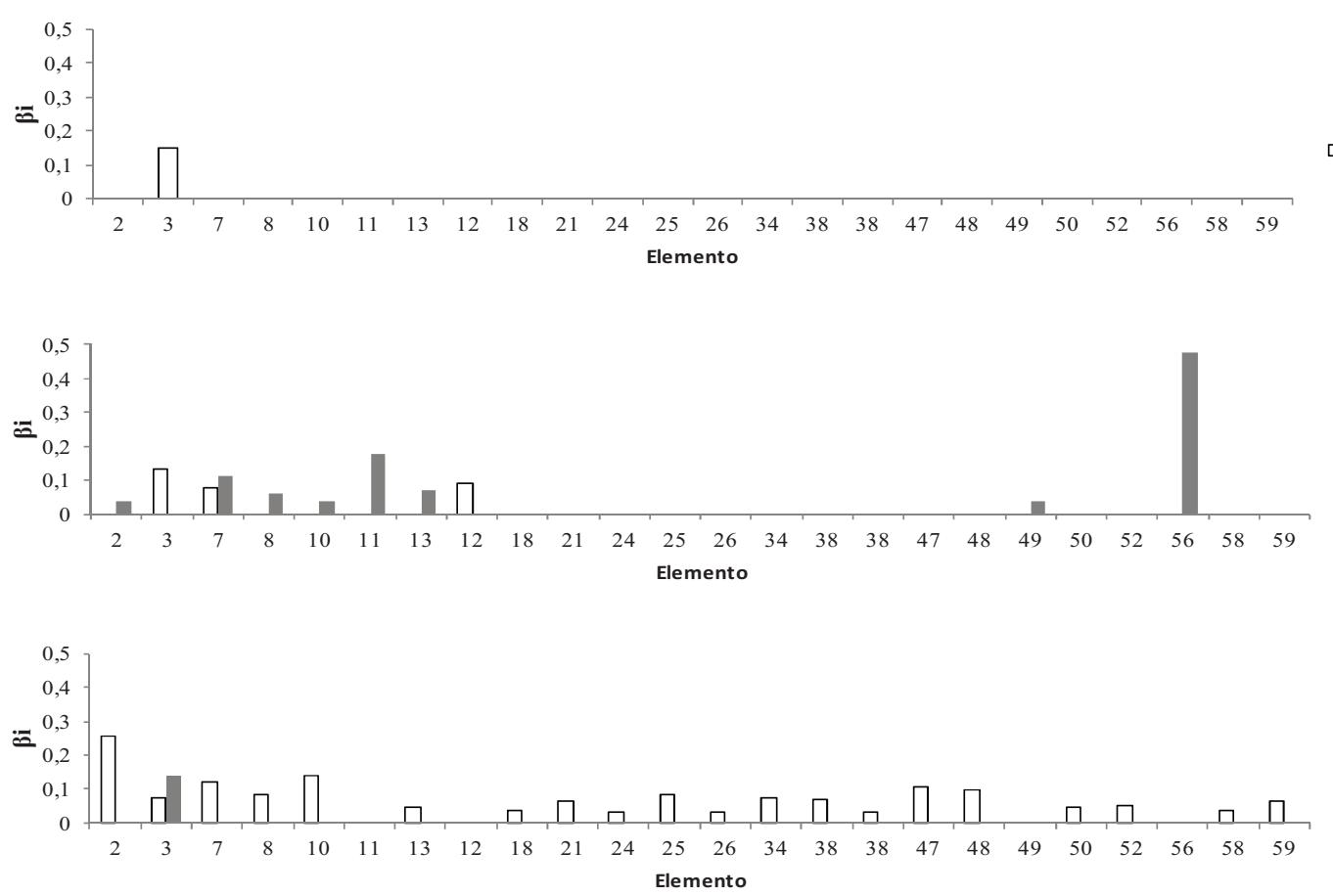

Figura 6. 2 Resultados da aplicação do DEA na detecção do cenário de dano T1. 

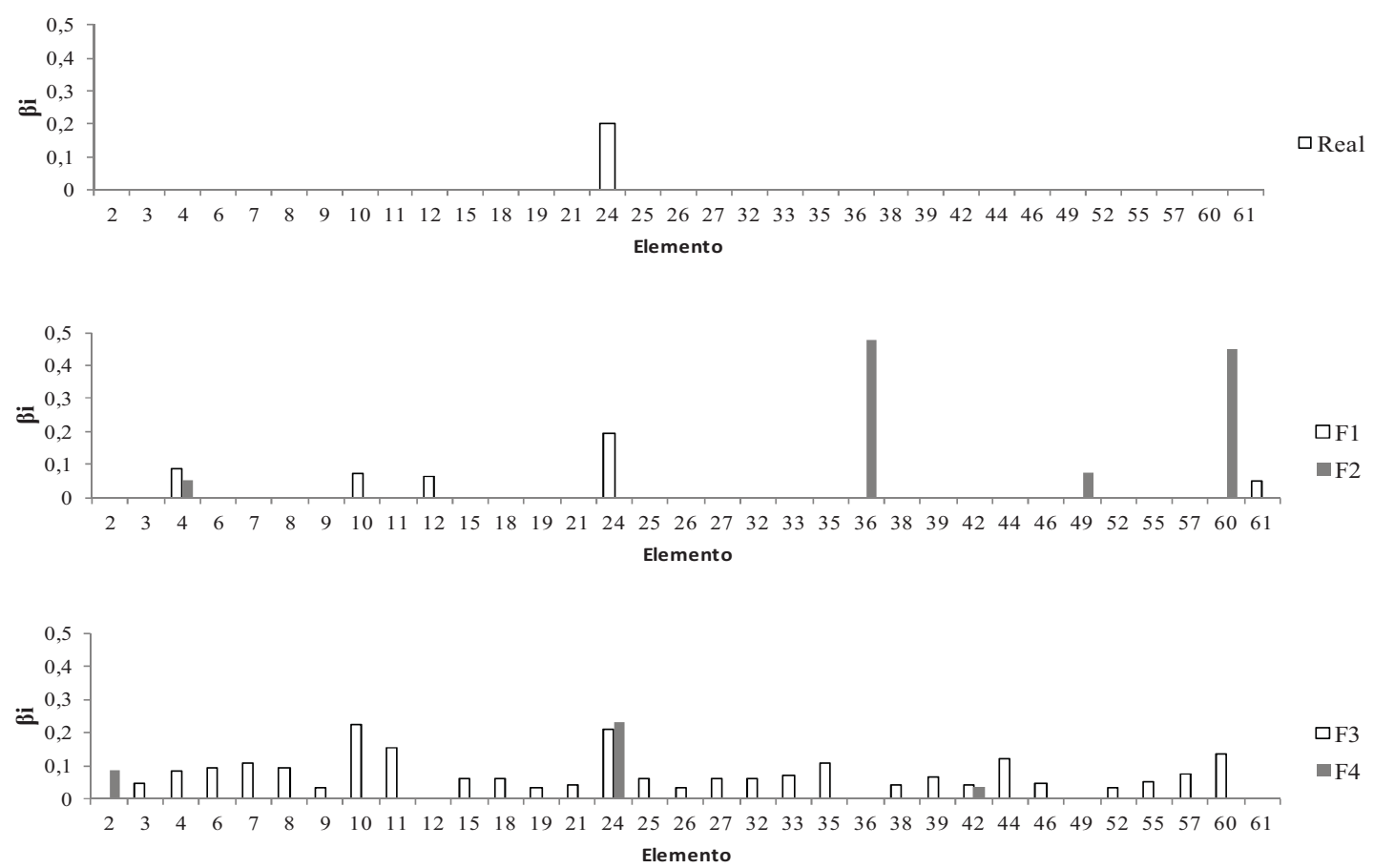

Figura 6. 3 Resultados da aplicação do DEA na detecção do cenário de dano T2.

\subsection{RESULTADOS}

Os resultados da aplicação da metodologia proposta para a detecção dos cenários de dano com um único elemento danificado (T1, T2 e T3) são mostrados nas Figuras 6.2 a 6.4. A metodologia detectou o elemento de dano real e uma extensão de dano próxima à real em todos os casos analisados. Os melhores resultados foram obtidos quando as funções $\mathrm{F} 1$ - frequências naturais e formas modais- e F4 -flexibilidade modal- eram utilizadas. A diferença entre a extensão do dano calculada para o elemento danificado e o valor real foi baixa - menor que 0,08 - e somente alguns elementos foram erroneamente identificados como danificados - falsos positivos. A utilização da função baseada no vetor de força residual (F3) resultou em um cenário de dano que apresentava muitas indicações de falsos positivos. Este tipo de erro aumenta a incerteza no desempenho da metodologia quando a função F3 é utilizada. Para todos os casos, o elemento danificado não foi encontrado quando a função objetivo baseada em frequências naturais e energia de deformação modal era utilizada. O algoritmo não foi capaz de diferençar entre soluções completamente diferentes - cenários de dano com 
diferentes elementos danificados e extensões do dano - e convergia a qualquer uma dessas soluções.
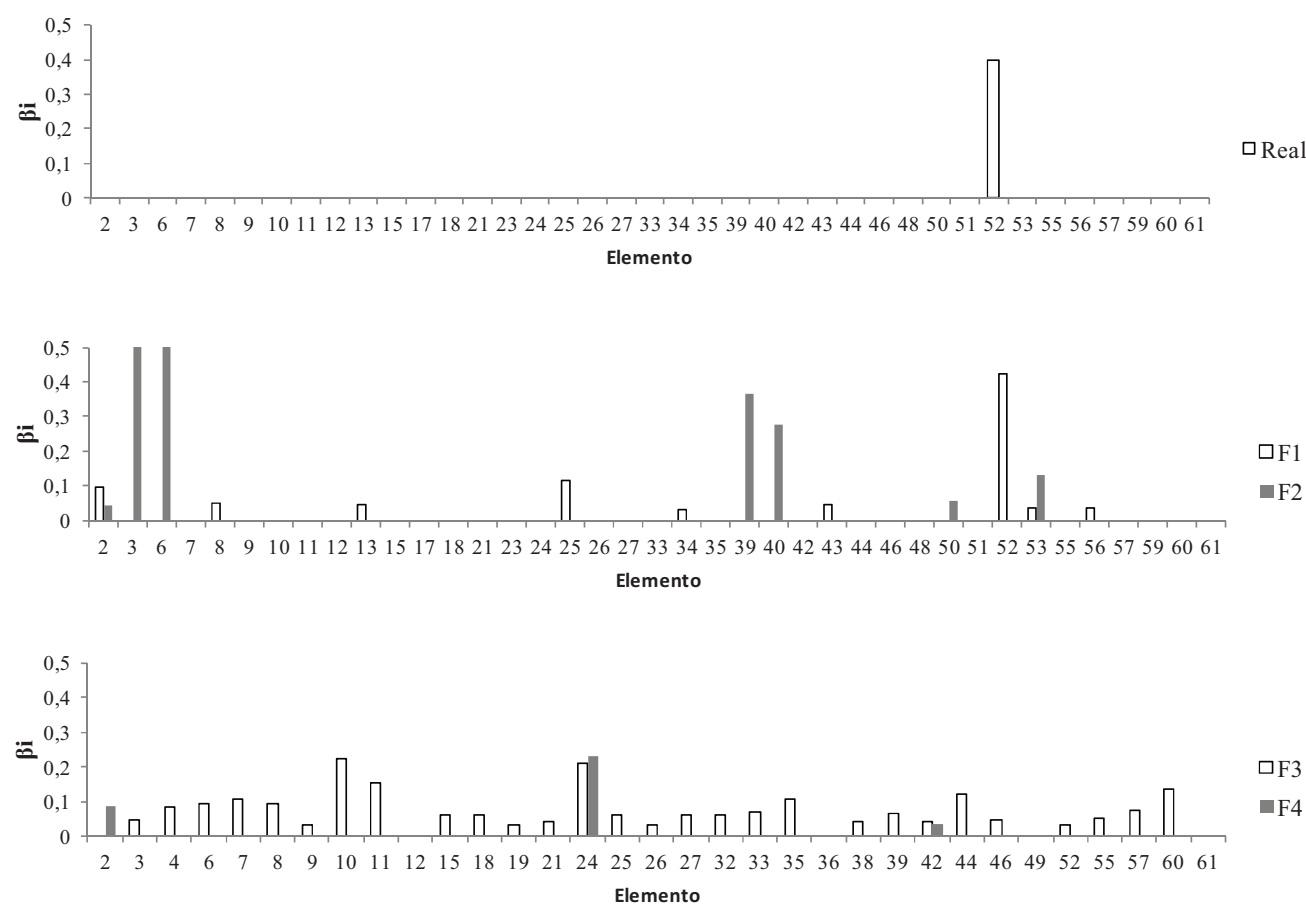

Figura 6. 4 Resultados da aplicação do DEA na deteç̧ão do cenário de dano T3.

Os resultados obtidos quando a estrutura apresentou mais que um elemento danificado, como nos cenários de dano T4, T5 e T6, são mostrados nas Figuras 6.5 a 6.7. O DEA proposto encontrou todos os cenários de dano reais para as funções objetivo F1, F3 e F4. A diferença no cálculo da extensão do dano é menor que 0.1 para cada elemento, para os três cenários. De forma semelhante aos resultados para os cenários de dano simples, a função objetivo F3 produziu a maior quantidade de falsos positivos. Para cenário T4, a função F1 identificou somente os elementos realmente danificados. Para cenário T5, a função F3 identificou erroneamente $40 \%$ dos elementos na estrutura, onde 7 deles apresentaram uma extensão de dano maior que 0.1. Portanto, é possível concluir que essa função objetivo é menos confiável que as outras funções. Para o cenário T6, os melhores resultados foram encontrados com a função F4, obtendo uma diferença média de 0,047 para a extensão do dano nos elementos danificados. Resultados para detecção de danos múltiplos utilizando a função F2 
não foram apresentados já que o desempenho da metodologia foi igual que quando aplicada para os cenários de dano simples.
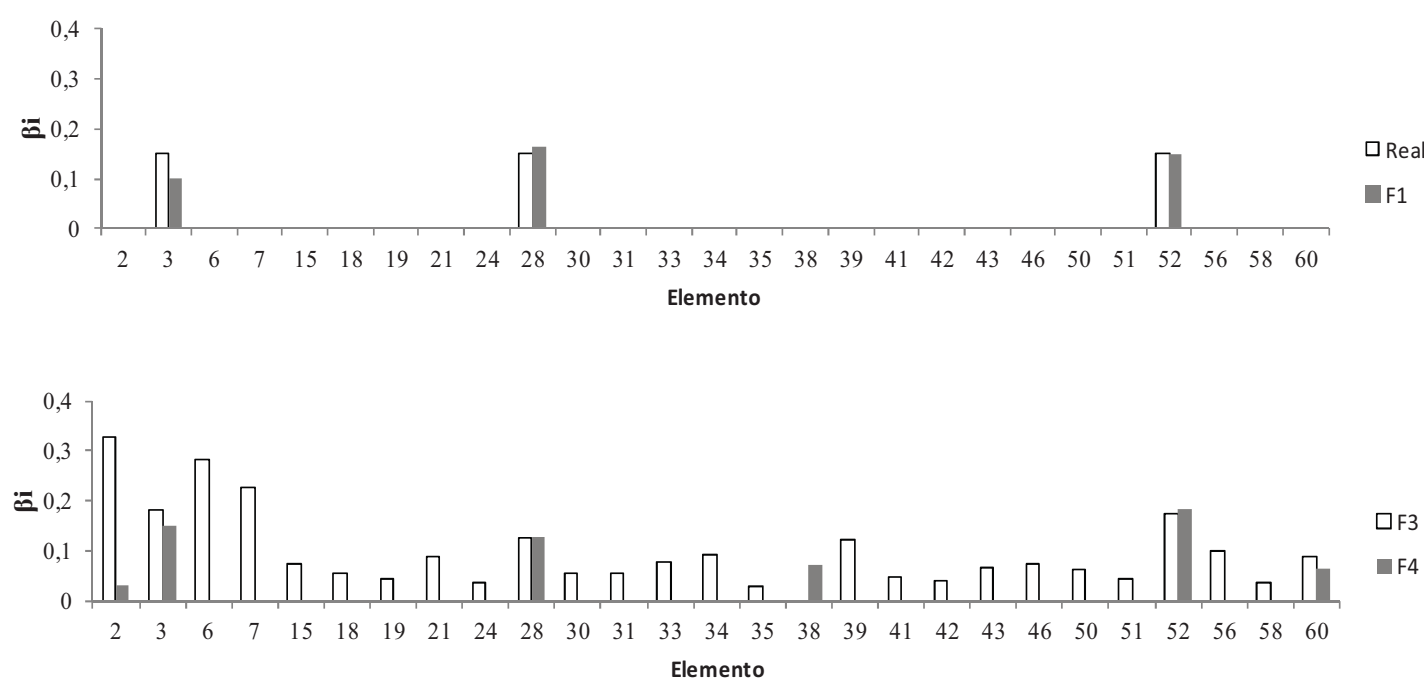

Figura 6. 5 Resultados da aplicação do DEA na detecção do cenário de dano T4.
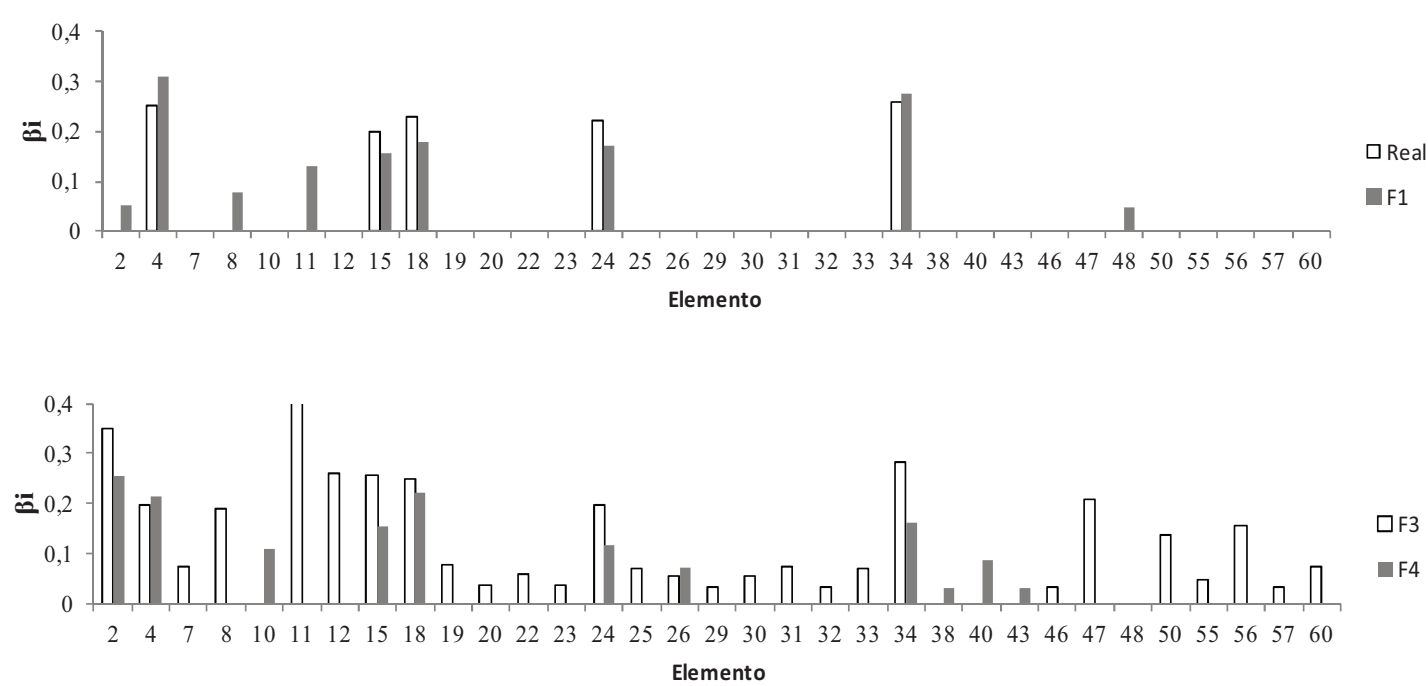

Figura 6. 6 Resultados da aplicação do DEA na detecção do cenário de dano T5. 

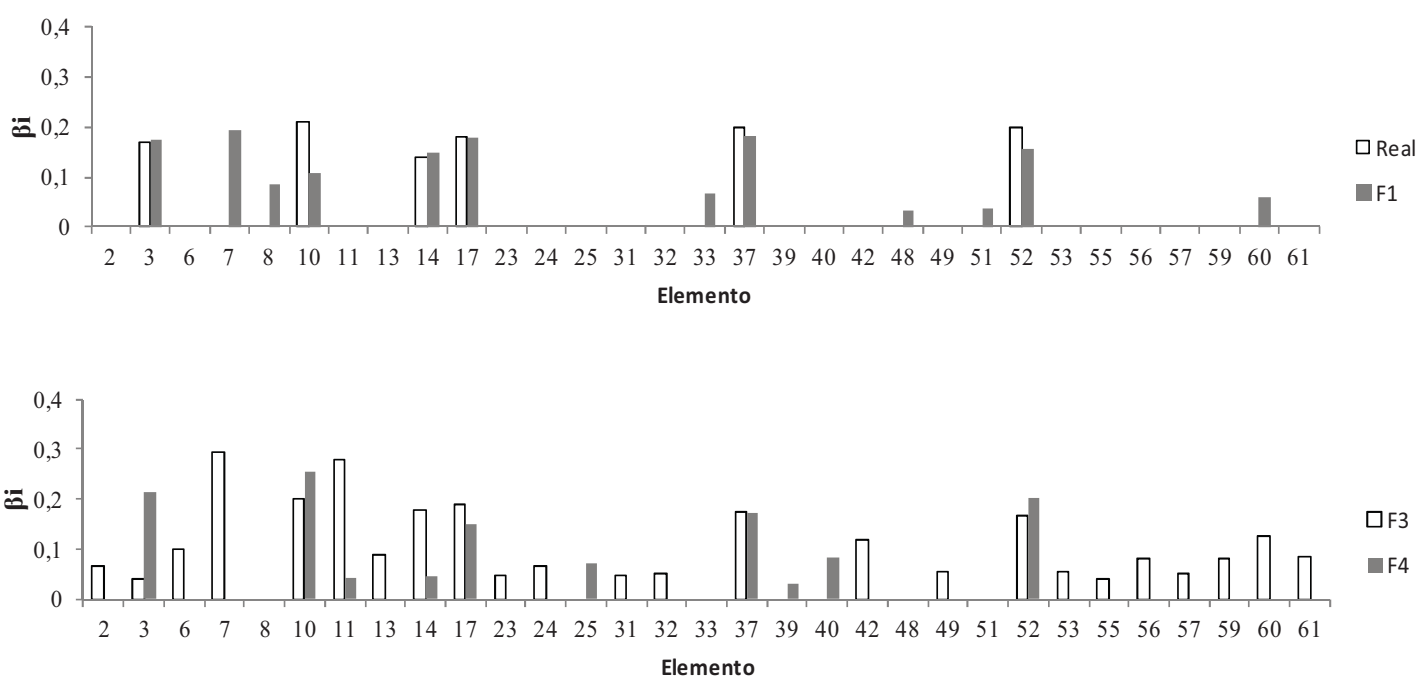

Figura 6. 7 Resultados da aplicação do DEA na detecção do cenário de dano T6.

Tabela 6.3 mostra o número de execuções nas quais o DEA proposto encontrou todos os verdadeiros elementos danificados para cada um dos cenários de dano analisados segundo a função objetivo utilizada. A partir dos resultados obtidos pode-se observar que a escolha de uma determinada função objetivo implica em um nível de desempenho específico para a metodologia proposta, sendo a função objetivo F4 -flexibilidade modal- a que apresentou os piores resultados. Embora o emprego da função objetivo baseada no vetor de força residual (F3) resulte em uma alta taxa de sucesso na determinação dos verdadeiros elementos danificados, sua utilização produz uma alta quantidade de indicações de falsos positivos. É importante notar que a metodologia proposta consegue determinar cenários de dano simples mais confiavelmente, independentemente da função objetivo utilizada, quando comparado à detecção de cenários de danos múltiplos.

Tabela 6. 3 Desempenho do DEA na identificação dos elementos realmente danificados.

\begin{tabular}{cccc}
\hline $\begin{array}{c}\text { Cenário } \\
\text { de } \\
\text { Dano }\end{array}$ & $\begin{array}{c}\text { Número de Execuções } \\
\text { com êxito }\end{array}$ \\
\cline { 2 - 4 } T1 & F3 & F4 \\
\hline T2 & 30 & 23 & 26 \\
\hline T3 & 30 & 29 & 25 \\
\hline T4 & 15 & 30 & 18 \\
\hline T5 & 19 & 15 & 8 \\
\hline T6 & 7 & 18 & 8 \\
\hline
\end{tabular}


Finalmente, a metodologia proposta foi também utilizada para detectar dano na treliça da Figura 6.1 considerando que as propriedades dinâmicas experimentais estivessem livres de ruído. Sob esta condição observou-se um excelente comportamento da metodologia: todos os cenários de dano analisados foram identificados em mais de $80 \%$ das execuções. Este resultado mostra a importância de se obter boas medições para a determinação do cenário de dano correto.

\subsection{DISCUSSÃO}

A seguir são apresentadas algumas observações que são obtidas desde os resultados encontrados para o presente exemplo:

- Neste exemplo foi observado que o DEA consegue determinar diferentes cenários de dano, elementos danificados e extensões de dano, com diferentes níveis de certeza dependendo da função objetivo utilizada. Quatro funções foram utilizadas, sendo os melhores resultados encontrados com a função $F 1$, a qual esta baseada em frequências naturais e formas modais.

- A principal desvantagem do uso da função objetivo F1 é que requer da definição de um fator de peso para ponderar a contribuição de cada um dos termos que a formam. Este valor é obtido seguindo um procedimento de tentativa e erro.

- Funções que utilizam o vetor de força residual e energias de deformação modal apresentam a desvantagem de requerer formas modais completas, as quais podem ser de difícil obtenção experimentalmente. Esta ultima função não produziu identificações corretas para a maioria dos cenários analisados.

- A partir dos resultados pode ser observado que a metodologia proposta consegue detectar mais facilmente cenários de dano simples quando comparados com cenários de danos múltiplos. 
- Apresentou-se uma forma fácil de definir os parâmetros do DEA de tal forma que foi evitado sua definição desde um processo de tentativa e erro.

- Os resultados aqui encontrados são validos para a combinação da metodologia de otimização utilizada, a tipologia estrutural analisada e as condições experimentais consideradas. 


\section{EXEMPLO IV: ALGORITMO GENÉTICO MULTI-CROMOSSOMO}

\subsection{INTRODUÇÃO}

A detecção de dano utilizando GAs tem sido amplamente estudada na literatura, sendo um dos trabalhos mais citados, e um dos primeiros, aquele de Mares e Surace em 1996. Nesse trabalho utilizou-se o GA binário clássico para a detecção de dano em uma treliça com 31 elementos e uma viga com 10 elementos. A utilização deste tipo de algoritmo pode ser inadequada quando a estrutura analisada é de maior porte, razão pela qual requere-se que sejam utilizados algoritmos mais sofisticados. Como por exemplo, o algoritmo com representação redundante utilizado em Raich e liszkai (2007) que leva em conta a natureza não estruturada do problema de detecção de dano. Nesta aplicação é proposta uma técnica de representação de soluções que utiliza múltiplos cromossomos para permitir a evolução tanto do número de variáveis de 
otimização como dos parâmetros do algoritmo (Villalba e Laier, 2012c). A escolha da representação da solução chega a ser um fator chave no desempenho de uma metaheurística quando aplicada a um problema específico. Talbi (2009) define que são 3 as características que deve ter uma representação determinada: toda solução possível deve poder ser representada, uma rota de busca deve existir entre qualquer dois soluções no espaço de busca e a representação deve ser facilmente tratada pelos algoritmos de busca. Uma descrição da representação proposta para o caso do problema de detecção de dano é dada na Seção 7.3.

Neste exemplo segue-se a mesma linha de trabalho apresentada na Figura 4.1, sendo que a meta-heurística utilizada é o GA multi-cromossomo, com as características apresentadas na seção 7.3 más conservando a mesma função objetivo utilizada no Exemplo II.

\subsection{ESTRUTURA ANALISADA E CENÁRIOS DE DANO}

Diversas estruturas do tipo treliça serão estudadas, como mostrado na Figura 7.1, que apresentam diferentes quantidades de elementos e configurações. O material para a construção das treliças analisadas apresenta módulo de elasticidade $\mathrm{E}=200 \times 10^{9} \mathrm{~N} / \mathrm{m}^{2}$ e densidade $\mathrm{p}=78 \times 10^{2} \mathrm{~kg} / \mathrm{m}^{3}$. Todos os elementos em cada uma das treliças apresentam a mesma seção transversal, cuja área vem dada por $A=1 \times 10^{-3} \mathrm{~m}^{2}$. Foi considerado que as primeiras 6 frequências naturais e formas modais completas estavam disponíveis com níveis de ruído de 1 e $3 \%$, respectivamente.

A verificação do desempenho da metodologia proposta será realizada a partir da sua aplicação na identificação de cinco cenários de dano para cada uma das estruturas apresentadas na Figura 7.1. Estes cenários podem ser classificados em simples ou múltiplos dependendo do número de elementos danificados, como mostrado nas Tabelas 7.1 e 7.2. 
T1

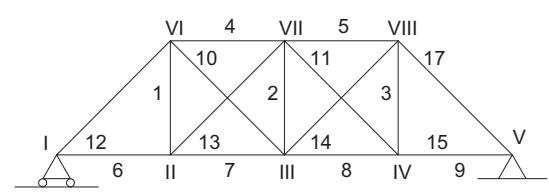

T2

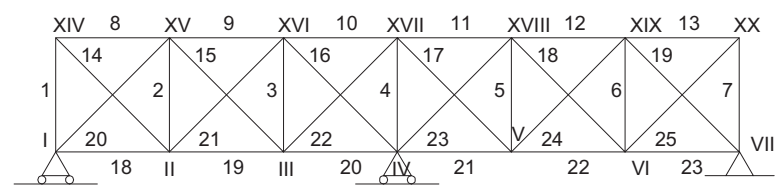

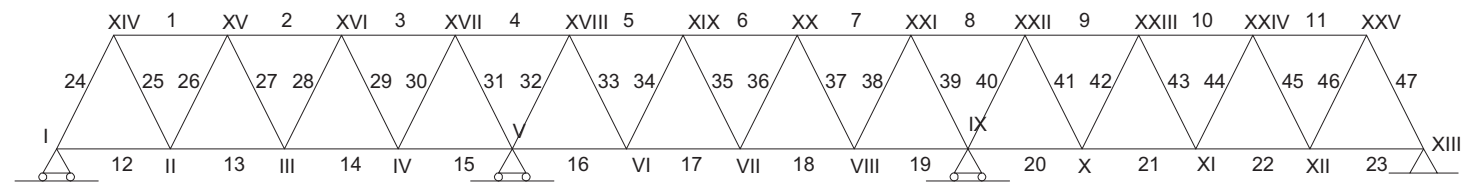

T4

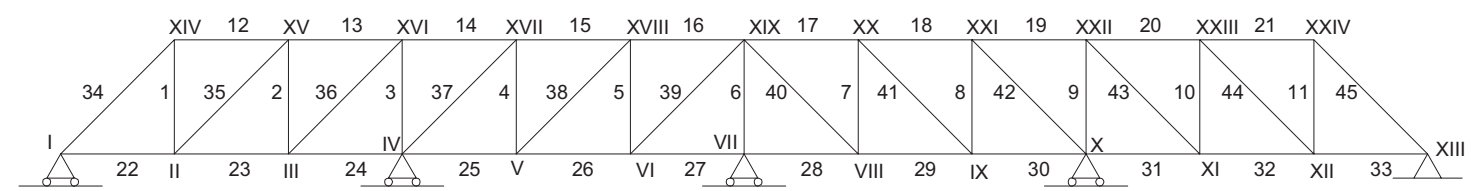

T5

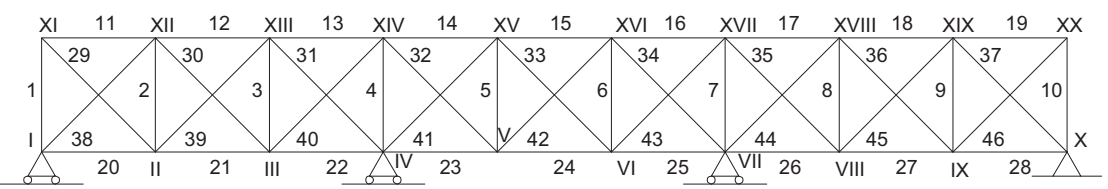

T6

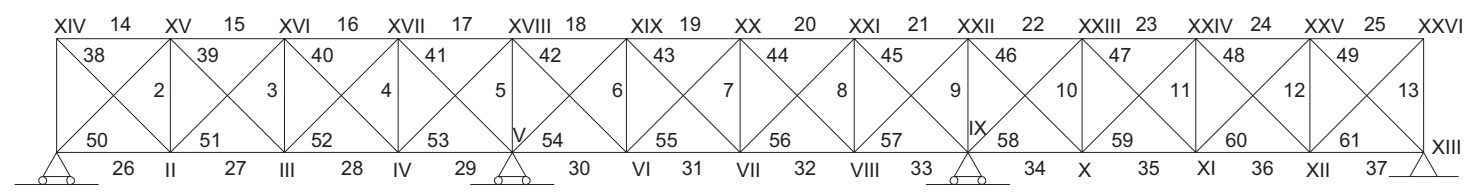

Figura 7. 1 Treliças analisadas.

Tabela 7. 1 Cenários de dano simples.

\begin{tabular}{|c|c|c|c|c|c|c|c|}
\hline Estrutura. & ID & $\begin{array}{c}\text { Elemento } \\
\text { Danificado }\end{array}$ & $\begin{array}{c}\text { Dano } \\
\beta\end{array}$ & Estrutura. & ID & $\begin{array}{c}\text { Elemento } \\
\text { Danificado }\end{array}$ & $\begin{array}{c}\text { Dano } \\
\beta\end{array}$ \\
\hline \multirow{3}{*}{ T1 } & $\mathrm{S} 1$ & 1 & 0,310 & \multirow{3}{*}{ T4 } & $\mathrm{S} 10$ & 5 & 0,480 \\
\hline & $\mathrm{S2}$ & 7 & 0,180 & & $\mathrm{~S} 11$ & 26 & 0,180 \\
\hline & S3 & 13 & 0,330 & & $\mathrm{~S} 12$ & 38 & 0,410 \\
\hline \multirow{3}{*}{$\mathrm{T} 2$} & S4 & 3 & 0,480 & \multirow{3}{*}{ T5 } & $\mathrm{S} 13$ & 8 & 0,220 \\
\hline & S5 & 9 & 0,350 & & S14 & 17 & 0,450 \\
\hline & S6 & 27 & 0,240 & & S15 & 35 & 0,280 \\
\hline \multirow{3}{*}{ T3 } & S7 & 1 & 0,290 & \multirow{3}{*}{ T6 } & S16 & 3 & 0,330 \\
\hline & S8 & 29 & 0,250 & & S17 & 31 & 0,300 \\
\hline & S9 & 30 & 0,450 & & $\mathrm{~S} 18$ & 44 & 0,190 \\
\hline
\end{tabular}


Tabela 7. 2 Cenários de danos múltiplos.

\begin{tabular}{|c|c|c|c|c|c|c|c|}
\hline Estrutura. & ID & $\begin{array}{l}\text { Elemento } \\
\text { Danificado }\end{array}$ & $\begin{array}{c}\text { Dano } \\
\beta\end{array}$ & Estrutura. & ID & $\begin{array}{c}\text { Elemento } \\
\text { Danificado }\end{array}$ & $\begin{array}{c}\text { Dano } \\
\beta\end{array}$ \\
\hline \multirow{6}{*}{ T1 } & & $\overline{1}$ & & \multirow{6}{*}{ T4 } & & 5 & 0,160 \\
\hline & M1 & 7 & 0,310 & & M7 & 26 & 0,200 \\
\hline & & 13 & & & & 38 & 0,180 \\
\hline & & 2 & & & & 7 & 0,340 \\
\hline & M2 & 6 & 0,180 & & M8 & 35 & 0,200 \\
\hline & & 11 & & & & 36 & 0,250 \\
\hline \multirow{6}{*}{ T2 } & & 3 & 0,330 & \multirow{6}{*}{ T5 } & & 8 & 0,400 \\
\hline & M3 & 9 & 0,230 & & M9 & 17 & 0,350 \\
\hline & & 27 & 0,260 & & & 35 & 0,450 \\
\hline & & 2 & 0,420 & & & 3 & 0,380 \\
\hline & M4 & 22 & 0,300 & & M10 & 5 & 0,280 \\
\hline & & 30 & 0,350 & & & 24 & 0,300 \\
\hline \multirow{6}{*}{ T3 } & & 1 & 0,270 & \multirow{6}{*}{ T6 } & & 3 & 0,150 \\
\hline & M5 & 29 & 0,230 & & M11 & 31 & 0,180 \\
\hline & & 30 & 0,260 & & & 44 & 0,150 \\
\hline & & 8 & 0,150 & & & 8 & 0,200 \\
\hline & M6 & 9 & 0,150 & & M12 & 39 & 0,240 \\
\hline & & 33 & 0,150 & & & 42 & 0,270 \\
\hline
\end{tabular}

\subsection{GA MULTI-CROMOSSOMO}

Uma das principais dificuldades envolvidas na resolução do problema de detecção de dano é que o número e a posição dos verdadeiros elementos danificados são desconhecidos no começo do processo de otimização. Como mostrado nos exemplos I, II e III, as representações utilizadas implicam na necessidade de se determinar o valor do fator de redução da rigidez para cada elemento na estrutura analisada. Portanto, neste trabalho utiliza-se uma representação com múltiplos cromossomos, que permite que o número de elementos danificados mude ao longo do processo evolutivo.

Um individuo com 3 cromossomos foi proposto seguindo as ideias apresentadas por Kouchmeshky et al. (2008) e Hinterding (1997). O primeiro cromossomo é de tipo real e representa a extensão do dano, que pode estar entre 0 e 1 . O segundo cromossomo é de tipo binário e é utilizado para localizar o dano com um valor de 1 indicando dano no elemento. Nos dois cromossomos anteriores cada gene corresponde a um elemento na estrutura; assim, uma estrutura com $L$ elementos apresenta $L$ genes. O terceiro cromossomo é do tipo real e é empregado para auto-adaptar os parâmetros genéticos. Desta forma, os 
parâmetros genéticos são considerados variáveis de otimização e seus valores mudaram com o passar das gerações. Cada tipo de variável utilizada, binária ou real, será evoluída utilizando operadores específicos para elas, como será mostrado mais adiante.

A Figura 7.2 mostra um exemplo de um indivíduo que representa uma estrutura com 6 elementos. Nesse cenário de dano os elementos 1 , 3 e 4 apresentam valores de dano de 0,25, 0,18 e 0,35, respectivamente. Os valores de dano nos elementos 2, 5 e 6 são desconsiderados devido ao fato dos valores dos genes correspondentes no cromossomo binário serem nulos. O terceiro cromossomo codifica, da esquerda para a direita, as taxas de cruzamento binária e real e as taxas de mutação binária e real.

Cromossomo Real - Quantificação

\begin{tabular}{|c|c|c|c|c|c|}
\hline 0,25 & 0,07 & 0,18 & 0,35 & 0,20 & 0,19 \\
\hline \multicolumn{6}{|c|}{ Cromossomo Binário - Localização } \\
\hline 1 & 0 & 1 & 1 & 0 & 0 \\
\hline & Cromossomo Real - Parâmetros Genéticos \\
\cline { 2 - 5 } & 0,85 & 0,90 & 0,01 & 0,04 \\
\hline
\end{tabular}

Figura 7. 2 Cromossomo típico para representar um indivíduo.

Como pode ser inferido da Figura 7.2, dois diferentes indivíduos na população poderiam representar cenários de dano que não apresentem a mesma quantidade de elementos danificados nem os mesmos elementos danificados. Porém, na medida em que o número de gerações incrementa é esperado que a população convirja para a combinação correta de elementos danificados e extensões de dano.

Em relação à geração da população inicial, define-se um valor aleatório, 0 ou 1, para o cromossomo binário e um valor aleatório entre 0 e 0,5 para o cromossomo real que representa a extensão do dano. Os valores para o cromossomo que codifica os parâmetros genéticos foram determinados aleatoriamente a partir dos intervalos apresentados na Tabela 7.3, que foram obtidos em função da experiência do autor e de alguns testes preliminares. 
Tabela 7. 3 Faixa de valores para os parâmetros genéticos.

\begin{tabular}{ccccc}
\hline \multirow{2}{*}{ Valores } & \multicolumn{2}{c}{ Taxa Cruzamento } & \multicolumn{2}{c}{ Taxa de Mutação } \\
\cline { 2 - 5 } & Binária & Real & Binária & Real \\
\hline Inferior & 0,70 & 0,80 & 0,005 & 0,03 \\
\hline Superior & 0,90 & 0,95 & 0,02 & 0,06 \\
\hline
\end{tabular}

A Tabela 7.4 mostra os operadores genéticos aplicados a cada tipo de cromossomo, sendo sua forma de aplicação disponível em Herrera et al. (1998) e Haupt e Haupt (2004). Na operação de cruzamento foram utilizadas as taxas de cruzamento pertencentes ao pai com a maior aptidão. As taxas de mutação que são utilizadas para mutar um gene específico corresponde aos valores dos indivíduos obtidos depois do cruzamento. O algoritmo podia realizar um total de 400 gerações.

Tabela 7. 4 Operadores genéticos.

\begin{tabular}{|c|c|c|c|}
\hline $\begin{array}{c}\text { Tipo de } \\
\text { Cromossomo }\end{array}$ & Seleção & Cruzamento & Mutação \\
\hline Real & \multirow{2}{*}{ Torneio, $n=3$} & $B I X-a, a=0,5$ & Creep \\
\hline Binário & & Dois pontos & Jump \\
\hline
\end{tabular}

Um parâmetro genético, o tamanho da população, permanece indefinido. Geralmente, o valor para este parâmetro é obtido depois de algumas tentativas que consistem em variar o tamanho da população até se obter um desempenho desejado da metodologia proposta. Moslem e Napasfour (2002) apresentam uma das poucas heurísticas que tem sido propostas para calcular o tamanho da população em função da estrutura analisada. Nesse trabalho, o tamanho da população foi definido como sendo diretamente proporcional ao número de elementos na estrutura. Baseado em nossa experiência, a população será formada por 200 indivíduos para todos os exemplos analisados. Este valor é adequado para o tipo e o tamanho das estruturas analisadas; porém poderia não ser suficiente para garantir um bom desempenho da metodologia quando treliças de maior tamanho ou outras estruturas do mesmo porte sejam analisadas.

Espera-se que a utilização da configuração do GA multi-cromossomo, como mostrado nos parágrafos anteriores, implique em uma melhor convergência para cenários de dano que apresentem uns poucos elementos danificados quando comparado à representação tradicional. A seguir serão 
apresentados os resultados da aplicação da metodologia proposta na avaliação dos cenários de dano apresentados nas Tabelas 7.1 e 7.2.

\subsection{RESULTADOS}

Tabelas 7.5 a 7.10 mostram os resultados encontrados pela metodologia proposta para os diferentes cenários de dano utilizados. Nessas tabelas, apenas os elementos que foram identificados no cromossomo binário e que tem uma extensão de dano maior que 0,03 são mostrados. Os cenários de dano reais são apresentados e os elementos erroneamente identificados como danificados são sublinhados para um melhor entendimento dos resultados.

Tabela 7.5 mostra os resultados para os cenários de dano simulados na estrutura T1, sendo observado que todos eles foram corretamente encontrados. Somente um elemento erroneamente identificado como danificado (falso positivo) foi reportado para o cenário de dano S2; porém, apresentava um baixo valor para a extensão do dano. O máximo erro no cálculo da extensão do dano foi de 0,009 e um mínimo erro de 0,002 foi encontrado para cenário S1. Um tamanho menor de população poderia ter sido usado para esta estrutura, mas o papel da variação do tamanho da população não foi analisado neste exemplo.

Tabela 7. 5 Resultados da aplicação do GA multi-cromossomo para a estrutura T1.

\begin{tabular}{|c|c|c|c|c|c|c|c|c|c|c|}
\hline & \multicolumn{10}{|c|}{ ID Cenário } \\
\hline & \multicolumn{2}{|c|}{ S1 } & \multicolumn{2}{|c|}{ S2 } & \multicolumn{2}{|c|}{ S3 } & \multicolumn{2}{|c|}{ M1 } & \multicolumn{2}{|c|}{ M2 } \\
\hline & Elem. & $\beta \mathbf{j}$ & Elem. & $\beta \mathbf{j}$ & Elem. & $\beta \mathbf{j}$ & Elem. & $\beta \mathbf{j}$ & Elem. & $\beta \mathbf{j}$ \\
\hline \multirow{3}{*}{ Real } & 1 & 0,310 & 7 & 0,180 & 13 & 0,330 & 1 & 0,470 & 2 & 0,160 \\
\hline & & & & & & & 7 & 0,250 & 6 & 0,200 \\
\hline & & & & & & & 13 & 0,300 & 11 & 0,200 \\
\hline \multirow{3}{*}{$\mathrm{GA}$} & 1 & 0,308 & 7 & 0,174 & 13 & 0,333 & 1 & 0,472 & 2 & 0,168 \\
\hline & & & $\underline{8}$ & 0,039 & & & 7 & 0,253 & 6 & 0,200 \\
\hline & & & & & & & 13 & 0,309 & 11 & 0,203 \\
\hline
\end{tabular}

O desempenho da metodologia proposta na detecção dos cenários de dano na estrutura T2 é mostrado na Tabela 7.6. Quase todos os cenários de dano resultaram em ao menos uma indicação de falso positivo, mas com dano menor que 0,07 . Os erros no cálculo da extensão do dano para os elementos 
verdadeiramente danificados foram menores que 0,012. Para esta estrutura, os mesmos cenários foram utilizados para detectar dano sem a presença de ruído. Nesses casos, o cenário de dano exato foi encontrado em todas as simulações, o que indica que resultados mais confiáveis podem ser obtidos se o nível de ruído nas medições diminui.

Tabela 7. 6 Resultados da aplicação do GA multi-cromossomo para a estrutura T2.

\begin{tabular}{|c|c|c|c|c|c|c|c|c|c|c|}
\hline & \multicolumn{10}{|c|}{ ID Cenário } \\
\hline & \multicolumn{2}{|c|}{ S4 } & \multicolumn{2}{|c|}{ S5 } & \multicolumn{2}{|c|}{56} & \multicolumn{2}{|c|}{ M3 } & \multicolumn{2}{|c|}{ M4 } \\
\hline & Elem. & $\beta \mathbf{j}$ & Elem. & $\beta \mathbf{j}$ & Elem. & $\beta \mathbf{j}$ & Elem. & $\beta \mathbf{j}$ & Elem. & $\beta \mathbf{j}$ \\
\hline \multirow{3}{*}{ Real } & 3 & 0,480 & 9 & 0,350 & 27 & 0,240 & 3 & 0,330 & 2 & 0,420 \\
\hline & & & & & & & 9 & 0,230 & 22 & 0,300 \\
\hline & & & & & & & 27 & 0,260 & 30 & 0,350 \\
\hline \multirow{4}{*}{ GA } & 3 & 0,475 & 9 & 0,346 & 27 & 0,239 & 3 & 0,331 & 2 & 0,386 \\
\hline & $\underline{18}$ & 0,068 & $\underline{18}$ & 0,041 & & & $\underline{6}$ & 0,046 & $\underline{18}$ & 0,075 \\
\hline & & & & & & & 9 & 0,229 & 22 & 0,312 \\
\hline & & & & & & & 27 & 0,258 & 30 & 0,344 \\
\hline
\end{tabular}

Tabela 7.7 mostra os resultados para diferentes cenários de dano que foram aplicados na estrutura T3. O erro no cálculo da extensão do dano foi menor que 0,015 em todos os casos. Mais de uma indicação de falso positivo foi realizada nos cenários de dano S7, M5 e M6. Estes elementos apresentaram valores de dano baixos; porém, o elemento 26 no cenário M6 apresentou um alto valor de dano. Este tipo de resultado deve ser evitado já que induz no analista estrutural uma falsa ideia de dano na estrutura e isto pode levar à realização de reparações ou reforços desnecessários. Apesar do erro anterior, o resultado da metodologia pode ser considerado satisfatório.

Tabela 7. 7 Resultados da aplicação do GA multi-cromossomo para a estrutura T3.

\begin{tabular}{|c|c|c|c|c|c|c|c|c|c|c|}
\hline & \multicolumn{10}{|c|}{ ID Cenário } \\
\hline & \multicolumn{2}{|c|}{ S7 } & \multicolumn{2}{|c|}{58} & \multicolumn{2}{|c|}{ S9 } & \multicolumn{2}{|c|}{ M5 } & \multicolumn{2}{|c|}{ M6 } \\
\hline & Elem. & $\beta \mathbf{j}$ & Elem. & $\beta \mathbf{j}$ & Elem. & $\beta \mathbf{j}$ & Elem. & $\beta \mathbf{j}$ & Elem. & $\beta \mathbf{j}$ \\
\hline \multirow{3}{*}{ Real } & 1 & 0,290 & 29 & 0,250 & 30 & 0,450 & 1 & 0,270 & 8 & 0,150 \\
\hline & & & & & & & 29 & 0,230 & 9 & 0,150 \\
\hline & & & & & & & 30 & 0,260 & 33 & 0,150 \\
\hline \multirow{5}{*}{ GA } & 1 & 0,290 & $\underline{26}$ & 0,039 & 30 & 0,448 & 1 & 0,274 & 8 & 0,160 \\
\hline & $\underline{9}$ & 0,036 & 29 & 0,262 & & & $\underline{12}$ & 0,042 & 9 & 0,146 \\
\hline & $\underline{30}$ & 0,042 & & & & & 29 & 0,269 & 10 & 0,034 \\
\hline & $\underline{37}$ & 0,061 & & & & & 30 & 0,443 & $\underline{26}$ & 0,229 \\
\hline & $\underline{42}$ & 0,061 & & & & & $\underline{34}$ & 0,032 & 33 & 0,181 \\
\hline
\end{tabular}


Os resultados para a estrutura T4 são mostrados na Tabela 7.8. Todos os cenários de dano apresentaram algumas indicações de falsos positivos. A metodologia não teve um excelente desempenho no caso de cenários de danos múltiplos, já que o elemento 38 no cenário M7 não foi identificado como danificado. Em uma análise mais detalhada foi observado que a metodologia conseguia encontrar o cenário de dano real em três das 10 execuções. Estas execuções apresentaram soluções com um valor ligeiramente abaixo daquele da melhor execução. Este fato indicaria que o método escolhido para definir a resposta final do algoritmo poderia não funcionar corretamente se existem soluções diferentes da real que apresentem valores similares da função objetivo. Este problema poderia ser solucionado seguindo três direções diferentes: 1) definindo outra função objetivo que permita diferenciar melhor as soluções, 2) utilizando uma estratégia para encontrar múltiplos ótimos ou 3) propondo um novo esquema que permita uma melhor definição sobre qual é a resposta da metodologia depois de ter-se executado o algoritmo varias vezes.

Tabela 7. 8 Resultados da aplicação do GA multi-cromossomo para a estrutura T4.

\begin{tabular}{|c|c|c|c|c|c|c|c|c|c|c|}
\hline & \multicolumn{10}{|c|}{ ID Cenário } \\
\hline & \multicolumn{2}{|c|}{$\mathbf{S 1 0}$} & \multicolumn{2}{|c|}{$\mathbf{S 1 1}$} & \multicolumn{2}{|c|}{ S12 } & \multicolumn{2}{|c|}{ M7 } & \multicolumn{2}{|c|}{ M8 } \\
\hline & Elem. & $\beta \mathbf{j}$ & Elem. & $\beta \mathbf{j}$ & Elem. & $\beta \mathbf{j}$ & Elem. & $\beta \mathbf{j}$ & Elem. & $\beta \mathbf{j}$ \\
\hline \multirow{3}{*}{ Real } & 5 & 0,480 & 26 & 0,180 & 38 & 0,410 & 5 & 0,160 & 7 & 0,340 \\
\hline & & & & & & & 26 & 0,200 & 35 & 0,200 \\
\hline & & & & & & & 38 & 0,180 & 36 & 0,250 \\
\hline \multirow{9}{*}{ GA } & 5 & 0,480 & 26 & 0,173 & 1 & 0,140 & 1 & 0,127 & 1 & 0,064 \\
\hline & 19 & 0,161 & 31 & 0,033 & $\overline{5}$ & 0,069 & $\overline{5}$ & 0,242 & $\overline{7}$ & 0,327 \\
\hline & $\overline{21}$ & 0,029 & & & $\overline{8}$ & 0,117 & 10 & 0,127 & 19 & 0,082 \\
\hline & $\overline{44}$ & 0,044 & & & $1 \overline{12}$ & 0,042 & $\overline{26}$ & 0,188 & $\overline{35}$ & 0,114 \\
\hline & & & & & $\underline{21}$ & 0,075 & $\underline{30}$ & 0,043 & 36 & 0,248 \\
\hline & & & & & 32 & 0,036 & 32 & 0,032 & 38 & 0,092 \\
\hline & & & & & 35 & 0,086 & & & & \\
\hline & & & & & 38 & 0,448 & & & & \\
\hline & & & & & 44 & 0,093 & & & & \\
\hline
\end{tabular}

A Tabela 7.9 mostra os resultados dos cenários de dano na estrutura T5. Cenário de dano S14 teve 4 indicações de falsos positivos, que é uma percentagem pequena do total de elementos na estrutura. A extensão do dano para estes elementos não foi maior que 0,08 , que é um valor relativamente baixo. O erro associado com o valor do dano em elementos verdadeiramente danificados foi menor que 0,035. 
Tabela 7. 9 Resultados da aplicação do GA multi-cromossomo para a estrutura T5.

\begin{tabular}{|c|c|c|c|c|c|c|c|c|c|c|}
\hline & \multicolumn{10}{|c|}{ ID Cenário } \\
\hline & \multicolumn{2}{|c|}{$\mathbf{S 1 3}$} & \multicolumn{2}{|c|}{ S14 } & \multicolumn{2}{|c|}{ S15 } & \multicolumn{2}{|c|}{ M9 } & \multicolumn{2}{|c|}{ M10 } \\
\hline & Elem. & Bj & Elem. & $\beta \mathbf{j}$ & Elem. & $\beta \mathbf{j}$ & Elem. & $\beta \mathbf{j}$ & Elem. & $\beta \mathbf{j}$ \\
\hline Real & 8 & 0,220 & 17 & 0,450 & 35 & 0,280 & $\begin{array}{c}8 \\
17 \\
35\end{array}$ & $\begin{array}{l}0,400 \\
0,350 \\
0,450\end{array}$ & $\begin{array}{c}3 \\
5 \\
24\end{array}$ & $\begin{array}{l}0,380 \\
0,280 \\
0,300\end{array}$ \\
\hline GA & $\begin{array}{r}8 \\
33 \\
\end{array}$ & $\begin{array}{l}0,185 \\
0,037\end{array}$ & $\begin{array}{l}\frac{9}{17} \\
\frac{27}{29} \\
\underline{30} \\
\end{array}$ & $\begin{array}{l}0,072 \\
0,446 \\
0,047 \\
0,063 \\
0,034\end{array}$ & $\frac{\frac{6}{19}}{\frac{27}{35}}$ & $\begin{array}{l}0,065 \\
0,046 \\
0,037 \\
0,256\end{array}$ & $\begin{array}{c}\frac{6}{8} \\
17 \\
\frac{33}{35}\end{array}$ & $\begin{array}{l}0,110 \\
0,377 \\
0,358 \\
0,049 \\
0,438\end{array}$ & $\begin{array}{c}3 \\
5 \\
24 \\
27 \\
\end{array}$ & $\begin{array}{l}0,378 \\
0,273 \\
0,320 \\
0,032\end{array}$ \\
\hline
\end{tabular}

Os cenários de dano analisados para a estrutura T6, simples e múltiplos, produziram o maior número de elementos erroneamente identificados como danificados, como pode ser observado na Tabela 7.10. Porém, todos os elementos realmente danificados foram identificados com diferenças nos valores do dano menores a 0,033. O melhor resultado foi obtido na identificação do cenário de dano S18 no qual um elemento horizontal estava danificado.

Tabela 7. 10 Resultados da aplicação do GA multi-cromossomo para a estrutura T6.

\begin{tabular}{|c|c|c|c|c|c|c|c|c|c|c|}
\hline & \multicolumn{10}{|c|}{ ID Cenário } \\
\hline & \multicolumn{2}{|c|}{ S16 } & \multicolumn{2}{|c|}{ S17 } & \multicolumn{2}{|c|}{$\mathbf{S 1 8}$} & \multicolumn{2}{|c|}{ M11 } & \multicolumn{2}{|c|}{ M12 } \\
\hline & Elem. & $\beta \mathbf{j}$ & Elem. & $\beta \mathbf{j}$ & Elem. & $\beta \mathbf{j}$ & Elem. & $\beta \mathbf{j}$ & Elem. & $\beta \mathbf{j}$ \\
\hline \multirow{3}{*}{ Real } & 3 & 0,330 & 31 & 0,300 & 44 & 0,190 & 3 & 0,150 & 8 & 0,200 \\
\hline & & & & & & & 31 & 0,180 & 39 & 0,240 \\
\hline & & & & & & & 44 & 0,150 & 42 & 0,270 \\
\hline \multirow{9}{*}{$\mathrm{GA}$} & 3 & 0,322 & $\underline{3}$ & 0,126 & 25 & 0,055 & 3 & 0,125 & 7 & 0,102 \\
\hline & 11 & 0,138 & $\overline{7}$ & 0,109 & $\overline{44}$ & 0,184 & $\underline{8}$ & 0,042 & $\overline{8}$ & 0,204 \\
\hline & 12 & 0,073 & 8 & 0,087 & & & 11 & 0,085 & 21 & 0,060 \\
\hline & $\underline{20}$ & 0,032 & 11 & 0,164 & & & 25 & 0,071 & 39 & 0,211 \\
\hline & $\overline{22}$ & 0,041 & $\overline{31}$ & 0,298 & & & $\overline{26}$ & 0,071 & 42 & 0,303 \\
\hline & $\overline{25}$ & 0,071 & 47 & 0,125 & & & $\overline{31}$ & 0,165 & 50 & 0,033 \\
\hline & 31 & 0,043 & 48 & 0,037 & & & 44 & 0,141 & & \\
\hline & $\underline{39}$ & 0,029 & $\underline{49}$ & 0,029 & & & $\underline{56}$ & 0,092 & & \\
\hline & & & 53 & 0,046 & & & 57 & 0,038 & & \\
\hline
\end{tabular}

O número de execuções corretas de um total de 10, o valor médio de elementos erroneamente identificados e o valor médio do número de gerações para cada cenário de dano simulado são mostrados na Tabela 7.11. O desempenho da metodologia é excelente para detectar cenários de dano simples produzindo poucos elementos erroneamente identificados, atingindo a convergência para uma solução com poucas gerações. Para múltiplos cenários de dano, a metodologia poderia não encontrar o cenário de dano real como 
aconteceu com o cenário M7. Uma média de 7 elementos erroneamente identificados como danificados foi encontrado; porém, esta quantidade corresponde apenas a $16 \%$ dos elementos na estrutura. A convergência foi encontrada antes de se completar o número máximo de gerações permitido para ambos os tipos de cenário.

Tabela 7. 11 Desempenho do algoritmo multi-cromossomo quando aplicado aos diferentes cenários de dano.

\begin{tabular}{|c|c|c|c|}
\hline $\begin{array}{l}\text { ID } \\
\text { Cenário }\end{array}$ & $\begin{array}{l}\text { Execuções } \\
\text { Corretas }\end{array}$ & $\begin{array}{c}\text { Elementos } \\
\text { Erroneamente. } \\
\text { Identificados }\end{array}$ & Gerações \\
\hline $\mathrm{S} 1$ & 10 & 3 & 87 \\
\hline $\mathrm{S} 2$ & 10 & 3 & 91 \\
\hline S3 & 10 & 2 & 87 \\
\hline S4 & 10 & 3 & 115 \\
\hline S5 & 10 & 2 & 92 \\
\hline S6 & 10 & 3 & 118 \\
\hline S7 & 10 & 6 & 150 \\
\hline 58 & 10 & 3 & 120 \\
\hline S9 & 10 & 3 & 145 \\
\hline $\mathrm{S} 10$ & 10 & 11 & 354 \\
\hline $\mathrm{S} 11$ & 9 & 10 & 343 \\
\hline $\mathrm{S} 12$ & 10 & 13 & 387 \\
\hline S13 & 10 & 4 & 137 \\
\hline S14 & 10 & 5 & 126 \\
\hline S15 & 10 & 4 & 127 \\
\hline S16 & 10 & 10 & 144 \\
\hline S17 & 10 & 8 & 138 \\
\hline S18 & 10 & 4 & 117 \\
\hline M1 & 10 & 3 & 72 \\
\hline M2 & 10 & 4 & 114 \\
\hline M3 & 10 & 6 & 197 \\
\hline M4 & 10 & 6 & 192 \\
\hline M5 & 9 & 6 & 173 \\
\hline M6 & 10 & 8 & 197 \\
\hline M7 & 3 & 12 & 383 \\
\hline M8 & 3 & 7 & 262 \\
\hline M9 & 10 & 7 & 170 \\
\hline M10 & 10 & 5 & 108 \\
\hline M11 & 9 & 8 & 184 \\
\hline M12 & 10 & 7 & 157 \\
\hline
\end{tabular}

Figuras 7.3 e 7.4 mostram como o número de elementos danificados no cromossomo binário do melhor indivíduo (NDEI) diminui com o número de gerações. O número de elementos danificados poderia aumentar entre gerações consecutivas, mas a tendência geral é reduzir esse número. Considera-se esta a principal característica do algoritmo genético proposto, o qual permite uma 
rápida convergência para uma solução com poucos elementos danificados. Para o cenário S9, 4 elementos danificados foram encontrados, mas a Tabela 7.3 mostra apenas um. Isto porque os outros elementos apresentavam extensões do dano menores de 0,03. Cenário de dano M5 tinha três elementos danificados e a metodologia proposta reportou 7 elementos identificados como danificados. Alguns desses elementos tinham valores de dano maiores que 0,03.

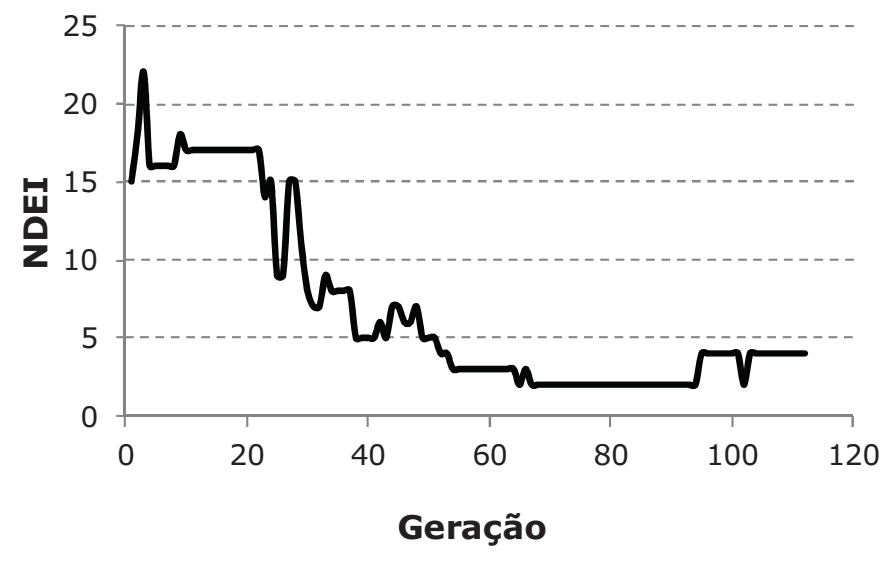

Figura 7. 3 Evolução do cromossomo binário para o melhor indivíduo. Cenário S9: um elemento danificado.

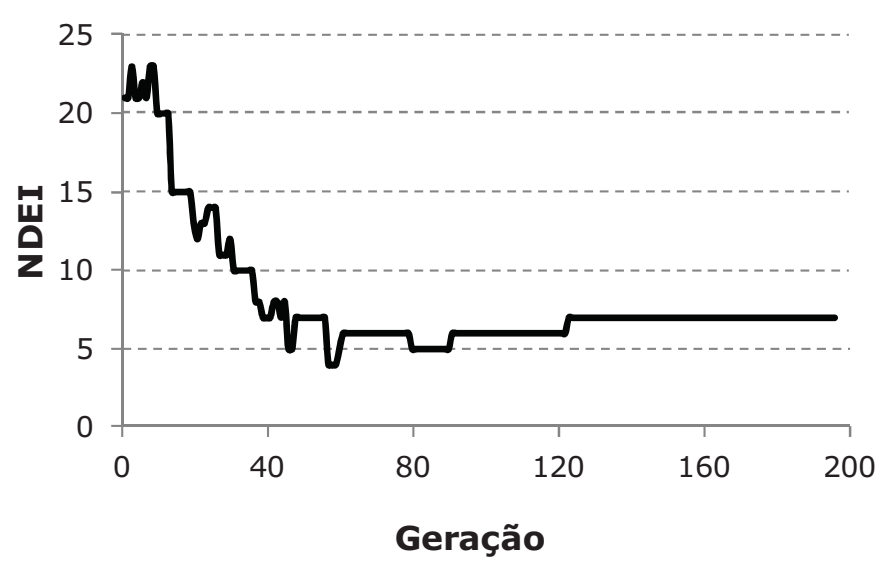

Figura 7. 4 Evolução do cromossomo binário para o melhor indivíduo. Cenário S9: um elemento danificado.Cenário M5: três elementos danificados. 


\subsection{DISCUSSÃO}

Neste exemplo foi proposto um GA multi-cromossomo auto-adaptado para localizar e quantificar dano em estruturas. Entre as principais conclusões obtidas tem-se:

- O tipo de algoritmo utilizado permite representar a solução do problema utilizando 3 cromossomos. Esse esquema de codificação permitiu evoluir o número de variáveis do problema e os valores dos parâmetros genéticos.

- Observou-se que na medida em que o número de gerações incrementa o cromossomo binário que representa a localização do dano tende para cenários de dano com poucos elementos danificados.

- Para a metodologia proposta os valores dos parâmetros genéticos são dados na forma de faixas de valores permitidos evitando assim o processo de tentativa e erro para sua definição. Assim como para as formulações dos exemplos II e III, o tamanho da população ainda tem que ser definido pelo usuário.

- A metodologia proposta mostrou-se capaz de determinar os elementos danificados e suas extensões de dano para estruturas do tipo treliça. No entanto, alguns cenários de danos múltiplos podem apresentar alguma dificuldade para serem identificados. No caso de cenários de dano simples tem-se que estes podem ser identificados quase em um total de $100 \%$ das execuções do algoritmo.

- Alguns elementos falsamente identificados como danificados foram observados quando a metodologia foi aplicada aos cenários de dano analisados. O número destes elementos e suas extensões de dano são relativamente baixos. 


\section{EXEMPLO V: REDES NEURAIS ARTIFICIAIS- QUANTIFICAÇÃO}

\subsection{INTRODUÇÃO E ESTRUTURA ANALISADA}

Neste exemplo apresenta-se uma metodologia que permite detectar dano utilizando ANNs e mudanças na matriz de flexibilidade modal (Villalba et al., 2012). Um total de 8 vigas, que apresentam entre 8 e 40 elementos, são estudadas. Na Figura 8.1 são ilustradas as 4 vigas de menor comprimento, sendo a configuração geométrica de cada uma das vigas analisadas mostrada na Tabela 8.1. Considera-se a presença de um apoio fixo no extremo esquerdo de cada viga, sendo as unidades de comprimento dadas em metros. Cada elemento nas diferentes vigas apresenta um modulo de elasticidade $E=200 \times 10^{9} \mathrm{~N} / \mathrm{m}^{2}$, densidade $\rho=78 \times 10^{2} \mathrm{~kg} / \mathrm{m}^{3}$, momento de inércia, $\mathrm{I}=5 \times 10^{-4} \mathrm{~m}^{4}$ e área da seção transversal $A=1 \times 10^{-3} \mathrm{~m}^{2}$. Além disso, supõe-se que para todas as vigas é possível obter informação das 8 primeiras formas modais medidas unicamente nos DOFs verticais. O dano é modelado como uma redução no modulo de 
elasticidade em forma equivalente à redução de rigidez utilizada nos exemplos anteriores.

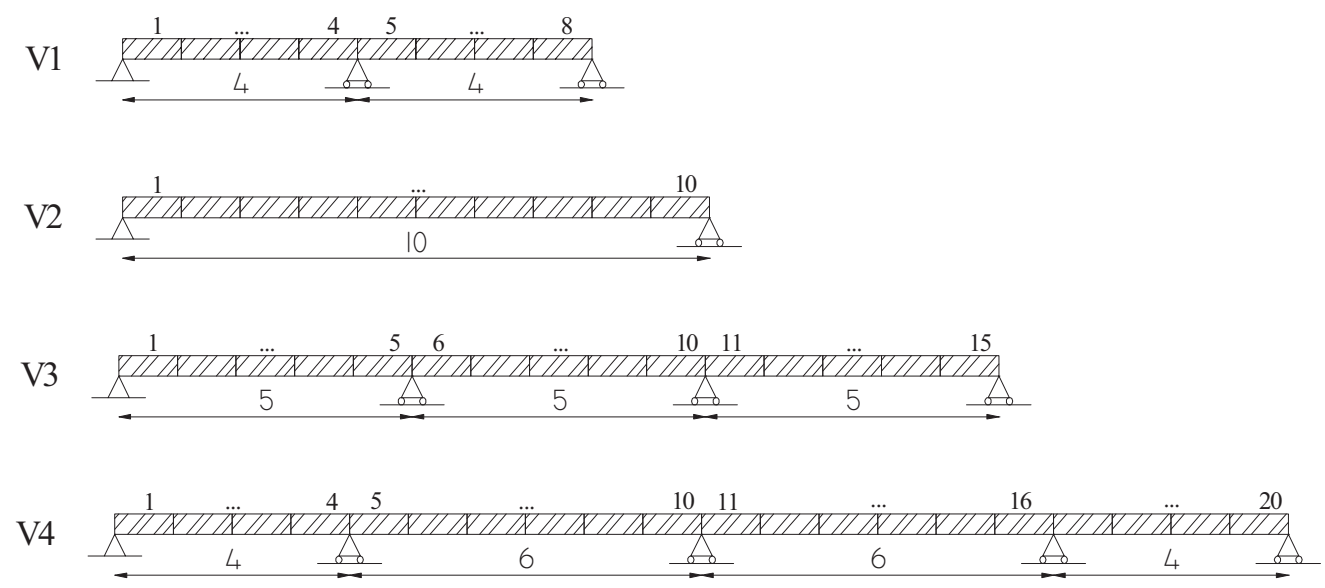

Figura 8. 1 Vigas utilizadas para avaliar o desempenho da ANN proposta.

Tabela 8. 1 Caracterização geométrica das vigas analisadas.

\begin{tabular}{ccccccccccc}
\hline \multirow{2}{*}{ Viga } & \multirow{2}{*}{$\begin{array}{c}\text { No } \\
\text { de }\end{array}$} & \multirow{2}{*}{$\begin{array}{c}\text { No } \\
\text { Elem. }\end{array}$} & \multicolumn{8}{c}{ Posição de apoios móveis definida a partir do apoio } \\
\cline { 5 - 13 } & & I & II & III & IV & V & VI & VII & VIII \\
\hline V1 & 8 & 3 & 4 & 8 & --- & --- & --- & --- & --- & --- \\
\hline V2 & 10 & 2 & 10 & --- & --- & --- & --- & --- & --- & --- \\
\hline V3 & 15 & 4 & 5 & 10 & 15 & --- & --- & --- & --- & --- \\
\hline V4 & 20 & 5 & 4 & 10 & 16 & 20 & --- & --- & --- & --- \\
\hline V5 & 26 & 4 & 10 & 16 & 26 & --- & --- & --- & --- & --- \\
\hline V6 & 30 & 7 & 5 & 10 & 15 & 20 & 25 & 30 & --- & --- \\
\hline V7 & 34 & 7 & 4 & 12 & 16 & 20 & 27 & 34 & --- & --- \\
\hline V8 & 40 & 9 & 5 & 10 & 15 & 20 & 25 & 30 & 35 & 40 \\
\hline
\end{tabular}

\subsection{ARQUITETURA DA REDE}

A arquitetura selecionada para detectar o dano foi a MLP, sendo implementada em MATLAB e treinada com o algoritmo Scaled Conjugate Gradient Backpropagation. Este algoritmo foi escolhido por apresentar boa capacidade de generalização para um tempo de processamento razoável, como será mostrado no Exemplo VI. 
A utilização de uma rede MLP requer da definição a priori de uma serie de parâmetros, como o número de camadas ocultas e a quantidade de neurônios em cada camada, tal e como apresentado no capítulo 2. Depois de alguns testes, definiu-se que duas camadas ocultas seriam utilizadas, sendo a quantidade de neurônios por camada igual a $80 \%$ do tamanho do vetor de valores de entrada, VVE. Esse vetor está conformado por frequências naturais e flexibilidades modais como se descreve a seguir:

$V V E=\left[\begin{array}{llllllll}W_{1} & W_{2} & \cdots & W_{n m} & F_{1} & F_{2} & \cdots & F_{n g l l}\end{array}\right]$

no qual $\mathrm{nm}$ é a quantidade de frequências naturais e formas modais disponíveis, e ngll é o número de graus de liberdade verticais, respectivamente. Os termos $W$ e $F$ são calculados como:

$W_{j}=\frac{\omega_{j, a n n}-\omega_{j, s d}}{\omega_{j, s d}}$

$F_{i}=\frac{f_{i i, a n n}-f_{i i, s d}}{f_{i i, s d}}$

sendo $\omega_{j}$ a j-ésima frequência natural e $f_{i i}$ a posição $i$ na diagonal da matriz de flexibilidade modal referida aos graus de liberdade verticais. ann refere-se a um valor obtido a partir do exemplo de treinamento e sd representa um dado obtido da condição sem dano. A matriz de flexibilidade pode ser obtida a partir das frequências naturais e as formas modais como:

$[f]=\sum_{j=1}^{n m} \frac{1}{\omega_{j}^{2}}\{\Phi\}_{j}\{\Phi\}_{j}^{t}$ 
onde $\Phi_{\mathrm{j}}$ é a $j$-ésima forma modal.

Por outro lado, os valores de saída correspondem ao fator de redução do módulo de elasticidade de cada elemento da estrutura e cujo tamanho é igual ao número de elementos.

Na Figura 8.2 apresenta-se um exemplo da configuração da rede MLP para uma viga simplesmente apoiada cujo FEM consta de 4 elementos e para a qual tem-se informação dos dois primeiros modos de vibração nos DOFs verticais. Sendo assim, esta rede apresenta 5 neurônios na camada de entrada (2 frequências naturais e 3 valores de flexibilidade modal), 4 neurônios em cada capa oculta e 4 valores de saída, que correspondem ao fator de redução de elasticidade de cada um dos 4 elementos do FEM.

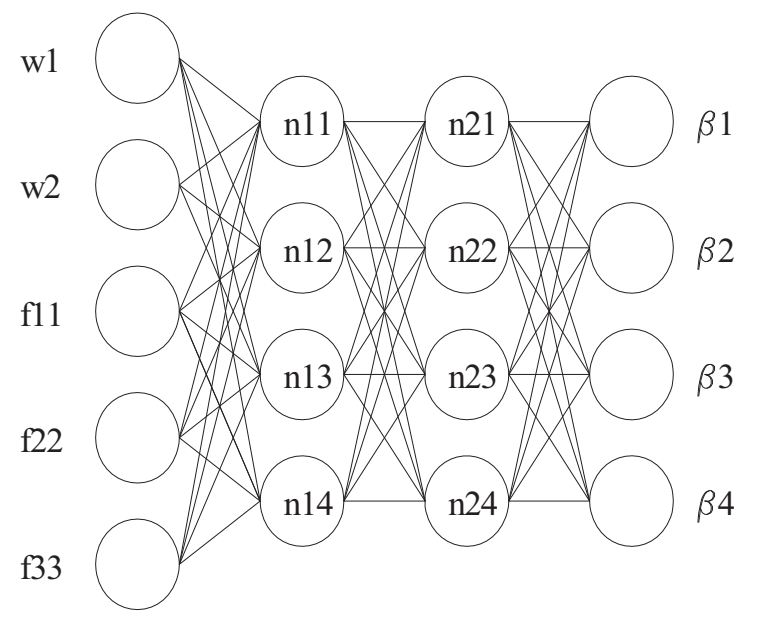

Figura 8. 2 Exemplo da topologia da ANN proposta para uma estrutura com 4 elementos finitos.

\subsection{DEFINIÇÃO DE ETAPAS ANTERIORES AO TREINAMENTO DA REDE.}

Nesta seção apresentam-se os passos requeridos para realizar o treinamento da rede e que foram resumidos na Figura 8.3. 


\section{Inicio}

1. Definir um FEM para a estrutura sem dano e calcular seus parâmetros dinâmicos.

2. Gerar $\mathbf{S}$ cenários de dano simples e M cenários de danos múltiplos.

3. Determinar os parâmetros dinâmicos de cada cenário de dano e definir os vetores de entrada, utilizando equações 8.1 a 8.4 , e os vetores de saída correspondentes.

4. Definir parâmetros da rede: Número de camadas ocultas, número de neurônios por camada, funções de ativação e algoritmo de treinamento.

Fim

Figura 8. 3 Passos prévios ao treinamento da ANN proposta.

Primeiro, deve-se definir um FEM que sirva para obter a resposta dinâmica da estrutura para a condição inicial ou sem dano. Este modelo é considerado estar atualizado.

No segundo passo, os cenários de dano que servirão ao aprendizado da rede são simulados a partir da introdução direta do dano na matriz de rigidez original. Esses cenários podem ser classificados como simples ou múltiplos, em função do número de elementos danificados presente. Cenários de dano simples são formados por um único elemento danificado com uma extensão de dano predefinida. Cada elemento na estrutura é utilizado para a geração dos cenários mencionados, sendo que para cada um deles se varia a extensão do dano de forma uniforme dentro de uma faixa de valores que para este exemplo corresponde a um $\beta$ entre 0,05 e 0,55. Se considerarmos 6 valores de dano por cada elemento, por exemplo, teríamos 6 cenários de dano diferentes com extensões de 0,$05 ; 0,15 ; 0,25 ; 0,35 ; 0,45$ e 0,55; respectivamente. Seguindo com a viga utilizada como exemplo na seção 8.2 temos que um exemplo de cenário de dano simples corresponderia a dano no elemento 2 com uma extensão igual a 0,25. Cenários de danos múltiplos incluem dois ou mais elementos danificados. Eles serão formados mediante a geração de um número aleatório entre 2 e 4 -número máximo de elementos danificados esperado-, que define o número de elementos danificados desse cenário. Assim mesmo, a escolha dos elementos que apresentam dano e das extensões de dano nesses elementos se realiza de forma aleatória. Um exemplo de um cenário de danos 
múltiplos corresponde a dano nos elementos 1 , 3 e 4 com fatores de redução de elasticidade de 0,15; 0,35 e 0,45, respectivamente. A determinação do número de cenários de dano necessários para treinar a ANN proposta será realizada em função do seu desempenho e será discutido na seção 8.5.

No passo 3, calculam-se as frequências naturais e formas modais utilizando as novas configurações estruturais para a viga. A partir desses valores os vetores de entrada podem ser gerados utilizando as equações 8.1 a 8.4. Os vetores de saída corresponderão ao cenário de dano introduzido.

No passo 4, são introduzidas as características que definem a tipologia da rede neural. Após a realização dos passos anteriores, a rede está pronta para ser treinada até obter-se a convergência ou um número de épocas máximo igual a 20000.

\subsection{APLICAÇÃO DA REDE E REFINAMENTO DOS RESULTADOS}

Um número pré-determinado de cenários de dano serão simulados para cada uma das vigas analisadas com o intuito de demonstrar o desempenho da rede. A geração destes cenários segue o mesmo procedimento utilizado para os casos de treinamento correspondente àqueles dos cenários de danos múltiplos; porém, o número de elementos danificados foi permitido a variar entre 1 e 4 . A aplicação desta metodologia consiste em gerar os vetores de entrada a partir dos cenários de dano simulados, substituindo os termos relacionados com a ANN proposta nas Equações 8.2 e 8.3 pelos valores obtidos via métodos experimentais ou numéricos.

Os resultados obtidos pela rede serão melhorados pela aplicação do Nelder-Mead Simplex, NMS, cuja configuração de parâmetros foi aquela utilizada por Begambre (2009). As variáveis a serem otimizadas correspondem àqueles elementos nos quais a rede determinou uma extensão do dano maior que 0,03. A função objetivo utilizada é a seguinte: 
$\operatorname{Max}\left(G=\sum_{j=1}^{n m} \frac{200}{1+\left|\frac{\omega_{j, N M S_{-} A N N}-\omega_{j, D}}{\omega_{j, D}}\right|}\right)$

na qual NMS_ANN refere-se à solução encontrada depois da aplicação do NMS.

O desempenho da metodologia proposta será analisado a partir da simulação de um total de 200 cenários de dano e da determinação dos três tipos de erro apresentados no Exemplo I.

\subsection{RESULTADOS PARA ERRO TIPO A}

Um parâmetro que influência o desempenho da ANN proposta é o número dos casos de treinamento utilizados e a sua origem. Neste exemplo considerouse que esse conjunto estava conformado por vetores de entrada originados a partir de cenários de dano simples e múltiplos. Para o primeiro caso, os exemplos foram gerados utilizando um elemento por vez e dividindo o intervalo de dano pré-definido anteriormente em 25 partes, assim o total deste tipo de casos poderia ser calculado como:

NES $=25 \times$ NElem

onde NES é o número de casos de treinamento provenientes de cenários de dano simples e NElem é o número de elementos na estrutura.

A determinação do número necessário de cenários de danos múltiplos foi realizada em forma iterativa. Diferentes quantidades de cenários de dano foram simuladas até garantir que pelo menos em $80 \%$ dos casos simulados o erro máximo no cálculo da extensão do dano fosse menor a 0,05. Na Tabela 8.2 e na Figura 8.4 apresentam-se o número de cenários de dano utilizado para cada uma 
das vigas estudadas e a variação do número de casos de treinamento de danos múltiplos em função do número de elementos na estrutura, respectivamente.

Tabela 8. 2 Quantidade de cenários de danos utilizados para o treinamento da rede.

\begin{tabular}{cccc}
\hline \multirow{2}{*}{ Viga } & \multicolumn{3}{c}{ Número de casos } \\
\cline { 2 - 4 } & Simples & Múltiplo & Total \\
\hline V1 & 200 & 320 & 520 \\
\hline V2 & 250 & 600 & 850 \\
\hline V3 & 375 & 1500 & 1875 \\
\hline V4 & 500 & 2600 & 3100 \\
\hline V5 & 650 & 3900 & 4550 \\
\hline V6 & 750 & 5100 & 5850 \\
\hline V7 & 850 & 6460 & 7310 \\
\hline V8 & 1000 & 9200 & 10200 \\
\hline
\end{tabular}

A partir dos resultados encontrados na Figura 8.4, derivou-se uma expressão que permitia calcular, em forma aproximada, o número de casos de treinamento com danos múltiplos, NEM, sob as condições utilizadas neste exemplo (quantidade de modos disponíveis, faixa de valores de dano e número de elementos danificados máximo).

$N E M=0,1423 \times \#$ Elem $^{3}-5,1046 \times \#$ Elem $^{2}+241,23 \#$ Elem $-1399,4$

Finalmente, a quantidade total de cenários de treinamento, NET, vem dada por:

$N E T=N E S+N E M$

A quantidade de cenários de treinamento reportados na Tabela 8.2 resultou em um desempenho da ANN proposta para o cálculo da extensão do dano como mostrado na Tabela 8.3. Os resultados são apresentados na forma de percentagens do número de casos nos quais uma determinada diferença entre o valor de dano real e o calculado, $\Delta \beta$, é encontrada, sendo os resultados em parêntesis aqueles encontrados pela rede sem a aplicação do NMS. Cabe lembrar 
que $\Delta \beta$ se calcula para cada elemento na estrutura e define-se o pior valor encontrado como aquele representativo para esse cenário. Em geral, a aplicação do NMS melhorou o resultado da rede, sendo muito visível para as vigas V5 e V7. Porém, o NMS não conseguiu melhorar os resultados para aqueles cenários nos quais o resultado da rede consistia do pior grau de erro. A definição dos distintos níveis de erro foi realizada de igual forma que para o Exemplo I.

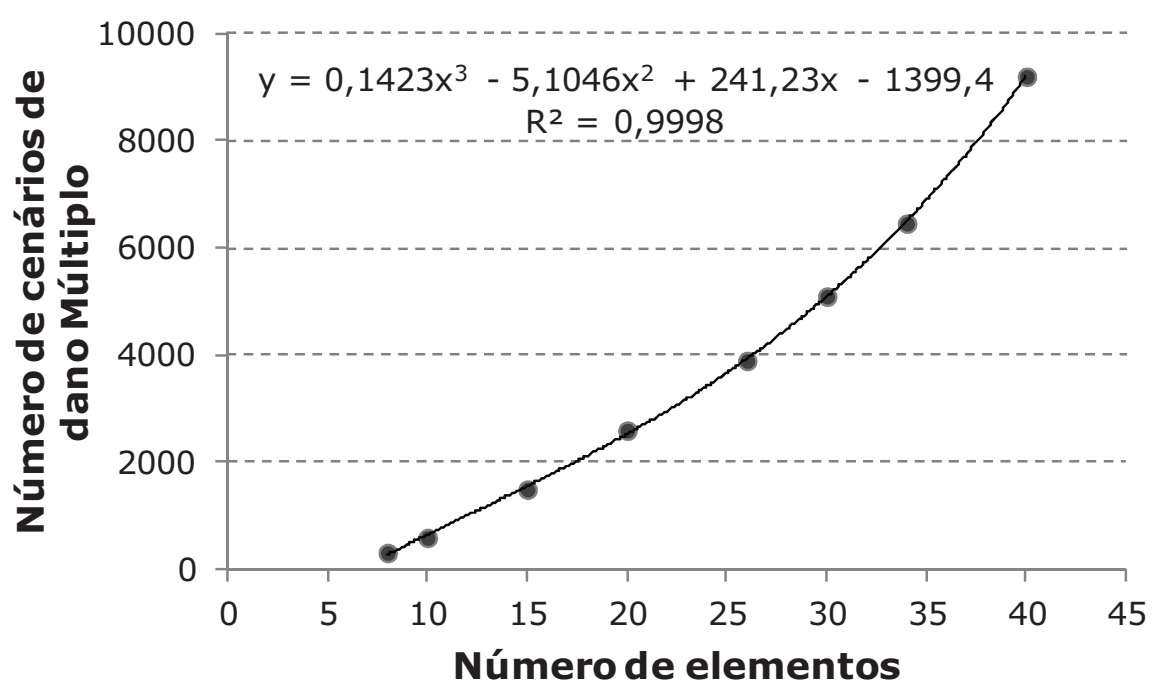

Figura 8. 4 Relação entre o número de cenários de danos múltiplos e o número de elementos da viga.

Tabela 8. 3 Percentagens de cenários simulados para os quais a ANN proposta apresentou um determinado grau do erro tipo A.

\begin{tabular}{ccccc}
\hline Viga & $\boldsymbol{\Delta} \boldsymbol{\beta}<\mathbf{0 , 0 2}$ & $\mathbf{0 , 0 2} \leq \boldsymbol{\Delta} \boldsymbol{\beta}<\mathbf{0 , 0 5}$ & $\mathbf{0 , 0 5} \leq \boldsymbol{\Delta} \boldsymbol{\beta}<\mathbf{0 , 1}$ & $\boldsymbol{\Delta} \boldsymbol{\beta} \geq \mathbf{0 , 1}$ \\
\hline V1 & $73(72)$ & $13(14)$ & $8(8)$ & $6(6)$ \\
\hline V2 & $63(60)$ & $18(21)$ & $13(12)$ & $6(7)$ \\
\hline V3 & $84(78)$ & $11(17)$ & $3(3)$ & $2(2)$ \\
\hline V4 & $83(80)$ & $10(13)$ & $3(3)$ & $4(4)$ \\
\hline V5 & $73(50)$ & $7(30)$ & $13(12)$ & $7(8)$ \\
\hline V6 & $84(78)$ & $10(15)$ & $5(6)$ & $1(1)$ \\
\hline V7 & $83(68)$ & $7(22)$ & $7(7)$ & $3(3)$ \\
\hline V8 & $84(78)$ & $11(17)$ & $3(3)$ & $2(2)$ \\
\hline
\end{tabular}




\subsection{RESULTADOS PARA ERRO TIPO B E C.}

Nas Tabelas 8.4 e 8.5 mostra-se o desempenho da metodologia proposta em relação aos erros de Tipo $B$, elementos falsamente identificados como danificados ou falsos positivos, e Tipo $C$, elementos danificados que não são identificados ou falsos negativos. Observa-se que a metodologia tende a produzir uma distribuição de falsos positivos com incrementos nos níveis de erro na medida em que o tamanho da estrutura aumenta; porém, a aplicação da metodologia resulta em um elemento erroneamente classificado como danificado com uma extensão de dano maior a 0,2 para aproximadamente 3\% dos cenários utilizados na etapa de validação da ANN. Em relação ao Erro Tipo C, a quantidade de casos nos quais um elemento com dano menor a 0,1 não é identificado manteve-se aproximadamente igual para todas as vigas analisadas, com um valor médio de 14,5\%. Em geral, em menos de $3 \%$ dos casos não foi determinada a presença de um elemento danificado que apresentara uma extensão de dano maior a 0,1 .

Tabela 8. 4 Percentagens de cenários simulados para os quais a ANN proposta apresentou um determinado grau do erro tipo $\mathrm{B}$.

\begin{tabular}{|c|c|c|c|c|}
\hline Viga & $\Delta \beta<0,05$ & $0,05 \leq \Delta \beta<0,1$ & $0,1 \leq \Delta \beta<0,2$ & $\Delta \beta \geq 0,2$ \\
\hline V1 & 70 & 19 & 8 & 3 \\
\hline $\mathrm{V} 2$ & 56 & 34 & 10 & 0 \\
\hline V3 & 75 & 19 & 6 & 0 \\
\hline V4 & 51 & 26 & 20 & 3 \\
\hline V5 & 19 & 51 & 30 & 0 \\
\hline V6 & 23 & 43 & 31 & 3 \\
\hline V7 & 18 & 56 & 26 & 0 \\
\hline V8 & 14 & 36 & 48 & 2 \\
\hline
\end{tabular}

Tabela 8. 5 Percentagens de cenários simulados para os quais a ANN proposta apresentou um determinado grau do erro tipo $C$.

\begin{tabular}{ccc}
\hline Viga & $\boldsymbol{\Delta} \boldsymbol{\beta}<\mathbf{0 , 1}$ & $\boldsymbol{\Delta} \boldsymbol{\beta} \geq \mathbf{0 , 1}$ \\
\hline V1 & 10 & 6 \\
\hline V2 & 11 & 2 \\
\hline V3 & 7 & 2 \\
\hline V4 & 12 & 3 \\
\hline V5 & 15 & 2 \\
\hline V6 & 17 & 1 \\
\hline V7 & 27 & 2 \\
\hline V8 & 17 & 2 \\
\hline
\end{tabular}


A partir dos resultados anteriores pode se concluir que algumas modificações deverão ser realizadas na metodologia proposta de forma a permitir a redução do erro observado.

\subsection{RESULTADOS PARA CENÁRIOS DE DANO INDIVIDUAIS}

Nas Figuras 8.5 a 8.7 são apresentados os resultados da detecção de cenários de dano simples e múltiplos na viga V5 com o intuito de ilustrar ao leitor sobre o desempenho da metodologia proposta. Nos exemplos analisados observa-se que a ANN proposta consegue detectar os elementos realmente danificados com uma extensão de dano próxima da real, assim como a presença de uma serie de elementos falsamente identificados com baixos níveis de dano.

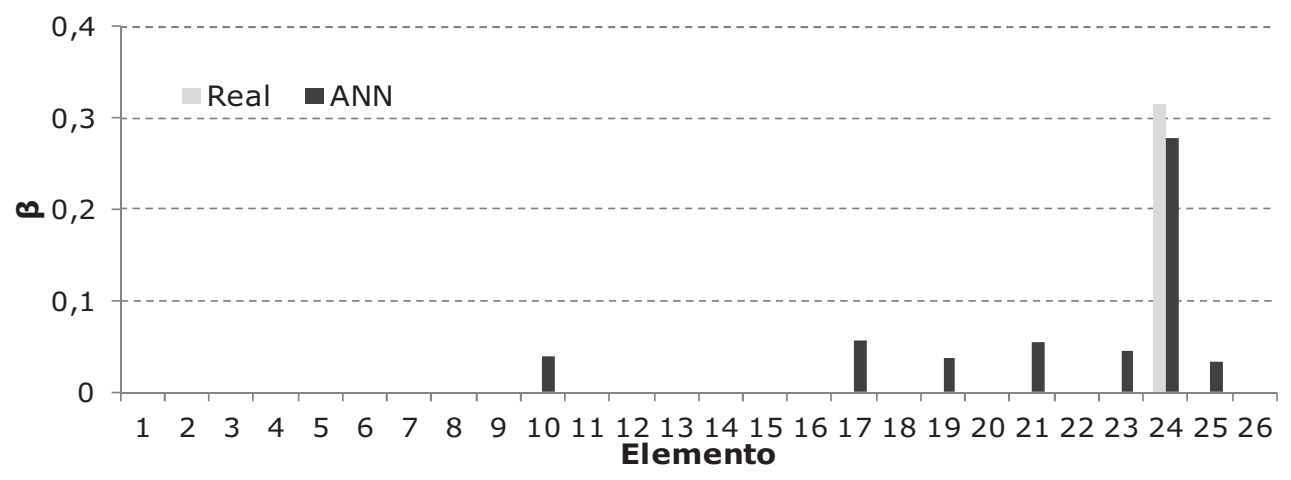

Figura 8. 5 Aplicação da ANN proposta na detecção de um cenário de dano simples.

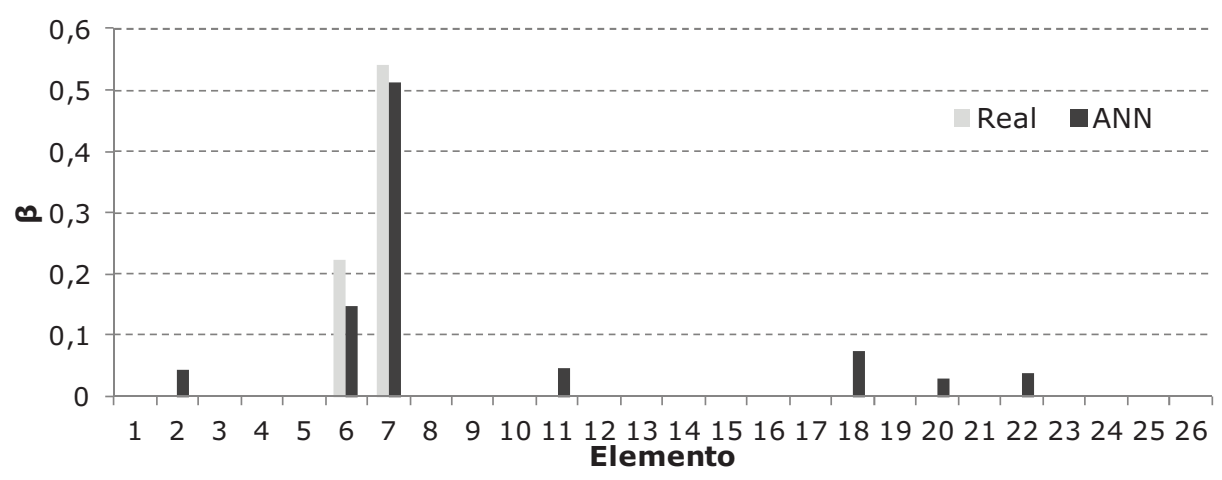

Figura 8. 6 Aplicação da ANN proposta na detecção de um cenário de danos múltiplos uniforme. 


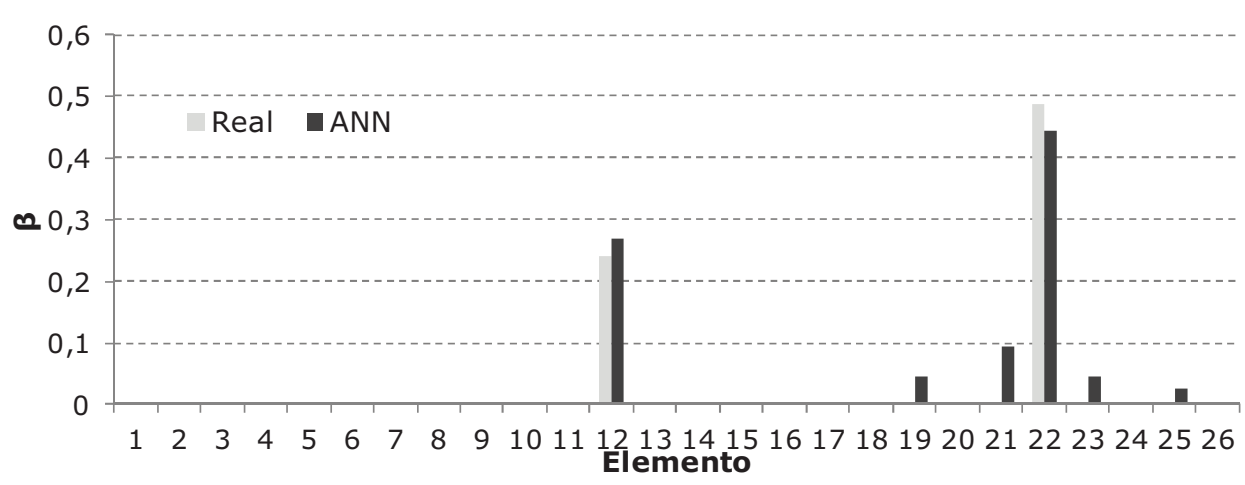

Figura 8. 7 Aplicação da ANN proposta na detecção de um cenário de danos múltiplos disperso.

\subsection{RELAÇÃo ENTRE A QUANTIDAdE DE MOdOS MEdidOS E O DESEMPENHO DA METODOLOGIA PROPOSTA.}

Para observar o efeito do número de modos medidos no desempenho da metodologia proposta se utiliza a viga V3 e se permite que o número de modos varie entre 2 e 12 . Os resultados mostrados na Tabela 4.6 indicam que a partir de 6 modos a ANN proposta apresenta um desempenho constante, sendo que 0 nível do Erro tipo A era menor a 0,02 em pelo menos um 85 dos cenários utilizados na etapa de validação da ANN.

Tabela 8. 6 Desempenho da ANN proposta em função do número de modos utilizados.

\begin{tabular}{ccccc}
\hline Modos & $\mathbf{\Delta} \boldsymbol{\beta}<\mathbf{0 , 0 2}$ & $\mathbf{0 , 0 2} \leq \boldsymbol{\Delta} \boldsymbol{\beta}<\mathbf{0 , 0 5}$ & $\mathbf{0 , 0 5} \leq \mathbf{\Delta} \boldsymbol{\beta}<\mathbf{0 , 1}$ & $\mathbf{\Delta} \boldsymbol{\beta} \mathbf{\mathbf { 0 } , \mathbf { 1 }}$ \\
\hline 2 & 62 & 11 & 16 & 11 \\
\hline 4 & 77 & 14 & 5 & 4 \\
\hline 6 & 86 & 6 & 5 & 3 \\
\hline 8 & 85 & 10 & 3 & 2 \\
\hline 10 & 88 & 5 & 5 & 2 \\
\hline 12 & 86 & 9 & 4 & 1 \\
\hline
\end{tabular}

No que diz respeito à aplicação prática da metodologia proposta, simulações numéricas deverão ser realizadas com o objetivo de determinar a quantidade ótima de modos que leva a um desempenho da metodologia determinado. Cabe salientar, que esse valor não tem um limite inferior; porém 
se encontra limitado superiormente pelo número de modos que podem ser obtidos experimentalmente.

\subsection{DISCUSSÃO}

Em relação à configuração e definição da metodologia de quantificação de dano baseada em ANNs pode-se comentar o seguinte:

- Parâmetros dinâmicos: Neste exemplo foram utilizadas frequências naturais e flexibilidades modais para a conformação dos vetores de entrada, sendo que poucas formas modais foram medidas nos graus de liberdade verticais. Observa-se que o número de formas modais disponível pode influenciar o resultado encontrado pela metodologia proposta. Portanto, cada estrutura em particular pode requer da determinação de qual é a quantidade mínima de formas modais que devem ser utilizadas para garantir um processo de valoração do estado da estrutura que seja confiável.

- Características da rede: A definição da quantidade de capas ocultas e o número de neurônios por camada foi realizada a partir de várias simulações. Uma equação foi proposta para calcular o número de casos de treinamento com o intuito de ajudar o analista a estimar um valor aproximado dos casos de treinamento; porém, não representa uma regra fixa e sua aplicabilidade está limitada a vigas com no máximo 40 elementos. Por outro lado, outros algoritmos de treinamento poderiam ser utilizados para tentar melhorar o desempenho da rede.

- Refinamento da solução: o algoritmo de busca pode ser substituído por outros algoritmos com o intuito de obter um maior refinamento da solução.

- Custo computacional: A aplicação desta metodologia a grandes estruturas está condicionada ao elevado custo computacional envolvido, que aumenta consideravelmente na medida em que o número de elementos da viga cresce. 


\section{EXEMPLO VI: REDES NEURAIS}

\section{ARTIFICIAIS- LOCALIZACCÃO}

\subsection{COMO UTILIZAR REDES NEURAIS EM LOCALIZAÇÃO DE DANO}

A aplicação de técnicas que levam em conta simultaneamente a localização e a quantificação do dano pode não ser adequada para estruturas cujo MEF presente uma quantidade elevada de elementos, agravado pelo fato do problema ser mal condicionado e cuja solução não se tem garantia de ser única (Perera e Ruiz, 2008).

Uma forma de se resolver esse problema é através da divisão do processo de detecção de dano em etapas, tal como mostrado na Figura 1.1. Neste exemplo, propõe-se uma metodologia de detecção de dano em estruturas do tipo viga com múltiplos apoios, que permita atingir um nível II de identificação do dano- considerando que foi identificada a presença do dano e que foi realizada uma identificação modal sobre a estrutura danificada. 


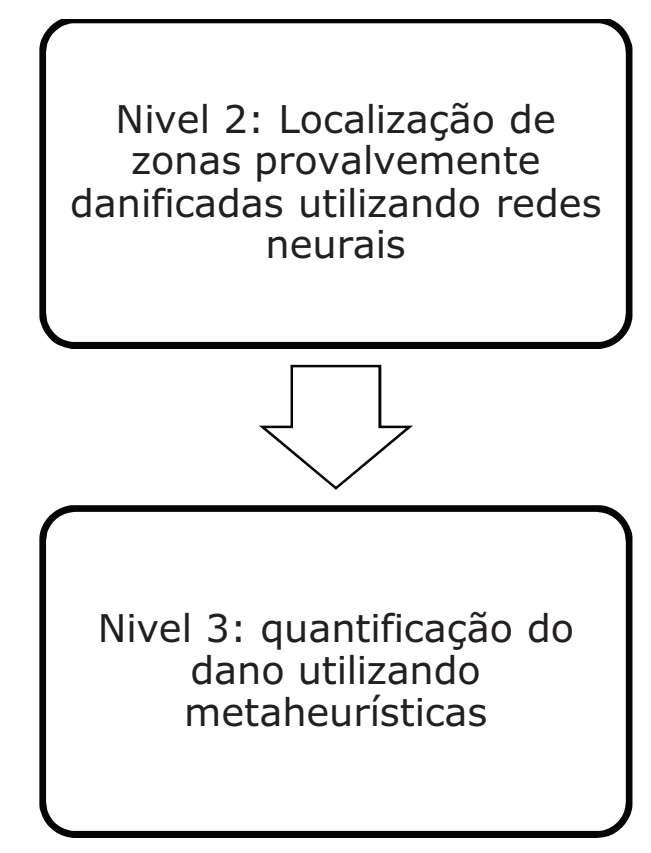

Figura 9. 1 Metodologia de detecção de dano de duas etapas.

No esquema apresentado na Figura 9.1 observa-se que a metodologia proposta pode ser parte de um processo de detecção de dano no qual ANNs sejam utilizadas para localizar possíveis zonas danificadas e, depois, uma metaheurística, como as apresentadas nos exemplos I a IV, para resolver o problema de otimização associado com a quantificação do dano. Em essência a rede terá duas saídas possíveis por cada zona da estrutura que descrevem as condições com e sem dano. Cabe salientar que a incorreta localização do dano faz com que a segunda etapa seja realizada com as variáveis equivocadas, resultando em um cenário de dano incorreto. Além disso, com a presente metodologia não se busca definir com exatidão a localização de um elemento danificado, mas determinar prováveis zonas danificadas. A justificativa da consideração anterior encontra-se na redução do espaço de busca de possíveis combinações de elementos danificados - variáveis de otimização- o que incrementa as chances da metodologia realizar uma quantificação do dano de forma mais confiável.

Vigas de diferentes tamanhos foram estudadas para validar o desempenho da metodologia proposta, sendo que os resultados foram analisados em função do número de elementos finitos do FEM de cada viga. 
Por outro lado, no exemplo $\mathrm{V}$ apresentou-se uma rede neural MLP para quantificar dano quando as medições estavam livres de ruído e eram tomadas em todos os graus de liberdade verticais de uma viga. Porém, essas condições são difíceis de acontecer na prática e neste exemplo consideramos as duas situações inversas: medições em uns poucos graus de liberdade verticais e a presença de ruído. Os parâmetros dinâmicos foram simulados numericamente e perturbados com ruído de $1 \%$ nas frequências naturais e de $3 \%$ nas formas modais. Para todas as vigas analisadas foi considerado que informação dos primeiros 8 modos encontrava-se disponível e que as medições das formas modais eram incompletas, sendo que o número de pontos com medições em cada uma das vigas foi definido a critério do autor. Na seção seguinte se introduz o sistema proposto para definição das zonas em que deve ser dividido o FEM das vigas

\subsection{EXEMPLOS DE DEFINIÇÕES DE ZONAS}

Como mostrado nos exemplos anteriores, a presença de ruído e de medições incompletas reduz a confiabilidade que se tem em uma metodologia de detecção de dano para identificar o cenário de dano correto. Se tal metodologia segue o esquema apresentado na Figura 9.1, então, recomenda-se que a localização do dano seja realizada determinando regiões da estrutura que contenham um determinado elemento danificado e não o elemento como tal. Essa consideração aumenta a confiabilidade nos resultados do processo de quantificação devido ao fato de que há uma diminuição da probabilidade de o elemento danificado não tenha sido localizado corretamente.

Neste exemplo, propõe-se um sistema de identificação de regiões danificadas baseado em um determinado esquema de agrupamento de elementos para estruturas do tipo viga. Cada conjunto de elementos recebe o nome de zona e um total de dois esquemas foi proposto com o intuito de se determinar se tais esquemas podem influenciar resultados. O primeiro esquema é formado pelo conjunto de elementos que se encontra adjacente a um sensor. Na Figura 9.2a ilustra-se uma das vigas analisadas, cujo MEF tem 20 elementos, 
e a distribuição de sensores (pontos pretos na figura) sobre ela. Os elementos foram agrupados em um total de 5 zonas nomeadas de Z1 - Z5. Assim, por exemplo, a zona 2 agruparia os elementos 5, 6, 7 e 8 . Se algum destes elementos, ou uma combinação deles, apresenta dano, então, a rede deverá identificar que aquela zona encontra-se danificada. O segundo esquema de definição de zonas consiste em agrupar os elementos entre dois sensores consecutivos ou entre um sensor e um apoio tal e como mostrado na Figura 9.2b. Neste caso, a zona 2 corresponde aos elementos 3, 4, 5 e 6.

a)

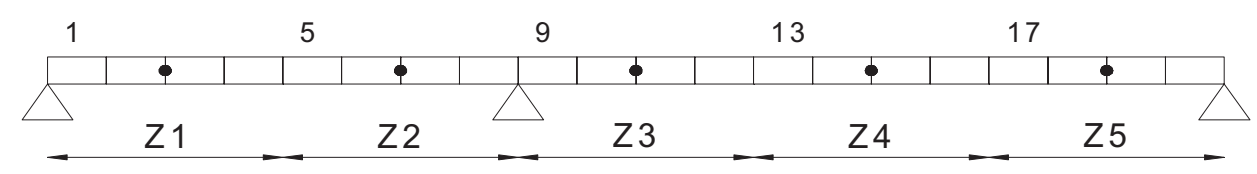

b)

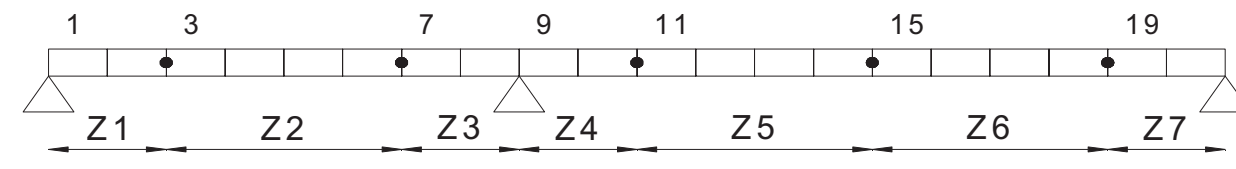

Figura 9. 2 Definição de zonas para uma estrutura do tipo viga: a) Esquema 1 e b) Esquema 2.

A Tabela 9.1 mostra a informação relacionada com cada uma das vigas (V1-V6) que foram utilizadas para demonstrar o desempenho da metodologia proposta. Uma faixa de quantidades de elementos entre 15 e 100 elementos divididos entre 5 e 20 zonas foi considerada. Uma quantidade máxima de elementos danificados foi definida para cada uma das vigas. Para as vigas V1 a V3 e V4 a v6 foram utilizados os esquemas de definição de zonas número 1 e 2, respectivamente. Além disso, utilizaram-se as seções transversais e materiais do exemplo $\mathrm{V}$ como propriedades dos elementos e considerou-se que os sensores estavam distribuídos uniformemente ao longo da viga. O número de casos de treinamento foi obtido depois de um processo de tentativa e erro. O número de casos para a verificação da capacidade de generalização de cada rede foi calculado como10\% do total de casos utilizados no treinamento Estes casos são gerados considerando cenários de dano aleatórios que apresentam entre 1 e a máxima quantidade de elementos danificados esperada. 
Tabela 9. 1 Especificação da informação sobre as vigas analisadas.

\begin{tabular}{cccccccc}
\hline Viga & $\begin{array}{c}\text { \# de } \\
\text { Elem. }\end{array}$ & $\begin{array}{c}\text { \# de } \\
\text { apoios }\end{array}$ & $\mathbf{L}$ & $\begin{array}{c}\text { \# de } \\
\text { pontos } \\
\text { medidos }\end{array}$ & $\begin{array}{c}\text { \# de } \\
\text { zonas }\end{array}$ & $\begin{array}{c}\text { \# de casos } \\
\text { de } \\
\text { treinamento }\end{array}$ & $\begin{array}{c}\text { \# Máximo } \\
\text { de } \\
\text { elementos } \\
\text { danificados }\end{array}$ \\
\hline V1 & 15 & 2 & 7,5 & 4 & 5 & 3125 & 2 \\
\hline V2 & 24 & 3 & 24 & 6 & 8 & 5160 & 2 \\
\hline V3 & 30 & 4 & 22,5 & 9 & 12 & 6450 & 3 \\
\hline V4 & 60 & 4 & 60 & 12 & 12 & 30900 & 4 \\
\hline V5 & 80 & 5 & 40 & 16 & 16 & 41200 & 4 \\
\hline V6 & 100 & 6 & 50 & 20 & 20 & 81500 & 5 \\
\hline
\end{tabular}

\subsection{CARACTERÍSTICAS DA REDE NEURAL UTILIZADA}

A ANN utilizada neste exemplo consiste de uma única camada oculta cujo tamanho é igual a 2 vezes +1 o tamanho do vetor de entrada (Nunes Da Silva et al., 2010). Tal vetor é composto pelos valores dos coeficientes dados pela Equação 8.3 cujos termos são calculados a partir da matriz de flexibilidade determinada a partir da Equação 8.4. Essa matriz pode ser reorganizada segundo se medições foram, ou não, realizadas em um determinado DOF, da seguinte maneira:

$[F]=\left[\begin{array}{ll}F_{m m} & F_{m n} \\ F_{n m} & F_{n n}\end{array}\right]$,

onde $m$ e $n$ referem-se aos graus de liberdade com e sem medições, respectivamente. Dado que a matriz de flexibilidade tem a propriedade de ser simétrica, e com o intuito de diminuir o tamanho do vetor de entrada à rede, só os valores nas diagonais e aqueles que se encontram abaixo dela serão utilizados.

O vetor de saída é formado por um neurônio por cada zona da viga, para o qual um valor de 1 ou -1 indica que há, ou não, a presença de dano na zona, respectivamente. 
Os cenários de dano utilizados para os casos de treinamento da rede foram gerados de forma similar ao exemplo $V$. A faixa de dano avaliada correspondeu a reduções da rigidez do elemento entre 0,15 e 0,45. Para cada cenário de dano foram então determinados seus parâmetros dinâmicos e estes, por sua vez, foram perturbados numericamente para levar em conta a presença do ruído na informação experimental. A quantidade dos casos de treinamento utilizados foi determinada na forma de prova e erro para cada uma das estruturas que foram analisadas.

Para cada uma das vigas da Tabela 9.1 se treinaram 3 redes diferentes durante um total de 3000 épocas (se não se especificar o contrario). O desempenho de cada rede foi calculado a partir da determinação do número de cenários simulados para os quais a rede não conseguia detectar as zonas que continham os verdadeiros elementos danificados. A rede que apresentava o menor erro durante a validação era escolhida. Como funções de ativação foram utilizadas a sigmoide e a linear para os neurônios das capas oculta e de saída, respectivamente.

Neste trabalho, os resultados do desempenho da metodologia proposta serão apresentados mediante a observação da influência que sobre eles tiveram três fatores: algoritmo de treinamento, ruído e extensão do dano.

\subsection{ESQUEMA DE POS-PROCESSAMENTO DOS RESULTADOS}

A viga com 60 elementos, agrupados em 12 zonas e com um máximo de 4 elementos danificados, será utilizada como exemplo para mostrar o pósprocessamento dos resultados da rede. Os resultados iniciais da rede mostraram que esta tinha dificuldade para produzir os valores de 1 e -1 -que identificam as condições com e sem dano, respectivamente- ocasionando que algum dos elementos danificados em um determinado cenário de dano possa não ser identificado. Se considerarmos o valor de zero como divisor da solução encontrada pela rede, valores maiores corresponderiam a zonas danificadas e valores menores a zonas não danificadas. Essa classificação funciona corretamente para alguns dos cenários analisados como mostrado nas Tabelas 
9.2 e 9.3. Para o cenário de dano número 1 que apresenta dano na zona 4 observa-se que a rede consegue determinar que essa é a única zona danificada. Na Tabela 9.3 apresenta-se um exemplo onde a rede consegue detectar eficientemente duas zonas contiguas danificadas sem que haja nenhuma outra zona apresentando um valor positivo na saída da rede. Porém, há casos onde alguma das zonas danificadas não é identificada como apresentado nas Tabelas 9.4 e 9.5. Para esses cenários a zona não identificada apresentou um valor negativo. Estes resultados levaram a propor um esquema de pós-processamento dos resultados que permita incrementar o número de zonas consideradas como provavelmente danificadas.

Tabela 9. 2 Resultado da resposta da rede neural: Cenário de dano 1.

\begin{tabular}{ccc}
\hline Zona & Estado & Rede \\
\hline 1 & -1 & $-0,54$ \\
\hline 2 & -1 & $-0,93$ \\
\hline 3 & -1 & $-0,43$ \\
\hline 4 & 1 & 1,51 \\
\hline 5 & -1 & $-0,81$ \\
\hline 6 & -1 & $-1,13$ \\
\hline 7 & -1 & $-0,62$ \\
\hline 8 & -1 & $-0,65$ \\
\hline 9 & -1 & $-1,29$ \\
\hline 10 & -1 & $-1,30$ \\
\hline 11 & -1 & $-0,87$ \\
\hline 12 & -1 & $-0,92$ \\
\hline
\end{tabular}

Tabela 9. 3 Resultado da resposta da rede neural: Cenário de dano 2.

\begin{tabular}{ccc}
\hline Zona & Estado & Rede \\
\hline 1 & -1 & $-1,04$ \\
\hline 2 & -1 & $-0,88$ \\
\hline 3 & -1 & $-0,76$ \\
\hline 4 & -1 & $-0,94$ \\
\hline 5 & -1 & $-1,01$ \\
\hline 6 & -1 & $-1,10$ \\
\hline 7 & 1 & 1,17 \\
\hline 8 & 1 & 0,70 \\
\hline 9 & -1 & $-0,74$ \\
\hline 10 & -1 & $-0,76$ \\
\hline 11 & -1 & $-0,68$ \\
\hline 12 & 1 & 0,66 \\
\hline
\end{tabular}


Tabela 9. 4 Resultado da resposta da rede neural incluindo o pos-processamento proposto:

Cenário de dano 3

\begin{tabular}{cccc}
\hline Zona & Estado & Rede & R2 \\
\hline 1 & -1 & $-0,71$ & -1 \\
\hline 2 & 1 & 1,08 & 1 \\
\hline 3 & 1 & $-0,29$ & 1 \\
\hline 4 & -1 & $-0,89$ & -1 \\
\hline 5 & -1 & $-0,51$ & 1 \\
\hline 6 & -1 & $-0,96$ & -1 \\
\hline 7 & -1 & $-0,63$ & 1 \\
\hline 8 & -1 & $-0,83$ & -1 \\
\hline 9 & -1 & $-0,42$ & 1 \\
\hline 10 & -1 & $-0,99$ & -1 \\
\hline 11 & -1 & $-0,59$ & 1 \\
\hline 12 & -1 & $-1,02$ & -1 \\
\hline
\end{tabular}

Tabela 9. 5 Resultado da resposta da rede neural incluindo o pos-processamento proposto: Cenário de dano 4.

\begin{tabular}{|c|c|c|c|}
\hline Zona & Estado & Rede & $\mathbf{R 2}$ \\
\hline 1 & -1 & $-1,06$ & -1 \\
\hline 2 & -1 & $-0,26$ & 1 \\
\hline 3 & 1 & 1,04 & 1 \\
\hline 4 & -1 & $-0,57$ & 1 \\
\hline 5 & -1 & $-0,43$ & 1 \\
\hline 6 & -1 & $-0,62$ & -1 \\
\hline 7 & 1 & $-0,28$ & 1 \\
\hline 8 & -1 & $-0,43$ & 1 \\
\hline 9 & -1 & $-0,88$ & -1 \\
\hline 10 & -1 & $-0,88$ & -1 \\
\hline 11 & -1 & $-1,22$ & -1 \\
\hline 12 & -1 & $-1,04$ & -1 \\
\hline
\end{tabular}

Propõe-se que se tomem as zonas que apresentarem os valores mais altos de saída da rede em uma quantidade igual à metade do número de zonas na estrutura. Nas Tabelas 9.4 e 9.5 mostra-se que esta forma de processar os resultados da rede permite que valores negativos sejam incluídos nas zonas provavelmente danificadas, incrementando dessa maneira a percentagem de sucesso da metodologia de localização. Cabe lembrar que a metodologia proposta tem como objetivo principal descartar zonas da estrutura sem dano para assim facilitar a aplicação de alguma das metodologias vistas nos exemplos I a IV. Com o pos-processamento proposto a redução do número de variáveis atingida será igual a $50 \%$. 
A porcentagem de redução do número de variáveis pode ser incrementada se o número de zonas escolhidas como danificada é diminuído a um valor menor que o 50\% do total de zonas na estrutura. Na Tabela 9.6 mostra-se o desempenho da metodologia quando o número de zonas consideradas como danificadas varia entre 4 e 6 . Observa-se, como esperado, que na medida em que mais zonas são consideradas obtém-se um melhor desempenho por parte da metodologia proposta e que a redução máxima possível, ou seja, quando é considerado que 4 zonas estão danificadas, produz uma probabilidade de detecção baixa.

Tabela 9. 6 Resultados em função do número de zonas consideradas como danificadas.

\# de Zonas

\begin{tabular}{cc}
$\begin{array}{c}\text { \# de Zonas } \\
\text { consideradas como } \\
\text { danificadas }\end{array}$ & $\begin{array}{c}\% \text { de } \\
\text { Sucesso }\end{array}$ \\
\hline 4 & 75,6 \\
\hline 5 & 84 \\
\hline 6 & 90,5 \\
\hline
\end{tabular}

\subsection{INFLuÊnCIA Do tipo De ALgoritmo De tReinamento ESCOLHIDO NO DESEMPENHO DA METODOLOGIA PROPOSTA}

A escolha de um algoritmo de treinamento que permita o menor custo computacional possível é muito importante devido à grande quantidade de variáveis do problema e de exemplos de treinamento necessários. Neste exemplo a ANN proposta foi treinada com os algoritmos Levenberg- Marquardt (LM), Broyden-Fletcher-Goldfarb-Shanno quase-newton (BFGS) e Scaled Conjugate Gradient (SCG).

Tabelas 9.7 a 9.9 mostram os resultados para vigas com 15, 24 e 30 elementos, respectivamente. Um desempenho maior a $90 \%$ foi observado para todos os exemplos independente do algoritmo de treinamento utilizado. $O$ algoritmo LM apresenta os melhores resultados; porém, precisa-se de uma alta quantidade de tempo de processamento. A utilização deste algoritmo se torna inviável pelos custos de tempo e memória exigidos para o caso de estruturas nos quais se tenha uma quantidade muito alta de informação medida. Já, o algoritmo 
SCG apresenta uma boa capacidade de generalização com um tempo de processamento muito menor que o gasto pelo LM. Pela razão anterior, este será o método utilizado neste exemplo para as análises realizadas nas seguintes seções. O algoritmo BFGS apresenta um desempenho não muito maior ao obtido pelo algoritmo SCG como observado nos três exemplos; porém, com tempos de treinamento muito maiores. Estes resultados mostram a importância da escolha de um algoritmo que permita realizar um treinamento da ANN de forma adequada.

Tabela 9. 7 Viga com 15 elementos.

\begin{tabular}{cccc}
\hline $\begin{array}{c}\text { Método de } \\
\text { Treinamento }\end{array}$ & $\begin{array}{c}\% \text { de } \\
\text { sucesso }\end{array}$ & $\begin{array}{c}\text { Número } \\
\text { de } \\
\text { épocas }\end{array}$ & $\begin{array}{c}\text { Tempo de } \\
\text { Treinamento }\end{array}$ \\
\hline SCG & 97,1 & 3000 & 2 min \\
\hline BFGS & 92,7 & 3000 & $6 \mathrm{~min}$ \\
\hline LM & 98,1 & 3000 & $45 \mathrm{~min}$ \\
\hline
\end{tabular}

Tabela 9. 8 Viga com 24 elementos.

\begin{tabular}{cccc}
\hline $\begin{array}{c}\text { Método de } \\
\text { Treinamento }\end{array}$ & $\begin{array}{c}\text { \% de } \\
\text { sucesso }\end{array}$ & $\begin{array}{c}\text { Número } \\
\text { de } \\
\text { épocas }\end{array}$ & $\begin{array}{c}\text { Tempo de } \\
\text { Treinamento }\end{array}$ \\
\hline SCG & 90,0 & 3000 & 17 min \\
\hline BFGS & 91,8 & 1000 & $3 \mathrm{~h}: 33 \mathrm{~min}$ \\
\hline LM & 93,8 & 1000 & $7 \mathrm{~h} 53 \mathrm{~min}$ \\
\hline
\end{tabular}

Tabela 9. 9 Viga com 30 elementos.

\begin{tabular}{cccc}
\hline $\begin{array}{c}\text { Método de } \\
\text { Treinamento }\end{array}$ & $\begin{array}{c}\text { \% de } \\
\text { sucesso }\end{array}$ & $\begin{array}{c}\text { Número } \\
\text { de } \\
\text { épocas }\end{array}$ & $\begin{array}{c}\text { Tempo de } \\
\text { Treinamento }\end{array}$ \\
\hline SCG & 94,5 & 3000 & 15 min \\
\hline BFGS & 94,9 & 500 & $22 \mathrm{~h}: 0$ min \\
\hline LM & 96,0 & 500 & $30 \mathrm{~h}: 30 \mathrm{~min}$ \\
\hline
\end{tabular}

Os resultados anteriores foram tomados mediante a execução da metodologia proposta em um computador Intel $($ Xeon $®$ X5355 de $2.67 \mathrm{GHz}$ e memória RAM de 12 GB. 


\subsection{INFLUÊNCIA DO RUIDO NO DESEMPENHO DA METODOLOGIA PROPOSTA}

Na Tabela 9.10 mostra-se a porcentagem de sucesso da metodologia proposta quando as medições apresentam ou não ruído. A capacidade da metodologia para todas as vigas analisadas é de quase $100 \%$ quando as medições estão livres de ruído enquanto que o desempenho chega a quase $90 \%$ se as medições são ruidosas. Estes resultados permitem concluir que o desempenho da metodologia proposta está ligado à qualidade das medições realizadas. Espera-se que a quantidade de identificações erradas incremente de forma proporcional à porcentagem de ruído nos dados de entrada. Como comentado anteriormente, cada metodologia de detecção de dano deverá determinar quais os efeitos do ruído sob os resultados já que essa condição estará presente na informação de entrada. Além disso, neste exemplo pode-se observar que os dois esquemas de definição de zonas são validos.

Tabela 9. 10 Efeito do ruído.

\begin{tabular}{ccc}
\hline \multirow{2}{*}{ Viga } & \multicolumn{2}{c}{ \% de Sucesso } \\
\cline { 2 - 3 } & $\begin{array}{c}\text { Sem } \\
\text { Ruído }\end{array}$ & $\begin{array}{c}\text { Com } \\
\text { Ruído }\end{array}$ \\
\hline V1 & 99,4 & 97,1 \\
\hline V2 & 97,8 & 90,0 \\
\hline V3 & 99,4 & 94,5 \\
\hline V4 & 99,5 & 90,5 \\
\hline V5 & 99,6 & 92,3 \\
\hline V6 & 99,6 & 93,6 \\
\hline
\end{tabular}

\subsection{INFLUÊNCIA DA EXTENSÃO DO DANO NO DESEMPENHO DA METODOLOGIA PROPOSTA}

Nesta seção, avalia-se o efeito que a faixa de valores de extensões de dano dos diferentes elementos danificados na estrutura tem sobre o desempenho da metodologia proposta. Para isso, diferentes faixas foram usadas e a 
porcentagem de sucesso da metodologia proposta foi determinada para cada uma delas.

Os resultados da aplicação da metodologia na viga V4 são apresentados na Tabela 9.11 e mostram que em geral, a detecção é mais provável na medida em que o nível de dano aumenta e com uma maior uniformidade nas extensões de dano. Para os exemplos analisados, aqueles elementos danificados com extensões de dano menores a 0,15 foram dificilmente identificados.

Tabela 9. 11 Influência da extensão do dano no sucesso da metodologia proposta.

\begin{tabular}{cc}
\hline $\begin{array}{c}\text { Extensão } \\
\text { de Dano }\end{array}$ & $\begin{array}{c}\% \text { de } \\
\text { Sucesso }\end{array}$ \\
\hline $0,15-0,25$ & 80,5 \\
\hline $0,15-0,35$ & 86,1 \\
\hline $0,15-0,45$ & 90,5 \\
\hline $0,25-0,45$ & 95,5 \\
\hline $0,35-0,45$ & 97,6 \\
\hline
\end{tabular}

\subsection{DISCUSSÃO}

Neste exemplo foi introduzida uma rede neural MLP para a localização de possíveis zonas danificadas. Algumas questões podem ser salientadas:

- A metodologia proposta busca determinar possíveis zonas danificadas com o intuito de aplicar uma segunda metodologia, como aquelas apresentadas nos exemplos I a IV e VI, que faça um processo de localização e quantificação mais detalhado.

- A utilização de um determinado algoritmo de treinamento pode tornarse inviável para ser utilizado no problema de detecção de dano devido ao fato de que são muitas as variáveis envolvidas.

- Devido à falta de informação das coordenadas modais e a presença de ruído não é possível obter uma descrição mais detalhada da localização dos elementos danificados.

- Cada cenário de dano possível tem uma probabilidade determinada de ser corretamente localizado pela rede que aumenta na medida em que o dano é mais uniforme. 
- A utilização de redes neurais artificiais para localização de dano na forma proposta neste exemplo é computacionalmente mais eficiente em comparação com a apresentada para quantificação dado que o número de possíveis combinações de entrada e saída é muito menor. Isto mostraria que redes neurais poderiam ser mais adequadas para só localizar dano que para atingir o nível III de identificação de dano, ou seja, para determinar a extensão do dano.

- Cabe ressaltar, que é muito importante que seja utilizado um algoritmo de aprendizagem que apresente o melhor compromisso entre a qualidade das soluções geradas e o custo computacional envolvido. Nesse sentido, observou-se que o algoritmo scaled conjugate gradient seria uma boa escolha para treinar a rede. 


\section{EXEMPLO VII: FORMULAÇÃO}

MULTI-OBJETIVO

\subsection{INTRODUÇÃo}

A definição de uma função objetivo é parte integrante na busca por uma solução de um problema de otimização, sendo que existe um grupo dessas funções que utiliza fatores de ponderação para determinar a contribuição de diferentes termos na função. O desempenho de um algoritmo de otimização está condicionado à definição de tais ponderadores, tal como ocorre com a Função dada pela Equação 6.3 que requer da alocação de um valor para o fator de peso W que pondera a contribuição entre um termo relacionado com frequências naturais e um segundo termo que considera os modos de vibração. O valor do peso $W$ é obtido a partir em um processo de tentativa e erro e não necessariamente é o ótimo para uma dada estrutura, nem para todos os cenários de dano possíveis. A utilização do fator de peso é evitada se o problema se 
considera como um com múltiplos objetivos. Esta forma de se estudar o problema de deteç̧ão de dano tem sido utilizada com anterioridade pela comunidade científica (Perera et al., 2007); (Perera e Ruiz, 2008); (Christodoulou et al., 2008); (Perera et al., 2010); (Jung et al., 2010). Neste exemplo aborda-se a formulação multi-objetivo do problema de deteç̧ão de dano com o intuito de se determinar os seus alcances.

O problema é definido pela maximização simultânea das seguintes funções:

$$
F_{1}=\sum_{j=1}^{n m} \frac{200}{1+\sqrt{\frac{\sum_{i=1}^{n g l l}\left(\phi_{i j}^{m h}-\phi_{i j}^{e x}\right)^{2}}{\sum_{i=1}^{n g l l}\left(\phi_{i j}^{e x}\right)^{2}}}},
$$

$$
F_{2}=\frac{200}{1+\frac{\sum_{j=1}^{n g l l} \sum_{i=1}^{n g l l}\left|f_{i j}^{m h}-f_{i j}^{e x}\right|}{\sum_{j=1}^{n g l l} \sum_{i=1}^{n g l l}\left|f_{i j}^{e x}\right|}}
$$

Cabe salientar que as funções anteriores não são conflitantes, ou seja, é possível que o conjunto ótimo de Pareto esteja composto de uma única solução que se caracteriza por ter o valor máximo possível para ambas as funções. Porém, no problema de detecção de dano, o conjunto de Pareto está formado por varias soluções devido à presença de erros na modelagem e nas medições, como indicado por Christodoulus et al. (2008).

Utiliza-se o NSGA-II e o SPEA-II como algoritmos de otimização tendo em vista que eles têm sido bastante utilizados na literatura (Yazdi e SalehiNeyshabouri, 2012), (Kaveh et al., 2012), (Lakshmi e Rama Mohan Rao, 2012). A formulação restante da metodologia de deteç̧ão de dano é a mesma apresentada na Figura 4.1. Os principais aspectos que serão observados são os seguintes:

- Definição das características que envolvem a formulação multi-objetivo. 
- Avaliação da influência do ruído no conjunto ótimo de Pareto encontrado.

- Observação das diferenças que existem entre as soluções que conformam o conjunto ótimo de Pareto obtido.

- Determinação da forma como evolui a diversidade da população para cada um dos algoritmos utilizados, dado que este é um aspecto crítico nos algoritmos evolutivos multi-objetivos (Drezewski e Obrocki, 2009).

Para efeitos de determinar o desempenho da metodologia proposta, a resposta escolhida desde o conjunto ótimo de Pareto encontrado corresponde a aquela que apresente o valor máximo para a seguinte expressão (Perera, Fang et al., 2010):

$\max G=\sqrt{F_{1}^{2}+F_{2}^{2}}$

\section{2 " NON-DOMINATED SORTING GENETIC ALGORITHM II (NSGA-II)"}

Este algoritmo foi proposto por Deb et al. (2000) como uma melhora ao algoritmo no elitista NSGA. Na Figura 10.1 apresenta-se o algoritmo do NSGA-II, sendo que o processo de definição dos conjuntos de Pareto que foi utilizado é aquele proposto por Deb (2001). Um operador de seleção especial chamado de Seleção por torneio crowded é utilizado. O operador emprega dois critérios para escolher um dos indivíduos que participa na competição: menor ranking de dominação e maior distancia crowding. O ranking refere-se ao número do conjunto de Pareto ao qual pertence uma solução dada, enquanto que a distancia crowding busca determinar a densidade das soluções de um conjunto dado que se encontram ao redor de uma solução em particular. Algumas vantagens do NSGA-II são que não requer da definição de parâmetros extras para levar em conta a distribuição da população no conjunto e que o mecanismo de elitismo implementado não permite que uma solução de Pareto ótimo já encontrada se perca pela implementação dos operadores genéticos (Deb, 2001). 


\section{Inicio}

1. Combinar Paes $\left(P_{t}\right)$ e filhos $\left(Q_{t}\right)$ em uma única população $R_{t}$. Determinar os distintos frentes de Pareto $\left(F_{i}\right)$ em $R_{t}$.

2. Preencher a população para a geração $P_{t+1}$ utilizando os indivíduos de cada frente seguindo um estrito ordem de dominação $\left(F_{1}, F_{2}, \ldots F_{i}\right)$. Tal processo deverá ser parado quando o tamanho da população já preenchida mais o número de indivíduos do frente supera o tamanho pré-definido para a população.

3. Preencher as vagas faltantes na população utilizando um critério crowding.

4. Gerar a nova população de filhos $Q_{t+1}$ utilizando seleção de torneio crowded, e os operadores de cruzamento e mutação

Fim

Figura 10. 1 Algoritmo do NSGA-II Fonte: Deb (2001).

\section{3 "STRENGTH PARETO EVOLUTIONAY ALGORITH II, (SPEA-II)"}

Este algoritmo foi proposto por Zitzler et al. (2001) para superar as desvantagens do SPEA e é mostrado na Figura 10.2. Neste algoritmo se mantém um arquivo externo de tamanho pré-determinado que contem as melhores soluções encontradas até uma geração dada. Uma única aptidão para cada indivíduo é calculada considerando tanto o número do conjunto ao qual pertence a solução como os indivíduos que ela domina. Dessa forma o operador de seleção utilizado é o clássico torneio binário. O operador de truncamento se encarrega de eliminar as soluções no arquivo que apresentem a menor distância a seu vizinho mais próximo. Esse operador tem a característica que soluções de fronteira não são eliminadas. A determinação de qual é o vizinho mais próximo é realizada no espaço de soluções. 


\section{Inicio}

1. Calcular a aptidão na população $\left(P_{t}\right)$ e no arquivo externo $\left(Q_{t}\right)$.

2. Copiar os indivíduos no dominados de $\mathrm{P}_{t}+\mathrm{Q}_{t}$ em $\mathrm{Q}_{t+1}$.Se a quantidade de indivíduos em $\mathrm{Q}_{\mathrm{t}+1}$ supera o tamanho permitido para o arquivo externo então utilize o operador de truncamento. Caso contrario preencha as vagas no arquivo externo com indivíduos não dominados.

3. Realizar seleção, cruzamento e mutação.

Fim

Figura 10. 2 Algoritmo do SPEA-II. Fonte: Zitzler et al (2001).

\subsection{ESTRUTURA ANALISADA E DEFINIÇÃO DAS CARACTERÍSTICAS DO NSGA-II E O SPEA-II}

A estrutura analisada ilustra-se na Figura 10.3 e apresenta um modelo de elementos finitos discretizado em 60 elementos. Um total de 8 formas modais com medições nos graus de liberdade verticais é considerado. Cada elemento na viga tem uma seção de área $A=1 \times 10^{-3} \mathrm{~m}^{2}$ e inércia $\mathrm{I}=5 \times 10^{-4} \mathrm{~m}^{4}$. A viga é construída de um único material cujas propriedades são modulo de elasticidade $\mathrm{E}=200 \times 10^{9} \mathrm{~N} / \mathrm{m}^{2}$ e densidade $\rho=78 \times 10^{2} \mathrm{~kg} / \mathrm{m}^{3}$. Considera-se que as frequências naturais e as formas modais contém ruído de $1 \%$ e $3 \%$, respectivamente.

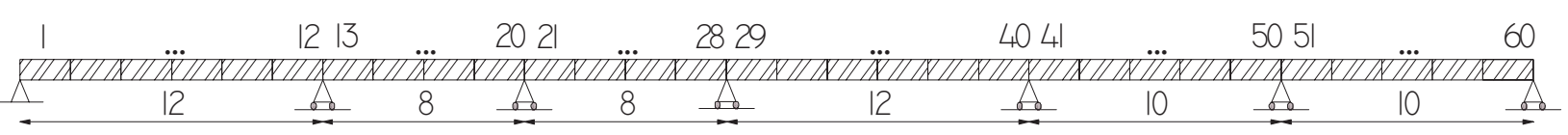

Figura 10. 3 Viga com múltiplo suportes.

Um total de 100 cenários de dano foi simulado contendo uma quantidade pré-definida de elementos que apresentam dano na faixa entre 0,1 e 0,5. Como 
mostrado no exemplo I, o RCGA proposto apresenta problemas para detectar cenários que apresentam dano em muitos elementos, e, portanto, neste trabalho adotaram-se cenários de com 4 elementos danificados.

Os operadores de cruzamento e mutação e suas respectivas taxas de aplicação foram definidos de igual forma que para o Exemplo I. Para todos os cenários de dano utilizou-se uma população de 200 indivíduos e um número máximo de gerações igual a 100.

Em relação ao número de execuções uma das características bastante comentadas na literatura sobre algoritmos evolutivos multi-objetivo é a sua habilidade para determinar diversas soluções do conjunto ótimo de Pareto em uma única execução do algoritmo. Porém, isto é verdade somente se o conjunto de Pareto encontrado corresponde ao ótimo ou está muito perto dele. Sendo assim, na análise é determinado o desempenho dos dois algoritmos quando 1 e 3 execuções foram realizadas.

\subsection{DETERMINAÇÃo DA VIABILIDAdE DA FORMULAÇÃo MULTI- OBJETIVO}

Na Tabela 10.1 mostram-se os resultados obtidos para os 100 cenários de dano quando aplicada a técnica de classificação proposta no Exemplo I. Tais resultados são organizados segundo o algoritmo empregado e o número de execuções. Pode ser observado que existe um incremento importante na efetividade dos algoritmos quando varias execuções são realizadas. Porém, o algoritmo apresenta problemas para convergir a cenários de dano que apresentem uma boa exatidão em relação à extensão de dano dos elementos verdadeiramente danificados, como evidenciado pelo baixo número de casos nos quais se apresentou o menor nível de erro. Por outro lado, observou-se que são muito poucos os elementos danificados que apresentando uma extensão de dano maior a 0,2 não foram detectados. Quase $20 \%$ dos cenários com dano entre 0,1 e 0,2 não foram detectados mostrando a dificuldade do algoritmo proposto para encontrar dano a níveis baixos. Cabe salientar que para a maioria destes 
cenários um único elemento não era identificado e que esse elemento apresentava dano menor a 0,15. Em relação à quantidade de falsos positivos observa-se que próximo de um $80 \%$ dos cenários apresenta um elemento falsamente identificado como danificado com um valor de dano menor a 0,1.

Tabela 10. 1 Resultados para os algoritmos propostos.

\begin{tabular}{cccccc}
\hline $\begin{array}{c}\text { Tipo de } \\
\text { Erro }\end{array}$ & ID & \multicolumn{2}{c}{ NSGA-II } & \multicolumn{2}{c}{ SPEA-II } \\
\cline { 2 - 6 } & & 1 Exec & 3 Exec & 1 Exec & 3 Exec \\
\hline \multirow{4}{*}{$A$} & EA_1 & 0 & 2 & 0 & 2 \\
\cline { 2 - 6 } & EA_2 & 7 & 17 & 9 & 15 \\
\cline { 2 - 6 } & EA_3 & 25 & 32 & 16 & 28 \\
\cline { 2 - 6 } & EA_4 & 68 & 49 & 75 & 55 \\
\hline \multirow{4}{*}{ B } & EB_0 & 0 & 0 & 0 & 0 \\
\cline { 2 - 6 } & EB_1 & 1 & 4 & 1 & 2 \\
\cline { 2 - 6 } & EB_2 & 28 & 28 & 14 & 25 \\
\cline { 2 - 6 } & EB_3 & 47 & 55 & 51 & 53 \\
\hline \multirow{4}{*}{ C } & EB_4 & 24 & 13 & 34 & 20 \\
\cline { 2 - 6 } & EC_0 & 69 & 79 & 65 & 82 \\
\cline { 2 - 6 } & EC_1 & 23 & 17 & 23 & 18 \\
\cline { 2 - 6 } & EC_2 & 8 & 4 & 12 & 0 \\
\hline
\end{tabular}

Resultados anteriores mostram que os algoritmos de otimização utilizados apresentam um desempenho similar em função dos tipos de erros e que se tem a necessidade de adicionar características especiais à metodologia proposta que ajudem a reduzir os níveis de erro com o intuito de que esta seja mais confiável.

A distribuição do número de elementos falsamente identificados como danificados para os diferentes cenários é mostrada na Tabela 10.2. Pode-se observar que não há diferenças significativas na quantidade de falsos positivos para quando se variava o número de execuções más que existe diferença nos resultados para os algoritmos, tendo o NSGA-II apresentado um melhor resultado. Além disso, a quantidade de falsos positivos é muito baixa para a maioria dos cenários, com pelo menos $10 \%$ dos cenários de dano apresentando mais de 10 falsos positivos. Cabe salientar que estes cenários na sua maioria correspondem a aqueles para os quais o resultado do algoritmo implicou em um falso-negativo. 
Tabela 10. 2 Distribuição de falsos positivos.

\begin{tabular}{cccccc}
\hline \multirow{2}{*}{ Algoritmo } & $\begin{array}{c}\# \\
\text { Exec. }\end{array}$ & $\mathbf{0}$ & $\mathbf{1 - 5}$ & $\mathbf{6 - 1 0}$ & $\mathbf{> 1 0}$ \\
\hline \multirow{2}{*}{ NSGA-II } & 1 & 0 & 42 & 52 & 6 \\
\cline { 2 - 6 } & 3 & 0 & 49 & 42 & 9 \\
\hline \multirow{2}{*}{ SPEA-II } & 1 & 0 & 22 & 55 & 23 \\
\cline { 2 - 6 } & 3 & 0 & 30 & 50 & 20 \\
\hline
\end{tabular}

Na Tabela 10.3 é apresentada a distribuição de elementos falsamente identificados segundo o nível de erro para 5 cenários de dano. Na maioria dos casos observaram-se poucos falso-positivos com extensões de dano destes elementos que, no geral, não superam 0,1. Esta é uma característica desejável de uma metodologia de detecção de dano para não subvalorizar o estado atual da estrutura.

Tabela 10. 3 Exemplos da distribuição de falsos positivos segundo a extensão do dano.

\begin{tabular}{|c|c|c|c|c|c|c|c|}
\hline \multirow{2}{*}{ Cenário } & \multirow{2}{*}{ Algoritmo } & \multirow{2}{*}{$\begin{array}{c}\text { Quantidade } \\
\text { de falsos } \\
\text { positivos }\end{array}$} & \multicolumn{5}{|c|}{ Extensão de dano } \\
\hline & & & E2_0 & E2_1 & E2_2 & E2_3 & E2_4 \\
\hline \multirow{2}{*}{1} & NSGA-II & 3 & 0 & 2 & 1 & 0 & 0 \\
\hline & SPEA-II & 7 & 0 & 4 & 1 & 2 & 0 \\
\hline \multirow[b]{2}{*}{2} & NSGA-II & 5 & 0 & 2 & 2 & 1 & 0 \\
\hline & SPEA-II & 5 & 0 & 0 & 4 & 1 & 0 \\
\hline \multirow{2}{*}{3} & NSGA-II & 6 & 0 & 2 & 3 & 1 & 0 \\
\hline & SPEA-II & 6 & 0 & 0 & 6 & 0 & 0 \\
\hline \multirow{2}{*}{4} & NSGA-II & 6 & 0 & 1 & 5 & 0 & 0 \\
\hline & SPEA-II & 9 & 0 & 4 & 3 & 2 & 0 \\
\hline \multirow{2}{*}{5} & NSGA-II & 7 & 0 & 1 & 3 & 2 & 1 \\
\hline & SPEA-II & 11 & 0 & 2 & 3 & 3 & 3 \\
\hline
\end{tabular}

\subsection{CARACTERÍSTICAS DO CONJUNTO DE PARETO OBTIDO}

Na Figura 10.4 apresentam-se vários dos conjuntos de Pareto obtido para diversos cenários utilizando o algoritmo NSGA-II. Dependendo do cenário de dano, nota-se que o conjunto ótimo de Pareto encontrado pode estar mais próximo do ótimo obtido quando as medições estão livres de ruído e que não converge para uma única solução. Nos exemplos mostrados, os dois conjuntos de Pareto que se encontram na parte inferior correspondem a cenários para os quais não foi detectada a presença de algum dos elementos danificados nesse 
cenário. Observa-se ainda que existe uma maior adaptação das soluções do conjunto com a função baseada só em formas modais dado que os valores para as diversas soluções no conjunto ótimo de Pareto são maiores que aqueles encontrados para a função baseada na flexibilidade modal e variam em uma faixa menor.

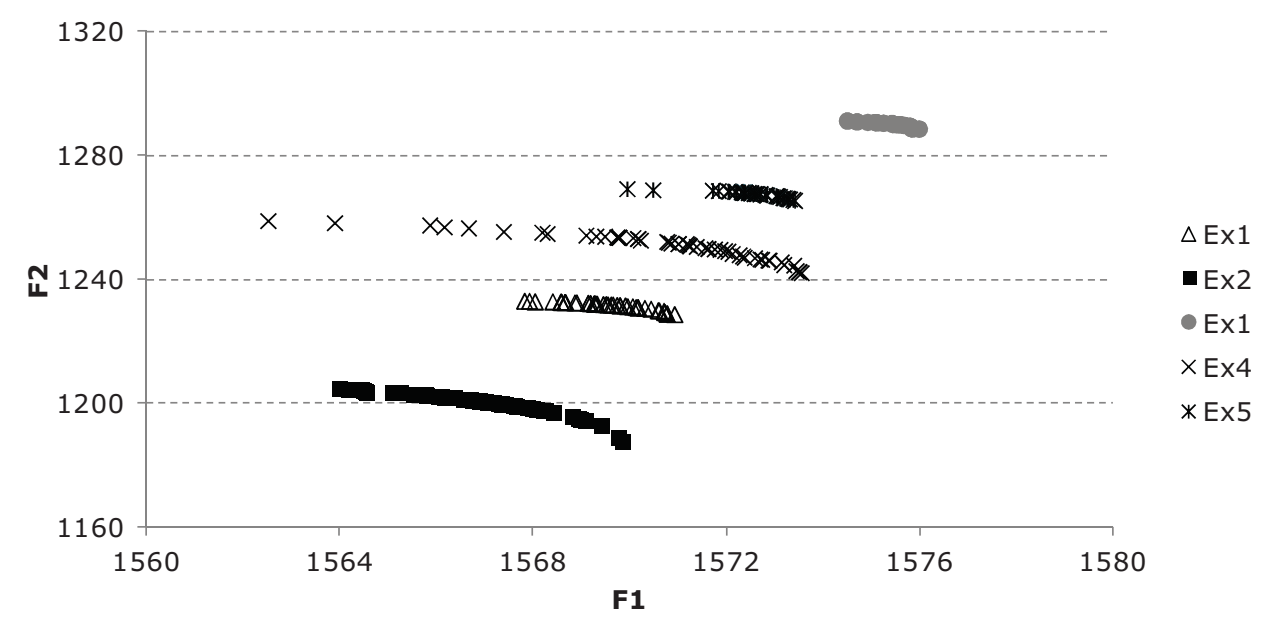

Figura 10. 4 Exemplos de conjuntos de Pareto obtidos.

A titulo de exemplo mostra-se na Figura 10. 5 o avanço no conjunto de Pareto na medida em que o número de gerações incrementa. Para o exemplo mostrado, a partir da geração 50 já o algoritmo tinha convergido praticamente para o conjunto de Pareto ótimo. É importante ressaltar que pequenas diferenças nos valores da função objetivo poderiam representar variações importantes no cenário de dano determinado pelo algoritmo.

O nível de ruído nos dados influencia o Pareto encontrado como se mostra na Figura 10. 6. Na medida em que o nível de ruído nos dados incrementa temse um decremento na qualidade do conjunto de Pareto, sendo que este tende a ser mais amplo e contem uma maior quantidade de soluções no Conjunto. Como esperado, observa-se que o ruído tem um efeito maior na função baseada na flexibilidade modal. 


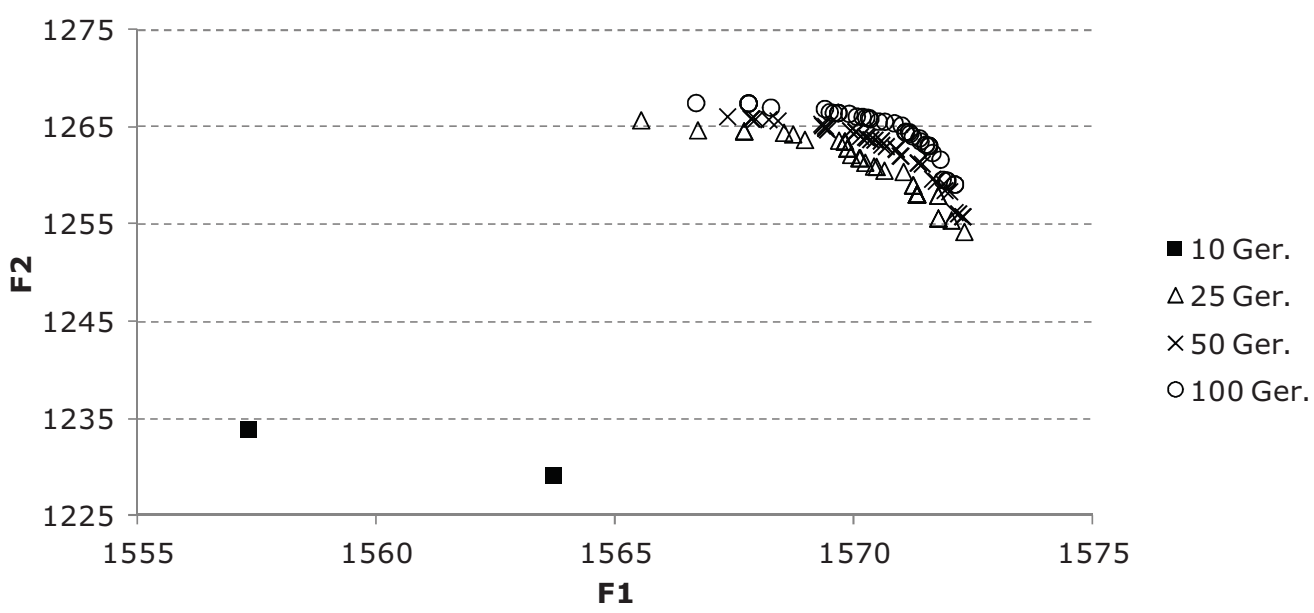

Figura 10. 5 Exemplo no avanço do conjunto de Pareto.

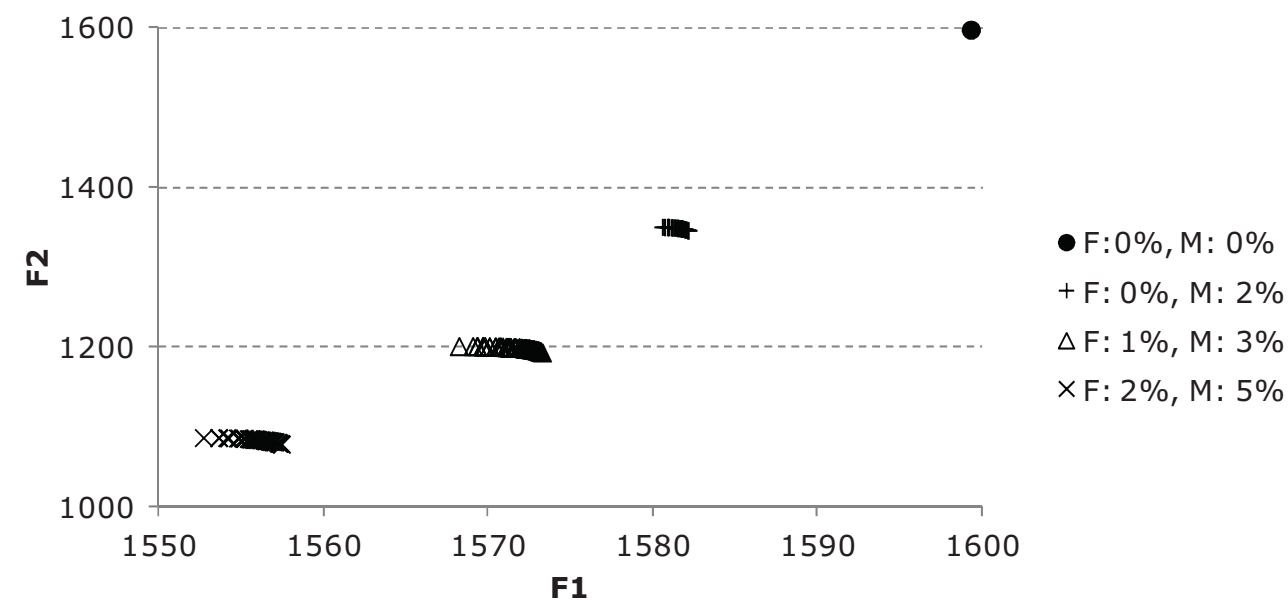

Figura 10. 6 Variação do conjunto de Pareto em função do nível de ruído nas medições.

$\mathrm{Na}$ Tabela 10.4 apresenta um exemplo da variação que existe entre soluções pertencentes ao conjunto ótimo de Pareto encontrado utilizado o SPEAII. Nessa tabela são reportados alguns dos cenários representativos do conjunto ótimo de Pareto composto por aqueles elemento para os quais determinou-se um valor da extensão do dano maior que 0,05. Em relação à diversidade das soluções que formam o conjunto de Pareto, observou-se que estas se caracterizam por ser relativamente semelhantes no que diz respeito aos elementos definidos como danificados, más por outro lado podem ter variações enquanto às extensões de dano. Este resultado justificaria a pouca convergência do algoritmo para cenários de dano que apresentam um nível de erro menor no 
cálculo da extensão do dano. Neste ponto é importante salientar que o espaço de busca dado por cada uma das funções independentes será diferente daquele formado pela sua combinação, sendo que isto pode beneficiar ou prejudicar o desempenho do algoritmo.

Tabela 10. 4 Conjunto de Pareto contendo indivíduos com diversidade no espaço de soluções.

\begin{tabular}{cccccc}
\hline \multirow{2}{*}{ Elem } & \multicolumn{5}{c}{ Extensão do dano $(\boldsymbol{\beta})$} \\
\cline { 2 - 6 } & Real & Cen1 & Cen2 & Cen3 & Cen4 \\
\hline 8 & 0,249 & 0,262 & 0,229 & 0,301 & 0,263 \\
9 & --- & --- & 0,050 & 0,108 & 0,132 \\
14 & --- & 0,091 & --- & --- & --- \\
18 & 0,441 & 0,449 & 0,441 & 0,411 & 0,452 \\
19 & --- & --- & --- & --- & 0,071 \\
24 & --- & --- & --- & 0,053 & --- \\
36 & --- & 0,103 & 0,054 & 0,127 & 0,105 \\
38 & 0,445 & 0,452 & 0,457 & 0,442 & 0,430 \\
43 & --- & --- & 0,052 & --- & --- \\
45 & 0,190 & 0,258 & 0,232 & 0,260 & 0,262 \\
48 & --- & 0,055 & --- & --- & 0,072 \\
60 & ---- & --- & 0,116 & --- & --- \\
\hline
\end{tabular}

Por outro lado, esperava-se manter soluções diferentes no espaço de busca para aqueles exemplos onde o algoritmo não encontrou a verdadeira resposta; porém não foi completamente possível. Isto pode ser solucionado se os algoritmos são equipados com ferramentas para manter a diversidade da população de forma que permita a formação de nichos ao redor de algumas soluções, que correspondem aos diversos ótimos locais, e que para certos casos seriam soluções quase globais, do problema.

\subsection{PERDA DE DIVERSIDADE NA POPULAÇÃo}

A perda de diversidade é um grande problema dos algoritmos evolutivos multi-objetivo como mostrado na Figura 10.7 para os algoritmos NSGA-II e SPEA-II. No eixo vertical encontra-se o valor da diversidade da população calculada como a soma do valor quadrático da diferença para todos os indivíduos da população, normalizada pelo valor da diversidade da população inicial. Observa-se que na geração 20 a diversidade tem diminuído para menos de 
um $40 \%$ da inicial, sendo mais crítico para o SPEA-II, e que para as últimas gerações mantém-se constante em um valor próximo a 10\%. Cabe salientar que o operador de mutação proposto (M-zero) é em parte responsável pela perda de diversidade. Estes resultados mostram como os algoritmos deverão ser equipados com características que lhes permitam uma maior conservação da diversidade ao longo do processo evolutivo.

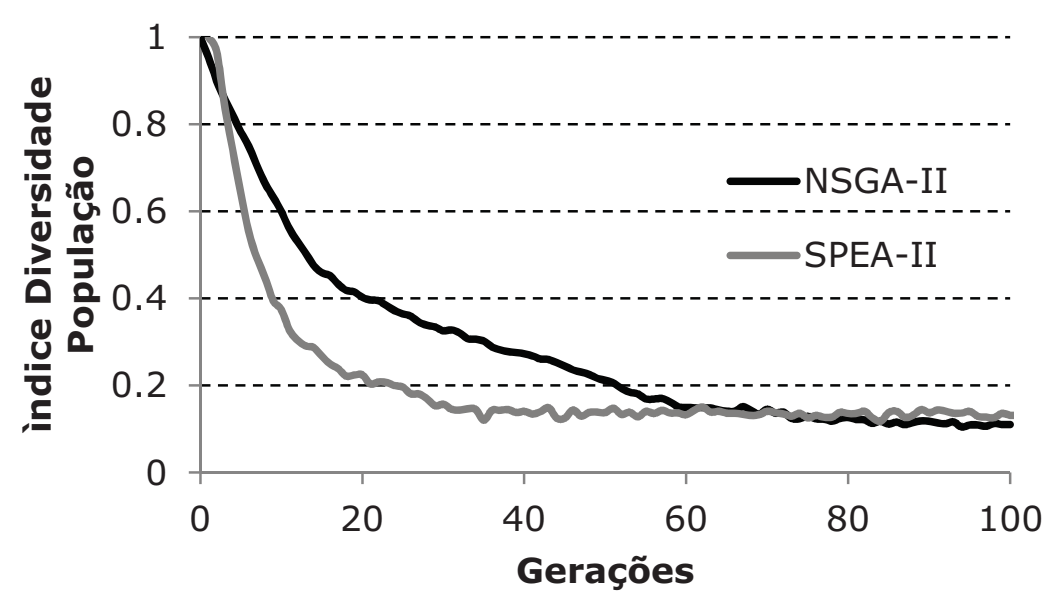

Figura 10. 7 Perdida da diversidade da população.

\subsection{DISCUSSÃO}

Neste exemplo um algoritmo genético multi-objetivo foi aplicado na detecção de dano de uma estrutura do tipo viga e cujos resultados permitem fazer as seguintes considerações:

- A formulação multi-objetivo elimina a necessidade de se definir um fator de peso para a contribuição de termos da função objetivo originados em diferentes parâmetros dinâmicos.

- A solução final para o usuário foi escolhida seguindo uma abordagem determinística; porém, no conjunto ótimo de Pareto encontrado existem soluções que podem ser ligeiramente diferentes à solução reportada. 
- Deve-se fazer uma inspeção que permita definir qual dos estados é finalmente o real, como proposto por Caicedo e Yun (2010), para os casos em que no conjunto de Pareto encontrem-se soluções que apresentam elementos danificados diferentes ou variações consideráveis para as extensões de dano.

- Propõe-se que os algoritmos sejam modificados utilizando técnicas próprias para análise de funções multi-modais, como técnicas niching ou crowding, para diminuir a perda de diversidade na população e manter a quantidade de soluções diferentes que poderiam ser candidatas ao cenário de dano real.

- Deve-se ter um compromisso entre a possibilidade de se detectar erradamente um cenário de dano e a utilização de esquemas que permitam manter varias soluções ao longo do processo evolutivo.

- Para o algoritmo NSGA-II, o cálculo da densidade de soluções é realizado no espaço das funções objetivo. No caso do problema de detecção de dano, soluções correspondentes a cenários de dano diferentes poderiam apresentar valores das funções objetivo similares e, portanto, seria desejável utilizar uma medida de densidade no espaço das variáveis de otimização. Seguindo tal processo pode-se diminuir a probabilidade do cenário de dano real não ser o verdadeiro.

- O incremento no nível de ruído nos parâmetros dinâmicos faz possível a formação do conjunto de Pareto composto por múltiplas soluções e na medida em que se incrementa tal nível se produz uma diminuição na qualidade do conjunto.

- O Conjunto de Pareto não é necessariamente atingido em uma única execução do algoritmo para o problema de detecção de dano.

- Recomenda-se que depois de se ter executado o algoritmo evolutivo seja realizada uma busca exaustiva ao redor das soluções que conforma o Conjunto de Pareto encontrado com o intuito de se refinar a solução.

- Os algoritmos NSGA-II e SPEA-II apresentaram um desempenho similar, porém o primeiro tende a produzir cenários de dano com uma menor quantidade de falsos positivos em comparação com os produzidos pelo SPEA-II. 


\section{CONCLUSÕES}

No presente trabalho foi desenvolvido um conjunto de metodologias não destrutivas de deteç̧ão de dano baseadas nas mudanças das propriedades dinâmicas da estrutura que acontecem com o dano e na utilização de técnicas de inteligência computacional para a solução do problema. Entre as principais conclusões observa-se que:

- As metaheurísticas utilizadas - algoritmos genéticos, particle swarm optimization e o algoritmo de evolução diferencial- apresentaram um bom desempenho para resolver o problema de otimização associado ao o problema de detecção de dano. Porém, recomenda-se a definição de características especiais que façam com que os algoritmos convirjam mais eficientemente para o cenário de dano correto. Exemplos dessas características são a formulação multi-cromossomo, que permite as variáveis de otimização possam ser diferentes ao longo do processo evolutivo, e o operador de mutação M-zero, que ajuda o algoritmo a convergir para uma solução com poucos elementos danificados. Outro 
aspecto importante está na definição da população inicial, sendo que neste trabalho foi definida de forma heurística com o intuito de orientar os algoritmos a regiões do espaço de busca onde nem todos os elementos da estrutura estão danificados. Por outro lado, em virtude dos No-Free-Lunch-Theorems não existe uma configuração de metaheuristicas, operadores e parâmetros cujo desempenho seja melhor independentemente do problema analisado; portanto, deve-se procurar pela melhor técnica para o problema estudado. Cabe salientar, que seria interessante explorar $\circ$ uso conjunto de várias metaheurísticas para a solução do problema de otimização.

- Redes neurais artificiais foram utilizadas para localizar e quantificar dano em estruturas do tipo viga. Em um primeiro exemplo, mostra-se como redes neurais seriam utilizadas para determinar a extensão do dano em vigas com poucos elementos. Porém, não há garantia que esta metodologia funcione para vigas contendo muitos elementos. Em um segundo exemplo, considerou-se a utilização de redes neurais para localizar zonas da estrutura que apresentem dano utilizando poucas medições nos graus de liberdade verticais. O tempo gasto para o treinamento desta rede é muito alto; más, dado o fato de a saída assumir unicamente um de dois valores, seria necessário um tempo menor que aquele requerido para treinar uma rede utilizada em quantificação. A rede proposta inicialmente apresentou problemas para diferenciar exatamente as zonas danificadas das não danificadas, razão pela qual foi proposto um pós-processamento dos resultados que leva a descartar que pelo menos a metade da estrutura se encontra danificada. Cabe salientar que isto é válido se considerarmos que a rede será utilizada como um passo prévio à determinação da extensão do dano por parte de uma metaheurística. Com o estado atual da literatura, a utilização de redes neurais estaria limitada a atingir no máximo um nível II de identificação do dano quando se trata de uma estrutura com uma considerável quantidade de elementos.

- Um conjunto de metaheurísticas com adaptação de parâmetros foi proposto com o objetivo do usuário não precisar definir os parâmetros das metaheurísticas por tentativa e erro. No entanto, o usuário deverá indicar o tamanho da população que será evoluída, já que este 
parâmetro é dependente da complexidade da estrutura e ainda não se conhece uma relação confiável entre tal característica e o tamanho da população. Este mesmo caso ocorre com a definição da quantidade de exemplos utilizados para o treinamento da rede. Neste trabalho obtevese uma expressão aproximada que permitia relacionar a quantidade citada anteriormente ao número de elementos de uma estrutura do tipo viga. Esta expressão está condicionada às características específicas que foram definidas durante sua obtenção.

- Foi proposto um esquema de avaliação de técnicas de detecção de dano nível III que permite ter uma descrição mais detalhada sobre qual é a confiabilidade da metodologia proposta. Nesse sentido são três os tipos de erro que uma metodologia de detecção de dano pode apresentar na hora de fornecer o cenário de dano encontrado. Estes tipos de erro correspondem a diferenças na extensão do dano entre o valor real e o calculado, a presença de elementos erroneamente considerados como danificados e a identificação negativa de alguns dos elementos danificados. Alem disso, é muito importante que seja fornecida uma descrição dos falsos positivos presentes no cenário de dano encontrado após a simulação numérica, com o intuito de se obter uma descrição mais detalhada do desempenho da metodologia. Por outro lado, a partir dos exemplos analisados observa-se que as técnicas propostas não identificam dano $100 \%$ das vezes, o que se deve a uma dificuldade intrínseca dos cenários procurados.

- Recomenda-se que seja aplicada uma técnica de busca local ao redor da solução encontrada pelas metaheurísticas depois que estas são aplicadas na solução do problema de detecção de dano. No exemplo I utilizou-se um RCGA para realizar tal processo (chamado de reinicialização). Esta técnica poderia ser trocada por um procedimento de busca específico que leve em conta que o cenário de dano encontrado geralmente tem poucos elementos danificados. Esse cenário inclui os elementos verdadeiramente danificados e alguns falsos positivos que apresentam frequentemente um baixo valor de dano.

- Existem dois aspectos experimentais que incidem diretamente no desempenho das metodologias de detecção de dano baseadas em vibração: medições incompletas e ruído. A definição da quantidade 
mínima de informação que poderá ser utilizada pela metodologia na avaliação da integridade estrutural é muito importante. Isso permite garantir que a informação disponível é suficiente para uma detecção de dano confiável. Ainda, existe a possibilidade de que um excesso de informação prejudique o processo de busca. Em relação ao ruído, este influencia negativamente o desempenho de uma metodologia de deteç̧ão de dano, portanto, é desejável que as medições sejam realizadas com o menor grau de perturbação possível. A presença das duas condições anteriores faz com que a complexidade do espaço de busca incremente com o consequente decremento do desempenho dos algoritmos de busca.

- A função objetivo escolhida na formulação do problema de otimização desempenha um papel importante para o correto sucesso de uma metodologia de detecção de dano, sendo que mesmo a utilização de vários parâmetros combinados de forma diferente pode resultar em desempenhos distintos da metodologia proposta. Além disso, a utilização de certos parâmetros pode ser inadequada se conduzir ao algoritmo de otimização a uma convergência para cenários de dano muito diferentes em diversas execuções, tal como aconteceu quando a função objetivo baseada na energia de deformação modal foi utilizada. Por outro lado, a avaliação da função objetivo é a etapa que consume maior quantidade de tempo no processo de otimização. Desde um ponto de vista computacional, isso geraria dificuldades quando a metodologia for aplicada para grandes estruturas. Nesse caso, poderá ser explorada a utilização de meta-modelos que permitam calcular a qualidade de cada uma das soluções na população de uma forma mais eficiente. Cabe salientar, que existe um trade-off entre a qualidade do meta-modelo e a sua complexidade.

- Uma formulação multi-objetivo foi estudada para o problema de deteç̧ão de dano, observando-se que a presença de várias soluções no conjunto ótimo de Pareto é o resultado da presença de erros nas medições. Em geral, este conjunto apresenta-se mais amplo no espaço das funções objetivo na medida em que o ruído aumenta. Enquanto as soluções que pertencem ao conjunto são comumente similares, apresentando algumas diferenças nos valores da extensão do dano em 
relação aos valores reais. Ainda, esta formulação mostrou ter problemas para atingir os mínimos erros no cálculo da extensão do dano dos verdadeiros elementos danificados, razão pela qual os algoritmos deverão ser modificados de forma a se resolver essa questão. Outra possível solução é através da utilização posterior de uma técnica de busca local como comentado anteriormente.

A realização deste trabalho permitiu definir alguns tópicos que podem ser objeto de trabalhos futuros:

- Identificação de dano a partir da resposta em aceleração da estrutura. Este tipo de formulação permitiria detectar online se a estrutura apresenta ou não dano e em alguns casos conseguiria uma localização aproximada do dano. Na literatura encontra-se um grande número destas metodologias que seguem uma abordagem estatística e que utilizam medições provenientes de vibrações ambientais como parâmetro de entrada para a metodologia.

- Uso da Transformada Wavelet. Existe um amplo campo de pesquisa que trata da utilização de transformadas de sinais de aceleração para detecção de dano, sendo uma das mais utilizadas a transformada wavelet. Neste campo tem-se a necessidade de se definir aspectos como o tipo de função wavelet, o nível de discretização que será utilizado na transformação, entre outros.

- Inclusão das incertezas no modelo de elementos finitos que representa a condição sem dano. Para todos os exemplos estudados assumiu-se que existia um modelo de elementos finitos que representava fielmente a condição inicial da sua estrutura e, por conseguinte, seus parâmetros dinâmicos. Esta característica não é sempre válida e deverá ser proposta uma forma sistemática de considerá-la na formulação de uma metodologia de detecção de dano de tal forma que esta possa fornecer resultados confiáveis.

- Aplicação a outros tipos de estruturas. O estudo realizado foi aplicado a estruturas de barras em duas dimensões, exatamente para vigas e treliças. Sendo assim, a viabilidade da utilização das técnicas propostas para a avaliação da integridade de estruturas de maior complexidade, tais como edifícios, deverá ser verificada. 
- Localização ótima de sensores. A utilização de diferentes configurações da localização dos sensores disponíveis na estrutura pode levar a diferentes desempenhos da metodologia de deteç̧ão de dano; portanto, seria desejável conhecer qual seria a melhor configuração. Um problema de otimização pode ser formulado e a utilização de metaheurísticas para sua solução é aconselhada.

- Maior utilização de técnicas de inteligência computacional. Na literatura tem-se uma maior utilização de redes neurais artificiais e algoritmos genéticos para resolver o problema de detecção de dano; porém, espera-se que outras técnicas, tais como, sistemas fuzzy, sistemas imunes artificiais ou sistemas híbridos sejam mais explorados no futuro. Além disso, comparações de CITs com técnicas clássicas deverão ser realizadas.

- Paralelização dos algoritmos. Problemas nos quais a avaliação da função objetivo requer grandes tempos de processamento podem ser resolvidos eficientemente por metaheurísticas baseadas em populações. Uma forma simples de se fazer a paralelização é a partir da distribuição da avaliação da aptidão dos indivíduos da população nos distintos processadores. Cabe salientar que existem técnicas reportadas na literatura para aumentar a eficiência de tais algoritmos quando formulados em paralelo.

- Utilização de técnicas de inteligência computacional para a solução de outros problemas no campo da engenharia de estruturas. Os bons resultados obtidos no presente trabalho incentivam a explorar a utilização destas técnicas não convencionais para resolver problemas como o de otimização de estruturas, controle de vibrações, avaliação da confiabilidade estrutural, entre outros. 
ABDO, M. A.-B.; HORI, M. A Numerical Study of Structural Damage Detection Using Changes in the rotation of mode shapes. Journal of Sound and Vibration v. 251, n. 2, p. 227-239, 2002.

AGUIRRE, J.; CONTRERAS, M. Utilización de los algoritmos genéticos en un problema de ingeniería sísmica: Separación de efectos de sitio y fuente. . II Congreso Internacional de Métodos Numéricos en Ingenierías y Ciencias, 2002, Guanajuato, México. CIMNE. p.325333.

ALBA, E. Parallel metaheuristic: A new class of algorithms. New Jersey: John Wiley \& Sons, Inc., Publication, 2005. 553.

ALI, M. M.; TORN, A. Population set-based global optimization algorithms: some modifications and numerical studies. Computers \& Operations Research v. 31, p. 1703-1725, 2004.

ALVANDI, A.; CREMONA, C. Assessment of vibration-based damage identification techniques Journal of Sound and Vibration v. 292, p. 179-202, 2006.

BAKHARY, N.; HAO, H.; DEEKS, A. Damage Detection Using Artificial Neural Networks with Consideration of Uncertainties. Engineering Structures v. 29, p. 2806-2815, 2007. 
BEGAMBRE, O.; LAIER, J. A hybrid Particle Swarm Optimization - Simplex algorithm (PSOS) for structural damage identification. Advances in Engineering Software v. 40, p. 883-891, 2009.

BEKDAŞ, G.; NIGDELI, S. M. Estimating optimum parameters of tuned mass dampers using harmony search. Engineering Structures, v. 33, p. 2716-2723, 2011.

BI, X.-J.; XIAO, J. Classification-based self-adaptive differential evolution with fast and reliable convergence performance Soft Computing, v. 15, n. 8, p. 1581-1599, 2011.

BORGES, C.; BARBOSA, H.; LEMONGE, A. A structural damage identification method based on genetic algorithm and vibrational data. International journal for numerical methods in engineering, v. 69, p. 2663-2686, 2007.

CAICEDO, J. M.; YUN, G.-Y. A novel evolutionary algorithm for identifying multiple alternative solutions in model updating. Structural Health Monitoring, v. 0, n. 0, p. 1$11,2010$.

CARDEN, E. P.; FANNING, P. Vibration based condition monitoring: A review. Structural Health Monitoring, v. 3, n. 4, p. 355-377, 2004.

CASCIATI, S. Stiffness identification and damage localization via differential evolution algorithms. Structural Control and Health Monitoring v. 15, p. 436-449, 2008.

CAWLEY, P.; ADAMS, R. D. The Locations of Defects in Structures from Measurements of Natural Frequencies. . Journal of Strain Analysis, v. 14, n. 2, p. 49-57, 1979.

CHANG, C. C. et al. Structural damage detection using an iterative neural network. Journal of Intelligent Material Systems and Structures v. 11, p. 32-42, 2000.

CHEN, B.; NAGARAJAIAH, S. Flexibility-based structural damage identification using Gauss- Newton method. SPIE- Sensors and smart structures, technologies for civil, mechanical, and aerospace systems, 2007, San Diego. SPIE. p.Part 1, paper 65291L.

CHEN, H. P. Application of regularization methods to damage detection in large scale plane frame structures using incomplete noisy modal data. Engineering Structures v. 30, p. 3219-3227, 2008.

CHEN, H. P.; BICANIC, N. Inverse damage prediction in structures using nonlinear dynamic perturbation theory. Computational Mechanics, v. 37, p. 455-467, 2006.

CHENG, J. Hybrid genetic algorithms for structural reliability analysis. Computers and Structures, v. 85, p. 1524-1533, 2007. 
CHOU, J. H.; GHABOUSSI, J. Genetic algorithm in structural damage detection. Computers and Structures, v. 79, p. 1335-1353, 2001.

CHRISTODOULOU, $\mathrm{K}$. et al. Structural model updating and prediction variability using Pareto optimal models. Computational Methods in Applied Mechanic and Engineering, v. 198, p. 138-149, 2008.

COELLO, C. Theoretical and numerical constraint-handling techniques used with evolutionary algorithms: a survey of the state of the art Computer Methods in Applied Mechanics and Engineering v. 191, p. 1245-1287, 2002.

COLEY, D. A. An introduction to genetic algorithms for scientists and engineers. Singapore: World Scientific Publishing Co. Pte. Ltd., 1999. 227.

CUNHA, A.; CAETANO, E.; MAGALHAES, F. Output-only dynamic testing of bridges and special structures. Strcutural Concrete, v. 8, n. 2, p. 67-86, 2007.

CURADELLI, R. O. et al. Damage detection by means of structural damping identification. Engineering Structures, v. 30, 2008.

DE CASTRO, L. N.; TIMMIS, J. Artificial immune systems: a new computational intelligence approach London: Springer, 2002.

DEB, K. Multi-objective optimization using evolutionary algorithms. Chichester: John Wiley \& Sons Ltd, 2001.

DEB, K. et al. A fast and elitist multi-objective genetic algorithm: NSGA-II. Tecnical Report 200001, Indian Institute of Technology. Kanpur. 2000

DEL PEZZO, E. et al. Discrimination of Earthquakes and Underwater Explosions Using Neural Networks. . Bulletin of the Seismological Society of America, v. 93, n. 1, p. 215-223, 2003.

DI, W.; LAW, S. S. Eigen-parameter decomposition of element matrices for structural damage detection. Engineering Structures, v. 29, p. 519-528, 2007.

DIAO, Y.-S.; LI, H.-J.; WANG, Y. A two-step structural damage detection approach based on wavelet packet analysis and neural network., Fifth International Conference on Machine Learning and Cybernetics, 2006, Dalian, China. IEEE. p.3128-3133.

DOEBLING, S.; FARRAR, C.; PRIME, M. A Summary Review of Vibration-Based Damage Identification Methods. The Shock and Vibration Digest, v. 30, n. 2, p. 91-105, 1998.

DREZEWSKI, R.; OBROCKI, K. Co-operative Co-evolutionary Approach to Multi-objective Optimization In: CORCHADO, E.;WU, X., et al, Proceedings of the 4th International 
Conference on Hybrid Artificial Intelligence Systems, 2009, Salamanca, Spain. SpringerVerlag. p.277-284.

EBERHART, R.; SHI, Y. Computational intelligence: Concepts to implementations. Burlington: Morgan Kaufmann, 2007. 496.

EIBEN, A. E.; HINTERDING, R.; MICHALEWICZ, Z. Parameter Control in Evolutionary Algorithms. IEEE Transactions on Evolutionary Computation, v. 3, n. 2, p. 124-141, 1999.

ENGELBRECHT, A. P. Computational Intelligence: An Introduction West Sussex, England: John Wiley \& Sons Ltd, 2007.

FADEL-MIGUEL, L. F. et al. Damage detection under ambient vibration by harmony search algorithm. Expert Systems with Applications, v. 39, p. 9704-9714, 2012.

FAN, W.; QIAO, P. Vibration-based Damage Identification Methods: A Review and Comparative Study. Structural Health Monitoring, v. 10, p. 83-111, 2011.

FUGATE, M. L.; SOHN, H.; FARRAR, C. R. Vibration- Based DamageDetection Using Statistical Process Control. Mechanical Systems and Signal Processing v. 15, n. 4, p. 707-721, 2001.

GANDOMI, A. H.; YANG, X.-S.; HOSSEIN, A. H. Mixed variable structural optimization using Firefly Algorithm. Computers and Structures, v. 89, p. 2325-233, 2011.

GONG, W.; CAI, Z.; JIANG, L. Enhancing the performance of differential evolution using orthogonal design method Applied Mathematics and Computation, v. 206, p. 56-69, 2008.

GONZÁLEZ, T. Handbook of approximation algorithms and metaheuristics. Taylor \& Francis Group, 2007.

GUO, H. Y.; LI, Z. L. A two-stage method to identify structural damage sites and extents by using evidence theory and micro-search genetic algorithm. Mechanical Systems and Signal Processing, v. 23, p. 769-782, 2009.

GUO, H. Y. et al. Optimal placement of sensors for structural health monitoring using improved genetic algorithms. Smart Materials and Structures, v. 13, p. 528-534, 2004.

HAM, F.; KOSTANIC, I. Principles of neurocomputing for science \& engineering. New York: Ed. McGraw-Hill Higher Education, 2001. 
HAN, J.-G.; REN, W.-X.; SUN, Z.-S. Wavelet packet based damage identification of beam structures. International Journal of Solids and Structures, v. 42, p. 6610-6627, 2005.

HAUPT, R.; HAUPT, S. Practical genetic algorithms. 2004.

HAYDAR, A.; ARMAGAN, K.; IRFANOGLU, A. Selecting and scaling real ground motion records using harmony search algorithm Soil Dynamics and Earthquake Engineering, v. 31, p. 941-953, 2011.

HERRERA, F.; LOZANO, M.; VERDERGAY, J. L. Tackling real-coded genetic algorithms: Operators and tools for behavioral analysis. Artificial Intelligence Review, v. 12, p. 265-319, 1998.

HINTERDING, R. Self-adaptation using multi-chromosomes. IEEE International Conference on Evolutionary Computation, 1997, Indianapolis, United States. IEEE Press. p.87-91.

HU, N. et al. Damage Assessment of Structures Using Modal Test Data. International Journal of Solids and Structures, v. 38, p. 3111-3126, 2001.

HULL, P. V.; TINKER, M. L.; DOZIER, G. Evolutionary optimization of a geometrically refined truss. Structural Multidisciplinary Optimization v. 31, p. 311-319, 2006.

ILONEN, J.; KAMARAINEN, J.-K.; LAMPINEN, J. Differential evolution training algorithm for feed-forward neural networks Neural Processing Letters, v. 17, p. 93$105,2003$.

JAISHI, B.; REN, W.-X. Damage detection by finite element model updating using modal flexibility residual. Journal of Sound and Vibration v. 290, p. 369-387, 2006.

JANG, J.-S. R. ANFIS: adaptive-network-based fuzzy inference system. IEEE Transactions on Systems, Man and Cybernetics, v. 23, n. 3, p. 665 - 685, 1993.

JUNG, S.; OK, S.-Y.; SONG, J. Robust structural damage identification based on multiobjective optimization International Journal of Numerical Methods in Engineeringg, v. 81, p. 786-804, 2010.

K., A. F. T. et al. Structural Damage Detection Based on a Micro-Genetic Algorithm Using Incomplete and Noisy Modal Test Data. Journal of Sound and Vibration, v. 259, n. 5, p. 1081-1094, 2003.

KAMINSKI, P. C. The approximate location of damage through the analysis of natural frequencies with artificial neural networks. Journal of Process Mechanical Engineering v. 209, p. 117- 123, 1995. 
KANG, F.; LI, J.-J.; XU, Q. Structural inverse analysis by hybrid simplex artificial bee colony algorithms. Computers and Structure, v. 87, p. 861-870, 2009.

KARABOGA, D.; BASTUR, B. A powerful and efficient algorithm for numerical function optimization: artificial bee colony $(A B C)$ algorithm. Journal of Global Optimization, v. 39, p. 459-471, 2007.

KARIMI, I.; HÜLLERMEIER, E. Risk assessment system of natural hazards: A new approach based on fuzzy probability Fuzzy Sets and Systems, v. 158, p. 987 - 999, 2007.

KAVEH, A.; LAKNEJADI, K.; ALINEJAD, B. Performance-based multi-objective optimization of large steel structures Acta Mechanica, v. 223, p. 355-369, 2012.

KENNEDY, J.; EBERHART, R. Particle swarm optimization., Proceedings of IEEE International Conference on Neural Network, 1995, Perth. IEEE. p.1942-1948.

KIRKPATRICK, S.; GELATT, A.; VECCHI, M. P. Optimization by simulated annealing. Science, v. 220, p. 671-680, 1983.

$\mathrm{KOH}, \mathrm{B} . \mathrm{H} . ; \mathrm{DYKE}$, S. J. Structural health monitoring for flexible bridge structures using correlation and sensitivity of modal data Computers and Structures, v. 85, p. 117130, 2007.

KOHONEN, T. Improved versions of learning vector quantization. 1990 IJCNN International Joint Conference on Neural Networks, 1990, San Diego, USA. IEEE Press. p. $545-550$.

KOUCHMESHKY, B.; AQUINO, W.; BILLEK, A. Structural damage identification using coevolution and frequency response functions. Structural Control Health Monitoring v. 15, p. $162-182,2008$.

LAIER, J. E.; VILLALBA, J. D. Improved Genetic Algorithm for Structural Damage Detection. 2009 International Symposium on Computer Structural Engineering, 2009, Shangai. Springer. p.833-839.

LAKSHMI, K.; RAMA MOHAN RAO, A. Comparative performances of three GA based multiobjective algorithms for optimal desing of laminate composites. Journal of Structural Engineering (India), v. 39, n. 1, p. 35-42, 2012.

LAM, H. F.; KO, J. M.; WONG, C. W. Localization of damaged structural connections based on experimental modal and sensitivity analysis. Journal of Sound and Vibration, v. 210, p. 91-115, 1998.

LAW, S. S.; SHI, Z. Y.; ZHANG, L. M. Structural Damage Detection from Incomplete and Noisy Modal Test Data. Journal of Engineering Mechanics v. 124, n. 11, p. 12801288, 1998. 
LEE, K. S.; GEEM, Z. W. A new meta-heuristic algorithm for continuous engineering optimization: harmony search theory and practice. Computer Methods in Applied Mechanics Engineering v. 194, p. 3902-3933, 2005.

LEE, Y. J.; CHON, H. C.; LEE, K. S. Immune algorithm based active PID control for structure systems. Journal of mechanical science and technology, v. 20, n. 11, p. 1823-1833, 2006.

LEMAITRE, J. A course on damage mechanics. Berlin: Springer, 1996. 228.

LI, H.; YANG, H.; JAMES, S. L. Modal Strain Energy Decomposition Method for Damage Localization in 3D Frame Structures. Journal of Engineering Mechanic v. 132, n. 9, p. 941-951, 2006.

LI, J. et al. Damage identification in civil engineering structures utilizing PCAcompressed residual frequency response functions and neural networks ensembles. Structural Control and Health Monitoring v. 18, p. 207-226, 2011.

LI, L. J. et al. A heuristic particle swarm optimizer for optimization of pin connected structures Computers and Structures, v. 85, p. 340-349, 2007.

LIU, D. K.; YANG, Y. L.; LI, Q. S. Optimum positioning of actuators in tall buildings using genetic algorithm. Computers and Structures, v. 81, p. 2823-2827, 2003.

LU, Q.; REN, G.; ZHAO, Y. Multiple damage location with flexibility curvature and relative frequency change for beam structures Journal of Sound and Vibration v. 253, n. 5, p. $1101-1114,2002$.

MALDONADO, E.; GÓMEZ, I. D.; CHIO, G. Aplicación de los conjuntos difusos en la evaluación de los parámetros de la vulnerabilidad sísmica de edificaciones de mampostería Ingeniería \& Desarrollo, v. 22, p. 1-22, 2007.

MARES, C.; SURACE, C. An Application of Genetic Algorithm to Identify Damage in Elastic Structures. Journal of Sound and Vibration, v. 195, n. 2, p. 195-215, 1996.

MOHAN RAO, A. R.; ANANDAKUMAR, G. Optimal placement of sensors for structural system identification and health monitoring using a hybrid swarm intelligence technique. Smart Materials and Structures v. 16, p. 2658-2672, 2007.

MOSLEM, K.; NAFASPOUR, R. Structural damage detection by genetic algorithms. AIAA Journal, v. 40, n. 7, p. 1395-1401, 2002.

MOVAFFAGHI, H.; FRIBERG, O. Optimal placement of dampers in structures using genetic algorithm International Journal for Computer-Aided Engineering and Software v. 23, n. 6, p. 597-606, 2006. 
NAGAI, K. et al. Genetic Algorithm Inversion of Rayleigh Wave Dispersionfrom CMPCC Gathers Over a Shallow Fault Model. Journal of Environmental and Engineering Geophysics, v. 10, n. 3, p. 275-286, 2005.

NDAMBI, J.-M.; VANTOMME, J.; HARRI, K. Damage assessment in reinforced concrete beams using eigenfrequencies and mode shape derivatives. Engineering Structures $v$. 24, p. 501-515, 2002.

NECATI-CATBAS, F.; BROWN, D. L.; EMIN-AKTAN, A. Use of Modal Flexibility for Damage Detection and Condition Assessment: Case Studies and Demonstrations on Large Structures Journal of Structural Engineering, v. 132, n. 11, p. 1699-1712, 2006.

NELDER, J. A.; MEAD, R. A Simplex method for function minimization. Computer Journal, v. 7, p. 308-313, 1965.

NI, Y. Q.; WANG, B. S.; KO, J. M. Constructing input vectors to Neural Networks for Structural Damage Identification. Smart Materials and Structures v. 11, p. 825-833, 2002.

NUNES DA SILVA, I.; SPATTI, D.; FLAUZINO, R. Redes neurais artificiais para engenharia e ciências aplicadas: curso prático. São Paulo: Artliber Editora, 2010. 399.

OMKAR, S. N. et al. Artificial immune system for multi-objective design optimization of composite structures. Engineering Applications of Artificial Intelligence, v. 21, p. 1416-1429, 2008.

PALACZ, M.; KRAWCZUK, M. Vibration Parameters for Damage Detection in Structures. Journal of Sound and vibration v. 249, n. 5, p. 999-1010, 2002.

PAN, D.-G.; LEI, S.-S.; WU, S.-C. Two-Stage Damage Detection Method Using the Artificial Neural Networks and Genetic Algorithms ICICA 2010 LNCS 6377. AL, R. Z. E.: Springer-Verlag Berlin Heidelberg: 325-332 p. 2010.

PANAKKAT, A.; ADELI, H. Recurrent Neural Network for Approximate Earthquake Time and Location Prediction Using Multiple Seismicity Indicators Computer-Aided Civil and Infrastructure Engineering., v. 24, p. 280-292, 2009.

PANCHAL, G. et al. Behaviour Analysis of Multilayer Perceptrons with Multiple Hidden Neurons and Hidden Layers International Journal of Computer Theory and Engineering, v. 3, n. 2, p. 332-337, 2011.

PANDEY, A. K.; BISWAS, M. Damage detection in structures using changes in flexibility Journal of Sound and Vibration, v. 169, n. 1, p. 3-17, 1994. 
PARSOPOULOS, K. E.; VRAHATIS, M. N. Parameter Selection and Adaptation in Unified Particle Swarm Optimization. Mathematical and Computer Modelling, v. 46, n. 198213, 2007.

PASSINO, K. M. Biomimicry of bacterial foraging for distributed optimization and control. IEEE Control Systems Magazine, v. 5, n. 3, p. 52-67, 2002.

PATJAWIT, A.; KANOK-NUKULCHAI, W. Health monitoring of highway bridges based on a Global Flexibility Index. Engineering Structures, v. 27, p. 1385-1391, 2005.

PAVLOVCIC, L.; KRAJNC, A.; BEG, D. Cost function analysis in the structural optimization of steel frames Structural Multidisciplinary Optimization, v. 28, p. 286295, 2004.

PERERA, R.; FANG, S.-E.; RUIZ, A. Application of particle swarm optimization and genetic algorithms to multiobjective damage identification inverse problems with modelling errors. Meccanica, v. 45, p. 723-734, 2010.

PERERA, R.; RUIZ, A. A multistage FE updating procedure for damage identification in large-scale structures based on multiobjective evolutionary optimization Mechanical Systems and Signal Processing, v. 22, p. 970-991, 2008.

PERERA, R.; RUIZ, A.; MANZANO, C. An evolutionary multiobjective framework for structural damage localization and quantification Engineering Structures, v. 29, p. 2540-2550, 2007.

PERRY, M. J.; KOH, C. G.; CHOO, Y. S. Modified genetic algorithm strategy for structural identification. Computers and Structures, v. 84, p. 529-540, 2006.

QIAN, Y.; MITA, A. Acceleration-based damage indicators for building structures using neural network emulators Structural Control and Health Monitoring., v. 15, n. 901920, 2008.

QIN, A. K.; HUANG, V. L.; SUGANTHAN, P. N. Differential Evolution Algorithm With Strategy Adaptation for Global Numerical Optimization IEEE Transactions on Evolutionary Computation., v. 13, n. 2, p. 398-417, 2009.

RAICH, A.; LISZKAI, T. Improving the Performance of Structural Damage Detection Methods Using Advanced Genetic Algorithms. Journal of Structural Engineering v. 133, n. 3, p. 449-461, 2007.

RATNAWEERA, A.; HALGAMUGE, S. K.; WATSON, H. C. Self-Organizing Hierarchical Particle Swarm Optimizer With Time-Varying Acceleration Coefficients IEEE Transactions on Evolutionary Computation, v. 8, n. 3, p. 240-255, 2004. 
REZA BANAN, M.; MEHDI-POUR, Y. Detection and assessment of damage in 2D structures using measured modal response. Journal of Sound and Vibration v. 306, n. 803-817, 2007.

RYTTER, A. Vibrational Based Inspection of Civil Engineering Structures 1993. (PhD). University of Aalborg, Aalborg, Denmark.

SAHOO, B.; MAITY, D. Damage assessment of structures using hybrid neuro-genetic algorithm. Applied Soft Computing v. 7, p. 89-104, 2007.

SAKA, M. P. Optimum Geometry Design of Geodesic Domes Using Harmony Search Algorithm. Advances in Structural Engineering, v. 16, n. 6, p. 595-606, 2007.

SALAJEGHEH, E.; HEIDARI, A. Optimum design of structures against earthquake by wavelet neural network and filter banks Earthquake Engineering and Structural Dynamics, v. 34, p. 67-82 2005.

SANDESH, S.; SHANKAR, K. Application of a hybrid of particle swarm and genetic algorithm for structural damage detection Inverse Problems in Science and Engineering, v. 18, n. 7, p. 997-1021, 2010.

SARENI, B.; KRÄHENBÜHL, L. Fitness Sharing and Niching Methods Revisited. IEEE Transactions on Evolutionary Computation, v. 2, n. 3, p. 97-106, 1998.

SENTHIL, M.; RAO, M. V. C. On the Improved Performances of the Particle Swarm Optimization Algorithms with Adaptive Parameters, Cross-over Operators and Root Mean Square (RMS) Variants for Computing Optimal Control of a Class of Hybrid Systems. Applied Soft Computing, v. 8, p. 324-336, 2008.

SHI, Y.; EBERHART, R. C. A Modified Particle Swarm Optimizer. IEEE International Conference on Evolutionary Computation, 1998, Piscataway. IEEE Press. p.69-73.

Empirical Study of Particle Swarm Optimization. In: Proceedings of the IEEE International Congress on Evolutionary Computation. IEEE International Congress on Evolutionary Computation, 1999, Washington. IEEE Press. p.1945-1950.

Fuzzy Adaptive Particle Swarm Optimization. In: PRESS, I., IEEE International Conference on Evolutionary Computation, 2001, Seoul. p.101-106.

SONME, M. Artificial Bee Colony algorithm for optimization of truss structures. Applied Soft Computing, v. 11, p. 2406-2418, 2011.

SPECHT, D. Probabilistic neural networks. Neural Networks v. 3, p. 109-118, 1990. 
STORN, R.; PRICE, K. V. Differential Evolution- A simple and efficient adaptive scheme for global optimization over continuous spaces. International Computer Science Institute. Berkeley. 1995

Differential Evolution- A simple and efficient heuristic for global optimization over continuous spaces. . Journal of Global Optimization, v. 11, n. 4, p. 341-359, 1997.

SU, R. et al. Multi-objective topology and sizing optimization of truss structures based on adaptive multi-island search strategy Structural Multidisciplinary Optimization, v. 43, p. 275-286, 2011.

SUBUDHI, B.; JENA, D. An Improved Differential Evolution Trained Neural Network Scheme for Nonlinear System Identification. International Journal of Automation and Computing, v. 6, n. 2, p. 137-144, 2009.

SUMATHI, S.; PANEERSELVAM, S. Computational Intelligence Paradigms:Theory and Applications using MATLAB Boca Raton: CRC Press-Taylor \& Francis Group, 2010.

SUN, Z.; CHANG, C. C. Statistical Wavelet-Based Method for Structural Health Monitoring Journal of Structural Engineering, v. 130, n. 7, p. 1055-1062, 2004.

TALBI, E.-G. Metaheuristics: From design to implementation. New Jersey: John Wiley \& Sons, Inc, 2009.

Metaheuristics: From design to implementation. New Jersey: John Wiley \& Sons, Inc, 2009. 624.

TANG, H.; XUE, S.; FAN, C. Differential evolution strategy for structural system identification. Computers and Structures, v. 86, p. 2004-2012, 2008

TASHAKORI, A.; ADELI, H. Optimum design of cold-formed steel space structures using neural dynamics model Journal of Constructional Steel Research, v. 58, p. 15451566, 2002.

TEODORO, F. R.; PARPINELLI, R. S.; LOPES, H. S. Otimização por colonia de bactérias aplicada a problemas de engenharia. Mecánica Computacional, v. 29, p. 9615-9627, 2010.

TEUGHELS, A.; MAECK, J.; DE ROECK, G. Damage assessment by FE model updating using damage functions. Computers and Structures, v. 80, p. 1869-1879, 2002.

TVRIDK, J. Differential Evolution: Competitive Setting of Control Parameters. International Multiconference on Computer Science and Information Technology 2006. p.207-213. 
VILLALBA, J. D.; GOMEZ, I. D.; LAIER, J. E. Detección de daño en vigas utilizando redes neuronales artificiales y parámetros dinámicos. . Revista Facultad de Ingeniería Universidad de Antioquia, v. 63, p. 141-153, 2012.

VILLALBA, J. D.; LAIER, J. E. Detección de daño estructural utilizando redes neurales artificiales: Un estado del arte 2012a.

Estado da arte sobre a aplicação de algoritmos genéticos para detecção de dano em estruturas 2012b.

Localising and quantifying damage by means of a multi-chromosome genetic algorithm Advances in Engineering Software, v. 50, p. 150-157, 2012c.

WANG, S.; REN, Q.; QIAO, P. Structural Damage Detection Using Local Damage Factor. Journal of vibration and control, v. 12, p. 955-973, 2006.

WEN, C. M. et al. Unsupervised fuzzy neural networks for damage detection of structures. Structural Control and Health Monitoring v. 14, p. 144-161, 2007.

WORDEN, K.; BURROWS, A. P. Optimal sensor placement for fault detection. Engineering Structures, v. 23, p. 885-901, 2001.

XIAO, N.; SU, L.; WANG, Y. Utilization of Particle Swarm Optimization in Equivalent Linearization Method Applied to Earthquake Engineering. Advances in Structural Engineering, v. 14, n. 2, p. 179-188, 2011.

XUE, S.; TANG, H.; ZHOU, J. Identification of structural systems using particle swarm optimization Journal of Asian Architecture and Building Engineering, v. 8, n. 2, p. 517-524, 2009.

YAM, L. H.; LI, Y. Y.; WONG, W. O. Sensitivity studies of parameters for damage detection of plate-like structures using static and dynamic approaches. Engineering Structures, v. 24, p. 1465-1475, 2002.

YANG, Q. W. A Flexibility-Based Method for Structural Damage Identification Using Ambient Modal Data International Journal of Space Structures, v. 24, n. 3, p. 153$159,2009$.

YANG, X. S. Firefly Algorithms for Multimodal Optimisation. Stochastic Algorithms: Foundations and Applications, SAGA 2009, Lecture Notes in Computer Sciences, v. 5792, p. 169-178, 2009.

YAZDI, J.; SALEHI-NEYSHABOURI, S. A. A. Optimal design of flood-control multireservoir system on a watershed scale Natural Hazards, v. 63, p. 629-646, 2012. 
YUN, G. J. et al. A Structural Damage Detection Method Based On Subset Selection and Evolutioinary Computation. 2008 Structural Congress: Crossing Borders, 2008, Vancouver, Canada. p.1-10.

ZHANG, Q.; BENVENISTE, A. Wavelet networks. IEEE Transactions on Neural Networks v. 3, n. 6, p. 889-898, 1992.

ZHANG, Q. W. Statistical damage identification for bridges using ambient vibration data Computers and Structures, v. 85, p. 476-485, 2007.

ZHAO, J.; DE WOLF, J. Sensitivity study for vibrational parameters used in damage detection. Journal of structural engineering v. 125, n. 4, p. 410-416, 1999.

ZITZLER, E.; LAUMANNS, M.; THIELE, M. TIK-Report 103, Swiss Federal Institute of Technology. Zurich. 2001

ZOU, Y.; TONG, L.; STEVEN, P. Vibration based model dependent damage (delamination) identification on health monitoring for composite structures: a review. Journal of Sound and Vibration, v. 230, p. 357-378, 2000. 